\title{
An economic perspective on school dropout prevention using microeconometric techniques
}

Citation for published version (APA):

Cabus, S. J. J. (2013). An economic perspective on school dropout prevention using microeconometric techniques. [Doctoral Thesis, Maastricht University]. Maastricht University. https://doi.org/10.26481/dis.20130918sc

Document status and date:

Published: 01/01/2013

DOI:

10.26481/dis.20130918sc

Document Version:

Publisher's PDF, also known as Version of record

\section{Please check the document version of this publication:}

- A submitted manuscript is the version of the article upon submission and before peer-review. There can be important differences between the submitted version and the official published version of record.

People interested in the research are advised to contact the author for the final version of the publication, or visit the DOI to the publisher's website.

- The final author version and the galley proof are versions of the publication after peer review.

- The final published version features the final layout of the paper including the volume, issue and page numbers.

Link to publication

\footnotetext{
General rights rights.

- You may freely distribute the URL identifying the publication in the public portal. please follow below link for the End User Agreement:

www.umlib.nl/taverne-license

Take down policy

If you believe that this document breaches copyright please contact us at:

repository@maastrichtuniversity.nl

providing details and we will investigate your claim.
}

Copyright and moral rights for the publications made accessible in the public portal are retained by the authors and/or other copyright owners and it is a condition of accessing publications that users recognise and abide by the legal requirements associated with these

- Users may download and print one copy of any publication from the public portal for the purpose of private study or research.

- You may not further distribute the material or use it for any profit-making activity or commercial gain

If the publication is distributed under the terms of Article $25 \mathrm{fa}$ of the Dutch Copyright Act, indicated by the "Taverne" license above, 


\section{An Economic Perspective on School Dropout Prevention using Microeconometric Techniques}


(c) Sofie Cabus, Maastricht 2013.

All rights reserved. No part of this publication may be reproduced, stored in a retrieval system or transmitted in any form, or by any means, electronic, mechanical, photocopying, recording, or otherwise, without the prior permission in writing, from the author.

ISBN 978-94-003-0055-2

Cover Design \& printproduction: Raadhuis voor creatieve communicatie

This book is no. III of the TIER Research Series, a $\mathrm{PhD}$ thesis series published by TIER. 


\title{
AN ECONOMIC PERSPECTIVE ON SCHOOL DROPOUT PREVENTION USING MICROECONOMETRIC TECHNIQUES
}

\author{
Proefschrift \\ ter verkrijging van de graad van doctor \\ aan de Universiteit Maastricht, \\ op gezag van de Rector Magnificus, \\ Prof. Dr. L.L.G. Soete \\ volgens het besluit van het College van Decanen, \\ in het openbaar te verdedigen \\ op woensdag 18 september 2013 om 14.00 uur
}

door

Sofie Josefina Johan Cabus 


\section{Promotors:}

Prof. Dr. W.N.J. Groot

Prof. Dr. H. Maassen van den Brink

\section{Copromotor:}

Dr. K. De Witte

\section{Beoordelingscommissie:}

Prof. Dr. R.K.W. van der Velden (voorzitter)

Prof. Dr. L. Borghans

Prof. Dr. S. Machin (University College London)

Prof. Dr. E.J.S. Plug (Universiteit van Amsterdam)

Prof. Dr. J.M.M. Ritzen 


\section{ACKNOWLEDGEMENTS}

Three years and four months. That is the time period between writing the first and the last pages of this dissertation. And it has been a journey, before and in between, with good days, and, of course, also less good days. Let me tell you the story.

The plane took off in Leuven, the Belgian city where I was born in 1984. Approximately 24 years later, and with the support of family and friends, I received the master degree in economics at the Catholic University of Leuven. Here, I met Wim Moesen and Kristof De Witte. They encouraged me to stay in academia, to cross boundaries, and to think and work scientifically. I am grateful to both of them for their indispensable support and feedback.

Next, I made two stops before reaching Maastricht: one at the Research Institute for Work and Society (HIVA-KULeuven) and one at the Center for Disability and Integration (CDI-USG). At the former institute, I had many colleagues who would play an important role in skilling me scientifically. In this respect, I am particularly grateful to Wim Van Opstal and Jef Pacolet. I still remember the 'econometric breakfasts' together with Wim on a coarse and wet bench near the Faculty of Business and Economics, both decisive to understand the econometric algebra. And Jef guided me through the very first step in the academic world, on which, at that time, I did not know anything about. At the latter institute, I had the opportunity to learn much on applied microeconometrics in a very short period of time. One of the very first days in Switzerland, I learned about the concepts of treatment effects; instrumental variables; and difference-in-differences. I do remember, while getting instructed, that I suggested that, maybe, we should clone people 
in order to find appropriate counterfactuals. I am still glad that the Swiss told me that would not be such a good idea... I am also grateful to former colleagues, especially Miriam Baumgärtner, Eva Deuchert, and Lukas Kauer, who offered me friendship and support.

The train took off in Switzerland, and I was heading to Maastricht, decisive to accomplish a PhD at the Top Institute for Evidence Based Education Research (TIER-Maastricht University). Here, I met Kristof again, who would become my co-promoter. For three years and four months he would be my prop and stay, and for this, I would like to thank him. I am also grateful to Kristof for our fruitful cooperation.

Wim Groot and Henriëtte Maassen van den Brink would become the promoters of my journey. Both of them were indispensable in teaching me Evidence-Based education research. They assisted me on my journey, created an inspiring environment in which I could study and work for the $\mathrm{PhD}$, always listened and contributed to the various school dropout stories I had to tell, offered me the opportunity to gain teaching experiences, encouraged me when I asked them for traveling abroad as a visiting scholar, said words of praise or corrected me when I could do better, and, above all, they had confidence in me that I would obtain the $\mathrm{PhD}$ degree. For all of those things I am particularly grateful to my promoters.

I had wonderful colleagues on my journey, and am particularly grateful to Iryna Rud and Marieke Heers, as they caught me up as from day one in Maastricht. I do remember our time together in Amsterdam in the first year of our $\mathrm{PhD}$, all of us following lectures from the Tinbergen Institute taught by David Card. We sat in this big lecture hall, writing, sweating, doubting, and, yes, also yawning..., as all first steps into nested logistic models are in some way... breathe taking. But we managed it to understand it by explaining the matter to each other. In general, I have learned during my journey that it is particularly important to pull each other through, but 
also to make joy in life and work with colleagues. In this respect, I am also grateful to: Dimona Bartelet, Astrid Lamers, Mieke Goos, Carla Haelermans, Chris van Klaveren, Carla Lenssen, Erik Pompen, Eline Sneyers, Emily Brounts, Erik Meyer, Frans Ronteltap, Geert Thyssen, Hans Duyx, Johan Coenen, Joris Ghysels, Marleen Gulikers, and Marton Csillag.

But, it should be said, too. All of those days that make up the time period of my journey, I also got the unconditional support of my partner in life, Goedroen Juchtmans. I hope we will have many more journeys together.

Sofie J. Cabus, Maastricht, 2013 



\section{Contents}

$\begin{array}{ll}\text { General Introduction } & 1\end{array}$

I An Introduction to School Dropout and Prevention 9

1 School Dropout and Prevention in the Literature 11

1.1 Introduction . . . . . . . . . . . . . . . . . 11

1.2 School dropout in the literature . . . . . . . . . . . . 14

1.2.1 The process of student attrition . . . . . . . . 14

1.2.2 The role of the labor market . . . . . . . . 16

1.3 A framework for dropout and prevention . . . . . . . . . 22

1.3.1 A conceptual model . . . . . . . . . . . . 22

1.3.2 Contemporary dropout prevention initiatives . . . . 26

1.3.3 A note on the effectiveness of dropout prevention . . . 31

1.4 Conclusion . . . . . . . . . . . . . . . . . . . 32

2 A Cross-Country Study on Dropout Prevention 35

2.1 Introduction . . . . . . . . . . . . . . . 35

2.2 A linear panel data model . . . . . . . . . . . . . 38

2.2 .1 Sources of endogeneity . . . . . . . . . . . 40

2.2.2 A panel data benchmarking model . . . . . . . . . 41

2.2 .3 Estimation procedure . . . . . . . . . 46 
2.3 School Dropout in the EU-12 . . . . . . . . . . . . 47

2.3.1 Theoretical background . . . . . . . . . 47

2.3.2 Data . . . . . . . . . . . . . . . . 49

2.4 Results. . . . . . . . . . . . . . . . . 53

2.4.1 Ranking cross-country differences in performances . . 53

2.4.2 Explaining the net policy influence . . . . . . . . 54

2.5 Conclusion . . . . . . . . . . . . . . . . 62

II Dropout Prevention in the Netherlands 67

3 The Registration of School Attendance 69

3.1 Introduction . . . . . . . . . . . . . . . . . . . . 69

3.2 Duration models for school dropout . . . . . . . . . . . 73

3.3 Data and descriptive statistics . . . . . . . . . . 80

3.4 Results of the Bayesian Cox model . . . . . . . . . . . . . . 90

3.5 Conclusion . . . . . . . . . . . . . . . . 94

4 The Dutch Dropout Prevention Program 99

4.1 Introduction . . . . . . . . . . . . . . . . 99

4.2 Prevention measures in the Netherlands . . . . . . . . . . 102

4.3 Data and definition . . . . . . . . . . . . . 110

4.4 Results . . . . . . . . . . . . . . . . . . 112

4.4.1 Analysis at the individual level . . . . . . . . . . . 112

4.4.2 Analysis at the school level . . . . . . . . . . . . . 119

4.5 Conclusion . . . . . . . . . . . . . . . . . . 121

5 The Compulsory Education Age 125

5.1 Introduction . . . . . . . . . . . . . . . . . 125

5.2 Identification strategy $\ldots \ldots \ldots \ldots$

5.3 Data and descriptive statistics . . . . . . . . . . . 135 
5.4 Impact of compulsory education . . . . . . . . . . . . 139

5.4 .1 Non-parametric results . . . . . . . . . . . . . . 139

5.4.2 Difference-in-differences estimation . . . . . . . . . 145

5.4 .3 Robustness analysis . . . . . . . . . . . . . 149

5.5 Conclusion ...................... 153

6 Student Commitment in Vocational Education 157

6.1 Introduction . . . . . . . . . . . . . . . . . . . 157

6.2 Identification strategy . . . . . . . . . . . . . . 163

6.2.1 Using regional borders as an instrument . . . . . . . 164

6.2.2 Some additional drawbacks . . . . . . . . . . . 169

6.3 Data and descriptive statistics . . . . . . . . . . . 171

6.4 Results . . . . . . . . . . . . . . . . . 176

6.4.1 Results ascribed to other policymaking . . . . . . . 178

6.4.2 Effectiveness of enhanced student commitment . . . 182

6.5 Conclusion . . . . . . . . . . . . . . . 186

\section{General Conclusion $\quad 189$}

7 Challenges for Prevention Policy: What and for Whom? 191

7.1 Introduction . . . . . . . . . . . . . . . . . . . 191

7.2 Theoretical Framework . . . . . . . . . . . . . . 196

7.2.1 Decision rule to attend school . . . . . . . . . . 201

7.2 .2 Policy influence . . . . . . . . . . . . . . 202

7.3 Empirical test for the decision rule . . . . . . . . . . . . 203

7.4 Results . . . . . . . . . . . . . . . . . 211

7.5 Conclusion . . . . . . . . . . . . . . . 217

7.6 Policy discussion . . . . . . . . . . . . . . . . . . 218

7.7 Further research . . . . . . . . . . . . . . 225 
CONTENTS

Summary 267

Samenvatting 281 


\section{List of Tables}

1 Contents overview. . . . . . . . . . . . . . . 6

1.1 Overview of selected studies on the process of student attrition. 17

1.2 Overview of selected studies on the role of labor market outcomes. . . . . . . . . . . . . . . . . 19

2.1 Dropout rates of the EU-12 countries. . . . . . . . . . . 50

2.2 Job market conditions in the EU-12 countries. . . . . . . . . 51

2.3 Economic development in the EU-12 countries. . . . . . . . 52

2.4 Absolute dropout rate performance of the EU-12 countries. . 56

2.5 Explaining the net policy influences by enrollment of boys in VET, quality of educational resources, and quality of human resources. . . . . . . . . . . . . . . 60

3.1 Descriptive statistics of school dropout rates in the Municipality of Amsterdam. . . . . . . . . . . . . 83

3.2 Duration Models for school dropout. . . . . . . . . . . . . 89

3.3 Estimation results for effectiveness of improved registration. . 95

4.1 Dropout prevention measures as outlined in the covenant. . . 105

4.2 Descriptive statistics of BRON. . . . . . . . . . . . . 113

4.3 Effectiveness of dropout prevention measures using a panel probit model. . . . . . . . . . . . . . . . . 117 
4.4 Effectivenss of dropout prevention measures using quantile regressions. . . . . . . . . . . . . . . . 118

5.1 Cross-table treatment and control group using two time periods.133

5.2 Descriptive statistics of compulsory education age evolution. . 136

5.3 DiD outcomes with various model specifications. . . . . . . 147

5.4 Estimation results of the robustness analysis. . . . . . . . . 150

6.1 Cross-table of treatment and control group using four cohorts and two time periods. . . . . . . . . . . . . 169

6.2 Descriptive statistics of student characteristics. . . . . . . 172

6.3 School characteristics and enrollment trends of RTC Amsterdam and RTC Utrecht. . . . . . . . . . . . . . . . . . 173

6.4 Estimation results for native Dutch students. . . . . . . . . 179

6.5 Estimation results for Ethnic minority students. . . . . . . . . 180

6.6 Job market opportunities for youngsters aged 17 or younger without a school-leaving certificate. . . . . . . . . . . . 184

7.1 The main contributions to the literature. . . . . . . . . . 193

7.2 Definition of the variables in the VOCL99 questionnaire. . . . 205

7.3 Descriptive statistics of a sample of pre-vocational students in the VOCL99 survey. . . . . . . . . . . . . . . . . 207

7.4 Correlation Matrix. . . . . . . . . . . . . . . . . . . 210

7.5 Estimation results of a probit regression. . . . . . . . . . 214

7.6 School attendance rate based on decision rule. . . . . . . . . . 215 


\section{List of Figures}

1.1 Dropout determinants in the literature. . . . . . . . . . . 21

1.2 An economic perspective on school dropout and dropout prevention: interaction between home, school, and labor market institutions. . . . . . . . . . . . . . . 24

1.3 An economic perspective on school dropout and dropout prevention: determinants, measures, and interventions. . . . . . 25

2.1 Percentage of the population aged 18-24 with at most lower secondary education and not in education or training (2009) and its evolution $2000-2009 . \ldots \ldots$. . . . . . . . 39

2.2 "Naming and shaming" based on policy influences. . . . . . . 55

2.3 Enrollment rates of boys in vocational education and training and change in dropout thanks to policy. . . . . . . . . . 57

2.4 Mean index of the quality of the schools' educational resources and change in dropout thanks to policy. . . . . . . . . . 58

2.5 Mean index for availability and quality of human resources and change in dropout thanks to policy. . . . . . . . . . . 58

3.1 Survival probabilities of regular school attendees compared with truants. . . . . . . . . . . . . . . 85

3.2 Average number of days in research by the compulsory education age officer. . . . . . . . . . . . . . . 91 
4.1 Flow chart of the Dutch Education System. . . . . . . . . . 103

4.2 Quantile estimates of dropout prevention measures. . . . . . . 120

5.1 Dropout rates in the municipality of Amsterdam. . . . . . . . 133

5.2 Percentage annual change in employment among 15-25 years olds. . . . . . . . . . . . . . . . . . . . 141

5.3 Normalized dropout rates among 16-17 years old. . . . . . . . 144

5.4 Normalized percentage monthly change in employment. . . . 145

6.1 Overview of the regional dropout authorities in the Netherlands. 165

7.1 Actual enrollment rates and predicted enrollment rates for the Netherlands, by policy intensity and over the years 2000-2008. 216 


\section{General Introduction}

Public expenditure on secondary education has increased substantially in OECD countries over the period 2000-2009. For example, total public expenditure rose by 40.7 percent in the United States of America from $€ 155,580$ million to $€ 218,943$ million, by 63.3 percent in the United Kingdom from $€ 27,938$ million to $€ 45,638$ million, and by 53.8 percent in the Netherlands from $€ 8,056$ million to $€ 12,390$ million (OECD Database, 2012; Eurostat, 2012). This finding is in line with the special attention paid to educational attainment over the last decade (OECD, 1983, 1999, 2001, 2009). Whereas one in five students aged 18-24 left secondary education without a higher secondary certificate in the EU-27 before the year 2000, the average dropout rate declined to 13.5 percent in 2011, representing about 6 million youngsters (Eurostat, 2012). A student below the age of 24 without a higher secondary certificate and who is not further enrolled in education or training is considered a school dropout. ${ }^{1,2}$

The observed level and decline of the average school dropout rate in

\footnotetext{
${ }^{1}$ In this dissertation 'early school-leaving' and 'school dropout' are synonyms. Also 'high school' and 'secondary education' are synonyms. The higher secondary level is equal to the European definition with respect to ISCED-3 level.

${ }^{2}$ Depending on the compulsory education age, the age of the dropout student ranges from 16-24 to 18-24, in some cases hampering comparison of the dropout rate between countries. Unless otherwise stated in this dissertation, we handle the definition with respect to students aged 18-24 (More information: U.S. Department of Education; European Commission, and Eurostat).
} 
the EU-27 differs greatly between its Member States. For example, in the United Kingdom average dropout rates have decreased from 18.2 percent in 2000 to 15.0 percent in 2011, in the Netherlands from 15.4 percent to 9.1 percent, in Spain from 29.1 percent to 26.5 percent, and in Portugal from 43.6 percent to 23.2 percent. In the US, the decline in early school-leaving is typically expressed by an increase in the average graduation rate from secondary education. Among students aged 18-24 year-olds going to school in the US, the average graduation rate was 86.5 percent in 2000 and increased to 89.9 percent in 2008, representing more than 1.2 million early leavers from education each year (US Department of Education, 2010). ${ }^{3}$ Average school dropout rates are more difficult to track for Austrialia; however, 43 percent of people aged 25-64 had at most a lower secondary certificate in 1999. This percentage may be compared with 13 percent in the United States, 21 percent in Canada, 38 percent in the United Kingdom,19 percent in Germany and 38 percent on average in the OECD (OECD, 2001, Tables A2.2a and A2.2b). Early school-leaving is part of many lives.

The alarming level of the school dropout rates has risen to the top of the education policy agenda of many OECD countries for several reasons. First, compared with high school graduates, school dropouts have higher private costs owing to increased risks of unemployment and bad health. Second, there are increased costs to society, as school dropouts are more often involved in criminal activities or social exclusion. Higher school dropout rates are also associated with a lower rate of economic growth. Third, there are losses in fiscal revenues due to lower tax payments, increased unemployment allowances or social benefits, further burdening social security (for an overview of the consequences of early school-leaving, see Psacharapoulos, 2007). As such, early school-leaving is not desirable, not only for the

\footnotetext{
${ }^{3}$ This percentage share denotes only high school completers from state schools, excluding students who obtained other credentials than a high school certificate or high school equivalency recipients (U.S. Department of Education, 2010).
} 
individual but also for society.

Accordingly, OECD countries are paying considerable attention to dropout prevention programs that successfully deal with the problem of leaving school early. Government officials and policymakers are working towards a target of an average school dropout rate of at most 10 percent (EU-27) or an average high school graduation rate of 90 percent (US). This target of 10 percent (90 percent) was established in 2000 among the Lisbon Agenda Targets, recently reestablished in, respectively, the Europe 2020 Initiatives and in the No Child Left Behind Act in the US. School dropout is hereby increasingly considered as "a pivot" or "key investment" for reaching other policy targets. The European Commission (2011a, p.2) states in this respect that: "Drastically reducing the numbers of young people leaving school early is a key investment not only in the prospects of each and every one of its young people but also in the future prosperity and social cohesion of the EU in general." And "[...] reducing early school-leaving is also a gateway to reaching other Europe 2020 targets (p.2)."

\section{Problem statement}

Determining the most effective way to tackle early school-leaving is not straightforward, as it depends on many underlying problems at home, at school, or in the neighborhood. The previous literature has developed various research strategies from different angles, e.g. literature reviews, linear regressions, probit and logistic (multi-level) models, and to a lesser extent duration models and experimental designs in order to better understand the nature and impact of the school dropout problem, as well as its determinants. Research output in this field has indicated that school dropout is heavily associated with gender, ethnicity, class composition, exam success, motivation, retention in grade, unauthorized truancy, and job market opportunities, among many other determinants. The existing literature fur- 
ther reveals that school dropout is a complex problem, dynamic in nature and heterogeneous among individuals (for a recent overview, see Rumberger, 2011).

Dropout prevention is moreover expensive. For instance, Levin and Rouse (2012) recently debated the true costs of US high school dropouts in the New York Times. They estimate a return on policy investment in reducing the number of school dropouts by as much as $\$ 1$ trillion over an 11 year time span. This large amount of money captures social security and unemployment benefits, higher costs of public services, and loss in tax revenues.

So what can be done effectively to prevent students from school dropout? Policy measures or interventions that tackle the problem of early schoolleaving should be assessed on their effectiveness, and only be continued if they have been proven to work. This is the subject of this dissertation.

\section{Evidence-based dropout prevention}

In this dissertation, we analyze the effectiveness of dropout prevention programs (as a bundle of activities), measures, or interventions. We have structured the dissertation in three parts covering a total of seven chapters (see Table 1). Part I, consisting of Chapter 1 and Chapter 2, deals with an introduction to school dropout and dropout prevention. We outline a conceptual model for school dropout and dropout prevention in Chapter 1 based on the previous literature on school dropout determinants and contemporary dropout prevention initiatives. It is followed by a cross-country study on dropout prevention in Chapter 2. In particular, we use a linear panel data benchmarking model to rank countries' performances with respect to dropout prevention over the last decade. From the cross-country study, the Dutch dropout prevention program is identified as an interesting case study for further analysis. 
Part II, consisting of Chapters 3 to 6 , deals with an evaluation of dropout prevention measures or interventions in the Netherlands. In Chapter 3, we evaluate the reliability and validity of registration of school attendance/absence in Dutch secondary schools. A good measurement instrument is indispensible when it comes to the evaluation of dropout prevention. We put emphasis on the registration of unauthorized truancy, which is one of the best predictors of a forthcoming school dropout decision. Data difficulties in this respect arise due to multiple definitions, missing values, or the nature of the truancy spell. We propose a Bayesian duration model to reveal data difficulties, as well as the timing of a forthcoming school dropout decision.

The Dutch dropout prevention program consists of a bundle of dropout prevention measures (called 'menu-items'). We explore all menu-items in Chapter 4, and evaluate them by a panel probit model (micro-level) and quantile regression techniques (meso-level). Using the former microeconometric technique, we associate the individual probability of dropping out with each dropout prevention measure. The latter estimation technique is used to deal with differences in the effectiveness of dropout prevention menu-items along the distribution of the dropout rate.

The impact of an increased compulsory education age on school dropout is estimated in Chapter 5. Changing the compulsory education age is a rather straightforward way of dropout prevention, because it compels students to stay in school until this age is reached. In the year 2007, there was a change in the compulsory education age from 17 to 18 in the Netherlands. We exploit this policy reform to estimate the impact of a one year increase in the compulsory education age on school dropout. We hereby use a difference-in-differences framework.

Chapter 6 estimates the impact on early school-leaving of enhanced commitment of the student to the school, peers, and teachers. Commitment deals with the optimal match of a student with the school, and therefore 
Table 1: Contents overview.

Part I:

An introduction to dropout prevention
Chapter 1: Dropout and prevention in the literature

Chapter 2: A cross-country study on dropout prevention
Part II:

Dropout prevention in the Netherlands

Part III:

General conclusion
Chapter 7: Challenges for prevention policy: what and for whom? 
finds its origin in theories of student attrition. Since the school year 200708, there has been improved care for students at-risk of dropping out in the Netherlands. Students enrolled in a pre-vocational track are considered atrisk of dropping out when they make their transition from the pre-vocational to the vocational school at the age of 16 . These pre-vocational students have to physically change schools, as the pre-vocational school does not offer advanced vocational subjects. They transfer to the vocational school during the 3-month summer break and may additionally lose connection with peers and teachers. A policy reform has enhanced commitment by smoothing the transition from the pre-vocational to the vocational school. From a methodological point of view, Chapter 6 follows naturally from Chapter 5 because it extends the difference-in-differences framework with a third difference.

Part III consists of only Chapter 7. This chapter presents a theoretical model, with an empirical application, on the enrollment decision of students in secondary education. It is the aim of this chapter to combine all findings of the various chapters in one framework, and to present a policy discussion and a scope for further research in line with these findings. 

Part I

An Introduction to School
Dropout and Prevention 



\title{
Chapter 1
}

\section{School Dropout and Prevention in the Literature}

\author{
"Early school-leaving can be prevented through systematic \\ evidence-based policies.” \\ (European Commission, 2011a, p.5)
}

\subsection{Introduction}

A bird's-eye view of existing conceptual frameworks has shown that previous research has identified most of the dropout determinants that are part of the process of student attrition (see De Witte et al., 2013). Students are often piling up problems before the actual decision is made. Several determinants in this respect have been highlighted that particularly contribute to the process of student attrition, for instance: low achievement in school (Dustmann and van Soest, 2007; Dalton et al., 2009); unauthorized truancy (Schaefer and Millman, 1981; Attwood and Croll, 2006; Henry, 2007); retention in grade (Roderick, 1994; Jimerson, 1999; Planc et al., 2005); a general dislike of school (Ehrenberg and Brewer, 1994); deteriorating student motivation (Adams and Becker, 1990; Jencks and Mayer, 1990; Wenger, 2002; De Witte and Rogge, 2009; Anderson, 2010); lack of commitment to peers or teachers (Spady, 1970; Tinto, 1975), student mobility (Rumberger and 
Larson, 1998; Strand and Demie, 2007); criminal behavior (Elliot and Voss, 1974; Phillips and Kelly, 1979); a history of drug abuse (Fergusson et al., 2003; ter Borgt et al., 2009); socioeconomic status (Nelson et al., 1996; Herbert and Reis, 1999; Rumberger, 2004; Bobonis and Finan, 2009); teenage pregnancy (Hibbert and Fogelman, 1990); and bad health shocks (Groot and Maassen van den Brink, 2007; Albouy and Lequien, 2009; Powdthavee, 2010).

However, in spite of a significant and high correlation between the above listed factors and school dropout, it is not possible to fully explain, by applying theories of student attrition, why the serious problem of early schoolleaving may substantially differ in nature and extent, depending on the country concerned. For example, the rate of early school-leaving in the year 2000 in Portugal was about 40 percent and in Sweden about 10 percent. We observe that the average school dropout rate in secondary education among the EU-27 Member States has declined from over 30 percent before 1990 to less than 15 percent in 2009 (Eurostat, 2011). We also observe that, in high income countries, more children are now participating in secondary education. The average number of years a student attends school in the EU Member States (i.e. school expectancy) is as much as 17 years in 2009. ${ }^{1}$ Women have also gained ground in education. For example, at the start of the 20th century, female high school students seldom went on to tertiary education. Nowadays, there are relatively more women than men in tertiary education (for an extensive overview, see European Commission, 2011b). These facts and figures are quite remarkable, given the complexity of the school dropout problem. If only the underlying factors of student attrition are responsible for students leaving school early, then increasing enrollment rates in secondary education should go hand in hand with a proportional

\footnotetext{
${ }^{1}$ The school entrance age (set as 5 years old) is substracted from the age at which the student leaves secondary or tertiary education to calculate the number of years of school expectancy (European Commission, 2011).
} 
rise of school dropout rates. But this is not the case.

A literature review reveals a second line of research, and adds meaningful insights to the traditional framework. This line of research argues that both the overall level of the economy, often expressed as per capita gross domestic product (GDP), and technological change are influencing the level and changes of school dropout rates in the long-run (for some studies in this field, see Aghion and Howitt, 1998; Benhabib and Spiegel, 2005; Krueger and Lindahl, 1998; Hanushek and Woessmann, 2010). And in the shortrun, the economic cycle is responsible for a volatile demand for labor among (early) school-leaving youth (Shavit and Müller, 1998; Gangl, 2002). The market mechanisms on the labor market and its interaction with the "education market" play a crucial role in this respect. For example, an increasing share of students may anticipate job market opportunities in times of an economic revival, and leave secondary education early (Cedefop, 2008, 2010; European Commission, 2005, 2010a, 2010b, 2011a). As such, school-leaving and dropout become a dynamic process that also depends on market conditions, innovation, and capability for the job (see also Chapter 2).

In this chapter, we add an economic perspective on school dropout and dropout prevention to the traditional model (i.e. dropout determinants as part of the process of student attrition). The economic perspective hereby incorporates labor market outcomes, directly or indirectly influenced by the overall level of the economy, technological change, and the economic cycle, into the traditional model.

This introductory chapter proceeds as follows. First, in Section 1.2 we elaborate on the determinants/triggers to drop out of school. It is important to understand why youngsters leave secondary education early before turning to dropout prevention. We hereby categorize the previous literature by (1) the process of student attrition; and (2) the role of the labor market. A conceptual model for school dropout and dropout prevention is presented 
in Section 1.3, followed by a discussion of contemporary dropout prevention initiatives in several countries. The idea is that these practices should anticipate (the leading) school dropout determinants. We conclude in Section 1.3 with a note on the effectiveness of dropout prevention. A conclusion and discussion are provided in Section 1.4.

\subsection{School dropout in the literature}

The following subsections consist of a literature summary by school dropout determinant and year of publication (see Tables 1.1 and 1.2). These tables are convenient for plotting tendencies over several decades of research in the field of school dropout.

\subsubsection{The process of student attrition}

Starting in the 1970s with the work of Tinto (1975) and Spady $(1970,1971)$, the previous literature on student attrition and school attendance behavior largely discusses the optimal match between the student and the school. Finn (1989) further argues that lack of participation in all kind of school activities affects the student's self-esteem and achievement and may lead to problematic behavior. The author describes student outcomes in two conceptual models: the participation-identification model, and the frustrationself-esteem model. In this connection, one way to prevent students from early school-leaving is to enhance the commitment of the student to the school, peers and teachers. It is shown in the literature that commitment may encourage the student to attend class (Firestone and Rosenblum, 1988; Pittman and Haughwout, 1987; Pittman, 1991; Lee and Burkam, 2003). School attendance may slow down or, ideally, avoid the process of student attrition, stimulating more youngsters to achieve a school-leaving certificate (Adams and Becker, 1990; Rumberger, 2001; De Witte and Rogge, 2009).

Later work of Rumberger (2001) and Rumberger and Larson (1998) has 
analyzed the optimal match of the student with the school from two perspectives: the individual and the institutional perspective. The authors ascribe the dynamic and cumulative process of disengagement (Newman et al., 1992) or withdrawal (Finn, 1985) to changing school too often. For example, in the United States there is a high turnover, partly because of poverty and family problems, and partly because of the school (e.g. students are expelled from school). Rumberger and Larson (1998) claim that at least half of the differences in student outcomes are the result of changing school. In addition, a very good indicator for the process of disengagement is unauthorized school absenteeism (hereafter referred to as truancy). Already in the 1980s, Schaefer and Millman (1981) argued for a positive relationship between truancy and school dropout. However, the previous literature used various measures for truancy and dropout (e.g. self-reported measures, or those defined by the teachers and/or school) providing no consistency due to multiple definitions and data difficulties (Bos et al., 1992; Attwood and Croll, 2006; Henry, 2007). One central database may offer the opportunity to trace a potential dropout and prevent him/her from dropping out of school (e.g. the unique identification number as established in the United Kingdom, the Netherlands, Germany, and Italy, and in most US states).

Following the optimal match of the student with the class/school; Rumberger (1983, 2004), Bynum and Thompson (1983) and Levin (1987) address school dropout on the basis of the school or class composition. For example, boys and students with a foreign ethnicity are more likely to leave school than girls or native students. In further research, Jencks and Mayer (1990), Wenger (2002), Rumberger and Palardy (2005) and Anderson (2010) address school dropout as influenced by class composition, otherwise known as 'peer effects': the interaction between students may lead to more or fewer dropouts. On the one hand, potential dropout students who have a general dislike of school may negatively influence the motivation exerted by peers 
and teachers. On the other hand, students who like school may positively motivate a potential dropout student to stay in class. The influence of others indicates the crucial role of parents, peers, and teachers to provide guidance through the study curriculum.

\subsubsection{The role of the labor market}

Bean (1978) and Bean and Metzner (1985) take a rather atypical stance in the literature by discussing the importance of "non-institutional" influences, i.e. those operating outside the school environment. Despite external influences, as addressed in, for example, the work of Tinto (1975), Bean (1978) and Bean and Metzner (1985) have developed a conceptual model for 'nontraditional' students in higher education (i.e. part-time or older students) in order to understand why these kinds of students are more inclined to leave without a certificate. They further discuss the existence of educational arrangements, which are of particular interest for youngsters who combine education with work. The authors aim at a conceptual model for higher education. However, educational arrangements also exist in secondary education, closely connecting the labor market with school and home. ${ }^{2}$

One of the oldest discussions related to educational attainment and labor market outcomes is definitely the regulation of the minimum school-age (or compulsory education age). Starting from the early 1900s, the compulsory education age gradually increased in most OECD countries (LlerasMuney, 2001, 2005; Murtin and Viarengo, 2009). Compulsory education age laws aim at: (1) protecting students from premature labor market entrance (OECD, 1983; Kaufman et al., 2004); (2) meeting the demand for high-skilled workers (Shavit and Müller, 1998; Gangl, 2002); and (3) investing the minimum amount in the human capital needed for prosperity and growth (Becker, 1992; Schultz, 1967; among others). The minimum school-

\footnotetext{
${ }^{2}$ One may think of dual tracks, or the National Vocational Qualifications (NVQs), where the former denotes a combination of learning and working, and the latter a certificate that can be obtained if a student passes a learning module (ROA, 2009/4).
} 
Table 1.1: Overview of selected studies on the process of student attrition.

\begin{tabular}{|c|c|c|c|c|}
\hline & $<1980$ & $1980-90$ & $1990-00$ & $2000-10$ \\
\hline commitment & $\begin{array}{r}\text { Spady } \\
\text { Tinto }\end{array}$ & & Pittman & Lee\&Burkam \\
\hline $\begin{array}{r}\text { intergenerational } \\
\text { mobility }\end{array}$ & Bowles & Stanton & & $\begin{array}{r}\text { Farré (et al.) } \\
\text { Ermisch\& } \\
\text { Pronzato } \\
\text { Currie\&Moretti }\end{array}$ \\
\hline $\begin{array}{l}\text { participation } \\
\text { or withdrawal }\end{array}$ & Becker & Finn & $\begin{array}{c}\text { Adams\&Becker } \\
\text { Ehrenberg\& } \\
\text { Brewer } \\
\text { Kaplan (et al.) }\end{array}$ & $\begin{array}{l}\text { Barron (et al.) } \\
\text { Eide\&Ronan }\end{array}$ \\
\hline juvenile crime & $\begin{array}{r}\text { Elliot\&Voss } \\
\text { Phillips\&Kelly } \\
\text { Hirschi }\end{array}$ & & $\begin{array}{r}\text { Garry } \\
\text { Jarjoura } \\
\text { Grogger }\end{array}$ & $\begin{array}{l}\text { Lochner\&Moretti } \\
\text { ter Borgt (et al.) }\end{array}$ \\
\hline $\begin{array}{r}\text { class } \\
\text { composition } \\
\text { (e.g. gender } \\
\text { ethnicity, peers) }\end{array}$ & Levin & $\begin{array}{l}\text { Rumberger } \\
\text { Bynum\& } \\
\text { Thompson }\end{array}$ & $\begin{array}{r}\text { Swadener } \\
\text { Herbert\&Reis } \\
\text { Farkas (et al.) } \\
\text { Jencks\&Mayer }\end{array}$ & $\begin{array}{c}\text { Kaufman (et al.) } \\
\text { Phinney (et al.) } \\
\text { Dalton (et al.) } \\
\text { Rumberger\& } \\
\text { Palardy }\end{array}$ \\
\hline truancy & & $\begin{array}{c}\text { Schaefer\& } \\
\text { Millman } \\
\text { Helm\&Burket }\end{array}$ & Roderick (et al.) & $\begin{array}{r}\text { Attwood\&Croll } \\
\text { Henry }\end{array}$ \\
\hline $\begin{array}{r}\text { student mobility } \\
\& \text { disadvantaged } \\
\text { neighborhoods }\end{array}$ & & Felner (et al.) & $\begin{array}{c}\text { Rumberger\& } \\
\text { Larson } \\
\text { Nelson (et al.) }\end{array}$ & $\begin{array}{r}\text { Strand\&Demie } \\
\text { Rumberger\& } \\
\text { Lamb } \\
\text { Blue\&Cook } \\
\text { Bobonis\&Finan }\end{array}$ \\
\hline
\end{tabular}

Note: Continued on the next page. 
CHAPTER 1. SCHOOL DROPOUT AND PREVENTION IN THE

\begin{tabular}{|c|c|c|c|c|}
\hline & $<1980$ & $1980-90$ & $1990-00$ & $2000-10$ \\
\hline health & & & $\begin{array}{r}\text { Hibbert } \\
\text { Fogelman }\end{array}$ & $\begin{array}{r}\text { Lleras-Muney } \\
\text { Ding\&Lehrer } \\
\text { Currie }\end{array}$ \\
\hline drug abuse & & & Yamada (et al.) & $\begin{array}{r}\text { Roebuck (et al.) } \\
\text { Fergusson (et al.) } \\
\text { ter Borgt (et al.) } \\
\text { Chatterji }\end{array}$ \\
\hline $\begin{array}{l}\text { retention in grade } \\
\text { and student age }\end{array}$ & & & $\begin{array}{l}\text { Roderick } \\
\text { Jimerson }\end{array}$ & $\begin{array}{l}\text { Entwisle (et al.) } \\
\text { Plank (et al.) }\end{array}$ \\
\hline $\begin{array}{l}\text { minimum } \\
\text { school-age }\end{array}$ & & & & $\begin{array}{r}\text { Lochner\&Moretti } \\
\text { Lleras-Muney } \\
\text { Albouy\&Lequien } \\
\text { Wenger }\end{array}$ \\
\hline
\end{tabular}

age is a rather straightforward way of dropout prevention. For example, if there is a difference between the compulsory school-age and the graduation age, the idea is that, by staying in school until the graduation age is reached, more students will eventually obtain a school-leaving certificate before entering the labor market. Or, in other words, by legislating on compulsory education, school dropout can be eliminated.

Economic research has often used the minimum school-age as an exogenous source for variation in educational attainment and differences in labor market outcomes (for some examples, see; Angrist and Krueger, 1991; Acemoglu and Angrist, 2000; Aakvik et al., 2003; Pischke and von Wachter, 2005; Oreopoulos, 2003, 2006, 2007). A substantial literature has estimated the returns to education using changes in compulsory education age laws. Several theories on the returns to education ascribe an important role to the labor market when it comes to optimal study choice and track. The theory suggests that students analyze the opportunity costs of an additional year in school. As such, they balance costs and benefits (often expressed in future earnings) of staying in school. If the costs of an additional year in 
Table 1.2: Overview of selected studies on the role of labor market outcomes.

\begin{tabular}{|c|c|c|c|c|}
\hline 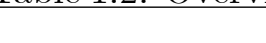 & $<1980$ & $1980-90$ & $1990-00$ & $2000-10$ \\
\hline $\begin{array}{l}\text { investment in } \\
\text { human capital }\end{array}$ & $\begin{array}{r}\text { Spence } \\
\text { Nelson\&Phelps } \\
\text { Schultz } \\
\text { Mincer }\end{array}$ & & Becker & \\
\hline $\begin{array}{r}\text { educational } \\
\text { arrangements }\end{array}$ & Bean & $\begin{array}{l}\text { Bean\& } \\
\text { Metzner }\end{array}$ & $\begin{array}{l}\text { Barron (et al.) } \\
\text { Heckman (et al.) }\end{array}$ & $\begin{array}{r}\text { Dustmann\& } \\
\text { van Soest } \\
\text { Dalton (et al.) }\end{array}$ \\
\hline $\begin{array}{r}\text { job market } \\
\text { opportunities }\end{array}$ & Reich\&Young & & Shavit\&Müller & $\begin{array}{r}\text { Gangl } \\
\text { Kaufman (et al.) } \\
\text { Marks\&Fleming } \\
\text { Allensworth } \\
\text { Pietro }\end{array}$ \\
\hline $\begin{array}{l}\text { returns to } \\
\text { education }\end{array}$ & & & $\begin{array}{r}\text { Angrist\&Krueger } \\
\text { Card } \\
\text { Colm\&Walker } \\
\text { Heckman\& } \\
\text { Vytlacil } \\
\text { Brunello\& } \\
\text { Raffaele } \\
\text { Kane (et al.) }\end{array}$ & $\begin{array}{r}\text { Acemoglu\&Angrist } \\
\text { Aakvik (et al.) } \\
\text { Oosterbeek\& } \\
\text { Webbink } \\
\text { Pischke\& } \\
\text { von Wachter } \\
\text { Oreopoulos }\end{array}$ \\
\hline $\begin{array}{l}\text { educational } \\
\text { attainment and } \\
\text { GDP growth }\end{array}$ & & & $\begin{array}{l}\text { Aghion\&Howitt } \\
\text { Krueger\&Lindahl }\end{array}$ & $\begin{array}{c}\text { Benhabib\&Spiegel } \\
\text { Hanushek\& } \\
\text { Woessmann }\end{array}$ \\
\hline
\end{tabular}


school exceed the benefits, the student will decide to leave school (early). Job market opportunities, aside from the underlying factors of student attrition, may then be considered a crucial dropout determinant. Allensworth (2005) argues in this respect that, from the early years on, the student will study with the view to searching for an optimal match with the labor market. Other authors reasonably add that work experience beyond school time also drives labor market wages (Coleman, 1984; Ruhm, 1997; Light, 1998, 1999).

Already in the 1970s, Reich and Young (1975) attributed as much as 53 percent of student dropout to job market opportunities. The more recent work of Shavit and Müller (1998), Müller and Gangl (2003) and Cabus and De Witte (2011a) ascribes differences in the dropout rate to heterogeneity across countries arising from the link between early school-leaving and the labor market and the general economic climate. The increasing necessity of high-skilled labor follows naturally from a rising knowledge society (Müller and Gangl, 2003). Low-skilled school-leaving youngsters are most vulnerable to technological change and job market conditions, causing youth unemployment in periods of economic decline or job market opportunities in periods of economic revival (see, among others, Shavit and Müller, 1998; Marks and Fleming, 1999; Gangl, 2002; Weltz, 2005; Rojvithee, 2005; Mikami, 2005; Schmidt Schilling, 2005; Cedefop, 2008, 2010; European Commission, 2005, 2010a, 2010b, 2011a). The evidence indicates that 42 percent of 25-64 year-olds school dropouts are unemployed in OECD countries. Among high school graduates aged 25-64 with at least a higher secondary certificate, this share declines to 24 percent (OECD, 2009). The incidence of early schoolleaving is highest among students in vocational study subjects, where the labor market literally penetrates the inner circle of the school. This finding may be awkward as almost 50 percent of students in the US are involved in vocational pathways as a major part of their study curriculum (Weltz, 


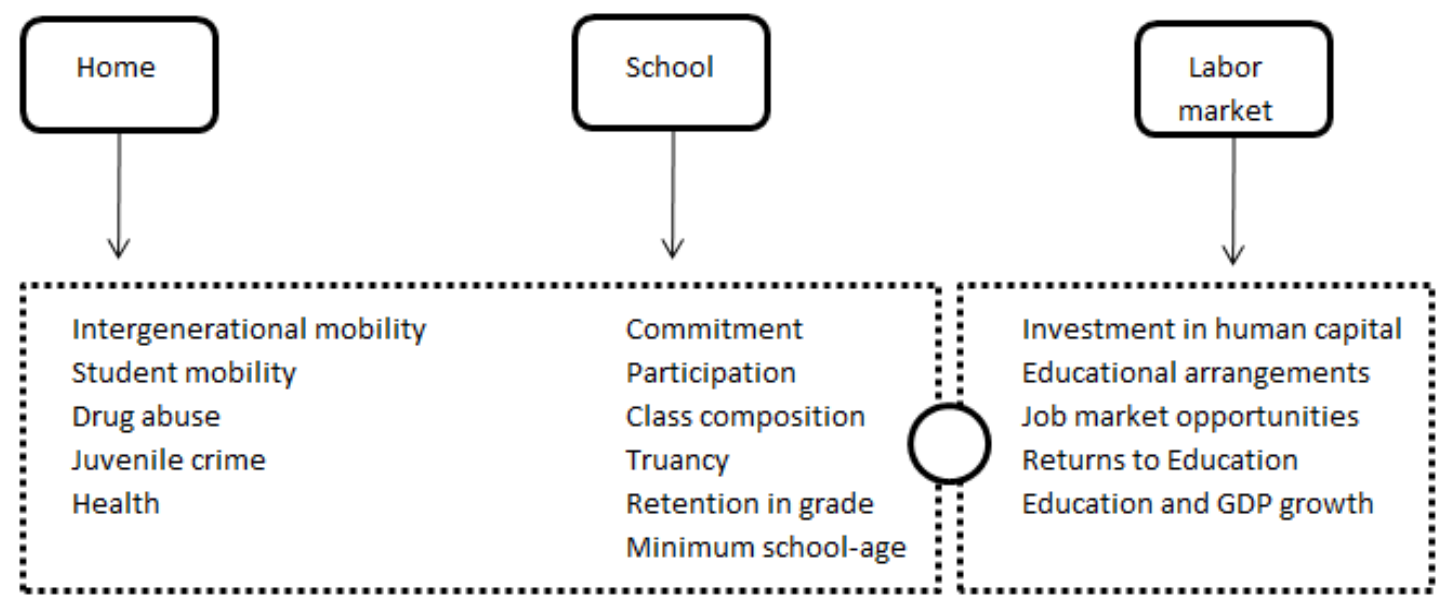

Figure 1.1: Dropout determinants in the literature.

2005). In the European Union this share increases to about 60 percent for male students and 50 percent for female students (Eurostat, 2008).

A dynamic market process should, however, be able to match the right person to the right job. From the past literature, it is known that a mismatch between employer and employee may occur due to several reasons (see, among others, Barron, 1997; Burgess and Profit, 2001; Hall, 2005; Pissarides, 1985, 2000, 2009). For example, children are put too often and too soon to work (Lochner and Moretti, 2004; Lleras-Muney, 2001, 2005); employers are trying to figure out the different types of school-leaving certificates among schools, countries, or states (Shavit and Müller, 1998; Gangl, 2002); or employees are overqualified for the job (Groot and Maassen van den Brink, 2000). In particular, there are major imbalances in most countries between vocational specialization and occupational needs, where schools fail to adjust their training to the needs of the job market. Consequently, there has been a debate between policymakers and practitioners, employers and unions, parents and students, over the last century about the minimum school-age and valid school-leaving certificates (see: Cedefop, 2008, 2010; 
European Commission, 2005, 2010a, 2010b, 2011a; OECD, 2009). And at the supra-national level there is a lively debate on valid school-leaving certificates and student mobility across countries (or states). For example, the European Union established the Bologna-agreement, which facilitates students to take up a particular study load during their school career in tertiary education institutes in other European Union countries (European Communities, 2009). From these long-lasting debates in education and labor market tendencies, school dropout has become an indicator heavily associated with bad prospects and intergenerational lifetime disadvantages.

\subsection{A framework for dropout and prevention}

\subsubsection{A conceptual model}

A new conceptual model for school dropout and dropout prevention is discussed as follows. The framework deals with school dropout and dropout prevention from an economic perspective, as the general economic climate literally penetrates the domain of the school, for example, by job market opportunities, vocational education and training, internships or apprenticeships. Thus, in line with the previous literature, here the role of the labor market is taken into account in influencing the level and change of school dropout rates. Thus, two parallel lines of research are connected by considering (1) home; (2) school; and (3) labor market school dropout determinants (see Figure 1.1). This largely follows Rumberger (2001) who used family, school, and communities as institutions. The institution of home captures the student and his/her family and in which community he/she lives. The student is part of a school, an institution that consists of peers, teachers and school staff (see also Rumberger and Larson, 1998). The ambitions of the student are influenced by the condition of the labor market in his/her community and beyond. The individual or student is part of, and influenced by, the three institutions of home, school, and labor market. As such, we 
position the individual at the inner triangle of Figure 1.2.

From the interaction between home, school and labor market institutions, school-based pathways, work-based pathways and a job market arise (see Figure 1.2). In this way, we present school dropout as dynamic in nature. As a result of the dynamic relationship directly or indirectly affecting the individual, dropout determinants interact with each other, even reinforce or cancel each other out. This is in line with the previous literature, which finds that students pile up problems before the decision to leave education early is made.

School-based pathways are largely organized by education at the school property and, are therefore, hardly influenced by labor market pull factors (e.g. short-term job market opportunities). Nonetheless, school attendance behavior may be driven by job market aspirations. The student mainly attends class to prepare him/her for higher/university education, meeting the demand for high-skilled labor. Work-based pathways, one the other hand, assign school time to learning on the job. They are closely connected with the labor market through vocational education and training, internships or apprenticeships. In particular countries, work-based or vocational-oriented pathways are no longer considered as part of secondary education. Nonetheless, they aim at (school-aged) students who enroll to obtain a valid schoolleaving certificate for labor market entrance.

On the job market, employers demand cognitive and non-cognitive skills that are necessary for the job. Already a few decades ago, Spence (1973) discussed educational attainment as a function of job market signaling. Investment in educational attainment may then be considered as an investment in human capital (Nelson and Phelps, 1966; Schultz, 1967; Becker, 1965, 1992; Mincer, 1974). A valid certificate indicates a particular level of cognitive and non-cognitive skills (Spence, 1973). It requires, however, a (sub)national (minimum) standard of what is considered a valid certificate 
CHAPTER 1. SCHOOL DROPOUT AND PREVENTION IN THE LITERATURE

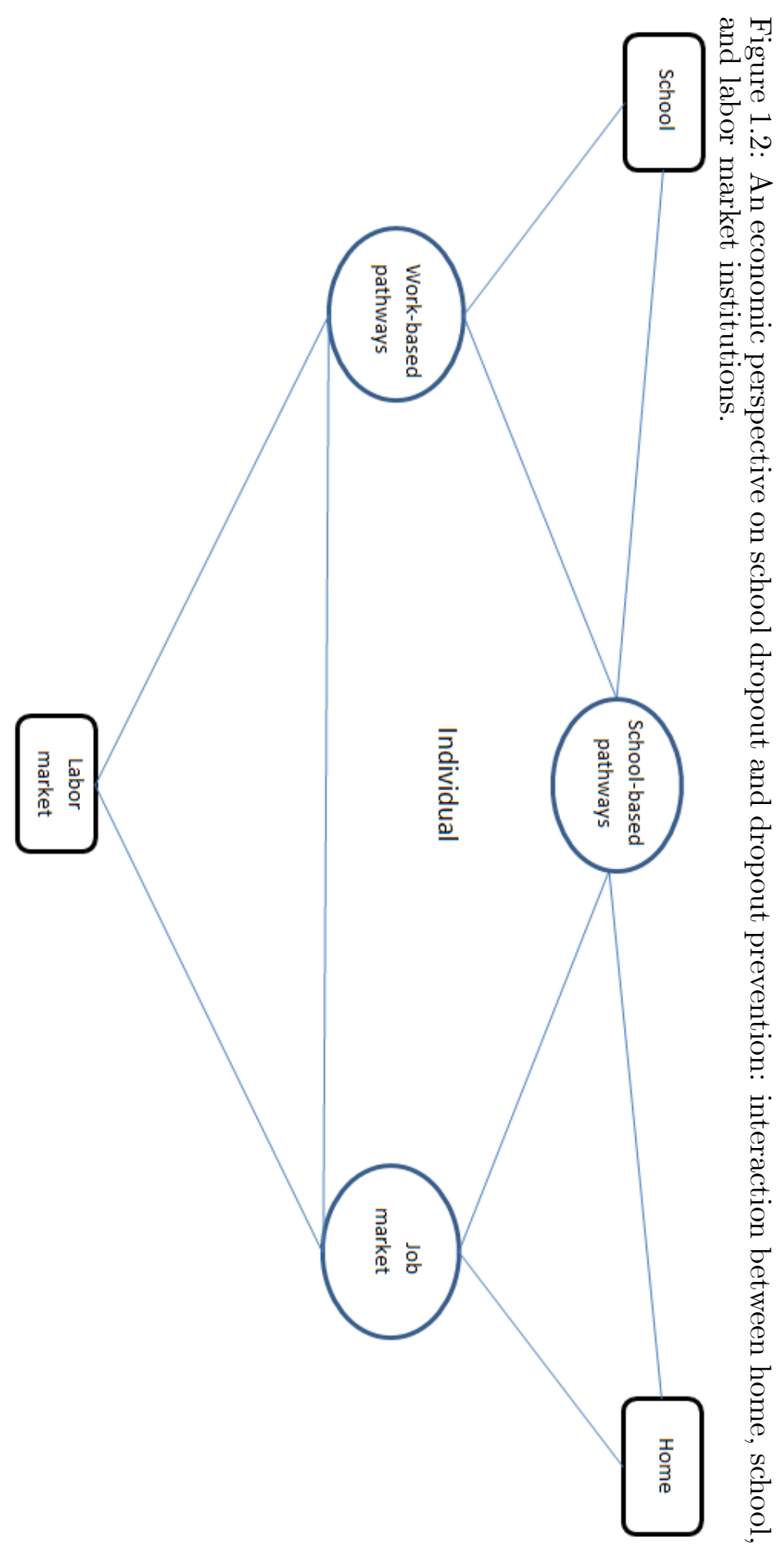




\subsection{A FRAMEWORK FOR DROPOUT AND PREVENTION}

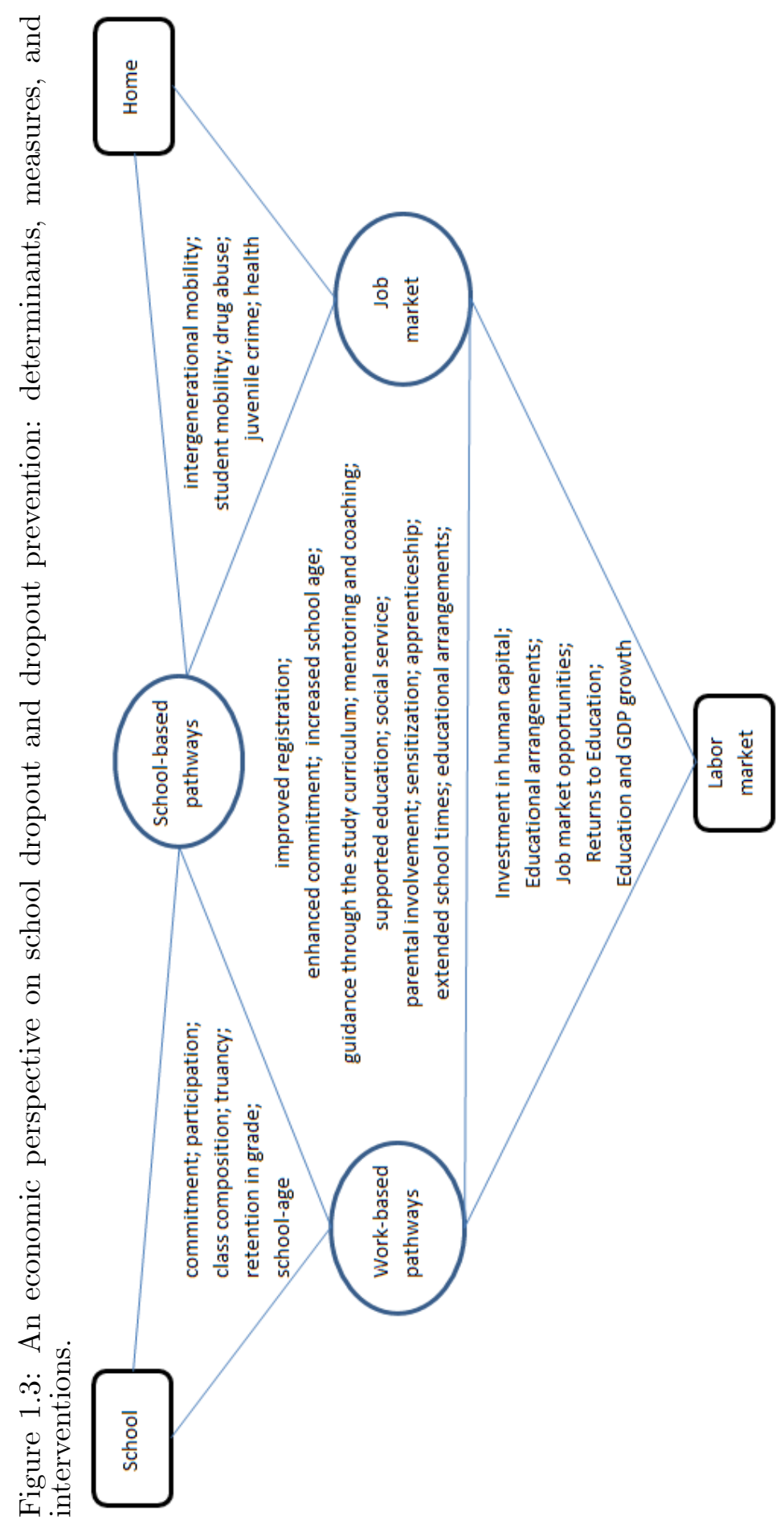


to make the signal work. Where school dropout is an indication of failing high school graduation, it starts with the beliefs and laws of policymakers and practioners, teachers and parents, and employers and workers on what is considered a valid certificate.

\subsubsection{Contemporary dropout prevention initiatives}

Figure 1.3 provides a summary of the leading dropout determinants (see Section 1.2) and a non-limited list of dropout prevention measures or interventions which nowadays are part of prevention programs that could successfully counteract school dropout determinants. Dropout prevention measures are positioned in the inner circle of the triangle because: (1) they mainly aim at the individual and not at institutions; and (2) dropout prevention initiatives are established and influenced by the institutions (and their interactions) (see also Chapter 4). Dropout prevention targets potential dropout students already in early childhood, or in basic/primary or secondary education, before the actual decision to leave school is made. The idea is that, to reduce the number of early school-leavers, prevention programs should be implemented, preferably as early as possible in their school career. By now many countries have developed dropout prevention programs that have engaged most stakeholders in education (OECD, 2010). In this present Section, we outline contemporary dropout prevention measures or interventions in the United States of America and the European Union. We discuss these contemporary dropout prevention measures or interventions in line with the conceptual model for school dropout and dropout prevention.

\section{United States of America}

The US National Dropout Prevention Center/Network summarizes the effectiveness of more than 300 programs aiming at youngsters at-risk of school dropout. Its primary goal is to evaluate dropout prevention programs devel- 
oped by states, communities and schools by research. ${ }^{3}$ In total 15 'strategies' for dropout prevention have been identified as effective in reducing the dropout rate. They are: systematic renewal; school-community collaboration; safe learning environments; family engagement; early childhood education; early literacy development; mentoring and tutoring; service-learning; alternative schooling; after-school opportunities; professional development; active learning; educational technology; individualized instruction; and Career and Technology Education (for an extensive description of these 15 US strategies for dropout prevention, see Smink and Shargel, 2004; National Dropout Prevention Center/Network, July 2012).

The above listed dropout prevention strategies typically aim for dropout triggers related to problems at home, at school, or both. For example, the National Dropout Prevention Center/Network argues for an educative community that may be enhanced by parental involvement or the establishment of community schools (see also Drew, 2004; Heers et al., 2011). Public funds are available for (low performance) schools that establish whole-school reforms. In particular, school reforms with solid evidence on their effectiveness are supported with grants (Borman et al., 2002). The President of the US Barack Obama recently committed financial support of $\$ 3.5$ billion to low-performing schools, and established financial incentives with the School Turnaround Grants of $\$ 900$ million (Office of the Press Secretary, Statements \& Releases, March 2010). One example of a whole-school reform is the development of an early warning system to identify potential dropouts as early as possible in their school career (Heppen and Therriault, 2008). Early dropout prevention is also of interest when it comes to (early) childhood education (Schweinhart and Widart, 1985). Interventions in this respect aim, for instance, at retention in grade (Goldsmith and Wang, 1999; Roderick et

\footnotetext{
${ }^{3}$ A broad spectrum of the Anglo-Saxon literature has been covered on the website of the National Dropout Prevention Center/Network, including academic and policy research, books and technical reports dating from the 1980s.
} 
al., 2000), special or alternative education (Smink and Schargel, 2004), and literacy development (Alexander and Entwisle, 1996).

However, it is increasingly acknowledged that only a few strategies are emphasizing school-work dropout determinants.

In the past, academic skills and vocational skills have been seen as two separate entities. This viewpoint has changed as the economy has become global rather than national. Businesses want workers with lifelong learning skills." [...] "Schools and community colleges are moving from the old model of vocational education to the new model of school-to-work programs (National Dropout Prevention Center/Network, July 2012).

Only one strategy especially focusses on the link between the school and the labor market: namely, Career and Technology Education (CTE). CTE consists of vocational-oriented pathways, such as apprenticeships/internships or school-work contracts.

\section{European Union}

Some recent policy documents of the European Commission summarize the contemporary dropout prevention initiatives of several EU countries (see European Commission, 2011a; European Commission, 2010b). One dropout prevention initiative in this respect is improved registration of school attendance and dropout, in order to follow a student through his study curriculum, and to provide information on student background and progress. The United Kingdom, the Netherlands, Germany and Italy have all improved the registration of school attendance (i.e. enrollment, school dropout, and unauthorized absenteeism) by establishing a unique identification number that tracks the student in and beyond the school site. The effectiveness of such a prevention measure can be evaluated from several angles (e.g. Chapter 3). First, these countries have or are heading towards nearly complete and reliable micro-data on school attendance behavior together with the 
history/background of a student at school and at home. Other convenient methods of data collection, like surveys, are always liable to sampling problems, such as overrepresentation or underrepresentation of particular student groups, missing values and attrition. Knowledge on school attendance behavior is crucial to retrieve dropout determinants and evaluate dropout prevention. Second, the literature review in this chapter reveals that school absenteeism encourages the process of student attrition. Improved registration of school attendance may therefore identify potential dropouts, and prevent those students from leaving education early. Third, the micro-data can be aggregated at school, regional or country level. This is useful to provide an overall picture of the school dropout problem in relation to aggregated indicators such as financial means invested in the school, criminality rates in the neighborhood, or per capita GDP. Comparable registration can also be a useful policy instrument to develop prevention measures aiming at specific needs or grant bonuses to schools according to their performance. In the Netherlands, for example, the identification of particular major dropout zones/regions has improved the awareness of the dropout problem, and policy is delegated to the regional authorities to meet the needs of the underlying student population. The Netherlands thereby enhances accountability and competitiveness between dropout zones/regions further supported by financial incentives of $€ 2,500$ per dropout saved compared with the base year 2005-06.

Second, schools in disadvantaged neighborhoods are financially supported, for example, to improve the number of study choices, to establish individualized learning programs or to provide students guidance through the study curriculum. This dropout prevention initiative can be found in many different forms across EU countries: Slovenia, France, and Belgium implemented an individualized learning environment. Here, potential dropout students regain their confidence in so-called transition classes in which students are 
individually guided from one school year to the next. Sweden and France have established individualized programs for students who have retention in grade or who have fallen behind in class. There also exists mentoring and coaching, guidance through the study curriculum, and care and advisory teams in the Netherlands (see also Chapter 4). Norway is developing a curative dropout program aiming at improved re-entry of the student into secondary education after a dropout decision. Nordic countries, in general, often offer the possibility of a break year between lower and higher secondary education, and ability tracking is postponed as late as possible in the school career.

A third dropout initiative is aiming for an extended duration of the compulsory education age and has been implemented in the Netherlands, Hungary, Poland and Italy (European Commission, 2010b). One of the most straightforward ways to prevent students from early school-leaving is by aligning the compulsory education age with the graduation age (see also Chapter 5). As such, students obtain a higher secondary certificate at the end of the compulsory education age. However, this dropout prevention measure may fail when students have been retained in grade and the graduation age is no longer aligned with the compulsory education age. "[...] the extension of the compulsory education age does not necessarily lead to successful graduation, better qualifications or a better transition from school to work (European Commission, 2010b, p.16)." In addition, law enforcement may be questioned, as the decision to drop out of school often takes place before the end of the compulsory education age (see also Chapter 3 ).

To conclude, as in the US, dropout prevention initiatives in Europe have aimed at the role of the labor market in the level and change of the school dropout rate are rather limited. In the Netherlands, for instance, the transition between the pre-vocational and vocational level has been simplified by an intake procedure for the student moving into the vocational school 
(see also Chapter 6). And, among other EU countries, Luxembourg, Italy and Denmark have developed work-based pathways for students who wish to combine school with work.

\subsubsection{A note on the effectiveness of dropout prevention}

Despite the increased attention to dropout prevention worldwide, we find only limited evidence available on the effectiveness of the dropout prevention measures or interventions. A recent systematic review of dropout prevention and intervention programs supports these findings.

There have been a handful of systematic reviews on the effects of prevention and intervention programs on school dropout and completion outcomes. However, the restrictive inclusion criteria and methodological weaknesses of these preclude any confident conclusions about the effectiveness of the broad range of programs with dropout outcomes, or the potential variation of effectiveness for different program types or participant populations (Wilson et al., 2011, p.14).

Wilson et al. (2011) found 167 experimental or quasi-experimental studies eligible for inclusion in their systematic review. The authors argue in this respect that, in the first instance, they expected fewer than 100 studies eligible for a review on dropout prevention. However, the authors have retrieved a larger sample, owing to unpublished technical reports. From the 167 studies reporting school dropout or school completion as an outcome variable, 152 studies dealt with general dropout programs, and 15 studies with dropout programs for teen parents. They show that the majority of eligible studies evaluated the effectiveness of school or class restructuring programs. A good share of studies have reported dropout prevention measures or interventions related to vocational education and training, supplementary academic services, mentoring and counseling, and alternative 
schools. The authors conclude that dropout prevention measures or interventions substantially contribute to lower dropout rates - with no single prevention measure or intervention better than any other.

There are two main reasons why high quality studies of dropout prevention measures or interventions are so limited. First, in line with the new conceptual model for school dropout and dropout prevention, various observed and unobserved factors are influencing the decision to leave school early. Evaluations of measures or interventions with respect to dropout prevention may therefore fail to show program effectiveness. Second, up till now, and depending on the country, region or school of analysis, there are multiple definitions in use to define what school dropout is. There is a lack of uniformity and transparency with respect to school attendance and enrollment registration (see also Chapter 3). Many studies have, therefore, to rely on surveys/questionnaires or (costly) local experimental settings. This may lead to difficult statistical inference due to self-reported data on attendance behavior and sample selection. As a result, research on the effectiveness of dropout prevention is scarce.

\subsection{Conclusion}

This chapter has discussed a new conceptual model for school dropout and prevention. The point of departure was an overview of the leading previous literature dealing with school dropout determinants. From this, two lines of research were positioned, namely the process of student attrition and educational attainment, on the one hand, and educational attainment and labor market outcomes, on the other. We provide a framework for school dropout and dropout prevention that connects educational and labor market outcomes, identifying home, school and labor market institutions, in which the individual takes part. The conceptual model thus incorporates the economic factors which play a crucial role in education and on the labor market. For 
example, a short-run economic upturn may create (temporary) job market opportunities particularly aimed at low-skilled labor. The previous literature indicates that vocational students are most vulnerable to leave school early due to opportunities on the labor market.

From the interaction between home, school, and labor market institutions, school-based pathways, work-based pathways, and a job market arise. Each institution and the interaction with other institutions cover a set of observable and unobservable dropout determinants influencing the individual's decision to drop out, such as gender, ethnicity, ability, motivation, commitment of the student to the school, class size and composition, a history of drug abuse and/or crime, unauthorized truancy, retention in grade, the end of the compulsory education age, and the accessibility of jobs. Students are often confronted with several incentives before taking the actual decision to leave school early.

Dropout prevention initiatives are established and influenced by the institutions (and their interactions) that implement the measures or interventions which directly affect their effectiveness. It should be noted in this respect that, if the decision to leave education early is a combination of home, school, and labor market dropout determinants, then dropout prevention policy established by only one institution might not achieve its effect. This argues for a versatile approach. As such, it is not one dropout prevention measure or intervention in particular, but a bundle of measures and interventions aiming at both home, school, and labor market dropout determinants that together should effectively deal with the problem of early school-leaving.

There are a wide variety of contemporary dropout prevention measures or interventions within the scope of the process of student attrition in the United States and in the European Union. The number of dropout prevention initiatives directly aiming at the role of labor market, or the connection 
CHAPTER 1. SCHOOL DROPOUT AND PREVENTION IN THE

of the labor market with other institutions, in the level and change of the school dropout rate is still rather limited.

Next, in Chapter 2, dropout prevention policy is evaluated as a bundle of activities (measures or interventions) in EU-12 Member States. 


\section{Chapter 2}

\section{A Cross-Country Study on Dropout Prevention}

"[...] there is very weak support for the notion that simply providing higher teacher salaries or greater overall spending will lead to improved student performance." (Hanushek, 2007, p.4)

\subsection{Introduction}

As supra-national organizations often have few tools to urge their Member States to undertake policy reforms, they frequently rely on peer pressure arising from cross-country comparisons (e.g. United Nations, 2003; European Commission, 2011a). Peer pressure is particularly aimed for in the 'naming and shaming' framework, in which the best performing countries are used as benchmarks and the least-performing countries are shamed as laggers. The previous literature indicates that naming and shaming is an effective incentive (e.g. for health care: Besley et al., 2009; human rights: Hafner-Burton, 2008; education: Elstad, 2009). Particularly the United Nations and the European Commission use this 'sunshine regulatory model' extensively in their evaluation of the policy outcomes of their Member States

\footnotetext{
${ }^{1}$ Chapter 2 is based on: Sofie J. Cabus and Kristof De Witte (2012). Naming and Shaming in a 'fair' Way. On Disentangling the Influence of Policy in Observed Outcomes. Journal of Policy Modeling 34(5), 767-787.
} 
(e.g. poverty reduction, unemployment rates, educational attainments, or production volume). Within the European Union (EU) many of the general 'Agendas' determined by the European Council are monitored by ranking the performance of the countries. Simultaneously, the rankings aim to provide incentives for improving performance.

Despite its widespread use, a mere comparison of outcome variables is nearly meaningless. Various other factors may have influenced the outcome variable of interest. If not properly accounted for, the "naming and shaming' will be inaccurate and favors countries which are influenced by positive exogenous influences (e.g. the economic cycle).

This chapter contributes to the literature from two perspectives. First, from a theoretical point of view, a benchmarking model is suggested in which outcomes are corrected for time- and country-invariant effects, as well as for economic conditions. This contributes particularly to the productivity literature and the method can be best compared to index numbers such as the Laspyres index or the Tornquiz index. Index numbers are convenient and heavily applied as they are non-parametric (i.e. they do not assume a priori specifications on the production frontier) and are relatively easy to interpret and estimate (Fried et al., 2008). They suffer, however, from difficulties in accounting for heterogeneity. The suggested parametric benchmark model proceeds by applying microeconometric panel data techniques to a macroeconomic setting. It is estimated by system ordinary least squares. Although the model is tailored to the application concerned (early school-leaving, see below), it is not limited to this particular application. One could easily apply the benchmarking framework to other 'naming and shaming' applications, such as fatal accidents, waste disposal, or the diffusion of new technologies. To facilitate its application, the Stata code used in this chapter is available upon request.

Second, from an empirical point of view, this chapter focusses on the 
European Lisbon Agenda (2000): a large framework to make "the EU the most competitive region by 2010". By now, it is clear that the EU did not reach its own targets. Skeptics may blame the European governments which refused to take the necessary actions. Others point to the difficult economic environment with two recessions during the last decennium.

To limit the scope, this chapter considers one of the outcomes of the Lisbon Agenda: early school-leaving or school dropout. Back in 2000, the European Council decided to aim for a reduction by 50 percent of the number of students younger than 23 who leave school without a higher secondary certificate. The policy target has recently been included in the new EU economic reform package 'Europe 2020'. ${ }^{2}$ The emphasize on early schoolleaving created an ongoing shift to so-called learning outcomes in European countries. The learning outcomes are defined as "[...] statements of what a learner knows, understands and is able to do on completion of a learning process (Cedefop, 2008, p.15)". Early school-leaving is a clear indication of an incomplete learning process, in that a high school certificate is not awarded. The latter is considered as a good proxy for the minimum required skills supply in the labor force, essential for economic productivity and growth (Cedefop, 2010). School dropout rates have been correlated with, for example, a higher risk on long-term unemployment, a lower health status, intergenerational poverty or exclusion from society. Within the EU, governments officials and policymakers have taken dropout prevention measures to a different extent and with a different scope of focus to tackle the dropout problem (for an extensive overview, see Chapter 1). If only policy measures influence the outcomes on early school-leaving, a naming and shaming incentive might be appropriate. If other influences co-determine the school dropout level, a corrected benchmarking model is necessary.

\footnotetext{
${ }^{2}$ Note, however, that the scope of the application in the chapter goes beyond the specific European agenda. Similar to Europe, the US aims for a high school success rate of 90 percent as confirmed in the 'No Child Left Behind Act' (2001). Similar targets have been adopted in Canada and Australia.
} 
In a recent policy document, the European Commission (2011a) seems to advocate the former idea, i.e. only policy measures trigger the outcomes on early school-leaving. The naming and shaming approach is clear in Figure 2.1 and the accompanying text

Since 2000 the average European early school-leaving rate has declined by 3.2 percentage points, but progress has been insufficient to reach the $10 \%$ target by 2010 as initially agreed within the Council. In addition, the average masks large differences between Member States. Seven Member States have already achieved the 10\% benchmark, while three have rates higher than $30 \%$ (European Commission, 2011a, p.3). ${ }^{3}$

We suggest an alternative approach in which the observed 'gross' outcomes are corrected for exogenous influences. The resulting 'net' outcome aims to capture the actual contribution of policymakers to the observed outcome.

The remainder of this chapter is structured as follows. Section 2.2 describes the empirical framework, in which a macroeconomic issue is estimated with microeconomic methods. A third section discusses the application which is further elaborated with data in Section 2.3.2. Section 2.4 presents the results. Finally, Section 2.5 concludes.

\subsection{A linear panel data model}

The observed outcome variable consists of two parts: (1) a part which is due to the general economic climate and country- and time-invariant effects; and (2) a 'net' part which is the direct result of policy interventions. This section outlines the methodology to reveal the net policy outcome.

\footnotetext{
${ }^{3}$ The dropout rate is expressed here as the percentage of early school-leavers in the age group 18-24 years old. An alternative, frequently used definition measures early schoolleavers relative to the number of people leaving education in a given year.
} 


\subsection{A LINEAR PANEL DATA MODEL}

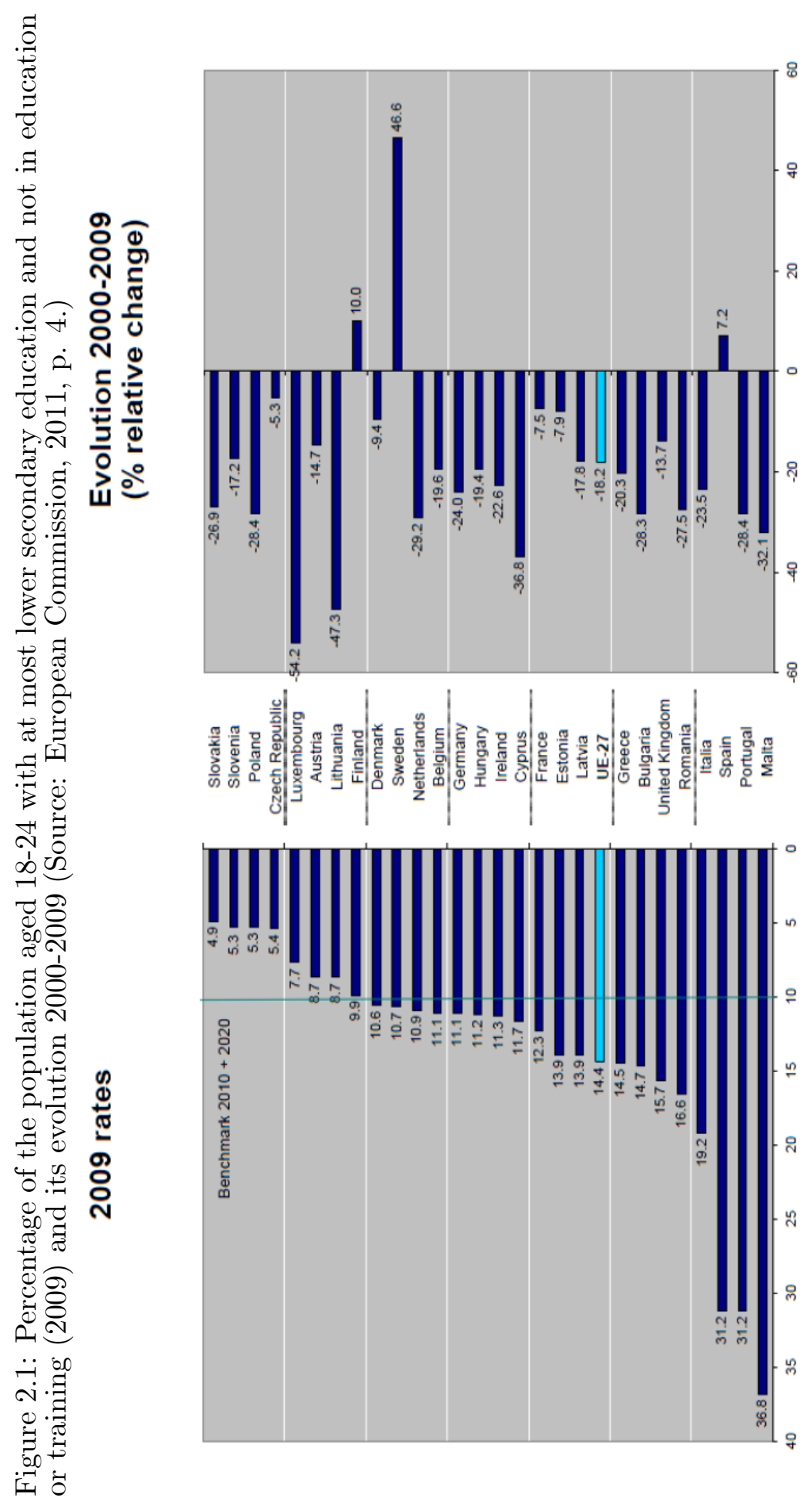




\subsubsection{Sources of endogeneity}

School dropout rates are considered as an outcome variable. Considering an educational outcome variable (in this case, school dropout) purely on its own raises three issues with respect to endogeneity. First, unobserved variables at the micro-level, such as student ability, might influence its outcomes. There is, however, no evidence that the abilities of students are unequally distributed across the EU-12 countries. Similarly, there is no evidence that other unobserved information such as parental education or students' motivation influences school dropout differently across the EU-12 (note that the level of parental education and motivation should not necessarily be homogeneous across countries, as long as it influences school dropout similarly).

Second, measurement error in school dropout rates can bias the results. Although reporting school dropout in the EU used to be problematic before 2000 , since 2000 it is possible to rely on Eurostat data which have a homogeneous definition, are similarly collected and, as such, have a low measurement error. Moreover, for the first two reasons of endogeneity, a major advantage arises when working at the aggregate level. Griliches (1977) suggests that there is no bias, because unobserved ability cancels out measurement error. This principle has been reinforced in the more recent work of Topel (1999) and Krueger and Lindahl (2001).

Third, school dropout is, in an unclear and complicated way, influenced by, for example, a country's financial inputs, industry structure, and potential to innovate. For instance, differences between the EU-12 countries in educational quality may be a serious issue of concern. However, one may argue that the considered time span 2000-2008 is too limited to fundamentally alter the educational system and drive educational quality up or down. For this reason educational quality is more or less a country- and time-specific constant. Using country- and time-fixed-effects in a benchmarking model structure with school dropout rates as an outcome variable largely solves 
the third endogeneity problem.

\subsubsection{A panel data benchmarking model}

To rank countries' performance on early school-leaving, a structural dropout equation model is formulated. First, outcomes are standardized using shortterm and long-term economic conditions. Second, country- and time-invariant effects are captured in the benchmarking model. This approach is similar to a within-group deviation from the mean, where the outcomes have been standardized for basic economic conditions (see Kapteyn, 2010; and Kapteyn et al., 2007). The following subsections gradually construct the school dropout benchmarking model using panel data techniques.

\section{Short-term economic conditions}

The link between early school-leaving and the labor market has been extensively discussed in the literature. The youth labor market appears to be highly sensitive to market conditions, in turn causing youth employment problems (see, among others, Müller and Gangl, 2003). An early study from Reich and Young (1975) already identified 53 percent of all dropout cases in their sample as work-oriented. Müller and Gangl (2003) have shown that the rising knowledge society was accompanied by the increasing necessity of high-skilled labor during the early 1990s. Consequently, wages increased. This has had a dual impact on education. On the one hand, the returns to education increased such that the average years of schooling increased. On the other hand, as also low-end wages increased, the opportunity cost of schooling increased as well. The higher the wage rate, the higher the (short-term) benefit from leaving school before a high school certificate is obtained.

To test the direction of the correlation, consider a simple regression model in which early school-leaving is related to the labor market opportunities: 


$$
y_{j t}=\phi_{j t} w_{j t}+\operatorname{error}_{j t}
$$

where $y_{j t}$ denotes the dropout rate of country $j(\in 1,2, \ldots J)$ at time period $t(\in 1,2, \ldots, T), w_{j t}$ indicates the hourly labor costs, and error $j t$ a countryand time-specific error term. The variables are expressed in their natural logarithm to estimate the proportional impact. The hourly labor cost, $w_{j t}$, consists of two components: (1) wages and salaries; and (2) other benefits. To make sure that $w_{j t}$ is not correlated with error ${ }_{j t}$ at time $(t=1,2, \ldots, T$ ) across the $\mathrm{j}$-index, $w_{j t}$ is expressed by its wage rate. To do so, the first differences of the natural logarithm of hourly wages $\left(w_{r, j t}\right)$ are taken. The intertemporal change in wage captures information on job market conditions and is, moreover, uncorrelated with the error term across the j-index. ${ }^{4}$ The wage rate is expressed as:

$$
w_{r, j t}=w_{j(t-1)}-w_{j t} .
$$

Plugging (2.2) into (2.1) results in:

$$
y_{j t}=\beta_{j t} w_{r, j t}+\text { error }_{j t} .
$$

From equation (2.3) it is clear why it is not possible to rely on simple ordinary least squares estimation (OLS). The OLS assumption of strict exogeneity implies that the error terms (error ${ }_{j t}$ ) are at any time period $t$ uncorrelated with past, present, and future values of the wage rate $w_{r, j t}$. This strict assumption is relaxed in system OLS, which relies on contemporaneous exogeneity. In contrast to cross-sectional OLS, system OLS does not require $w_{r, j t}$ to be uncorrelated with error ${ }_{j t}$ at all time periods in panel data contexts. In system OLS it suffices that $w_{r, j t}$ is uncorrelated with error $_{j t}$

\footnotetext{
${ }^{4}$ Note that we do not observe a significant correlation between the differences in the log wages and salaries and early school-leaving.
} 
at time $(t=1,2, \ldots, T)$ across the $\mathrm{j}$-index (note that $w_{r, j t}$ is differently composed than it is in OLS; Wooldridge, 2010).

Estimating equation (2.3) does not suffice as it captures only short-term economic conditions. The next subsection extends this by adding long-term economic conditions.

\section{Long term economic conditions}

To standardize for long-term economic growth, we use economic development as a proxy. In particular, we include a country's growth in per capita GDP as an indicator for a country's industry structure, demand for lowskilled labor, and the potential to innovate. ${ }^{5}$ An extensive literature thoroughly analyzes the role of education in explaining the GDP growth rate (e.g. Solow, 1957; Nelson and Phelps, 1966; Asteriou and Agiomirgianakis, 2001). Topel (1999) suggests a positive association between economic development, on the one hand, and the level and change of education, on the other. Rumberger and Lamb (2003) are even more specific and indicate that the overall level of the economy influences the level of early school-leaving. Krueger and Lindahl (2001, p.1111) confirm, and argue that "[...] countries below their steady-state income level should grow quickly, and those that are above it should grow slowly". Irrespective of the direction of the association between education and growth, i.e. causality, Krueger and Lindahl (ibid.) indicate that a country with a rather high economic growth rate performs better with respect to a change in the educational attainment of its population than a country with a rather low economic growth rate. The positive correlation between economic growth and education has also been indicated in various other places in the literature (see, among others, e.g. Barro, 1991; Hanushek and Woessmann, 2010; Krueger and Lindahl, 1998).

\footnotetext{
${ }^{5}$ The underlying analysis indicates that changes in per capita GDP are uncorrelated with the error terms.
} 
Similar to the short-term influences, taking the first difference in GDP avoids any correlation between $G D P_{j t}$ and error $_{j t}$. Although a correlation is observed between the wage rate $w_{r, j t}$ and the growth rate $G D P_{r, j t}$ of 0.8617 (significant at the 1\%-level), the two variables are complementary and focus on a different time horizon. In general, an increasing wage rate correlates positively and significantly with increasing dropout levels. If wages increase, the opportunity cost of staying in school increases such that (probably) less motivated students leave school for a job. On the other hand, an increase in GDP decreases the level of dropouts (e.g. Martin and Rogers, 2000). Shortterm changes are reflected by the wage rate; long-term changes are captured in the growth rate. This results in:

$$
y_{j t}=\beta_{j t} w_{r, j t}+\theta_{j t} G D P_{r, j t}+\text { error }_{j t}
$$

Although equation (2.4) estimates the correlation of $w_{r}$ and $G D P_{r}$ on early school-leaving, and although it does not allow for a causal interpretation per se, we can make a strong case for the direction of the correlation. It is indeed very unlikely that, in aggregate (and in Western countries), school dropout influences the wage rate or the change in GDP (Asteriou and Agiomirgianakis, 2001). It is more likely that the correlation runs from the wage and growth rate towards school dropout. Although this nonexperimental setting does not allow for a strict causal interpretation, we can argue in the empirical section below that changes in wage rates and economic growth rates cause early school-leaving.

\section{Country- and time-invariant effects}

Using only the EU-12 countries among the EU-27 Member States is wellconsidered. The EU-12 countries are a rather homogeneous group with respect to law and order and economic characteristics (see also Soukiazis and Castro, 2005). Moreover, economic swings do not (or only to a very 
limited extent) induce movement of secondary education students across borders (for more information on the relevance of considering student mobility across borders, see Christou and Haliassos, 2006). Indeed, inter-job market mobility of 15 to 25 year-olds working in the EU-12 countries is low (Eurostat). Therefore, economic upturns or downturns in one Member State will not affect the dropout decision of students in a neighboring Member State. Nevertheless, three issues arise.

First, the interaction between the labor market and the education sector might differ across the analyzed countries. The benchmarking model in equation (2.4) assumes that the link between the labor market and school dropout is similar for all countries. This is not necessarily true in reality. Second, and as indicated above, the organization of education differs across countries. Third, the effectiveness of policy relies on unobserved factors as country-specific institutional factors or time trends across all countries. ${ }^{6}$ Panel data techniques and balanced data make it possible to control for similar country- and time-invariant effects. Equation (2.4) is extended by time dummies $\left(\delta_{1}, \ldots, \delta_{T}\right)$ and country dummies $\left(\xi_{1}, \ldots, \xi_{J}\right)$ capturing timeand country-fixed-effects. ${ }^{7}$

\section{A standardized dropout rate}

After standardization of the school dropout rate, a country- but not timespecific constant $\psi_{j}$ is captured in equation (2.5), where $\psi_{j}$ is denoted by the conditional average dropout rate. It can be argued that this constant $\psi_{j}$ is closely related to a country's educational policymaking. The observed gradual decline in early school-leaving across all countries (arising, for example, from technological change and the increasing demand for high-skilled youth) is removed from $\psi_{j}$ by a within-group estimation procedure (see subsection

\footnotetext{
${ }^{6}$ We note that time trends, e.g. the sensitization of youngsters to obtain a schoolleaving certificate, may differ from labor-market-specific time trends.

${ }^{7}$ Fixed effects are prefered to random effects, as we are interested in the individual means across the country levels (and not the variance of means, as in the random effects model).
} 
2.2.3). In this sense, $\psi_{j}$ captures the average dropout rate conditional on economic conditions, and time- and country-invariant effects, and therefore, differs to some extent from the unconditional average dropout rate $y_{j t}$.

Note that this approach is similar to Kapteyn (2010), and Kapteyn et al. (2007). Both these studies use within-country panel data analysis to deal with international comparison of health outcomes.

In sum, the following equation is estimated:

$$
y_{j t}=\psi_{j}+\beta_{j t} w_{r, j t}+\theta_{j t} G D P_{r, j t}+\sum_{t=1}^{T} \alpha_{t} \delta_{t}+\sum_{j=1}^{J} \gamma_{j} \xi_{j}+\text { error }_{j t} .
$$

\subsubsection{Estimation procedure}

Equation (2.5) is estimated by system OLS using fixed coefficient models that vary over different cross-sectional units. The regression coefficients are time-invariant but vary from one unit to another (see also Hsiao, 2003). Thus, $J$ equations, referred to as 'system', are estimated and least squares are applied separately to the time-series observations of each cross-sectional unit. Fixed coefficient models are preferred as the labor market data comes from a heterogeneous population (i.e. respondents from different countries).

As system OLS estimates each equation separately, $\left(\sum_{t=1}^{T} \alpha_{t} \delta_{t}+\sum_{j=1}^{J} \gamma_{j} \xi\right)$ is left out of the regression for obvious reasons of multicollinearity. ${ }^{8}$ Therefore, the following is estimated:

$y_{j t}=\psi_{j}+\beta_{j t} w_{r, j t}+\theta_{j t} G D P_{r, j t}+$ error $_{j t}, \quad$ using system OLS.

In a 'naming and shaming' framework, the outcomes of the first period (before the policy intervention) are compared with the outcomes in

\footnotetext{
${ }^{8}$ Multicollinearity exists as (1) time effects are captured through differencing wages and per capita GDP; and (2) country effects are captured by the estimation of each equation separately.
} 
the last period (during or after the policy intervention). Comparing $y_{j(t=T)}$ to $y_{j(t=1)}$ in a 'naming and shaming' framework can only be insightful if and only if only policy influences the average school dropout rate $\left(y_{j}\right)$. Following our central argument, a more reliable benchmarking model can be obtained by comparing the change in the school dropout rate between the end period $T$ and the initial period 1 with a conditional or 'net' outcome

$\hat{\psi}_{j}$. The net outcome $\hat{\psi}_{j}$ is the estimated value of $\psi_{j}$ in equation (2.5), and captures the average school dropout rate by country standardized for basic, however, good (measurable and available) approximates for economic conditions $\left(w_{r, j t},\right)$ and $\left(G D P_{r, j t}\right)$ and controlled for country- and time-invariant effects. The gross (observed) change in the outcome variable may then be decomposed into two components:

$$
=E\left[\Delta y \mid \Delta w_{r}, \Delta G D P_{r}, \delta, \xi\right]+E\left[\Delta y_{\text {policy }}\right]
$$

The first component denotes the change in outcome variable due to influences beyond the control of the educational policymaker. This change is denoted by the expected value of the change in the dropout rate conditional on the change in the wage rate $\left(\Delta w_{r}\right)$, the change in economic development $\left(\Delta G D P_{r}\right)$, and country- and time-fixed-effects. ${ }^{9}$ The second component captures the net change in the outcome variable school dropout. Based on these two components, it is possible to rank countries' absolute performances with respect to early school-leaving of all observations $(j=1,2, \ldots J)$.

\subsection{School Dropout in the EU-12}

\subsubsection{Theoretical background}

As one of the key drivers of prosperity, education has attracted significant attention in both the policy debate and the academic literature (e.g. Lisbon

\footnotetext{
${ }^{9}$ Note that in equation (2.7), time-fixed effects are captured by taking the first differences of the outcome variable $\left(\Delta y_{j t}\right)$, whereas country-fixed effects are captured by estimating each equation separately in system OLS.
} 
Agenda; No Child Left Behind Act; Hanushek and Woessmann, 2010). This section focusses on one educational outcome, in particular, early schoolleaving.

At the micro-level, school dropout is triggered by students' individual and family background characteristics (see Chapter 1). At the macro-level, it is clear that policymakers have to simultaneously tackle various factors which might influence school dropout. While it is often the case, the Ministry of Education, Culture, and Science cannot always influence the dropout determinants. For example, problems in disadvantaged neighborhoods should be addressed by the Ministry of Internal Affairs, not of Education. Therefore, to reduce early school-leaving, policymakers should cooperate across departments and ministries. Individual policy measures, focussing on one of the micro-level determinants are often observed as non-effective or insignificant. Taking into account publication bias (i.e. only studies with significant outcomes are published), some illustrative evidence can be found in Cabus and De Witte (2011a) and De Witte and Csillag (2010). Each of these studies finds only limited impact of individual policy measures on school dropout. Given the complexity of the problem, this is not surprising. Here, by evaluating the effectiveness of the policy at the macro-level, individual policy measures are not evaluated on their own, but in terms of the general outcomes across all policy measures.

Consider the average dropout rates for the EU-12 countries over the period 1992-2009. An overall decline in dropout rates is observed: from 32.27 percent in 1992 to 14.41 percent in 2009. Remarkably, since the European Council in 2000, the EU-12 countries' performances are rather low compared with the previous period 1992-2000. Before the implementation of the Lisbon Strategy, average dropout rates reduced by 14.67 percentage points. Since 2000, a reduction of only 2.87 percentage points can be observed. Several reasons might explain this discrepancy. 
First, dropout rates might already be at a minimum level. Following this argument, in the early 1990s, it was relatively easy to convince students to stay at school. Since 2000, the more problematic students are not that easy to convince. Consequently, there is little scope for further reduction in dropout level. A 'natural dropout rate' emerges (for further intuition, see Rumberger, 2011, p.55). This, however, does not fully explain the large observed differences in dropout rates between European countries. Comparing Sweden or Denmark with, for example, Portugal or Spain shows that the average dropout rate significantly differs by country. If early school-leaving depends on country-specific factors such as institutions or policymaking, the existence of a 'natural dropout rate' is less likely, or is at least significantly lower than 15 percent of the age group of 18-24 year-olds.

Second, the policy measures taken by the different the EU Member States may not have had any effect, or even a negative effect. Although individual policy measures might have little or insignificant effects, it seems very unlikely that the increased attention to early school-leaving would not result in a decrease of dropout rates. More likely, and similar to our central argument, the policy measures can interact with the labor market or other economic policy.

Finally, and most likely, the definition of early school-leaving used to differ across the EU countries. While before 2000 definitions were heterogeneous, after 2000 the definition was harmonized to monitor the outcomes. We encounter this problem using data of the EU-12 countries from the European Statistical Agency (Eurostat). Moreover, we limit the scope to the 2000-2008 period and, in estimating the benchmarking model systematic errors in reporting are captured in the country-specific fixed effect.

\subsubsection{Data}

Similar to the European Commission in its 'naming and shaming' framework, we use data provided by the European Statistical Agency (Eurostat). This 
Table 2.1: Dropout rates of the EU-12 countries: ranking the observed average dropout rate over the period 2000-2008

\begin{tabular}{rrrrrrrrrrr}
\hline country & 2000 & 2001 & 2002 & 2003 & 2004 & 2005 & 2006 & 2007 & 2008 & $\bar{y}$ \\
\hline Finland & 9.0 & 9.5 & 9.7 & 10.1 & 10.0 & 10.3 & 9.7 & 9.1 & 9.8 & 9.7 \\
Austria & 10.2 & 10.2 & 9.5 & 9.0 & 9.5 & 9.1 & 9.8 & 10.7 & 10.1 & 9.8 \\
Denmark & 11.7 & 9.2 & 9.0 & 10.4 & 8.8 & 8.7 & 9.1 & 12.5 & 11.5 & 10.1 \\
Sweden & 7.3 & 10.2 & 10.0 & 9.2 & 9.2 & 10.8 & 13.0 & 12.2 & 12.2 & 10.5 \\
France & 13.3 & 13.5 & 13.4 & 13.2 & 12.8 & 12.2 & 12.4 & 12.6 & 11.9 & 12.8 \\
Germany & 14.6 & 12.3 & 12.5 & 12.8 & 12.1 & 13.5 & 13.6 & 12.5 & 11.8 & 12.9 \\
Belgium & 13.8 & 13.8 & 14.1 & 14.3 & 13.1 & 12.9 & 12.6 & 12.1 & 12.0 & 13.2 \\
Netherlands & 15.4 & 15.1 & 15.3 & 14.3 & 14.1 & 13.5 & 12.6 & 11.7 & 11.4 & 13.7 \\
Luxembourg & 16.8 & 18.1 & 17.0 & 12.3 & 12.7 & 13.3 & 14.0 & 12.5 & 13.4 & 14.5 \\
UK & 18.2 & 17.8 & 17.6 & 12.1 & 12.1 & 11.6 & 11.3 & 16.6 & 17.0 & 14.9 \\
Spain & 29.1 & 29.7 & 30.7 & 31.6 & 32.0 & 30.8 & 30.5 & 31.0 & 31.9 & 30.8 \\
Portugal & 43.6 & 44.2 & 45.0 & 41.2 & 39.4 & 38.8 & 39.1 & 36.9 & 35.4 & 40.4 \\
\hline
\end{tabular}

Note: $\bar{y}$ denotes the average observed dropout rate in EU-12 countries (i.e. EU-12 countries leaving Greece, Ireland, and Italy aside) over the time period 2000-2008. This average is ranked from smallest to largest (as it is often used in a naming and shaming framework).

data on early school-leaving is extended by labor market data from the EU Labour Force Survey (LFS), a large survey among private households. It covers 1.5 million people every quarter of the year and is considered as one of the most important data sources for conditions and trends in the EU labor market.

The data concerned have some limitations. First, survey participants may answer a question differently across countries, or answers may be highly correlated with the current economic conditions (Kapteyn et al., 2007). By using system OLS, we avoid this limitation. Second, as argued above, the definition of early school-leaving used to differ across EU countries. We account for this by using data over the period 2000-2008, in which there was agreement on a uniform definition. Third, similar to other macroeconomic studies, one may argue that the number of data points are limited (i.e. $12 * 9)$. Nevertheless, both other macroeconomic studies and policymakers use a similar amount of data.

To provide some additional insights into the underlying data, Table 2.1 presents the yearly dropout rates for each of the 12 countries over the period 
2000-2008. The last column in this table presents the average dropout rate for that period. Following the naming and shaming idea, the average is used to rank countries' performances from smallest to largest. For most countries, we observe a decline in the dropout rates of the analyzed countries. Portugal and the Netherlands are the best performers in absolute values with a decrease of, respectively, -8.2 and -4.0 percentage points. Also Luxembourg (-3.4 percentage points), Germany (-2.8), Belgium (-1.8), France (-1.4), the United Kingdom (-1.2), Denmark (-0.2), and Austria (-0.1) experienced a decreasing level of early school-leavers. Remarkably, in three countries an increase in the dropout rate is observed between 2000 and 2008. The latter are Sweden $(+4.9$ percentage points $)$, Spain $(+2.8)$, and Finland $(+0.8)$.

The wage rate $w_{r, j t}$

Table 2.2: Job market conditions in the EU-12 countries (denoted by the first differences of the log hourly labor costs).

\begin{tabular}{rrrrrrrrrr}
\hline Country & 2000 & 2001 & 2002 & 2003 & 2004 & 2005 & 2006 & 2007 & 2008 \\
\hline Austria & 1.49 & 2.57 & 2.01 & 3.46 & 1.35 & 1.57 & 1.12 & 1.22 & 0.64 \\
Belgium & & 4.70 & 4.49 & 1.40 & 2.40 & 1.05 & 2.61 & 3.53 & 3.32 \\
Denmark & 2.33 & 7.30 & 1.81 & 4.18 & 1.31 & 4.08 & 3.41 & 4.87 & - \\
Finland & 3.36 & 6.52 & 0.97 & 3.95 & 2.23 & 5.23 & 1.86 & 2.43 & 5.28 \\
France & 5.25 & 4.56 & 3.92 & 2.34 & 2.78 & 2.87 & 3.23 & 3.22 & 2.31 \\
Germany & 4.08 & 2.37 & 2.32 & 2.26 & 0.37 & 0.74 & 1.83 & 0.72 & - \\
Luxembourg & 8.35 & 3.65 & 3.18 & 3.04 & 10.36 & 3.70 & 2.79 & 3.14 & 1.89 \\
Netherlands & 5.39 & 6.80 & 5.34 & 4.88 & 2.91 & 0.66 & - & - & - \\
Portugal & 1.74 & 5.62 & 5.65 & 5.35 & 6.06 & 3.85 & 3.43 & 3.14 & 3.56 \\
Spain & 0.00 & -8.43 & 4.20 & 4.17 & 3.80 & 3.07 & 3.55 & 3.86 & - \\
Sweden & 11.61 & -4.11 & 4.70 & 5.75 & 2.11 & 1.50 & 1.91 & 3.48 & - \\
UK & 12.90 & 3.32 & 2.93 & -6.89 & 4.77 & -0.98 & 4.16 & 3.39 & - \\
& & & & & & & & & \\
\hline
\end{tabular}

The wage rate $w_{r, j t}$ captures the short-term push factors arising from labor market conditions and opportunities. It is calculated from the hourly wage costs, and in particular their component 'wages and salaries', which includes compensation in cash and kind and workers' social security contributions. The data are also available from Eurostat. The wage rate $\left(w_{r, j t}\right)$ is 
Table 2.3: Economic development in the EU-12 countries (denoted by the first differences of the log per capita GDP).

\begin{tabular}{rrrrrrrrrr}
\hline Country & 2000 & 2001 & 2002 & 2003 & 2004 & 2005 & 2006 & 2007 & 2008 \\
\hline Austria & 4.34 & 1.91 & 2.62 & 1.47 & 3.57 & 3.79 & 4.94 & 5.32 & 3.59 \\
Belgium & 5.43 & 2.41 & 3.13 & 2.28 & 4.77 & 3.52 & 4.40 & 4.21 & 2.20 \\
Denmark & 5.70 & 3.03 & 2.65 & 1.73 & 4.20 & 4.81 & 4.84 & 3.66 & 1.90 \\
Finland & 7.32 & 4.97 & 2.94 & 1.08 & 4.21 & 3.05 & 4.88 & 7.64 & 2.33 \\
France & 4.31 & 3.32 & 2.42 & 2.36 & 3.44 & 2.96 & 3.94 & 4.12 & 2.33 \\
Germany & 2.42 & 2.36 & 1.16 & 0.77 & 2.26 & 1.48 & 3.61 & 4.85 & 2.01 \\
Luxembourg & 8.70 & 1.38 & 5.15 & 6.13 & 4.78 & 8.31 & 9.64 & 8.41 & 3.89 \\
Netherlands & 7.50 & 5.91 & 3.17 & 2.06 & 2.68 & 4.21 & 4.95 & 5.30 & 3.93 \\
Portugal & 6.67 & 4.73 & 3.77 & 1.47 & 3.58 & 2.78 & 3.37 & 5.16 & 1.87 \\
Spain & 7.95 & 6.17 & 5.82 & 4.96 & 5.75 & 5.91 & 6.48 & 5.24 & 1.69 \\
Sweden & 9.73 & -5.79 & 4.80 & 3.93 & 4.10 & 1.83 & 5.88 & 5.01 & -2.20 \\
UK & 12.52 & 2.18 & 3.53 & -3.89 & 6.63 & 2.67 & 5.75 & 4.55 & -12.97 \\
& & & & & & & & & \\
\hline
\end{tabular}

computed from the wage cost $\left(w_{j t}\right)$. In general, when a sufficient number of time periods are included, job-market conditions are considered as stationary within each country. They fluctuate above and below a given expected value of the wage rate (Wooldridge, 2010). For the EU-12 countries, Table 2.2 indicates a bound between -1 and 1 percentage points while the wage rate has a mean stationary approximately equal to zero. In other words, although the wage rate may be situated above or below zero over time, its expected value is approximately equal to zero.

\section{Economic development $G D P_{r, j t}$}

A second component which standardizes a country's average dropout rate in equation (2.5) is economic development. As a proxy, we use the first difference in the natural logarithm per capita GDP at market prices $\left(G D P_{r, j t}\right)$ (current prices, euros per inhabitant). We observe a strong negative association between economic development $\left(G D P_{r, j t}\right)$ and early school-leaving of -0.6896 (significant at the $1 \%$-level). The negative sign suggests that a flourishing economy reduces early school-leaving. Although the correlation might also run the other way around (i.e. school dropout hampers economic 
development), the small proportion of early school-leavers in the total population makes this assumption unlikely: more early school-leavers cannot influence the yearly change in economic development (see also Asteriou and Agiomirgianakis, 2001).

In the data, an economic revival between 2003 and 2007 can be observed. Correspondingly, we observe accelerating economic growth for the EU-12 countries between 2003-07 (see Table 2.3). The first signs of the financial crisis caused a slowdown or even decline in economic growth in 2008. In particular, for the United Kingdom and Sweden the start of the current economic recession was most pronounced in the data.

\subsection{Results}

\subsubsection{Ranking cross-country differences in performances}

Equation (2.5) is estimated using system OLS. As such, the change in dropout level is decomposed into (1) a component due to the economic conditions, country- and time-invariant effects; and (2) the net result owing to policy interventions. The results are presented in Table 2.4. The estimated $\left(\hat{\psi}_{j}\right)$ in column (4) represents the average dropout rate conditional on short-term $\left(w_{r, j t}\right)$ and long-term $\left(G D P_{r, j t}\right)$ economic conditions, as well as country- and time-fixed-effects. Comparing $\psi_{j}$ to the initial dropout rate reveals to what extent economic conditions influenced the dropout rate of a country. The 'corrected' naming and shaming results are presented in the third column of Table 2.4 and in Figure 2.2. The results reveal that, for example, in the Netherlands, the dropout rate decreased between 2000 and 2008 by -4 percentage points. Out of this 4 percentage points, -2.81 percentage points can be attributed to economic growth and a positive but declining wage rate. Besides the Netherlands, Portugal and Denmark have benefitted the most from economic influences. In contrast, economic influences were pushing dropout rates up for Sweden and Finland, while, in fact, their job 
market conditions and economic development do not statistically differ from the other EU-12 countries.

Of particular interest is the decline of the dropout rate that cannot be explained by economic conditions or country- and time-fixed-effects. In Column (6) of Table 2.4, $\Delta y_{\text {policy }}$ captures the effectiveness of educational policymaking. In the example of the Netherlands, the unexplained part of -1.19 percentage points reflects the active government involvement on early school-leaving. It can be observed that Portugal $(+12.91$ percentage points), Spain $(+5.02)$, Denmark $(+2.90)$ and Sweden $(+1.65)$ performed poorly. In contrast, Finland (-0.62) succeeded in reducing the dropout rate despite its negative economic conditions. Austria $(+0.00)$, the United Kingdom $(+0.09)$ and France $(+0.73)$ did not succeed in changing the dropout rate significantly despite the policy interventions. Among the 12 countries, Luxembourg (-2.40) was the best performer over the last decade (a relative decrease of 14.29 percent compared with 2000). However, one may point to the relative small size of Luxembourg, and consider its performance as an outlier. The Netherlands (-1.19 in absolute terms; 7.72 percent relative to 2000) follows in second position, before Belgium (-0.87; 6.30 percent) and Germany (-0.68; 4.65 percent).

Given the above observations, it is interesting to explain cross-country differences in performance. This is discussed in the next Subsection 2.4.2.

\subsubsection{Explaining the net policy influence}

Students with the highest risk of dropping out are in vocational education (e.g. Rumberger, 1987; De Witte and Cabus, 2011a; Cabus, 2013). In explaining why some countries have better policy results than others, a natural starting point is enrollment trends in vocational tracks. As such, enrollment in VET and its organization may influence the effectiveness of policy. Additional insights into the organization of schooling markets, and with empha- 


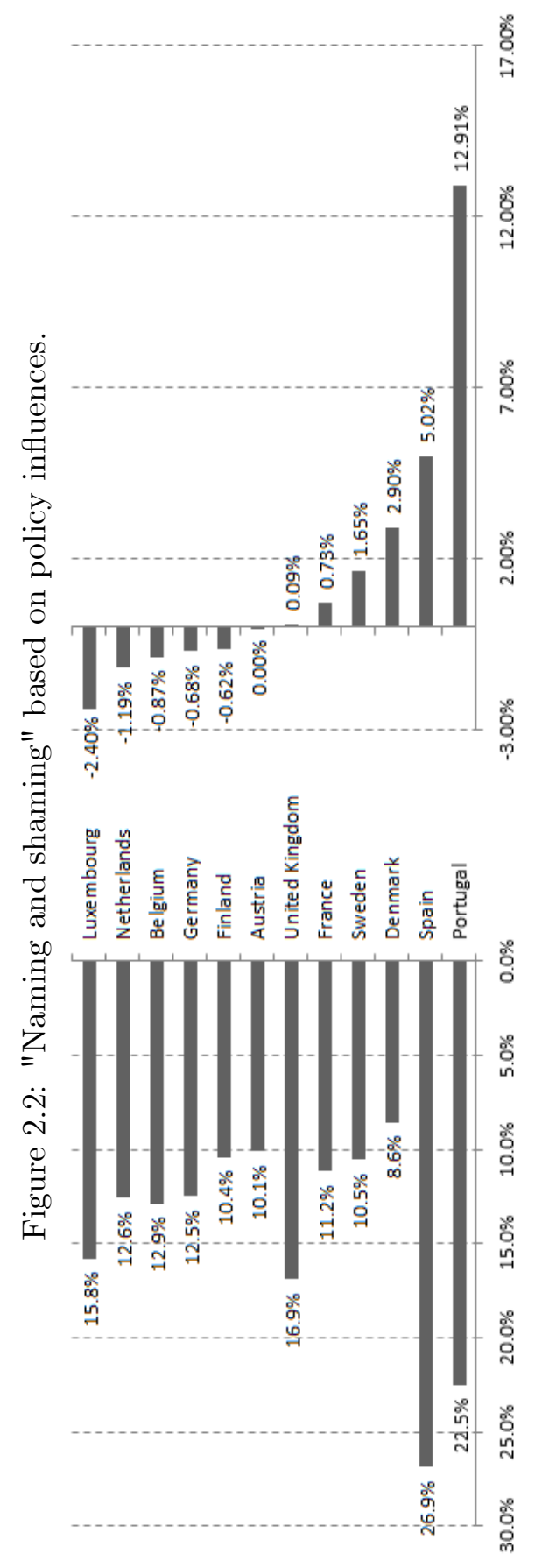


Table 2.4: Absolute dropout rate performance of the EU-12 countries (percentage points).

\begin{tabular}{rrrcccc}
\hline Country & \multicolumn{1}{c}{2000} & \multicolumn{1}{c}{2008} & \multicolumn{1}{c}{$y_{00}-y_{08}$} & $\psi_{j}$ & $E[\Delta y \mid \cdot]^{(2)}$ & $\Delta y_{\text {policy }}$ \\
\hline & \multicolumn{1}{c}{$(1)$} & $(2)$ & $(3)=(2)-(1)$ & $(4)$ & $(5)=(4)-(1)$ & $(6)=(3)-(5)$ \\
\hline Luxembourg & $16.80 \%$ & $13.40 \%$ & -3.40 & $15.80 \%$ & -1.00 & -2.40 \\
Netherlands & $15.40 \%$ & $11.40 \%$ & -4.00 & $12.59 \%$ & -2.81 & -1.19 \\
Belgium & $13.80 \%$ & $12.00 \%$ & -1.80 & $12.87 \%$ & -0.93 & -0.87 \\
Germany & $14.60 \%$ & $11.80 \%$ & -2.80 & $12.48 \%$ & -2.12 & -0.68 \\
Finland & $9.00 \%$ & $9.80 \%$ & 0.80 & $10.42 \%$ & 1.42 & -0.62 \\
Austria & $10.20 \%$ & $10.10 \%$ & -0.10 & $10.10 \%$ & -0.10 & 0.00 \\
UK & $18.20 \%$ & $17.00 \%$ & -1.20 & $16.91 \%$ & -1.29 & 0.09 \\
France & $13.30 \%$ & $11.90 \%$ & -1.40 & $11.17 \%$ & -2.13 & 0.73 \\
Sweden & $7.30 \%$ & $12.20 \%$ & 4.90 & $10.55 \%$ & 3.25 & 1.65 \\
Denmark & $11.70 \%$ & $11.50 \%$ & -0.20 & $8.60 \%$ & -3.10 & 2.90 \\
Spain & $29.10 \%$ & $31.90 \%$ & 2.80 & $26.88 \%$ & -2.22 & 5.02 \\
Portugal & $43.60 \%$ & $35.40 \%$ & -8.20 & $22.49 \%$ & -21.11 & 12.91
\end{tabular}

Note 1: Column (1) and column (2) present a country's dropout rate in, respectively, 2000 and 2008. Column (3) shows the total decline in dropout between 2000 and 2008. Column (4) reveals the average dropout rate conditional on economic influences. Column (5) presents the change in the dropout rate as a result of economic influences. Column (6) shows the change in the dropout rate, which is unexplained by the benchmarking model. Note 2: $E\left[\Delta y \mid \Delta w_{r}, \Delta G D P_{r}, \delta, \xi\right]$.

sis on vocational education and training in the selected EU-12 countries are provided in the following paragraphs. Thereafter, the estimated 'net' policy outcomes are associated with observed enrollment and organizational trends among these EU-12 countries.

Although enrollment in, and organization of, VET is a natural starting point in explaining the 'net' policy influence, so is the quality of education. It can be expected that the quality of educational resources positively correlates with the effectiveness of policy measures. The higher the educational quality, the higher the discretionary influence of policy. The last subsection provides associations between the estimated 'net' policy outcomes and educational quality measures, such as quality of educational resources and quality of human resources. Note that potential associations have been investigated carefully, such as other associations between the 'net' policy outcome and population growth or immigration rates (see also Rosenzweig, 


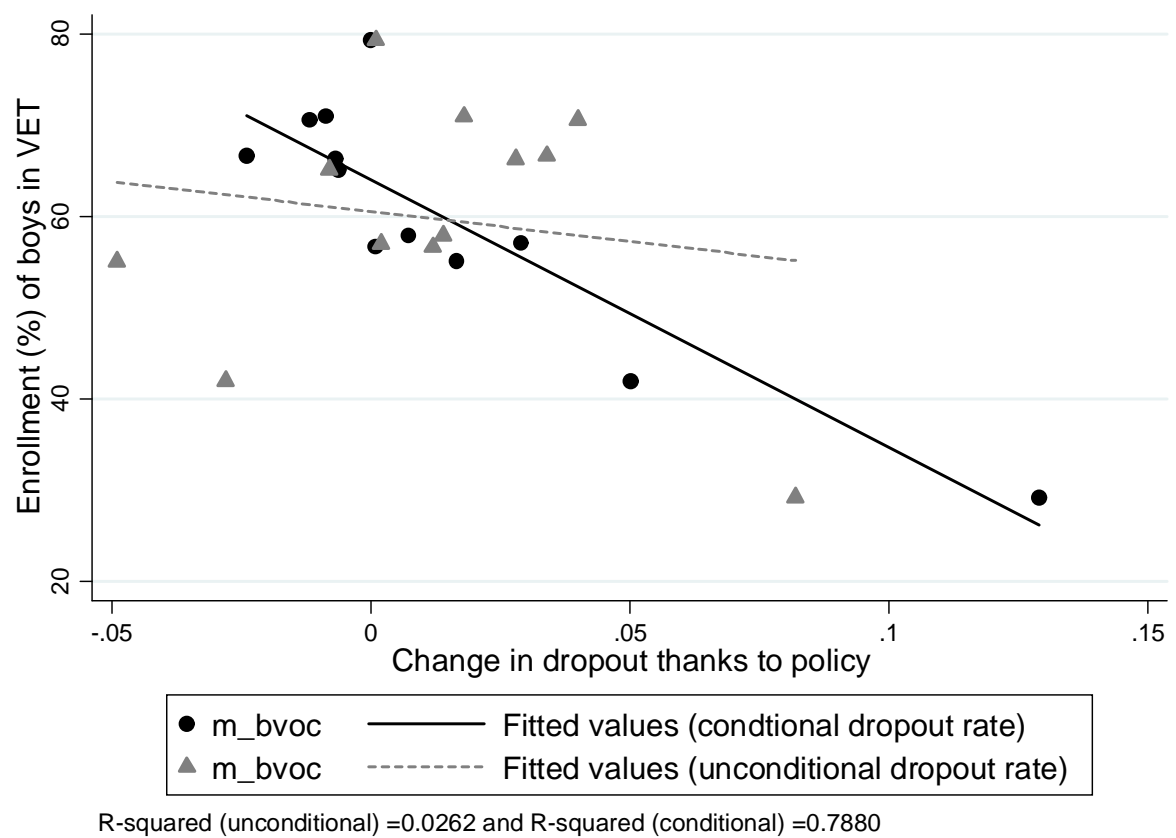

Figure 2.3: Enrollment rates of boys in vocational education and training (ISCED 3) and change in dropout as a result of the policy interventions (data EUROSTAT).

1988; Srinivasan, 1988), youth unemployment rates, expenditure on higher secondary education and educational expenditure as a percentage share of GDP (see also Jung and Thorbecke, 2003), and the student-teacher ratio. However, a significant relationship is not found between these listed determinants and the estimated policy variable. The results are, therefore, left out of this chapter.

\section{Organization of schooling markets}

Before turning to the association between the estimated policy outcome and several explanatory variables, we start with a study of Gangl (2002) who classified schooling markets into different categories. Countries are positioned in relation to each other according to their level of stratification (in- 


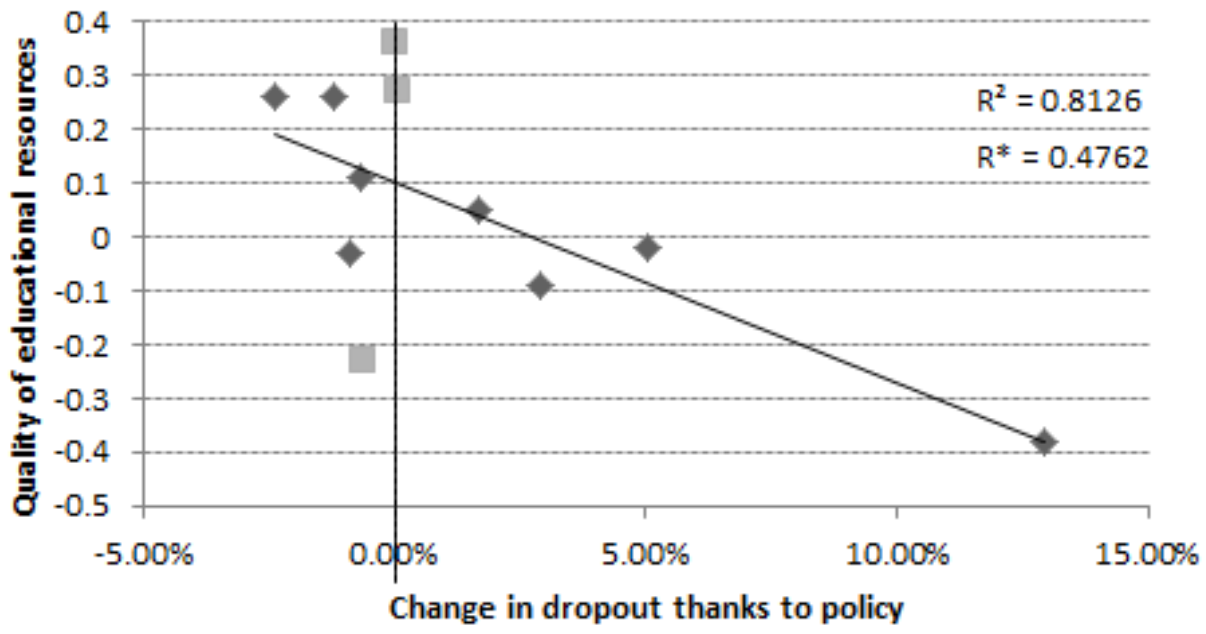

$\bullet$ EU-12 (excl. AT, Fl, FR, UK) a AT, FI, UK EU-12

Figure 2.4: Mean index of the quality of the schools' educational resources and change in dropout as a result of the policy interventions (data OECD PISA 2006); $R^{*}$ denotes the R squared of the EU-12.

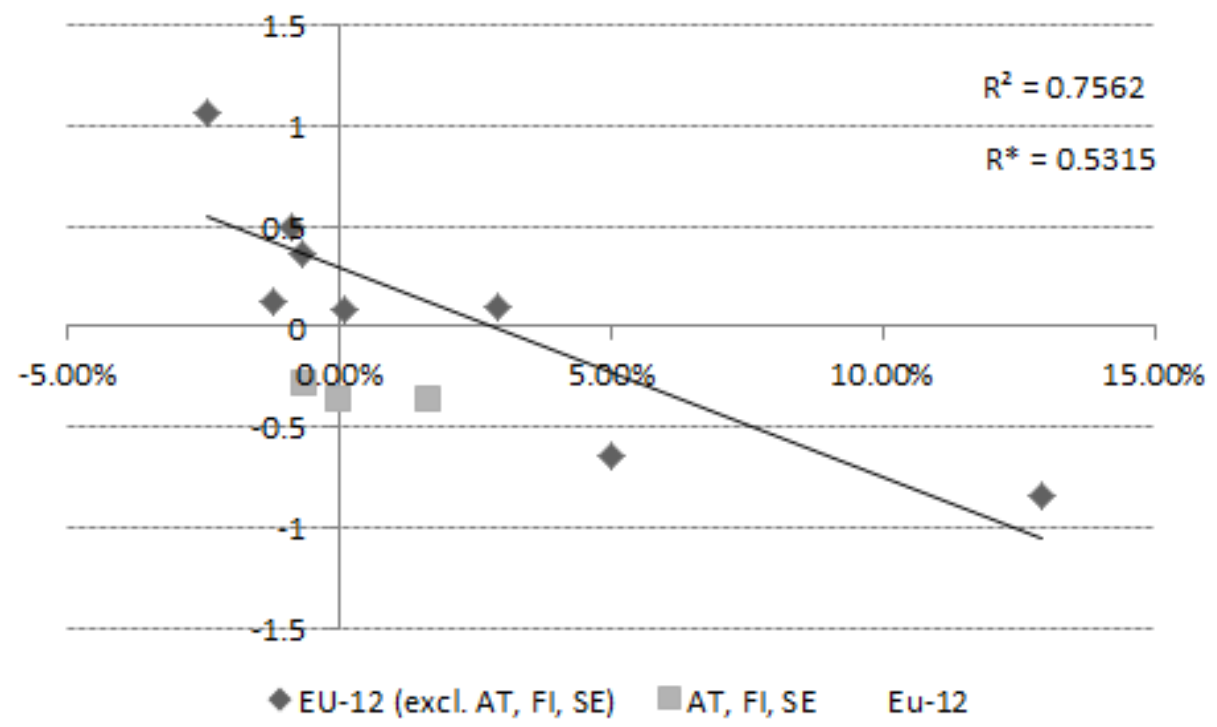

Figure 2.5: Mean index for availability and quality of human resources and change in dropout as a result of the policy interventions (data OECD PISA 2006); $\mathrm{R}^{*}$ denotes $\mathrm{R}$ squared the EU-12. 
ternal labor market) or standardization (occupational labor market). Stratification deals with the extent and form of tracking in secondary education. Stratification is relatively high in the Netherlands, Belgium, and Germany where early ability tracking takes place to enter secondary education. Within these countries, vocational tracks are well-organized within the scope of internships or what are called dual tracks. As a result, the labor market is closely connected with the schooling market. During the school career, however, there is little inter-track mobility possible. Once entered, it is difficult to 'escape' the assigned school track. Other examples of occupational labor market systems are Austria and Denmark.

More inter-track mobility is observed in standardized educational systems, where tracking occurs at a later age in the school career. Consequently, students obtain a school-leaving certificate that has the same quality (or signal for employers) nationwide. Among the EU-12 countries, we find a comparable level of standardization in France and Belgium. In these two countries, it is possible to follow either a general school track which results in a school-leaving certificate providing access to post-secondary education institutions, or to follow a vocational school track.

In contrast, the educational system in Ireland is much more loosely organized. Nevertheless, the student's cognitive knowledge is of high importance for successful labor market entrance. Applicants have to take standardized examinations organized by employers. The results on those tests strongly determine the future career path.

The highest interaction between the school and the labor market is found in Italy, Greece, Spain, and Portugal where there is significant on-the-job training of youngsters. Although school-leaving certificates are important, socioeconomic background plays a crucial role in the recruitment process.

In Nordic countries, the state has a major role. In a similar institutional environment, educational systems are financially subsidized and politically 
Table 2.5: Explaining the net policy influences by enrollment of boys in VET, quality of educational resources (PISA 2006 index) and quality of human resources (PISA 2006 index).

\begin{tabular}{rrrrr}
\hline Country & $\begin{array}{r}\text { Enrollment } \\
\text { of boys in VET }\end{array}$ & $\begin{array}{r}\text { Evolution } \\
\text { of boys in VET }\end{array}$ & $\begin{array}{r}\text { Quality of } \\
\text { educational } \\
\text { resources }\end{array}$ & $\begin{array}{r}\text { Quality of } \\
\text { human } \\
\text { resources }\end{array}$ \\
\hline Austria & 79.4 & $0.92 \%$ & 0.36 & -0.36 \\
Belgium & 71.0 & $0.77 \%$ & -0.03 & 0.49 \\
Denmark & 57.1 & $-0.67 \%$ & -0.09 & 0.1 \\
Finland & 65.2 & $2.26 \%$ & -0.23 & -0.28 \\
France & 57.9 & $-2.33 \%$ & - & - \\
Germany & 66.3 & $-1.02 \%$ & 0.11 & 0.36 \\
Luxembourg & 66.7 & $-0.21 \%$ & 0.26 & 1.06 \\
Netherlands & 70.6 & $-0.23 \%$ & 0.26 & 0.13 \\
Portugal & 29.2 & $43.75 \%$ & -0.38 & -0.84 \\
Spain & 42.0 & $4.52 \%$ & -0.02 & -0.64 \\
Sweden & 55.1 & $2.80 \%$ & 0.05 & -0.36 \\
UK & 56.7 & $-6.27 \%$ & 0.27 & 0.08 \\
\hline
\end{tabular}

organized. Employers use standardized qualifications during the recruitment process and the school-to-work transition is considered as an important task of the unions.

\section{The link between vocational education and school dropout}

The front runners with an overall high participation rate of boys in vocational education and training (VET) are Austria (79.4 percent), Belgium (71.0 percent), the Netherlands (70.6 percent), Luxembourg (66.7 percent), Germany (66.3 percent), and Finland (65.2 percent). Over the period 2000 to 2008, the share of students enrolled in higher secondary education VET programs increased considerably in Spain $(+4.52$ percent), Portugal $(+43.8$ percent), Finland $(+2.26$ percent $)$ and Sweden $(+2.80$ percent $)$. These countries seem to have failed to manage the increasing enrollment rates in VET. Table 2.4 and Figure 2.3 present the negative relationship between boy's enrollment in VET and early school-leaving. Enrollment in VET can explain 
79 percent of the variation in early school-leaving across countries.

Concerning the link between pre-vocational and vocational education, Belgium and the Netherlands have both pre-vocational and vocational education programs in lower secondary level. In other countries, these tracks have very low enrollment rates or are non-existent (Ostenk and Blokhuis, 2007). A smooth transition between pre-vocational and vocational education seems to favor the scope for policy interventions. Also, countries with larger possibilities for a smooth school-to-work transition have a greater scope for effective policy (OECD, 2006; Quintini et al., 2007). For example, a well-developed apprenticeship system in Germany and Austria can be observed. On the contrary, Portugal lacks "pronounced occupational structures of youth labor market integration (Gangl, 2002)." In line with Gangl (ibid.), the results indicate that Portugal fails to manage the increasing $(+43.75$ percent) enrollment rate of boys in VET over the period 2000 to 2008: as much as +12.91 percentage points is attributed to $\left(\Delta y_{\text {policy }}\right)$.

After Portugal, we observe highest increase in enrollment rate of boys in VET in Spain with +4.52 percent over the period 2000 to 2008. In Spain the transition from school-to-work is hard. It takes about 6 years to find a permanent job due to a high certificate of labor market segmentation between temporary and permanent jobs (Quintini et al., 2007). As a result the share of students neither in education nor in employment is relatively high in Spain, where we attributed +5.02 percentage points to $\left(\Delta y_{\text {policy }}\right)$. Thus, youth unemployment spells are common in Spain, and this is in marked contrast to Germany and Austria, where a large share of youngsters find a job without experiencing any unemployment (ibid.).

The observed close link between our outcomes on policy effectiveness and VET contradict earlier assumptions of the OECD (1999), in that occupational systems lack the capacity to adapt to structural change. The Netherlands and Germany, for example, experienced a positive impact of 
short-term and long-term influences on early school-leaving. Both countries, however, perform well in terms of fewer school dropouts and have a wellorganized interaction between the labor market and vocational education. One can argue that this part of dropout reduction attributed to $\left(\Delta y_{\text {policy }}\right)$ is more durable than the part subscribed to economic swings.

\section{The link between educational quality and school dropout}

Educational quality on its own can explain 47 percent of the variation in the 'net' policy estimate. If one excludes Austria, Finland, and the United Kingdom from Figure 2.4, the link between educational quality and school dropout increases to 81 percent. This is observed in Figure 2.4. In a similar vein, we expect that the quality of teachers and school management positively correlates with potential policy impact. This is graphically presented in Figure 2.5 where the quality of human resources explains 53 percent of the variation in the 'net' policy outcomes. Excluding Austria, Finland and Sweden from Figure 2.5, the explanatory value increases to $76 \%$. Figures 2.4 and 2.5 may indicate, for example, that better employees are more able to translate policy interventions into practice. In developing an effective policy, it seems, therefore, worthwhile to invest in the quality of educational and human resources.

\subsection{Conclusion}

The naming and shaming of policymakers based on observed outcomes leads to biased results, as noncontrollable factors also influence these outcomes. This chapter has suggested a simple linear benchmarking model which estimates a country's average dropout rate conditional on short-term and longterm economic conditions, country- and time-invariant effects. From the conditional average dropout rate, a 'net' policy outcome may be obtained. The results are then used for a reliable and meaningful 'naming and sham- 
ing' framework, where the estimated policy outcome may be associated with several explanatory variables.

The procedure works in four steps. In the first step, one should decide on the outcome variable of interest. As argued before, regulatory frameworks often use an outcome-oriented procedure whereby the selection of the outcome variable is straightforward. In the second step, the relevant macro- and micro variables which influence the outcome indicator should be discussed. To avoid an extensive list of control variables, one should clearly indicate for each variable why it matters. If possible, evidence on the influence should be looked for in the academic literature. In the third step, the proposed panel data benchmarking model should be applied. In the fourth and final step, the 'net' policy indicator can be related to more general variables at the system level. This might yield some evidence on why some units (e.g. countries, regions, schools) perform better than other units. This in turn provides new ways for making and evaluating policy. Note that it may be argued that 'best performance' should not only be measured by its outcomes. It may also be desirable to account for input factors (e.g. what measures did a country take to reach the policy goal?). In an indirect way, the proposed panel data benchmarking model is able to capture input measures that drove the outcome, or, at least, is able to correlate with meaningful input factors, such as the organization of schooling and the quality of human resources.

In this chapter, the benchmarking model was applied to early schoolleaving outcomes in the EU-12. Without controlling for exogenous influences, Portugal and the Netherlands are the best performers in absolute values, with a decrease in the dropout rate of, respectively, -8.2 and -4.0 percentage points. These numbers, however, mask heterogeneity across countries and cannot unambiguously be attributed to educational policymaking. Short-term economic influences arise from the opportunity cost of schooling: labor. If students take classes, they do not earn a wage. The 
results indicate that an increase in wages (the opportunity cost) increases early school-leaving. Long-term economic influences originate from economic development (a change in GDP). The economic growth rate is negatively correlated with early school-leaving. Finally, the benchmarking model accounts for time- and country-fixed-effects. The former capture, e.g. the increasing awareness of the importance of a high school certificate, the latter capture the non-economic incentives to drop out.

The results indicate that Portugal, Denmark, and the Netherlands have benefitted the most from job market conditions and economic growth. In contrast, economic circumstances have had unfavorable influences on early school-leaving in Sweden and Finland. Controlled for short and long-term economic environment, and for time- and country-fixed-effects, Luxembourg's educational policy was most effective, with a decrease in early school-leaving of 2.4 percentage points (a relative decrease of 14 percent). Also named are the Netherlands (-1.19 percentage points), Belgium (-0.87 percentage points) and Germany (-0.68 percentage points). The following three countries can be shamed, as they experienced clearly positive short- and long-term economic influences, but these were accompanied with an ineffective educational policy. The economic environment pushed dropout down in Portugal by 21 percentage points, while the policy component caused dropout rates to soar by 12.91 percentage point. Also Spain (+5.02 percentage points) and Denmark $(+2.9$ percentage points $)$ did not succeed in developing an effective early school-leaving policy.

Although only limited evidence is available to explain the 'net' policy effect, a close link with vocational education and its organization is observed. Students enrolled in vocational education are more at risk of dropping out. Policy makers in countries with a higher enrollment rate in vocational education can more easily develop effective policy, for example, by limiting the impact of economic conditions on student outcomes. One may thus ar- 
gue from the existing literature (see Müller and Gangl, 2003; Allensworth, 2005), in line with the results of our panel data benchmarking model, and in line with our conceptual model for school dropout and prevention (see Chapter 1), that the vocational school is intertwined with the labor market. The Netherlands is an interesting case study in this respect, given its long history in organizing vocational education and training and its number 2 position among the best performers in the EU-12. Here, Part II of this dissertation, focusses on the effectiveness of prevention interventions in the Netherlands. 

Part II

\section{Dropout Prevention in the Netherlands}





\section{Chapter 3}

\section{The Registration of School Attendance}

"Exactly what counts as authorized and unauthorized is a matter of interpretation and also involves the extent to which parents may condone truanting by their children." (Attwood and Croll, 2006, p.468)

\subsection{Introduction}

This third chapter examines the importance of school absenteeism to identify students at-risk of school dropout. ${ }^{2}$ The previous literature focused on the determinants of school absenteeism and its relationship with school dropout in static model estimations (for an extensive overview, see Sutphen et al., 2010). Several authors observe that truants and school dropouts are associated with similar student characteristics, such as male students, ethnic minority students, students from disadvantageous families, and low-ability students (see Chapter 1). This chapter takes an atypical stance as it estimates (1) the extent to which unauthorized truancy accelerates the process

\footnotetext{
${ }^{1}$ Chapter 3 is based on: Sofie J. Cabus and Kristof De Witte (2012). School Absenteeism and Dropout. - A Bayesian Duration Model. TIER, Maastricht University, Working Paper.

${ }^{2}$ In this paper, the terms 'truancy' and 'school absenteeism' are used interchangeably. They denote authorized and unauthorized school absenteeism, unless specifically mentioned.
} 
of early school-leaving; and (2) to what extent such truancy may be considered a practical tool for policymakers and schools that wish to perform dropout prevention programs. This approach needs to account for inevitable measurement errors in the nature and extent of the truancy spell.

It is necessary to make a precautionary remark in that the causal inference between truancy and school dropout is not straightforward. Both are influenced by unobserved variables, such that endogeneity may arise. However, as truancy cannot follow from school dropout (by construction), the direction of the correlation is known, so that a causal interpretation can be given. This is also argued in the data Section 3.3 and the empirical Section 3.4 below.

\section{Duration models in education}

Students do not leave school overnight. Given the chronological nature of events before the actual decision to leave school is made, one could argue for a dynamic model. Duration models allow us to examine the timing of the dropout decision, as well as the increased hazard in dropout due to a preceding truancy record.

Duration models have only been occasionally applied in the educational literature (see, among others, Singer and Willett, 1993; DesJardins et al., 1999, 2002; Murtaugh et al., 1999). In addition, previous studies with duration models have mainly focused on dropout at university level. To our best knowledge, there are four exceptions which study early school-leaving. First, using a non-parametric competing risk hazard model, Bradley and Lenton (2006) estimate the timing of the dropout decision among 16 to 18 year-olds voluntarily enrolled in continuing education in the UK (i.e. before entering university or higher education). The authors show that students drop out more frequently towards the end of the study period (April, July). However, once they are controlled for observable and unobservable characteristics, the probability of dropout is basically constant. Next, Light (1995) and Light 
and Strayer (2000) considered the re-enrollment decision of students, defined as the decision to go back to school after a dropout decision has been taken. Using the semi-parametric proportional hazard model, they find that students re-enroll in school when costs are relatively low and benefits are relatively high, for example, in times of an economic recession. Fourth, Olsen and Farkas (1989) discuss school dropout and childbearing outcomes using a continuous time hazard model. They estimate what is called 'waiting the time' to drop out of school, and retrieve the determinants to delay this decision. For example, they provide evidence that the schooling level of the mother delays the dropout decision of the child.

\section{Contributions}

Chapter 3 contributes to the literature along two major lines. First, it focusses on school absenteeism and its influence on the timing of the dropout decision. This contrasts with previous conceptual and static models (starting from Tinto, 1975) whose adequacy has been questioned (Braxton et al., 1997). The timing of the event is estimated by a survival (or duration) analysis. This is convenient in the setting concerned as it creates a dynamic perspective, and allows us to handle censored data arising from uncompleted spells. The chapter will thus provide an answer to the question whether, and to what extent, truancy accelerates the dropout process.

Second, it accounts for data uncertainty in a Bayesian duration model. Very often, even within the same data set, schools use different definitions or interpretations of school absenteeism. This is resulting in a lack of transparency, accuracy, and reliability of the data, which makes the consistency of the outcomes intricate (e.g. Bos et al., 1992). This can be resolved by using an unequivocal definition of what is considered unauthorized school absenteeism. We therefore exploit an exceptionally rich Dutch administrative data set.

The Netherlands is a particular interesting case study, as the Dutch Min- 
istry of Education, Culture, and Science has developed various measures to reduce dropout (for an extensive description, see Chapter 4). One of the measures was improved reporting and registration of truants and dropouts. As from 2005 onwards, every student who attends school in the Dutch educational system obtains a personal identification number, which is used to register truancy and school dropout. Similar information is only available in three other European Union countries: namely, the United Kingdom, Germany, and Italy (European Commission, 2011a). Furthermore, there are uniform definitions in the Netherlands of what is considered (un)authorized truancy and school dropout. Here, a school dropout is defined as a youngster who leaves school without a higher secondary certificate between the age of 12-23. A truant is defined as a student who is not at school for one or more days. Within three days, the school reports the truancy to the 'truancy officer' who independently examines the nature and extent of the absence problem of the student. Only in the case of unauthorized truancy, does the student end up in the data with an unauthorized truancy spell. ${ }^{3}$ If the spell was authorized, the data is corrected using a unique variable called report status. Hence, the previous incidence of supposed truancy is still visible for the researcher. In other words, the data reveal the measurement error for each truancy spell: it is observed whether the school considered a student as an unauthorized truant, but in fact was not.

This is extremely useful in a Bayesian framework, where this superior information on authorized and unauthorized truancy can be exploited. It provides feasible insights into the measurement error in the underlying data. In particular, a semi-parametric Cox proportional hazard model is estimated for school-aged students that appropriately accounts for the proportional hazard assumption, and easily deals with Bayesian data properties. It is shown that only a Bayesian structure on the data yields insightful and con-

\footnotetext{
${ }^{3}$ If the period of truancy was legitimated, the information is updated and the student is no longer considered as truant.
} 
sistent results. The idea to use a Bayesian approach in this chapter is, therefore, alike to that used in the previous literature on perceived risk, where one may dispute what is perceived unauthorized truancy (for some examples on perceived risk and Bayesian modeling (see Viscusi and Magat, 1992; Lundborg and Lindgren, 2002, 2004).

The chapter unfolds as follows. Section 3.2 outlines the Bayesian duration model in an education context. Section 3.3 discusses the data and descriptive statistics, and Section 3.4 presents the results. A conclusion and discussion is provided in Section 3.5.

\subsection{Duration models for school dropout}

\section{Survival analysis}

Denote by $T$ the time to an event (e.g. school dropout), and by $t$ the time under study. ${ }^{4}$ Further, denote by $t_{0}$ the time that an observation enters the analysis (e.g. day of birth). From $t_{0}$ onwards, all observations become at-risk of dropping out at school. We are interested in the likelihood that a student does not drop out of school (i.e. likelihood of survival) and estimate:

$$
S(t)=1-F(t)=\operatorname{Pr}\left(T>t_{0}\right),
$$

where $S(t)$ denotes the survival function, and $F(t)$ the likelihood that an event occurs at time $T$, which is assumed to be a later time period than $t_{0}$ (van den Berg, 2000; Hjort, 2003). As students age, they face a higher risk of dropping out (Wenger, 2002; Entwisle et al., 2004, 2005; Plank et al., 2005). This is easily captured in the cumulative or integrated hazard function (Kalbfleisch, 1978b; Kalbfleisch and Prentice, 1973, 2002; van den Berg, 2000; Hjort, 2003) ${ }^{5}$ :

\footnotetext{
${ }^{4}$ From a statistical perspective, we assume that the time to an event is random.

${ }^{5}$ The probability density function (pdf), $f(t)$ may be derived from $F(t)$ as follows:

$$
f(t)=\frac{d F(t)}{d t}=\frac{d}{d t}\{1-S(t)\}=-S^{\prime}(t) .
$$
}




$$
\begin{aligned}
H(t) & =\int_{0}^{t} \frac{f(u)}{S(u)} d u \\
& =-\int_{0}^{t} \frac{1}{S(u)}\left\{\frac{d\left(-S^{\prime}(u)\right)}{d u}\right\} d u \\
& =-\ln (S(t))
\end{aligned}
$$

where the integrated hazard function $H(t)$ is equal to the natural logarithm of the survival probabilities or the accumulated age-specific failure rate. Equation (3.2) is equal to (3.1) when the survival distribution is continuous (Kalbfleisch, 1978b; Ibrahim et al., 2005).

Central in a survival analysis is the unobserved rate at which an event occurs, known as the 'hazard rate' $h(t)$. A hazard is defined as the agespecific failure rate and denotes, for observations who are under study (i.e. $T>t_{0}$ ), the (limiting) probability that the observation will fail at a certain moment in time (i.e. in $(t, t+\triangle t)$ ) (van den Berg, 2000):

$$
h(t)=\lim _{\Delta t \rightarrow 0} \frac{\operatorname{Pr}\left(t+\Delta t>T>t \mid T>t_{0}\right)}{\Delta t},
$$

where $\Delta t$ is the interval between being at-risk and failure.

As a student becomes at-risk of dropping out of school from his/her birth onwards, the time under analysis $(t)$ may be expressed as years to the event since birth. This corresponds to:

$$
t=\frac{\text { date of dropout }- \text { date of birth }}{365.25} .
$$

Using equation (3.4), the output of the survival analysis can be expressed as the age of the student at the time of dropout.

To examine the relationship between truancy and school dropout, the survival probability function is made conditional on (truancy $\in\{0,1\}$ ) and time $(t)$. This is denoted by $S($ truancy, $t)$, where $S(0)$ denotes the survival curve of regular school attendees, and $S(1)$ of truants. The division between 
truants and regular school attendees is retrospective: it has been assigned after failure. The analysis proceeds in three steps: (1) the non-parametric Kaplan-Meyer estimator is used to compute the survival probabilities; (2) a Cox proportional hazard model controls for multiplicative effects; and (3) a Bayesian duration model accounts for data validity issues.

\section{Step 1. Nonparametric Kaplan-Meyer estimator}

In the first step, the data is described. The simplest way is to present the data in life tables (Cox, 1972). A life table estimates, for each age, the likelihood of dropping out of school at that age (i.e. before the next birthday is reached). The additional probability to drop out of school due to preceding school absenteeism is then obtained by subtracting $S(1)$ from $S(0)$ at a given age:

$$
\Delta S(t)=S(0)-S(1)
$$

The accumulated probability of dropping out at a given age is obtained by estimating the difference in the integrated hazard rate between truants $\left(H_{1}(t)\right)$ and regular school attendees $\left(H_{0}(t)\right)$. Therefore, $S(0)$ is divided by $S(1)$, written as:

$$
H_{0}(t)-H_{1}(t)=\ln \left(\frac{S(0)}{S(1)}\right) .
$$

Survival probabilities in a life table and the integrated hazard rates can be computed from the Kaplan-Meyer estimator (1958). The Kaplan-Meier estimator is the product of the probabilities that an observation survives at the end of a time interval, given that it was present at the beginning of this time interval. This is a fully non-parametric estimation procedure, and in the literature is also called the 'product limit estimator'.

$$
S(t)=\prod_{t_{i} \leq t}^{T} \frac{n_{i}-r_{i}}{n_{i}}
$$


where $r_{T}$ denotes the number of failures at time $T$, and $n_{T}$ the number of survivors just before time $T$. If time is discrete, a plot of the Kaplan-Meyer survival function is characterized by a step-wise function that visualizes failures (i.e. school dropouts). In the application below, time is considered continuous, such that the survival plot will be smoother (i.e. it looks like a reversed S-function).

\section{Step 2. Multiplicative effects in a Cox proportional hazard model}

To account for the influence of covariates, the semi-parametric Cox model (Cox, 1972) is employed. The model consists of two parts: (1) a nonparametrically estimated baseline hazard $\lambda_{o}(t)$ which is assumed to be constant over time; and (2) a parametrically-estimated set of covariates which have a multiplicative effect on the baseline hazard. The multiplicative effect is estimated by:

$$
\begin{aligned}
\lambda_{i}(t) & =\lambda_{o}(t) \exp \left(x_{i}^{\prime} \beta\right) \\
& =\lambda_{o}(t) \exp \left(\beta_{1} x_{i 1}+\ldots+\beta_{k} x_{i k}\right),
\end{aligned}
$$

where $h_{o}(t)=\log _{e} h_{0}(t)$ denotes the unspecified base-line hazard at time $t$, and $\beta$ the vector of unobserved coefficients to the vector of characteristics $x\left(x_{1}, \ldots, x_{k}\right)$ for observation $i$ (with $\left.i=1, \ldots, n\right) .{ }^{6}$ For a correct interpretation of the estimates, the baseline hazard is required to be constant over time. This is referred to as the 'proportional hazard' $(\mathrm{PH})$ assumption. If the baseline hazard is not a constant over time, it is argued that the event (i.e. school dropout) is associated with the analysis time. In other words, time would have an effect on school dropout. In our application, it is likely that school dropout is correlated with time as (1) as older students are more likely to drop out of school than younger students; and (2) as the compulsory

\footnotetext{
${ }^{6}$ As the hazard is assumed to be positive, we specify the function of $x$ as an exponential distribution. Indeed, an exponential distribution satisfies $g(x) \geq 0$ and $g(0)=1$.
} 
education age is a clear cut-off between compulsory and voluntary education, and may alter the dropout behavior of students. The validity of the proportional hazard assumption for the application is tested and discussed in Section 3.4. It is shown that the Cox proportional hazard assumption holds for students below age 18, such that dropout is independent of time for those students.

\section{Step 3. A Bayesian duration model}

As has been argued before, the administrative data set reveals the measurement error and data validity of the truancy variable. By using a Bayesian structure, this superior information is exploited. Bayesian duration models are increasingly popular (e.g. Gamerman, 1991; Kalbfleisch, 1978; Kalbfleisch and Prentice, 2002; Kooper et al., 2007; Aitkin and Clayton, 2009). The Bayesian framework models start from the prior and posterior density on the data:

$$
p(\theta \mid y)=\frac{p(y \mid \theta) * p(\theta)}{p(y)},
$$

where $y$ denotes the data sample; $\theta \sim(E(\Lambda(t))$; $\operatorname{var}(\Lambda(t)))$ the population parameters; $p(\theta)$ the prior density; $p(\theta \mid y)$ the posterior (observed) density; and $p(y)$ the marginal density of the observed data. The likelihood function $p(y \mid \theta)$ is the likelihood function of interest: the probability that $\theta$ may be estimated from the data $y$. In other words, the Bayesian framework includes information on: (1) the data $y$; and (2) the knowledge of the researcher with respect to the likely range of values of the population parameters $\theta=$ $(\beta, h, \sigma)$. For example, the right-hand side of equation (3.8) may be plotted to visualize the shape of $p(\theta \mid y)$, or the data $y$ may be used to update beliefs on $p(\theta)$.

Bayesian structure in a non-parametric Kaplan-Meyer estimator. The Bayesian ideas can be included in the non-parametric Kaplan-Meyer esti- 
mator. At this point, it is insightful to briefly discuss the prior density used in a survival analysis. Koop et al. (2007, p.12) argue that, if the prior density belongs to the exponential family, the prior density may be chosen so that the posterior density falls within the same elementary family of distributions as the prior. The (piecewise) exponential class of distributions (PE) have often been used in a non-parametric survival analysis (Gamerman, 1991). The latter partitions the analysis time into a finite number of $K$ disjoint intervals, where the random variable $T$ follows a $P E$ distribution $T \sim P E(\lambda, \tau)$ with $\lambda=\left(\lambda_{1}, \ldots, \lambda_{k}\right)$ and $\tau=\left\{t_{1}, \ldots, t_{k-1}\right\} .{ }^{7}$ In each interval, one can estimate (Kalbfleisch, 1978):

$$
\lambda(t)=\left\{\begin{array}{c}
\lambda_{1}, t \in w e_{1}=\left[t_{0}, t_{1}\right] \\
\lambda_{i}, t \in w e_{i}=\left[t_{i-1}, t_{i}\right] \quad, \quad 1<i<k \\
\lambda_{k}, t \in w e_{k}=\left[t_{k-1}, t_{k}\right]
\end{array}\right.
$$

where the hazard estimated for the ith interval or the probability to survive at time $T \in\left[t_{i-1}, t_{i}\right]$ is conditional on $T \geq t_{i-1}$. The intervals can be chosen as yearly intervals (i.e. $\left.\left[t_{12}, t_{13}\right),\left[t_{13}, t_{14}\right), \ldots,\left[t_{21}, t_{22}\right)\right)$. On the day of birth, there is no risk of school dropout, such that $\lambda\left(t_{0}\right)=0$. As from the age of 12 onwards $(t=12)$, the hazard may be estimated as:

$$
\lambda\left(t_{i}\right)=\sum_{j=1}^{k} r_{j}(i=1, \ldots, n),
$$

where $r$ denotes the cumulative risk of school dropout as from time $\left(t_{1}=12\right)$ to $\left(t_{k}=22\right)$ (i.e. the risk accumulated over all time intervals before event time $T$ ). It follows that $r_{12}, \ldots, r_{22}$ are a posterori independent, and that $r_{i} \sim G\left(\alpha_{i}-\alpha_{i-1}, c\right)$ have independent gamma distributions with a scale parameter $\alpha_{i}=c \lambda^{*}\left(t_{i}\right)$ and a shape parameter $c$. Correspondingly, the prior

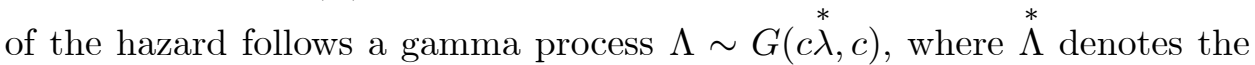
initial knowledge of the researcher on $E(\Lambda(t))=\stackrel{*}{\Lambda}(t), \operatorname{var}(\Lambda(t))=\stackrel{*}{\Lambda}(t) / c$

\footnotetext{
${ }^{7}$ Note that the analysis time is ranked by $t_{0} \leq t_{1} \leq \ldots \leq t_{k-1}$.
} 
and $c$ the weight attached to that knowledge (Kalbfleisch, 1978, p.216). One may now see that the posterior distribution of $\Lambda(t)$ is the sum of all independent risks over the intervals $(j=1, \ldots, k)$ (cf. increments), given that $t_{1}<t_{2}<\ldots t_{k}$ and for a particular $c$.

If $c$ is near 0 , only little faith is attached to the initial knowledge of range of parameters $\theta$. In this case, the likely range of parameters $\theta$ is unknown such that a fully non-parametric method (e.g. the Kaplan-Meyer estimator) is consistent with $c$. If $(c \rightarrow \infty)$, the likely range of parameters $\theta$ is assumed to be completely known. Here, one may find support for a fully parametric survival analysis (Kalbfleisch, 1978; Kalbfleisch and Prentice, 2002). The data Section 3.3 below starts from the assumption that $c$ equals 0 such that a Kaplan-Meyer estimator is estimated.

Bayesian structure in a semi-parametric Cox model. Under the Cox model (1976), the joint probability of survival of $n$ subjects, given the covariate matrix $X$, is given by:

$$
P\left(T>t_{0} \mid \beta, X, \lambda_{0}\right)=\exp \left\{-\sum_{j=1}^{k} \lambda_{0}(t) \exp \left(x_{i}^{\prime} \beta\right)\right\}
$$

where the baseline hazard $\lambda_{0}=\stackrel{*}{\Lambda}^{(}\left(t_{j}\right)-\stackrel{*}{\Lambda}^{(}\left(t_{j-1}\right)$ is assumed to be the result of a stochastic process. The gamma process is often used as a prior for the cumulative baseline hazard function (Ibrahim et al., 2005).

$$
\lambda_{0}(t) \sim G(c \stackrel{*}{\Lambda}, c)
$$

The gamma process prior in equation (3.12) implies that $\stackrel{*}{\Lambda}$ over the $\mathrm{j} t h$ intervals are independent. However, in practice, it is only necessary to obtain a joint prior distribution for $(\beta, \lambda)$ as the baseline hazard is eliminated from equation (3.7), and enters the likelihood function by estimation of $(\lambda=$ $\lambda_{1}, \lambda_{2}, \ldots, \lambda_{j}$ ). For example, comparing two observations $i$ (e.g. a regular 
school attendee) and $j$ (e.g. a truant), the following likelihood function for $\beta$ (Kalbfleisch and Prentice, 2002; Ibrahim et al., 2005) is estimated ${ }^{8}$ :

$$
\begin{aligned}
L(\beta, \lambda \mid \text { data })= & \prod_{i=1}^{n} \prod_{j=1}^{k}\left(\lambda_{j} \exp \left(x_{i}^{\prime} \beta\right)\right)^{\delta_{i j} v_{i}} \\
& \times \exp \left\{-\delta_{i j}\left[\lambda_{j}\left(y_{i}-t_{j-1}\right)\right.\right. \\
& \left.\left.+\sum_{g=1}^{j-1} \lambda_{g}\left(t_{g}-t_{g-1}\right)\right] \exp \left(x_{i}^{\prime} \beta\right)\right\}
\end{aligned}
$$

where $v=\left(v_{1}, v_{2}, \ldots, v_{n}\right) ; v_{i}=1$ if the ith subject failed, and 0 otherwise; and $\delta_{i j}=1$ if the ith subject failed or was censored in the $\mathrm{j}$ th interval, and 0 otherwise. The observed data is denoted by data $=(n, y, X, v)$. A typical prior for $\beta$ is the normal distribution, where $\mu_{0}$ is the mean value, and $\Sigma_{0}$ the variance. The joint posterior of $(\beta, \lambda)$ may be written as (Kalbfleisch and Prentice, 2002; Ibrahim et al., 2005) ${ }^{9}$ :

$$
\pi(\beta, \lambda \mid D) \propto \prod_{j=1}^{k}\left[G_{j} \lambda_{j}^{\left(\alpha_{0 j}-\alpha_{0, j-1}\right)-1} \exp \left(-c_{0} \lambda_{j}\right)\right] \times \exp \left\{-\frac{1}{2}\left(\beta-\mu_{0}\right) \Sigma_{0}^{-1}\left(\beta-\mu_{0}\right)\right\}
$$

\subsection{Data and descriptive statistics}

The application relies on a rich and unique administrative data set from the Municipality of Amsterdam. The data consists of 12 to 22 year-olds students

\footnotetext{
${ }^{8}$ Remark that $\stackrel{*}{\lambda}(t)=(d / d t) \stackrel{*}{\Lambda}(t)$ and $\stackrel{*}{\Lambda}(t)=\lambda t$ correspond to the unspecified baseline
} hazard from the Cox model.

${ }^{9}$ For further intuition on the estimate of $\beta$, one may consider:

$$
\begin{aligned}
& \stackrel{*}{\Lambda}(t \mid \text { truancy }=0)=P\{T \geq t \mid \text { truancy }=0, \lambda)=\lambda_{0}(t) \\
& \stackrel{*}{\Lambda}(t \mid \text { truancy }=1)=P\{T \geq t \mid \text { truancy }=1, \lambda)=\lambda_{0}(t) \exp \left(\beta^{\prime} \text { truancy }\right)
\end{aligned}
$$

where the relative risk ratio or hazard rate is equal to $\exp \left(\beta^{\prime}\right.$ truancy $)$, the multiplicative effect of truancy on the baseline hazard, and given that regular school attendees are the reference category. 
enrolled in secondary education in the Municipality of Amsterdam over the period 2005 to 2009. Only a limited sample of students can be used for three reasons. First, it is clear that for a duration model only observations with an eventual event are relevant. Second, owing to data constraints, we consider only students who experienced an event in secondary education such that the data become left-censored (although the total number of subjects dropping out of primary education is expected to be very low; Wenger, 2002; Entwisle et al., 2004, 2005; Plank et al., 2005). Third, again owing to data restrictions, school dropout above the age of 22 is ignored so that the data are right-censored as well. The left- and right-censoring provides an under bound estimate, as the true effect will be higher or equal to the estimated effect.

We count 13,538 unique students who dropped out of school in the period 2005 to 2009 . This corresponds to about 5 percent of the data. ${ }^{10}$ The analysis time is expressed as the total number of years since birth (following equation (3.4)), such that it is equal to the age of a youngster on the day of dropout. In line with the previous literature, a positive and significant correlation of 0.456 between age and school dropout is observed. ${ }^{11}$ Descriptive statistics for the Municipality of Amsterdam are summarized in Table 3.1. The dropout rate was 6.3 percent in 2005-06 and decreased to 4.7 percent in 2009-10 (Statistics Netherlands, 2011). The relative share of dropouts increases by age, with a major jump between the age of 17 and 18 . The average dropout student leaves secondary education at age 18. Higher dropout rates are observed for men than for women, with a steady difference over the

\footnotetext{
${ }^{10}$ Note that some (although a minority of the students) may possibly return to school after having dropped out. This might be the case, for example, in the subsequent school year after their first dropout decision. The average number of dropouts per student is 1.14 with a very low standard deviation of 0.46 , indicating that the majority of students only drop out once.

${ }^{11}$ Recall that a truant is defined as a student who is not at school for one or more days. A school dropout is a youngster below the age of 23 without a higher secondary degree and who is no longer enrolled in secondary education (Dutch Ministry of Education, Culture, and Science).
} 
years of about 2 percentage points. Furthermore, it is observed that ethnic minority students (in particular students from Aruba and the Dutch Antilles) have relatively higher dropout rates than native Dutch students, who have a dropout rate of around 4 percent. Most dropout students are situated in vocational pathways or study subjects. The poverty measure (APCG) indicates if a student is living in a disadvantaged area which is characterized by lower incomes, more benefits receivers, and higher unemployment status (Statistics Netherlands). A positive association is observed between living in these disadvantaged neighborhoods and the school dropout rate, with a multiple of about 2 compared with residential areas outside the poverty area. Finally, in line with the previous literature (e.g. Wenger, 2002; Entwisle et al., 2004, 2005; Plank et al., 2005), in the bivariate analysis it is observed that large municipalities ( $>250,000$ inhabitants) have higher dropout rates than medium (between 100,000 to 250,000 inhabitants) or small municipalities (below 100,000 inhabitants).

\section{A non-parametric visualization}

Using the non-parametric Kaplan-Meyer estimator (1958), survival probabilities of regular school attendees and truants are plotted in Figure 3.1. The $\operatorname{Pr}\left(T \geq t_{i-1}\right)$ conditional on precedent truancy $(\in\{0,1\})$ and years since birth is denoted by $\hat{S}$ (truancy, $t) .{ }^{12}$ We count 7,254 (53,58 percent) dropouts among regular school attendees and 6,284 (46,42 percent) dropouts among the truants. ${ }^{13}$

Figure 3.1 reveals a significant difference between truants and non-truants, although the two curves move in parallel over the analysis time. This indicates that there are, depending on the truancy status, differences in the timing of the dropout decision. In general, lower survival probabilities for

\footnotetext{
${ }^{12} S($ truancy, $t)$ is abbrevated by $S(0)$ for regular school attendees, and $S(1)$ for truants throughout this chapter.

${ }^{13}$ Note that the first failure denotes the first school dropout decision. As such, a small number of students re-enroll in school after the first dropout decision was taken. However, at a later point in time, they drop out one or more times in addition to the first failure.
} 


\subsection{DATA AND DESCRIPTIVE STATISTICS}

Table 3.1: Descriptive statistics of school dropout rates in the Municipality of Amsterdam by gender, age, ethnicity, poverty, residence, and vocational stream (expressed as the number of dropout students as a percentage of the total number of students in this category).

\begin{tabular}{|c|c|c|c|c|c|}
\hline & $2005-06$ & $2006-07$ & $2007-08$ & $2008-09$ & $2009-10$ \\
\hline \multicolumn{6}{|l|}{ Total dropout rate } \\
\hline & 6.3 & 5.7 & 5.5 & 4.4 & 4.7 \\
\hline \multicolumn{6}{|l|}{ Gender } \\
\hline men & 7.5 & 6.8 & 6.8 & 5.4 & 5.7 \\
\hline women & 5.2 & 4.5 & 4.3 & 3.4 & 3.7 \\
\hline \multicolumn{6}{|l|}{ Age } \\
\hline$<13$ & 0.9 & 0.8 & 0.7 & 0.4 & 0.6 \\
\hline 14 & 1.4 & 1.2 & 1.1 & 0.9 & 0.9 \\
\hline 15 & 1.8 & 1.5 & 1.3 & 1.2 & 1.1 \\
\hline 16 & 4.3 & 3.4 & 3.0 & 2.0 & 2.3 \\
\hline 17 & 8.5 & 6.9 & 6.0 & 4.5 & 4.2 \\
\hline 18 & 10.8 & 9.7 & 10.7 & 9.1 & 9.5 \\
\hline 19 & 12.8 & 12.8 & 12.1 & 10.4 & 11.2 \\
\hline 20 & 14.6 & 12.8 & 13.2 & 10.0 & 11.6 \\
\hline 21 & 15.2 & 13.5 & 14.0 & 10.6 & 11.0 \\
\hline 22 & 16.9 & 15.3 & 13.9 & 12.2 & 12.4 \\
\hline \multicolumn{6}{|l|}{ Ethnicity } \\
\hline Native Dutch & 4.8 & 4.5 & 4.3 & 3.5 & 3.5 \\
\hline Suriname & 9.5 & 8.2 & 8.4 & 6.9 & 7.4 \\
\hline Aruba/Antilles & 8.7 & 8.6 & 10.5 & 7.8 & 8.7 \\
\hline Turkey & 7.9 & 6.9 & 6.8 & 5.2 & 5.8 \\
\hline Marocco & 8.1 & 6.6 & 7.4 & 5.4 & 6.7 \\
\hline Other non-Western & 7.5 & 6.6 & 5.9 & 4.6 & 5.2 \\
\hline Other Western & 6.3 & 5.4 & 5.5 & 4.4 & 4.7 \\
\hline Unknown & 26.9 & 28.4 & 22.6 & 23.7 & 22.3 \\
\hline \multicolumn{6}{|l|}{ Poverty } \\
\hline Residence out of APCG & 4.9 & 4.5 & 4.3 & 3.6 & 3.5 \\
\hline Residence in APCG & 8.3 & 7.2 & 7.3 & 5.6 & 6.4 \\
\hline \multicolumn{6}{|l|}{ Residence [inhabitants] } \\
\hline$<20,000$ & 4.1 & 3.7 & 3.7 & 3.1 & 2.9 \\
\hline$[20,000-50,000]$ & 5.0 & 4.7 & 4.3 & 3.3 & 3.6 \\
\hline$[50,000-100,000]$ & 4.8 & 4.9 & 4.4 & 3.6 & 3.5 \\
\hline$[100,000-250,000]$ & 5.2 & 4.7 & 4.6 & 4.0 & 3.6 \\
\hline$>250,000$ & 7.8 & 6.7 & 6.8 & 5.3 & 6.1 \\
\hline Vocational stream & & & & & \\
\hline without pre-vocational certificate & 2.3 & 2.0 & 1.9 & 1.5 & 1.5 \\
\hline with pre-vocational certificate & 10.5 & 8.4 & 6.7 & 4.9 & 5.3 \\
\hline vocational & 14.3 & 13.1 & 13.0 & 10.8 & 11.5 \\
\hline
\end{tabular}

Source: Statistics Netherlands. 
older secondary school students are intuitive and in line with previous observations. Nonetheless, there is a significant difference in relative risk ratio. For example, for regular school attendees, the likelihood to survive at age 18 conditional on survival at age $18, \hat{S}(0,18)$, amounts to 56.9 percent. This likelihood drops to $\hat{S}(1,18)=20.6$ percent for truants. This indicates that more than one in five students with a truancy record leaves school before the compulsory education age is reached. Furthermore, the survival function shows that most of the truants leave secondary education between the age of 16 and 18 with a drop in survival probability from 72.5 percent to 20.6 percent. This is a remarkable difference compared with regular school attendees who have a survival probability at the age of 16 of 89.6 percent and dropping to 56.9 percent at age 18 . These results provide us with a first indication that the process of school dropout is substantially accelerated when a youngster has experienced a truancy spell.

\section{Bayesian methodology for data validity}

There are basically two sources of school absenteeism: authorized and unauthorized. Up to this point in the chapter, and similar to previous literature, we have not made a distinction between them. This ignorance, as well as using multiple definitions and self-reported measures, makes the analysis intricate since it is a source of uncertainty and measurement error (Bos et al., 1992). More precisely, the estimated integrated hazard for regular school attendees and truants $\left(\ln \frac{\hat{S}(0)}{\hat{S}(1)}\right)$ may be significantly different from the true hazard $\left(\ln \frac{S(0)}{S(1)}\right)$ once misspecifications in the data have been accounted for. As outlined earlier, one can account for this by updating prior beliefs in the data structure (i.e. a Bayesian model).

To do so, we exploit an exceptional richness in the data: the administrative data indicate for every truancy spell whether: (1) the absence was authorized (e.g. sick leave, wrongly reported); (2) unauthorized; or (3) still 


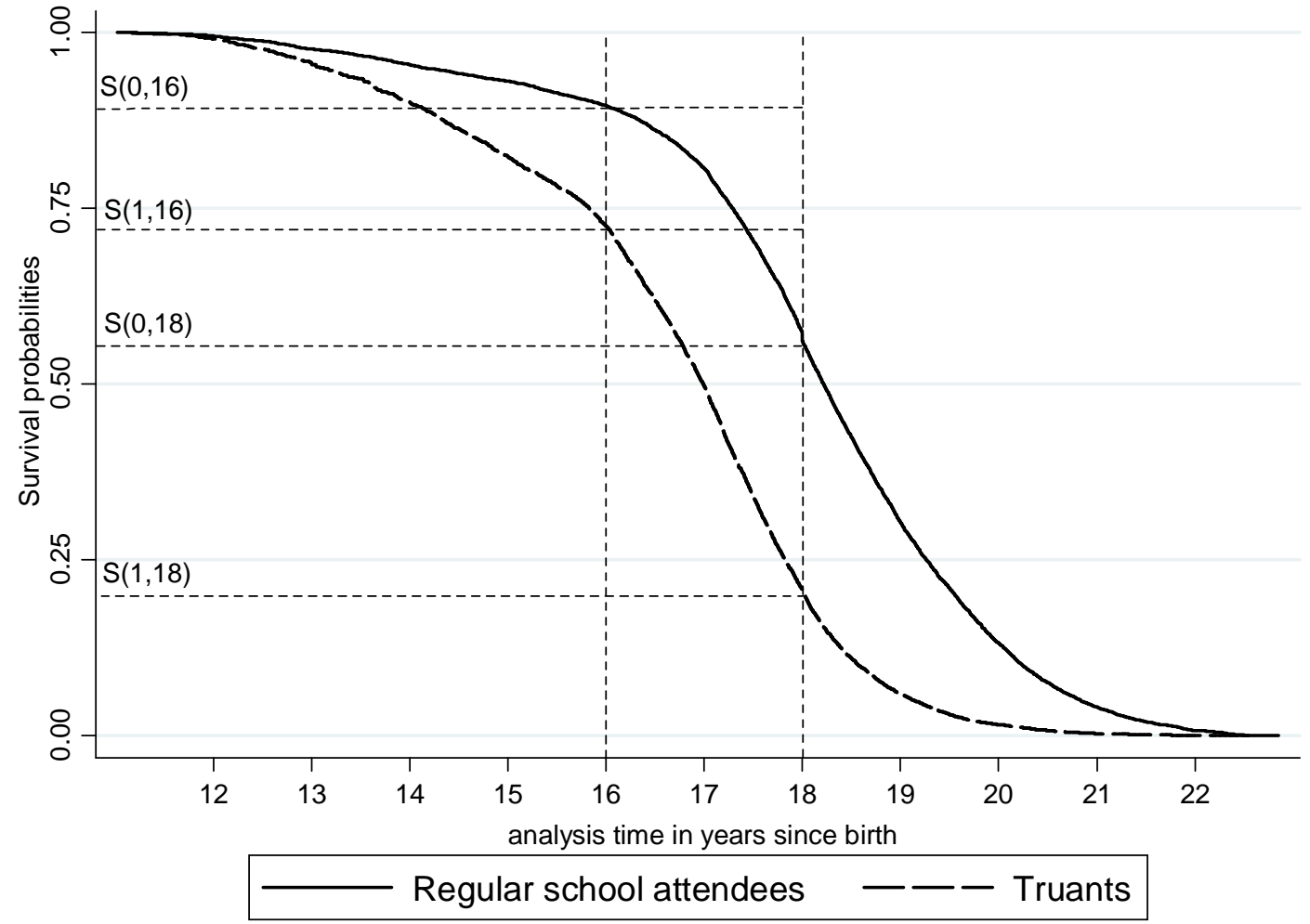

Figure 3.1: Survival probabilities of regular school attendees compared with truants. 
under investigation (i.e. the final settlement on the nature of the truancy spell is missing). This variation in the settlement of the truancy spell allows us to obtain information on the data validity, which is used in the Bayesian framework to impose assumptions on the data. This contrasts with the standard approach which assumes the data as 'clean' and without any error.

The data assumptions allow us to distinguish three models: a standard duration model, and two Bayesian models. First, consider the standard model, called Model 1. Model 1 is a standard duration model which assumes that the observed data are valid. In this sense, it follows the previous literature. The results are summarized in Table 3.2. The first, second, and third column provide, respectively, the ratio, the integrated hazard, and the differences between the survival probability of regular school attendees, $S(0)$, and the survival probability of truants, $S(1)$, at different points in time (i.e. at different ages of the student). Whereas the likelihood to survive at a given age, conditional on still being at school at this age (column (1)), steadily increases with age, a break can be observed at age 18. In particular, the likelihood is about three times higher at age 18 for regular school attendees than for truants. This was only 1.6 times higher at age 17, and about the same until age 14. Age 18 corresponds to the age when youngsters without retention in grade may legally leave high school (i.e. compulsory education age). The second column indicates the relative risk of dropping out of school at a given age. Until age 17, this risk is relatively low, but heavily increases from age 18 on. For example, we observe a huge leap between the ages of $17\left(\ln \frac{S(0)}{S(1)}=0.4821\right)$ and $18\left(\ln \frac{S(0)}{S(1)}=1.0151\right)$, indicating an increased proportional hazard or relative risk of dropping out of school once the post-compulsory age has been reached (for an elaborated systematic review on retention in grade and its effect on at-risk students, see Valentine et al., 2011). As can be observed from column (3), truants have a higher risk of dropping out of school than non-truants. At age 15, a 
truant has a 15 percentage point higher risk of leaving education early than a non-truant. This increases to 17 percentage points at age 16, 30 percentage points at age 17, and further to 36 percentage points at age 18. After this age, a decline in the relative risk is observed.

Next a Bayesian structure is added to the data. This enables superior information in the data on truancy to be exploited. We distinguish two groups of truants. The first group are 'effective truants' as their truancy status has been confirmed by the truancy officer after in-depth research. Those students were illegally absent from school. A second group of truants consists of 'false truants'. Those students were reported by the school as truants, but, in fact, after research by the truancy officer, they had a valid reason to be absent. The second and third model specifications exploit the difference between the 'false truants' and the 'effective truants'. The difference gives some insight into the validity of the data, and thus into the posterior information structure of the data.

Model 2 estimates an upper-bound to the estimates by considering only truants with an unconfirmed truancy status (i.e. false truants). Those students were reported by the school as truants, but in fact were not. In this sense, those students were falsely reported, resulting in a too high truancy level. Focusing on those students gives an indication of the estimation bias, as implying this information as posterior beliefs in the Bayesian structure yields an upper-bound estimate. The results in Table 3.2 indicate a considerable upward bias due to misspecification in the data. The relative risk ratio shows that the values in column (1) and column (2) from Table 3.2 are systematically higher in Model 2 than in Model 1. In other words, the 'false truants' are responsible for an overestimation of the influence of truancy on school dropout.

Model 3 estimates a lower-bound estimation by considering only truants with a confirmed truancy status (i.e. effective truants). Those are all stu- 
dents for whom we can be sure that they were, without any reason or with an invalid reason, absent from school. In this sense, it is a rigorous definition without data error. This results in a lower-bound estimation. It is observed that the lower-bound in Model 3 approximately follows Model 1 before $(t=18)$ with respect to the relative risk ratio.

Combining the lower- and upper-bound (Bayesian) estimations with the standard duration model delivers some insights into the validity of the data. Data are trustworthy if the outcomes of the standard model (Model 1) lie between the Bayesian lower and upper-bound (Model 2 and Model 3 in Table 3.2). Some clear differences are observed after age 18. In particular, the estimates of Model 1 are lower than the lower-bound estimates of Model 3. This difference can be attributed to the underlying data where from age 17 onwards more truancy spells are not finally settled. This indicates that the administration (in this case, the truancy officer) puts less effort into those students who are of post-compulsory education age. This is also presented in Figure 3.2, where, by the age of 19, the average number of days that a truancy spell is under research doubled compared with age 16. In sum, the results of Model 1 are not falling between the lower and upper-bound because of unresolved research: the actual nature of the truancy spell is unknown, so it may falsely declare school absenteeism to be unauthorized. Given the illustrated data difficulties from age 17 onwards, the data are limited to school-aged students only. ${ }^{14}$ This finding has implications for our results, provided next in Section 3.4, and is now discussed.

\footnotetext{
${ }^{14}$ From the Martingale residuals we observe further evidence for restricting the data to age 17. A plot of the estimated Martingale residuals is available on request.
} 


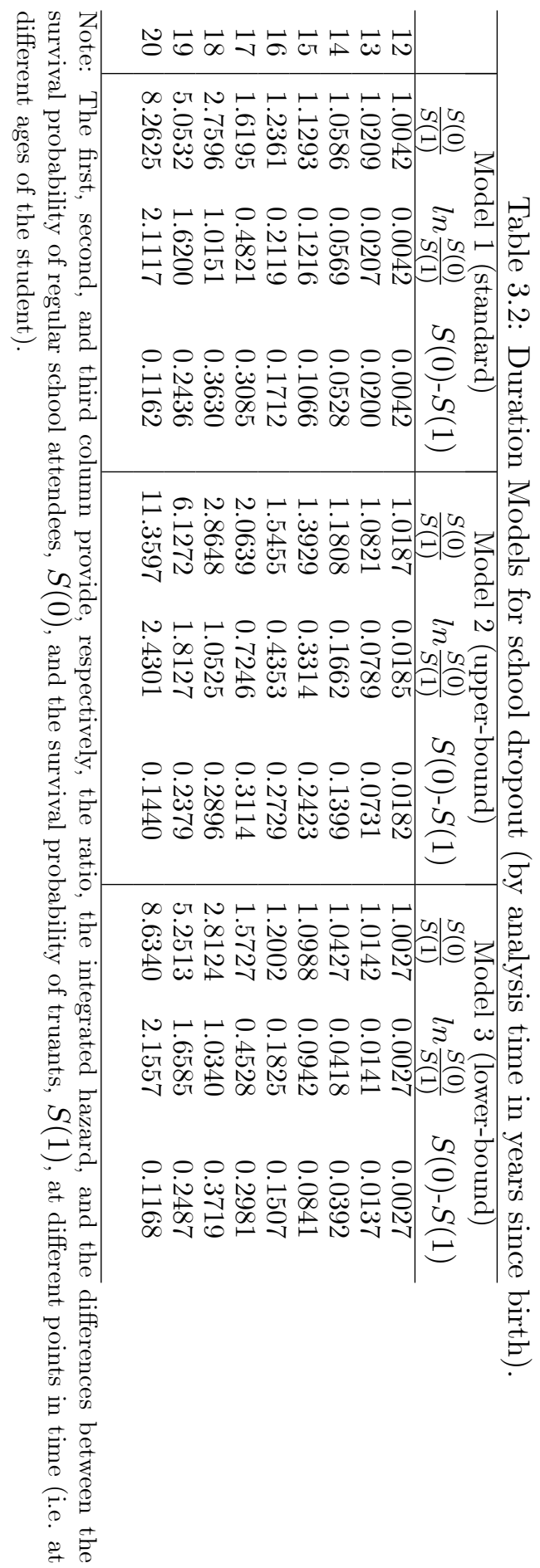




\subsection{Results of the Bayesian Cox model}

The previous section argued that the data should be limited to age 12-17, and prior beliefs on the data should be updated by a Bayesian model. The remainder of the chapter presents the results for the lower-bound estimations (i.e. prior beliefs are equal to unauthorized school leave by 'effective truants'). Upper-bound estimates are available upon request. Four different model specifications with an increasing number of multiplicative effects are estimated. The results are presented in Table 3.3.

It was argued in Section 3.2 that one needs to examine whether the proportional hazard $(\mathrm{PH})$-ratio is not violated. The proportional hazard test $($ Chi-square $=0.32 ;$ Prob $>$ Chi-square $)$ amounts to 0.570 , which supports the crucial identification restriction of a constant baseline hazard in the limited sample (students are equal to or younger than age 18). The PHratio stresses the importance of the Bayesian modeling assumptions. If the uncertainty and measurement error in the underlying data had been ignored, and thus a standard duration model is estimated, the PH-test $($ Chi-square $=$ 214.74; Prob > Chi-square) amounts to 0.000, such that the PH is violated. Only a Bayesian structure on the data yields insightful and consistent results.

Model 1 is a basic Bayesian lower-bound model which does not control for any source of heterogeneity. The estimate of interest is $\hat{\beta}$ : the multiplicative effect of unauthorized school absenteeism on the constant baseline hazard of dropout. The regular school attendees are thus the reference category. An estimated coefficient of 1 would indicate that regular school attendees and truants have an equal probability of dropping out over the analysis time; an estimated coefficient larger (smaller) than 1 indicates a higher (lower) additionally probability to drop out during the analysis time. The estimate of $\hat{\beta}$ in Model 1 equals 1.347 (significant at the 1\%-level) indicating that truants have a 34.7 percent higher likelihood to drop out of school compared 


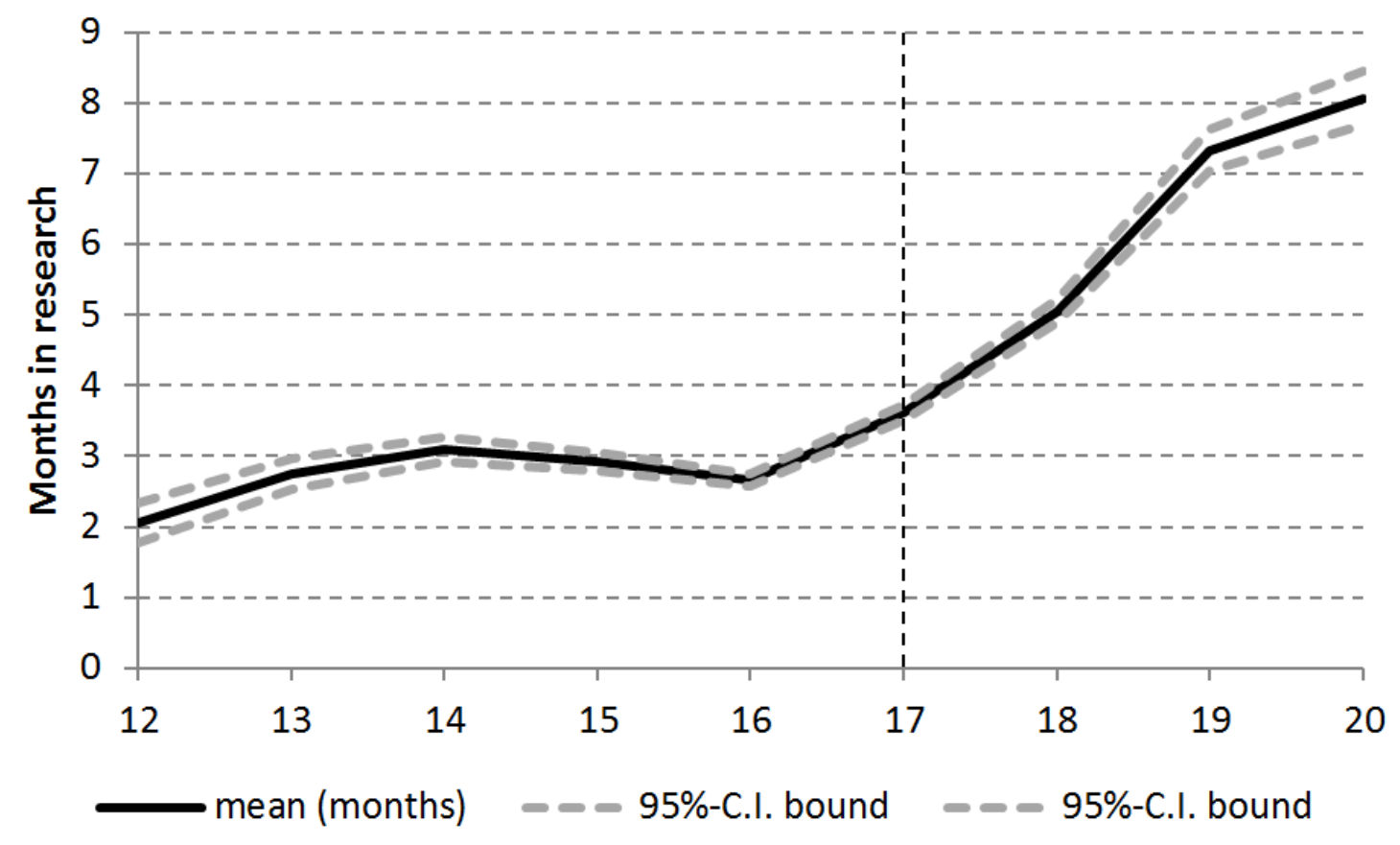

Figure 3.2: Average number of days in research undertaken by the compulsory education age officer before final settlement of the nature of the truancy spell over the analysis time with a 95\%-confidence bound. 
to regular school attendees. ${ }^{15}$

Cox Model 2 controls for individual, family and neighborhood characteristics. The estimated coefficients are in line with the previous literature (e.g. Rumberger 1983, 2004). It has been argued in the previous literature that students living in urban areas have a higher risk of dropout. A similar correlation is not observed in the data, as place of residence has only a limited and insignificant impact on the dropout decision. Next, conditional on truancy status, significant differences between male and female students are not observed. Ethnic minority students are considerably more likely to drop out of school compared with native Dutch students. Particularly other non-Western and other Western nationalities drop out more frequently. Students from single family households leave school significantly more without a higher secondary certificate than students from two-parent households.

In addition to the multiplicative variables, Model 3 includes school-type characteristics. As the school-type is strongly correlated to ability, students in different school types have different risks of early school-leaving. For example, 12 year-olds students enrolled in supported education due to learning difficulties are more likely to be absent from school or dropout at a younger age than students who are enrolled in a pre-university pathway (Entwisle et al., 2004, 2005; Henry, 2007; Sutphen, 2010). Consequently, there is a higher relative risk ratio for lower ability education levels. The different school types (6 in total) are included in Model 3 by stratification. The stratification ensures that, even with varying subpopulations within an overall population, the proportional hazard assumption imposed on $(\hat{\beta})$ is not violated. We use stratification based on school-type additionally in Model 3. The Dutch education systems allows for 5 strata (Tieben and Wolbers, 2008): supported pre-vocational education (abbreviated as lwoo); pre-vocational education (vmbo); vocational education (mbo); general education (havo); and

\footnotetext{
${ }^{15}$ Note that if the Bayesian structure would have falsely been ignored, the estimation coefficient for $\hat{\beta}$ would equal 2.233 , a clear overestimation of the effect of truancy.
} 
pre-university education (vwo). One may assume unique baseline hazard for each specified stratum. However, we estimate equal coefficients across strata. The hazard ratio estimated in Model 3 drops to $(\hat{\beta}=1.266)$ significant at the $1 \%$-level, indicating that the model overestimates the true impact of truancy if one does not account for (approximates of) ability.

In a final and fourth Cox model, we additionally control for (approximates of) ability. In particular, Model 4 limits the sample to only vocational students (lwoo, vmbo, mbo). This is in line with the previous literature which indicates that vocational students are most at risk of early school-leaving (e.g. Shavit and Müller, 1998; Gangl, 2002; Weltz, 2005). The total number of observations drops from 4,203 to 3,331. The small decline in the number of observations confirms that truancy is less of an issue in stronger educational tracks. Moreover, compared with the previous models, the estimated coefficient of the relative risk $\hat{\beta}$ increases to 1.374 . This increase indicates that the relative risk ratio in higher ability levels is relatively small, and lowers the estimated influence of truancy.

Overall, for all the four model specifications, the estimate of $(\hat{\beta})$ is rather robust. Adding control variables does not significantly change the estimate, which ranges from 1.26 in Model 3 to 1.37 in Model 4. Truants have a higher (accumulated) risk of school dropout by the age of 17 than regular school attendees. Note, however, that the underlying determinants of the truancy decision may be driven by particular exogenous covariates, e.g. by unobserved ability or motivation (for the determinants of unauthorized school absenteeism, see Schaefer and Millman, 1981; Attwood and Croll, 2006; Henry, 2007; Sutphen, 2010). This calls for caution with respect to a causal interpretation of estimates (Hausman and Woutersen, 2010). This chapter does not aim for a causal interpretation but rather explores unauthorized school absenteeism as a signal to identify at-risk students. Furthermore, the direction of the effect of truancy on school dropout is known, as unauthorized 
truancy is a continuation of school dropout and the sign of the association is unambiguously positive. In sum, an unauthorized truancy decision leads to considerably higher probabilities for students to drop out earlier in their school career, but that the decision itself may be associated with student background.

\subsection{Conclusion}

This chapter has developed a non-parametric duration model to estimate the influence of school absenteeism (also denoted by truancy) on the risk of leaving education without a higher secondary certificate (i.e. early schoolleaving). It was observed that five out of ten truants leave school before the compulsory education age is reached, compared with only two out of ten for regular school attendees.

The previous literature struggled with the definition and measurement of truancy. If truancy is measured by questionnaires, significant measurement error arises from self-reporting. But, even in administrative data, on which this chapter relies, measurement error can arise from the nature and extent of the reported school absenteeism. Using a rich administrative data set of the Municipality of Amsterdam, it was possible to capture and exploit this measurement error. In particular, the data makes a difference between two administrative types of truants: first, 'effective truants', whose truancy status has been confirmed by an independent 'truancy officer' after in-depth research. Those students were illegally absent from school; and second, 'false truants', who were reported by the school as truants, but, in fact, after research by the truancy officer, they had a valid reason to stay absent. The difference between the two types gives some insight into the validity of the data, and is exploited in a Bayesian duration model. By adapting the prior beliefs on the data, both lower (by relying on the effective truants) and upper (by relying on the false truants) bounds on the survival probability 


\subsection{CONCLUSION}

Table 3.3: Estimation results for effectiveness of improved registration for regular school-aged students compared with students with an unauthorized absence from school.

\begin{tabular}{|c|c|c|c|c|}
\hline & $\begin{array}{c}\text { Cox } \\
\text { Model } 1 \\
\end{array}$ & $\begin{array}{c}\text { Cox } \\
\text { Model } 2 \\
\end{array}$ & $\begin{array}{c}\text { Cox } \\
\text { Model } 3 \\
\end{array}$ & $\begin{array}{c}\text { Cox } \\
\text { Model } 4^{(3)} \\
\end{array}$ \\
\hline $\exp \left(x_{i}^{\prime}-x_{j}^{\prime}\right) \hat{\beta}$ & $\begin{array}{l}1.347 \\
(9.64)\end{array}$ & $\begin{array}{l}1.358 \\
(9.74)\end{array}$ & $\begin{array}{l}1.266 \\
(7.31)\end{array}$ & $\begin{array}{l}1.374 \\
(5.32)\end{array}$ \\
\hline 1. gender & & $\begin{array}{l}1.049 \\
(1.53)\end{array}$ & $\begin{array}{l}1.021 \\
(0.67)\end{array}$ & $\begin{array}{l}1.026 \\
(0.73)\end{array}$ \\
\hline $\begin{array}{r}\text { 2. ethnicity } \\
\text { Suriname, Aruba }\end{array}$ & & $\begin{array}{c}0.979 \\
-(0.47)\end{array}$ & $\begin{array}{c}1.008 \\
(0.18)\end{array}$ & $\begin{array}{c}0.996 \\
-(0.08)\end{array}$ \\
\hline Turkey & & $\begin{array}{l}1.084 \\
(1.44)\end{array}$ & $\begin{array}{l}1.081 \\
(1.37)\end{array}$ & $\begin{array}{l}1.153 \\
(2.27)\end{array}$ \\
\hline Marocco & & $\begin{array}{l}1.093 \\
(1.83)\end{array}$ & $\begin{array}{l}1.106 \\
(2.05)\end{array}$ & $\begin{array}{l}1.174 \\
(2.96)\end{array}$ \\
\hline Other non-Western & & $\begin{array}{l}1.338 \\
(5.83)\end{array}$ & $\begin{array}{l}1.289 \\
(5.03)\end{array}$ & $\begin{array}{l}1.247 \\
(3.82)\end{array}$ \\
\hline Other Western & & $\begin{array}{l}1.271 \\
(3.60)\end{array}$ & $\begin{array}{l}1.242 \\
(3.23)\end{array}$ & $\begin{array}{l}1.232 \\
(2.64)\end{array}$ \\
\hline 3. family composition & & $\begin{array}{c}0.794 \\
-(5.44)\end{array}$ & $\begin{array}{c}0.811 \\
-(4.93)\end{array}$ & $\begin{array}{c}0.794 \\
-(4.86)\end{array}$ \\
\hline $\begin{array}{l}\text { 4. residence } \\
\text { Medium-size }\end{array}$ & & & $\begin{array}{l}1.030 \\
(0.34)\end{array}$ & $\begin{array}{l}1.016 \\
(0.16)\end{array}$ \\
\hline Small & & & $\begin{array}{l}1.040 \\
(0.47)\end{array}$ & $\begin{array}{l}1.132 \\
(1.25)\end{array}$ \\
\hline Covariates & - & $\begin{array}{l}\text { Individual, } \\
\text { family, } \\
\text { neighb. }\end{array}$ & $\begin{array}{l}\text { Individual, } \\
\text { family, } \\
\text { school, } \\
\text { neighb. }\end{array}$ & $\begin{array}{l}\text { Individual, } \\
\text { family, } \\
\text { school, } \\
\text { neighb. }\end{array}$ \\
\hline Specifications & - & - & $\begin{array}{c}\text { Stratefied } \\
\text { School type }\end{array}$ & $\begin{array}{c}\text { Stratefied } \\
\text { School type }\end{array}$ \\
\hline Ties & Efron & Efron & Efron & Efron \\
\hline No. subjects & 4,277 & 4,205 & 4,203 & 3,331 \\
\hline No. failures & 4,277 & 4,205 & 4,205 & 3,331 \\
\hline LR Chi-sq & 93.49 & 174.85 & 118.86 & 112.12 \\
\hline Prob $>$ chi-sq & 0.000 & 0.000 & 0.000 & 0.000 \\
\hline
\end{tabular}

Note 1: T-values between brackets.

Note 2: Only school-aged students of 17 year-olds and younger are included in the analysis. With respect to truancy, only unauthorized school absenteeism is considered as defined and established by the compulsory education age officer. The analysis time corresponds to the age of the dropout students.

Note 3: Only vocational students are included in Model 3 (i.e. lwoo, vmbo, mbo). 
are estimated. The results indicate that the data are accurate for students below the compulsory school-age of 17 , suggesting a poor follow-up of postcompulsory school-age students.

Using a semi-parametric Bayesian Cox regression with multiplicative effects, this chapter compares the dropout decision of truants with regular school attendees. The results indicate that students with a preceding truancy record considered unauthorized school leave at an earlier point in time in their school career than regular school attendees. Unauthorized truancy is less problematic among higher ability levels than among lower ability levels. Bayesian Cox regression without Bayesian structure yields a coefficient for $\hat{\beta}$ equal to 2.233. Compared with the Bayesian semi-parametric Cox model, the likelihood of truants, compared with regular school attendees, to leave school before the end of the compulsory education age drops to $\hat{\beta}$ equal to 1.347. The Bayesian structure imposed on the data allowed us to deal appropriately with problems arising from measurement error and is crucial for any further statistical inference. For school-aged students enrolled in vocational education, the Bayesian lower-bound estimates (controlled for covariates) indicate that the dropout risk of truants compared with regular school attendees is 37.4 percent higher. Truancy can therefore be considered as a strong predictor of early school-leaving.

However, a major drawback of the duration model is that it is not possible to make inference on the causal process. Students may self-select into the group of truants or regular school attendees. The truancy decision itself is caused by unobserved factors that may significantly differ between truants and regular school attendees (for more information on the determinants of school absenteeism and dropout, see Rumberger, 1983, 2001, 2004; Henry, 2007; Sutphen, 2010).

In terms of policy implications, this chapter indicates that the identification of school-aged students with a preceding truancy record early in their 
school career can be a useful tool for dropout prevention. One straightforward way to use this tool as a prevention measure is to implement school attendance interventions or programs (i.e. the sensitization of youngsters to attend class). Epstein and Sheldon (2002) and Sheldon (2007) argue that truancy rates can be influenced by preventive policies in elementary education. Helm and Burket (1989) and Roderick et al. (1997) provide evidence on the effectiveness of parental involvement on student attendance by telephone calls to the student's home from the school, or timely information on student absences and school policies aimed at reducing truancy. Also class size composition and school policy may play a crucial role in student motivation and commitment (Spady, 1970; Tinto, 1975; Pittman, 1991; Lee and Burkam, 2003). In addition, various influences at the student's place of residence or school may trigger both the dropout decision and truancy: for example, a general dislike of school (Ehrenberg and Brewer, 1994), failing law enforcement, or being part of discriminated communities (Blue and Cook, 2004; Rumberger and Lamb, 2003; Rumberger, 2004).

In connection with improved school attendance, at-risk students may be provided with guidance and/or care through their study curriculum (Pittman, 1991; Phinney et al., 2006; Allen and Meng, 2010). Further research on the total number of days of the truancy spell may provide more insight into truancy as a dropout prevention measure. For example, not only the frequency of the truancy decision but also the duration of the truancy spell may be crucial for the school and/or teachers to undertake action.

Chapter 4 will now further explore the Dutch dropout prevention program. 



\section{Chapter 4}

\section{The Dutch Dropout Prevention Program}

"[Schools] could also receive more credit for successfully graduating a student the longer the student remains in school. So a school that educated a student for three years would be more accountable for that student than a school that educated a student for only one year."

(Rumberger, 2011, p.273)

\subsection{Introduction}

Before the school year 2002-2003, a coherent policy towards early schoolleaving was lacking in the Netherlands. Because of large differences in the underlying population, different regions and cities require different policy measures. Therefore, a decentralized policy has been developed. A task force on early school-leaving within the Ministry of Education, Culture, and Science (called 'Projectdirectie Voortijdig Schoolverlaten') created 39 regional dropout authorities ('Regionale Meld- en Coördinatiepunt', further abbreviated by RMC) in 2002. At that time, each of the RMC regions could take (or could not take) different actions towards policy goal settings.

\footnotetext{
${ }^{1}$ Chapter 4 is based on: Kristof De Witte and Sofie J. Cabus (2013). Dropout Prevention Measures in the Netherlands, an Explorative Evaluation. Educational Review 65(2), $155-176$.
} 
To facilitate the policy, the Ministry of Education, Culture, and Science outlined a general framework, known as the 'covenants' (Holter and Bruinsma, 2009). A covenant is a written agreement between the Ministry of Education, Culture, and Science, on the one hand, and the RMC and the schools, on the other. It stipulates the interventions of the RMC region. Examples of interventions in the covenants are improved truancy registration, increased flexibility in changing educational tracks, intensified counseling for students or increased possibilities for apprenticeships. In the school year 2005-06, 14 regions with the highest dropout levels signed a first round of covenants. The first covenant agreements consist of a financial incentive of $€ 2,000$ per dropout less in every subsequent year after 200506, and compared to the reference school year 2005-06. ${ }^{2}$ Van der Steeg et al. (2008) exploited this dual implementation by a difference-in-differences design. They observed that the immediate impact of the covenant (i.e. evaluation only one year after the implementation) was not effective in reducing early school-leaving. A second round of covenants was signed by all 39 RMCs in the school year 2007-08. The 2007-08 covenants replaced the first covenant agreements and increased the performance bonus to $€ 2,500$ per dropout less in every subsequent school year after 2007-08, and compared to the reference school year $2005-06 .^{3}$

The contributions of this chapter are threefold. First, the effectiveness of the early school-leaving incentives are examined by analyzing which of the incentives significantly correlate with a lower probability of student dropout in secondary education. We use an exceptionally rich panel data set (BRON;

\footnotetext{
${ }^{2}$ To our best knowledge, we are not aware of any document or overview which discusses the implementation of dropout prevention measures before the school year 2005-2006. Qualitative research points to the diversity of policy measures in the 39 regions in the period before 2005-2006 (De Bruijn et al., 2010). Even if some dropout strategies in place before 2005-06 were renamed to follow the convenants, given the limited budgets available for dropout prevention in the 2002-2006 period and the large budgets afterwards, it is unlikely that they would significantly bias the estimates below.

${ }^{3}$ The decentralized policy has great accountability. Well-performing schools and regions are 'named', while poorly performing regions and schools are 'shamed'. The naming and shaming incentive is implemented by the website www.aanvalopschooluitval.nl.
} 
Basis Register Onderwijsnummer) which covers all students in the Netherlands. Thanks to postcode information, the data are enriched with neighborhood characteristics obtained from Statistics Netherlands. The analysis begins at the individual level. In particular, a panel Probit model examines the probability of a student dropping out. While controlling for student characteristics (e.g. gender, school track, migrant status), neighborhood characteristics (e.g. income per capita, green areas, employment in the area), a time trend (controlling for the increased awareness of obtaining a certificate), and region-fixed-effects, we correlate the dropout prevention measures to the individual probability of dropping out. We argue that the obtained outcome provides a lower-bound of the effect.

Second, we aggregate all data at the school level. This provides an indication of schools with low and high dropout rates. Using a quantile analysis, and controlling for the student, neighborhood, time and regional influence, this chapter examines the influence of dropout prevention policy measures for schools with few (i.e. 25th quantile), average (i.e. 50th quantile) and many (i.e. 75th quantile) dropouts. As selecting quantiles is rather arbitrary, the influence of the dropout measures for a continuum of quantiles is also estimated.

Third, this chapter is to our best knowledge the first to describe the dropout prevention incentives in one of the EU Member States. The Dutch Ministry of Education, Culture, and Science spends $€ 313$ million a year (anno 2007-08) on dropout prevention policy, which implies 0.83 percent of its total budget (Statistics Netherlands). It has been foreseen that this budget will increase to 400 million euros a year by 2011 (Ceulenaere et al., 2009; Statistics Netherlands). This is not a negligible budget, whose effectiveness is worth analyzing.

The remainder of the Chapter is structured as follows. The Dutch dropout prevention policy is described in Section 4.2. Section 4.3 briefly 
presents the data, its structure and some descriptive statistics. The influence of the Dutch dropout prevention measures at the individual level is examined in Section 4.4.1, and at the school level in Section 4.4.2. The final Section 4.5 contains a conclusion and discussion.

\subsection{Prevention measures in the Netherlands}

This section briefly describes the Dutch policy on early school-leaving. It starts with the Dutch education system, and continues with a conceptual model to classify the policy measures. Subsequently, the policy measures are discussed, and linked to the academic literature.

\section{The Dutch education system}

The Dutch education system consists of three main streams: pre-university education (vwo); general higher secondary education (havo); and vocational secondary education (vmbo-mbo). There is strong ability tracking at the end of primary education. Based on standard testing, students are assigned to one of the three main streams. The streams are systematically presented in Figure 4.1. A student who wants to obtain a school-leaving certificate, enrolls in a pre-vocational, general secondary or pre-university education stream at the age of 12 . Between the ages of 16 to 18 , a student has the option to enroll in school-based (full-time) or work-based (part-time) educational arrangements. Only after completion of vocational education with level-2 (graduation age 18), general secondary education (graduation age 17), or pre-university education (graduation age 18), does a student obtain a valid school-leaving certificate (and will not be registered as a school dropout) (for an extensive discussion, see Cabus and De Witte, 2011a; Tieben and Wolbers, 2008). 


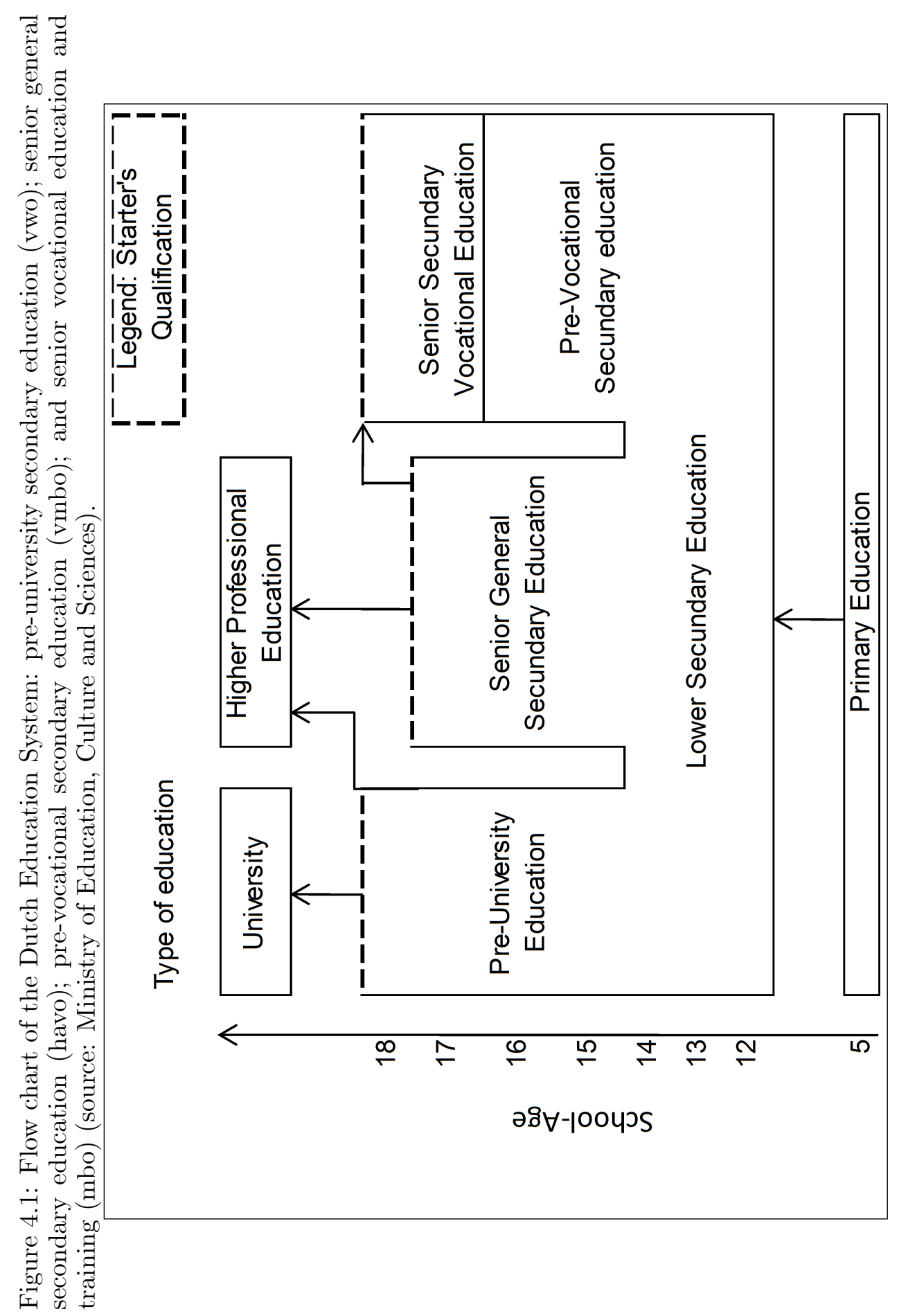




\section{Programmatic versus systemic approach}

Rumberger (2001) suggests two perspectives to categorize the triggers for school dropout: (1) a framework based on the individual perspective; and (2) a framework based on an institutional perspective that consists of family, school, communities and peers. Sutphen et al. (2010) discuss a similar classification of policy measures for school attendance interventions: namely measures aimed at (1) the individual level; (2) the family level; (3) the school level; and (4) the community level. Using Bell et al. (1994), the authors discuss a fifth category for interventions that combine these four levels: the multimodel interventions.

Accordingly, policy interventions from the individual perspective aim at identifying at-risk students by, for example, providing them with increased student counseling or guidance through their study curriculum. Conversely, policy interventions from the institutional perspective aim at creating a new institutional environment or a fundamental change, for example, in the way school programs or educational settings are organized. They do not affect one individual, but rather aim at all students going to school in this institutional setting. The former kind of measures follow a programmatic approach, and the latter a systemic approach (Rumberger, 2001).

\section{Programmatic interventions}

Most Dutch dropout prevention measures follow a programmatic approach as they "[...] do not attempt to change the institutional setting, but rather create alternative programs or institutions to target students who are somehow identified as at-risk of dropping out (Rumberger, 2001, p. 23)." The dropout prevention measures are systematically summarized in Table 4.1, namely: (1) reporting truants; (2) changing subject; (3) guidance towards the students' optimal track or profession; (4) apprenticeship; (5) mentoring and coaching; (6) care and advisory team; (7) smoothing the transition 
Table 4.1: Summary: dropout prevention measures as outlined in the covenant.

\begin{tabular}{|c|c|c|}
\hline & Measure & Implementation \\
\hline 1 & Reporting truants & Reporting and tackling truancy at a very early stage \\
\hline 2 & Changing subject & $\begin{array}{l}\text { A tailored track for students who choose a wrong subject or who } \\
\text { prefer another subject }\end{array}$ \\
\hline 3 & $\begin{array}{l}\text { Guidance towards to the students' } \\
\text { optimal track or profession }\end{array}$ & $\begin{array}{l}\text { Work placement, writing a letter of application, apprenticeship } \\
\text { programs, creating a portfolio }\end{array}$ \\
\hline 4 & Apprenticeship & $\begin{array}{l}\text { Coordination with local private firms and adhanced apprentice- } \\
\text { ship programs for students who prefer to do manual jobs }\end{array}$ \\
\hline 5 & Mentoring and coaching & $\begin{array}{l}\text { Students are matched with a coach from public or private or- } \\
\text { ganisations }\end{array}$ \\
\hline 6 & Care and advisory team & $\begin{array}{l}\text { Coordination of student care by social workers, youth assistance, } \\
\text { school attendance officers, health services and police }\end{array}$ \\
\hline 7 & $\begin{array}{l}\text { Smoothing the transition from the } \\
\text { pre-vocational level to the voca- } \\
\text { tional level }\end{array}$ & $\begin{array}{l}\text { Intake talks at the vocational school, providing more informa- } \\
\text { tion on the educational tracks, and checking wheter the students } \\
\text { effectively enroll at and start in the new vocational school }\end{array}$ \\
\hline 8 & Extended school-time & $\begin{array}{l}\text { Add more sports and culture to schools in order to make school } \\
\text { more attractive }\end{array}$ \\
\hline 9 & Dual track & $\begin{array}{l}\text { Offering the possibility for dropout students to re-enter educa- } \\
\text { tion by a tailored educational track }\end{array}$ \\
\hline 10 & Frequent intakes & $\begin{array}{l}\text { Increasing the number of times that students may enter sec- } \\
\text { ondary education }\end{array}$ \\
\hline
\end{tabular}

from the pre-vocational to the vocational level; (8) extended school; (9) dual track; and (10) frequent intakes. Examples of the programmatic approach are, from Table 4.1, mentoring and coaching, guidance through the study curriculum, and care and advisory teams.

First, consider the interventions 'mentoring and coaching' and 'changing subject'. The previous literature argues that the enrollment reason for a particular educational track (e.g. vocational education and training versus pre-university education) is a strong indication for school dropout. Students with a too heavy study load, a wrong track choice, or without peer or family support have a higher probability of school dropout (Pittman, 1991; Phinney et al., 2006). About 21 percent of all dropouts in the Netherlands indicate a wrong study choice as the main trigger for leaving school (Allen and Meng, 2010). The interventions 'mentoring and coaching' and 'changing subject' aim to tackle these problems by more professional advice and follow up of 
students.

Second, and in addition to the guidance through the study curriculum, care and advisory teams have been established to align internal (i.e. at the school) and external (i.e. from outside the school) care for potential dropouts. Although different settings are possible, a care and advisory team typically consists of psychologists, pedagogues, social workers, a representative of the region and a policy officer.

Third, the intervention 'frequent intakes' aims at continuous enrollment moments. This actually means that pupils can enter the school year after 1 October (which is one month after the official start of the school year). The 'Centraal Toegangsloket voor het Onderwijs' (Central Entry Office for Education) organizes frequent intakes for pupils who are following vocational tracks. Furthermore, early school-leavers can also enter a 'reception class', which is a special class for previous dropout students. After a possible revision of the study choice, students can continue along another track as soon as possible.

\section{Multimodel interventions}

Dropout prevention measures beyond the individual level consist of reporting truants, apprenticeships, dual tracks and smoothing transition. They are part of multimodel interventions (Bell et al., 1994), which are dropout prevention measures aiming at both the individual level and the institutional level. Consequently, they are more difficult to realize in a short time-span.

First, consider truancy reporting. Truancy or school absenteeism is considered one of the best predictors of early school-leaving (e.g. Bos et al. ,1992; Attwood and Croll, 2006; Henry, 2007). Truancy is defined as one or more days absenteeism from school for students who did not obtain a higher secondary certificate (Schaefer and Millman, 1981). It is positively associated with juvenile crime (e.g. Garry, 1996), teenage pregnancy (e.g. Hibbert and Fogelman, 1990), drugs or alcohol use (Roebuck et al., 2004), 
and eventually may lead to school dropout (Rumberger, 2001; DesJardins et al., 2006; Henry, 2007). Truancy rates are highest among students enrolled in vocational tracks (Shavit and Müller, 1998; Gangl, 2002; Weltz, 2005). The research on truancy as an indicator for school dropout discusses and describes the nature and extent of school absenteeism. For example, Bos et al. (1992) analyze a 1980s government experiment in the Netherlands. An improved computer-assisted registration system was launched in 36 schools in four major dropout cities: Haarlem, Amsterdam, Utrecht, and Rotterdam. ${ }^{4}$ On average, they find a truancy rate of 16 percent, where heterogeneity was observed among different school curricula (e.g. vocational education and training versus general secondary or pre-university education), study subjects, and ethnic groups. However, the experiment suffered from multiple definitions of truancy and, as a consequence, a lack of transparency. Attwood and Croll (2006) and Henry (2007) also stress definitional problems due to the concept of 'illicit' or 'unauthorized' school absenteeism. Researchers often rely on self-reported school absence, where the answers may differ according to the survey question asked to classify the extent the interviewees skip class. ${ }^{5}$

The dropout prevention measure 'reporting truants' aims at improved registration of unauthorized truancy, using a uniform definition and registration of truants and school dropouts in a central database, known as the 'digital office' (for an extensive description, see Section 4.3). A central data-

\footnotetext{
${ }^{4}$ The authors mainly use descriptive statistics and multiple regressions to point out that average class size and ethnic minority groups are responsible for about 56 percent of the variance in the observed truancy rate.

${ }^{5}$ Attwood and Croll (2006) have used the British Household Panel Survey and in-depth interviews to ask persistent truants about the extent, consequences, and explanations for truancy at secondary schools. Poor relationships with teachers, bullying, and a more general dislike of the school's atmosphere are considered as triggers for the dropout decision. They authors suggest a distinction between socioeconomic and attitudinal factors. Davis and Lee (2004) also adhere to the above findings. They went into discussion with truants, as well as with attendees and some parents. The authors add to the discussion that, in contrast to professionals, the study curriculum is not considered as a dropout trigger. This finding has been weakened by Beekhoven and Dekkers (2005) who put emphasis on learning problems, lack of motivation, and problems arising from choosing the wrong vocational track.
} 
base offers the opportunity to better detect potential dropouts (Auditdienst Ministry of Education, Culture, and Science, 2007). Furthermore, if truancy reporting is accompanied with an adequate truancy policy (for a discussion, see De Witte and Csillag, 2010), an important feature can be attributed to this truancy reporting: the discouraging of potential truants or dropouts. It is likely that pupils are afraid to 'be caught', as their parents will know about their truancy behavior. Therefore, increasing the probability of truancy detection can discourage students from truancy.

Second, consider the intervention on apprenticeships. Apprenticeships are interesting learning methods, where students develop interpersonal skills and increase their employability (Lucas and Lammont, 1998). A lack of workplaces for apprentices is considered an important incentive for school dropout. Finding better matches between apprenticeship and labor organizations, and improving information and support for students can make the dropout problem less persistent (for an extensive discussion on various aspects of national vocational training systems and the importance of apprenticeships, see Gangl, 2002; Onstenk, 2004; Onstenk and Blokhuis, 2007; Bosch and Charest, 2009).

Third, some students do not intend to follow a full-time education program, instead they would rather opt for an employment contract and a work-based pathway at school. By allowing for a combination of learning and working, a dual track may trigger students to obtain a higher secondary certificate (ROA, 2009a, 2009b). For instance, part-time learning about construction techniques and part-time working in construction. In a similar program, EVC (cf. NVQ or National Vocational Qualifications) is a certificate that can be obtained if a student passes a learning module. EVC and dual track measures also aim at (unemployed) dropouts (as a curative measure). In the Netherlands, unemployment rates increased at the end of 2008: for pre-vocational dropouts from 6 percent in 2007 to 9 percent 
in 2008 and for dropouts in the first year of vocational education from 10 percent in 2007 to 16 percent in 2008 (2009a, 2009b). The dual tracks and EVC should be attractive for these dropouts.

Fourth, a necessary condition for a better connection between the school and the labor market consists of a successful transition into vocational education and training. In the Netherlands, enrollment in the first year of vocational education and training is considered difficult due to the long summer break (of about three months) after graduation from pre-vocational education. ${ }^{6}$ Students have to physically enroll in another school, as the prevocational school does not offer vocational study subjects, and they may lose contact with their teachers and school. Therefore, there was a shift in Dutch policy from horizontal alignment to crossing system boundaries or "smoothing transition" (Onstenk and Blokhuis, 2007). The policy towards smoothing transition consists of increased care for at-risk students. For example, they are followed during the summer break, go through an intake procedure, and communication between the pre-vocational and vocational school is enhanced. In some cases, students could attend classes in their pre-vocational school to follow classes with familiar peers and teachers. ${ }^{7}$ In sum, the policy measure aimed at enhanced student commitment to the school, peers and teachers by simplifying the transition between the pre-vocational and the vocational level. Enhanced student commitment to school, peers, and teachers may effectively reduce school dropout, as conceptually discussed by Spady $(1970,1971)$ and Tinto (1975) in theories of student attrition (see also Chapter 6). Evidence on the effectiveness of this measure has been found by Felner et al. (1981, 1982) who conducted a randomized experiment in the

\footnotetext{
${ }^{6}$ In line with the European definition, vocational education is denoted by ISCED 3.

${ }^{7}$ On 1 August 2008, a total of 20 schools were selected for a government experiment. If students were going to a selected school, they had the possibility to attend classes in their pre-vocational school. As such, they did not have to switch from a pre-vocational to a senior vocational school. Most schools were located in Amsterdam and Rotterdam (rijksoverheid.nl).
} 
US, called the Transition Project. The experiment had two goal settings: restructuring the role of teachers, and reorganizing the school's environment. Students with improved transition reported significantly higher levels of teacher support, teacher affiliation and involvement than students without the additional transition. As a result, students belonging to the treatment group had better scores on the assessment instruments. The experiment indicates that preventive community-based programs may help pupils during school transitions and may actually reduce dropout rates.

Student commitment and motivation may be further enhanced beyond school time. One particular policy measure aimed at extended school(time) by offering a range of additional services and activities to students. For example, schools may offer sport and leisure activities to augment their attractiveness for students (de Zwart et al., 2009). It offers the chance to motivate students to take part in sport activities, to combat the problem of obesity, and to develop talented youngsters towards professional sports careers. By keeping students longer at school, they can be better followed, given a more comprehensive education and a more attractive study program. In turn, it is expected that the students' well-being and motivation will be enhanced, which should reduce early school-leaving.

\subsection{Data and definition}

A measurement instrument is indispensable when it comes to the evaluation of policy. In the past, the registration of early school-leavers was inaccurate and unreliable (see Section 4.2). As from school year 2005-06, the program 'Aanval op de uitval' or 'fighting dropout' improved the registration system remarkably. Thanks to the Dutch program, complete and reliable data on dropout levels are available. The registration of school dropout takes place as follows. Every pupil who attends school in the Dutch educational system obtains a personal identification number. All schools register students using 
this personal identification number and provide the registration to the Ministry of Education, Culture, and Science. Finally, all registrations end up in one nationwide database called 'het Basisregister Onderwijs' or BRON.

We follow the Dutch definition of a dropout student. ${ }^{8}$ If a youth below the age of 23 was enrolled in school on 1 October of a given year, but is not enrolled in the following year on 1 October and has not obtained a higher secondary certificate, then the youth is designated as an early school-leaver. Despite the difficulties with this definition (e.g. it looks only at one date in time), it is a clear and uniform definition.

This chapter follows the BRON-data, a unique administrative data set that covers all students going to school in the Netherlands. The data include information on: the student (e.g. gender, ethnicity); educational support at school (i.e. receives additional student counseling at school); school track (e.g. pre-university, general secondary or vocational school-type); and the parents (e.g. single-parent household). ${ }^{9}$ Using postcode information, the data can then be matched to neighborhood characteristics. The data comprise all Dutch students enrolled between the school years 2005-06 and 2007-08.

After a careful reading of the covenants, dummy variables were constructed which capture the implementation of the agreements at regional level. As schools and municipalities are collaborating extensively within each of the 39 regions, and as information at the local level is lacking, it is assumed that all schools within a region are implementing the agreements in a similar way. Some summary statistics on the data are presented in Table 4.2 .

\footnotetext{
${ }^{8}$ We realize there is no general accepted definition of dropout (in all its nuances of, for example, event and status dropouts). It is beyond the scope of this chapter to discuss the various definitions. However, we follow the 'official' European and Dutch definition.

${ }^{9}$ Some of these variables (e.g. school type) are endogenous with respect to the risk of dropping out. An instrumental variable (IV) approach would be appropriate to deal with this endogeneity. However, due to data restrictions, the appropriate instruments are as yet unavailable. We consider the endogeneity issue as scope for further research.
} 
Table 4.2: Descriptive statistics of BRON.

\begin{tabular}{|c|c|c|c|c|}
\hline & & $2005-06$ & $2006-07$ & $2007-08$ \\
\hline Number of students & & $1,347,162$ & $1,370,886$ & $1,399,068$ \\
\hline \multicolumn{5}{|l|}{ Student characteristics } \\
\hline Dropout & & 56,790 & 54,954 & 51,156 \\
\hline \multirow[t]{8}{*}{ School type } & vocational edu. & 424,776 & 442,177 & 453,383 \\
\hline & practice-oriented edu. & 10,140 & 10,196 & 27,083 \\
\hline & first class & 153,987 & 150,777 & 149,105 \\
\hline & supported edu. & 98,652 & 99,996 & 101,820 \\
\hline & pre-vocational edu. & 302,934 & 294,221 & 281,030 \\
\hline & general secondary edu. & 160,962 & 166,244 & 170,425 \\
\hline & pre-university edu. & 195,711 & 204,038 & 211,686 \\
\hline & other & 0 & 3,237 & 4,536 \\
\hline \multirow{5}{*}{ City } & Amsterdam & 48,391 & 48,764 & 49,799 \\
\hline & Rotterdam & 47,578 & 48,312 & 48,938 \\
\hline & The Hague & 33,588 & 34,668 & 35,832 \\
\hline & Utrecht & 16,123 & 16,618 & 17,280 \\
\hline & other city & $1,199,830$ & $1,220,709$ & $1,245,034$ \\
\hline Gender & Female & 656,707 & 669,051 & 681,305 \\
\hline \multirow[t]{8}{*}{ Origin } & Netherlands & $1,044,608$ & $1,061,931$ & $1,080,004$ \\
\hline & Suriname & 40,323 & 40,777 & 41,417 \\
\hline & Aruba & 17,267 & 17,957 & 18,900 \\
\hline & Turkey & 46,693 & 48,972 & 51,513 \\
\hline & Morocco & 43,613 & 45,122 & 46,713 \\
\hline & non-Western migrant & 67,987 & 70,308 & 72,544 \\
\hline & Western migrant & 82,044 & 83,043 & 84,274 \\
\hline & Unknown & 4,627 & 2,776 & 3,703 \\
\hline \multirow[t]{4}{*}{ Generation of migrant } & Autochton & $1,044,608$ & $1,061,931$ & $1,080,004$ \\
\hline & First-generation & 87,338 & 86,455 & 85,342 \\
\hline & Second-generation & 210,589 & 219,724 & 230,019 \\
\hline & Unknown & 4,627 & 2,776 & 3,703 \\
\hline Living in poor area & & 545,589 & 555,578 & 569,329 \\
\hline
\end{tabular}

Note 1: Values in numbers, unless otherwise stated in second column.

Note 2: Continued on the next page. 
(Table 4.2 - Continued)

\begin{tabular}{|c|c|c|c|c|}
\hline & & $2005-06$ & $2006-07$ & $2007-08$ \\
\hline \multicolumn{5}{|l|}{ Characteristics of the municipality } \\
\hline Number of inhabitants & mean & 3387 & 3380 & 3393 \\
\hline Population density & mean & 3934 & 3939 & 4022 \\
\hline$\%$ one person household & mean & 28.888 & 28.762 & 29.371 \\
\hline$\%$ Allochton & mean & 9.194 & 9.140 & 9.243 \\
\hline Average income & mean & 16.395 & 16.412 & 16.399 \\
\hline Green areas $(\mathrm{km} 2)$ & mean & 40.649 & 40.663 & 40.547 \\
\hline Number of households moving & mean & 95.996 & 95.882 & 96.542 \\
\hline Average house value & mean & 134.998 & 135.255 & 135.039 \\
\hline Employment in the area & mean & 64.107 & 63.030 & 64.996 \\
\hline \multicolumn{5}{|l|}{ Dropout prevention } \\
\hline Initial implementation & & 774,770 & 774,770 & 774,770 \\
\hline Number of prevention items & mean & 2.354 & 2.354 & 4.886 \\
\hline Care and advisory team & & 667,198 & 667,198 & $1,406,188$ \\
\hline Smoothing the transition & & 646,830 & 646,830 & $1,305,316$ \\
\hline Mentoring and coaching & & 397,911 & 397,911 & 752,125 \\
\hline Changing subject & & 128,053 & 128,053 & 276,347 \\
\hline Optimal track or profession & & 346,551 & 346,551 & 766,340 \\
\hline Apprenticeship & & 127,940 & 127,940 & 246,567 \\
\hline Frequent intakes & & 452,063 & 452,063 & 835,898 \\
\hline Extended school-time & & 0 & 0 & 202,601 \\
\hline Reporting truants & & 657,507 & 657,507 & $1,228,348$ \\
\hline Dual track & & 0 & 0 & 149,715 \\
\hline Number of schools & & 723 & 728 & 728 \\
\hline
\end{tabular}

Note: Values in numbers, unless otherwise stated in second column. 


\subsection{Results}

The previous section described the dropout interventions in the Netherlands. Similar to the previous literature (Rumberger, 2001), we examine their influence at the individual level (see Section 4.4.1), and the school level (see Section 4.4.2).

A panel Probit model is used to estimate the probability that a student will drop out of secondary education. Controlling for: (1) student; (2) neighborhood; and (3) regional characteristics, we relate the dropout probability to the dropout prevention measures. ${ }^{10}$ A Probit model is appropriate in the setting concerned as the dependent variable is a dichotomous variable and the estimated standard error has a normal distribution. ${ }^{11}$ Students, who leave education without a higher secondary certificate, are designated as early school-leavers and receive a value 1 ; non-dropout students obtain a value 0 . The model allows us to examine which of the policy interventions correlate with a lower probability of early school-leaving.

\subsubsection{Analysis at the individual level}

This subsection starts by analyzing the effectiveness of the policy measures by considering the correlation at the micro-level (i.e. student level). While controlling for observed heterogeneity, a panel Probit model is employed to estimate the probability of dropping out and the influence of particular prevention measures. The results are presented in Table 4.3.

\footnotetext{
${ }^{10}$ Extensive additional robustness checks were performed. First, some measures may have been implemented in only a very few regions. Their effects may be confounded with autonomous time trends in these regions. Given that dropout rates have been falling substantially in recent years, we included region*time trend into the regression model: if the autonomous time trend in the fall in dropout rate differs between regions, then betweenregion differences in time trends may be confounded with effects of certain measures that were implemented in these regions. The analysis delivered robust results. Second, some measures are implemented by almost all regions. Both removing these measures and clustering the measures at a higher level delivered robust outcomes.

${ }^{11}$ Using an ordinary least squares regression model could yield probabilities outside the $(0,1)$ boundary. As an alternative econometric technique, multi-level modelling could be employed. We consider this as scope for further research.
} 
In line with the previous literature, gender, ethnicity and family background are indicated as triggers of the individual dropout decision (see, among others, Rumberger, 1983; Astone and Mclanahan, 1991, 1994; Mayer, 1991; Steinberg et al., 1992; Berktold et al., 1998; Pong and Ju, 2000). It is observed that neighborhood characteristics play an important role. Students living in poor and high density areas have a higher probability of dropping out, as well as students living in neighborhoods with more single-parent households and migrant families. Better labour market opportunities also increase the student's probability to dropout. This confirms earlier research by McNeal (1997).

To better control for unobserved heterogeneity, various levels of fixedeffects are included. First, school-type fixed-effects relate to the educational track of the pupil (i.e. pre-university, pre-vocational or vocational education). The estimates indicate that students in tracks with lower ability levels (i.e. students with additional counseling) have a relatively higher probability of dropping out of secondary education. These results are in line with van der Steeg and Webbink (2006), who argue that early school-leavers are concentrated in the lowest level of pre-vocational and vocational education.

Second, region-fixed-effects are considered. Most of the region-fixedeffects are significant. This is intuitive as there are large differences in dropout rates among the regions.

Third, a time trend is included. This serves two purposes. First, it captures a general trend in which, since the 1960s, education has become more important. As pupils are more aware of the importance of obtaining a higher secondary certificate, the dropout rate can fall over time without any influence of dropout prevention measures. The results, presented in Table 4.3, confirm that this kind of sensitization takes place in the Netherlands. Second, the time trend allows us to interpret the obtained estimates as an under bound. As the time trend captures general policy influences and 
sensitization, estimates can be obtained which have a stronger influence than general policy/sensitization. In other words, the resulting estimates provide a lower-bound of the estimated influence - without the time trend, the estimated coefficients would be larger.

Focusing on the correlation coefficients of the ten menu-items used in the dropout prevention policy delivers interesting insights. Out of the ten prevention measures, only three turn out to have a significant impact on the individual's dropout decision: (1) mentoring and coaching (estimated coefficient of -0.0403); (2) optimal track or profession (estimated coefficient of -0.0434); and (3) dual tracks (estimated coefficient of -0.0626). Not unexpectedly, those three measures correspond to preventions which regions cannot implement overnight. They are innovative, in a way that it is impossible for the school to re-label existing procedures, and require a clear follow-up of the student. Moreover, there is no evidence that doing more is better. The number of items that regions are implementing does not have a significant impact.

Finally, it is observed that the individual dropout decision did not alter in regions that implemented dropout prevention programs one year before other regions. These 'early implementor regions' were the 14 regions with the highest dropout rates in 2005-06 (as such, there was not a random selection). ${ }^{12}$ This is in line with previous results of van der Steeg et al. (2008), who analyzed the effectiveness of the covenant based on a difference-indifferences approach in those two regions. However, their model considered the general influence of the convenant, and not the various menu-items which constitute it.

\footnotetext{
${ }^{12}$ Careful exploration of the data does not show a significant difference in measures used by early implementors and the other regions.
} 
Table 4.3: Effectiveness of dropout prevention measures using a panel probit model (menu-items at the individual level).

\begin{tabular}{|c|c|c|c|c|}
\hline & coeff. & St. error & t-statistic & p-value \\
\hline Student characteristics & & & & \\
\hline Gender & -0.1426 & 0.0064 & -22.4000 & 0.0000 \\
\hline Origin (Netherlands $=$ reference) & & & & \\
\hline Suriname & 0.7051 & 0.0276 & 25.5800 & 0.0000 \\
\hline Dutch Antilles & 0.7165 & 0.0284 & 25.2300 & 0.0000 \\
\hline Turkey & 0.6408 & 0.0270 & 23.7400 & 0.0000 \\
\hline Morocco & 0.6930 & 0.0268 & 25.8300 & 0.0000 \\
\hline Non-Western migrant & 0.6874 & 0.0212 & 32.3600 & 0.0000 \\
\hline Western migrant & 0.6686 & 0.0238 & 28.1200 & 0.0000 \\
\hline Unknown & 3.2450 & 0.1173 & 27.6600 & 0.0000 \\
\hline Generation of migrant & -0.2629 & 0.0122 & -21.5500 & 0.0000 \\
\hline Postcode characteristics & & & & \\
\hline Poor area & 0.0804 & 0.0106 & 7.5600 & 0.0000 \\
\hline Number of inhabitants & 0.0000 & 0.0000 & -0.8200 & 0.4120 \\
\hline Population density & 0.0000 & 0.0000 & -2.2100 & 0.0270 \\
\hline One person household & 0.0007 & 0.0003 & 2.3600 & 0.0180 \\
\hline Number of migrants & 0.0008 & 0.0004 & 2.1800 & 0.0290 \\
\hline Income per capita & -0.0047 & 0.0016 & -2.8500 & 0.0040 \\
\hline Green areas & -0.0007 & 0.0011 & -0.7100 & 0.4770 \\
\hline Frequency of moving & 0.0014 & 0.0003 & 4.9800 & 0.0000 \\
\hline Average housing cost & -0.0005 & 0.0002 & -2.8100 & 0.0050 \\
\hline Employment in the area & -0.0003 & 0.0001 & -5.3000 & 0.0000 \\
\hline Dropout prevention measures & & & & \\
\hline Early implementation (first 14 convenant regions $=1$ ) & 0.0095 & 0.0117 & 0.8100 & 0.4150 \\
\hline Number of implemented prevention items & 0.0203 & 0.0172 & 1.1800 & 0.2380 \\
\hline Care and advisory team & -0.0083 & 0.0280 & -0.3000 & 0.7670 \\
\hline Smoothing the transition & -0.0130 & 0.0382 & -0.3400 & 0.7320 \\
\hline Mentoring and coaching & -0.0403 & 0.0244 & -1.6500 & 0.0990 \\
\hline Changing subject & -0.0275 & 0.0299 & -0.9200 & 0.3580 \\
\hline Optimal track or profession & -0.0434 & 0.0226 & -1.9200 & 0.0550 \\
\hline Apprenticeship & -0.0264 & 0.0347 & -0.7600 & 0.4470 \\
\hline Frequent intakes & -0.0243 & 0.0207 & -1.1700 & 0.2410 \\
\hline Extended school & 0.0315 & 0.0345 & 0.9100 & 0.3620 \\
\hline Reporting truants & -0.0221 & 0.0246 & -0.9000 & 0.3700 \\
\hline Dual tracks & -0.0626 & 0.0329 & -1.9000 & 0.0570 \\
\hline Constant & Yes & & & \\
\hline Region fixed-effects & Yes & & & \\
\hline School-type fixed-effects & Yes & & & \\
\hline Time trend & Yes & & & \\
\hline
\end{tabular}




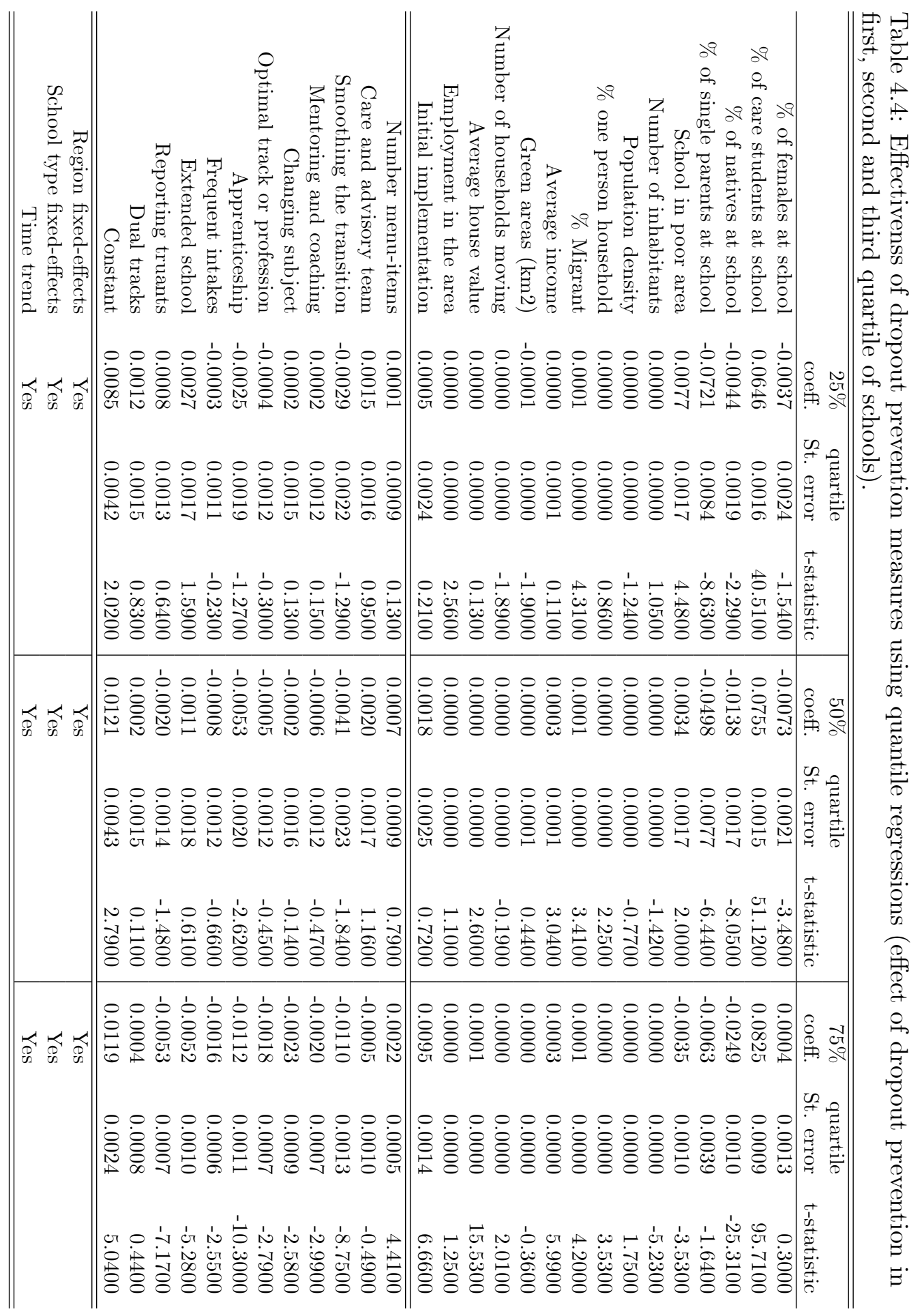




\subsubsection{Analysis at the school level}

The number of early school-leavers differs significantly across schools. Some schools have few dropouts, while the number of dropouts is high in other schools. To account for this heterogeneity across schools, a quantile analysis is estimated on school level data (Koenker and Bassett, 1978). Quantile regressions are convenient to estimate the impact on other levels than the mean (i.e. other quantiles). In this way, the whole conditional distribution of the dependent variable $y$ can be estimated. In the quantile analysis, and in contrast to the analysis of Table 4.3, it is necessary to consider aggregated data on the school level. The aggregated data set includes, therefore, one observation per school per year.

Aggregation of data yields an additional advantage. Various unobserved exogenous variables may influence the dropout decision at the individual level. ${ }^{13}$ Therefore, an evaluation at the individual level may fail to indicate program effectiveness (e.g. Dynarski and Gleason, 1998; Slavin and Fashola, 1998). At the aggregated school level, the influence of multimodel interventions can be better estimated.

In the school level analysis, three kinds of schools are considered: (1) schools with a low dropout rate; (2) schools with a median dropout rate; and (3) schools with a high dropout rate. They are decided on the first (25 percent), second (50 percent) and third quantile (75 percent), respectively. Besides a time trend, we control for school-type and region-fixed-effects. Table 4.4 report the results of the quantile analysis.

It is observed that schools with relatively high dropout rates benefit most from dropout prevention measures. All dropout prevention measures, except for advisory team and dual track projects, are associated with lower dropout rates. In contrast, no significant impact of dropout prevention measures on schools with low or median dropout rates is found.

\footnotetext{
${ }^{13}$ Note, however, that there might also be unobserved heterogeneity at the school level. This unobserved heterogeneity might arise from a different source.
} 

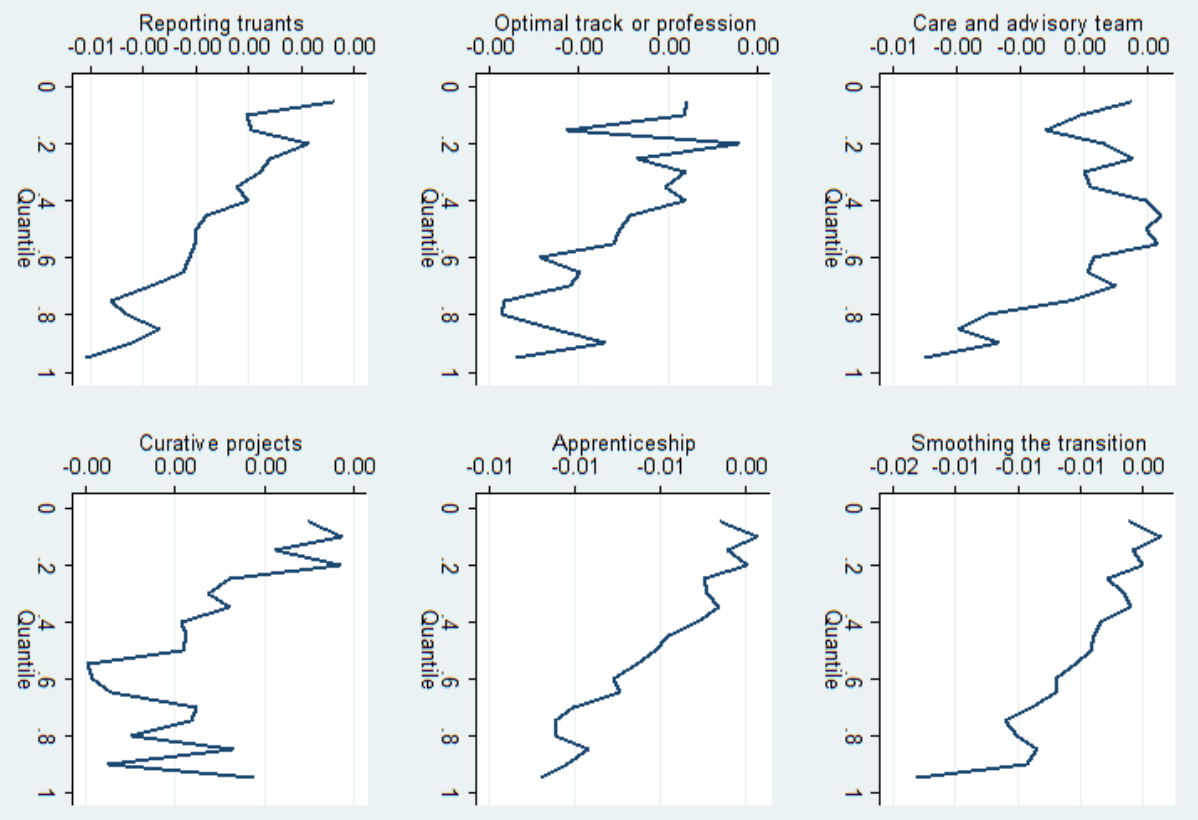

ن
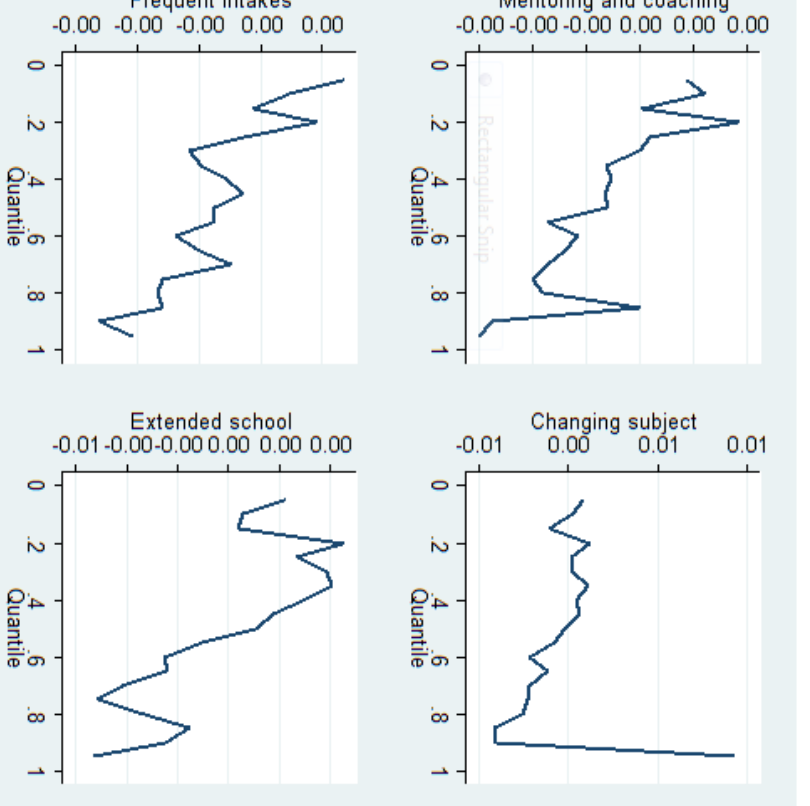

0
0
0
0
0
0
0
0
0
0
0
0
3
0
0
0
0
0
0
0 
Obviously, schools cannot simply be divided into three groups. The distribution of dropout rates is more a continuum (Rumberger and Thomas, 2000). Therefore, we estimate the impact of each dropout prevention measure on the dropout level of schools for all centiles (i.e. a continous distribution). The corresponding graphs are plotted in Figure 4.2. A negative slope is observed in almost all graphs. This indicates that the higher the dropout level of the school, the larger the impact of the dropout prevention measure.

\subsection{Conclusion}

The Dutch government has created a policy framework to reduce dropout of secondary education that is in line the Lisbon Agenda. Regions can select intervention measures from a list provided by the central government. This chapter has analyzed the impact of the policy measures at both the individual level (i.e. Do the selected policy measures of the covenant change the dropout decision of the student?) and at the school level (i.e. Do the selected prevention measures change the number of students dropping out of schools?).

First consider the micro-level, i.e. the individual perspective in the conceptual model of Rumberger (2001). While most policy measures correlate negatively with the individual dropout decision, only 'mentoring and coaching' (i.e. matching of students with a coach from public or private organizations), 'optimal track or profession' (e.g. work placement) and 'dual track' (i.e. re-entering education for dropout students) have a significant negative impact on the individual dropout decision. This might not be coincidence, as these measures are difficult to implement overnight and require a change in the process (see also De Bruijn et al., 2010). Second, it is observed that

the number of policy measures implemented by a region does not have a significant impact. More is not necessarily better (and vice versa).

An analysis at the individual level hides significant heterogeneity across 
schools as some schools have few dropouts while others have many early school-leavers. By means of quantile regressions, the correlation between the menu-items and the percentage of dropouts in school has been estimated. It has been observed that, for different quantiles of schools (e.g. the schools with the 25 percent lowest or 25 percent highest percentage of students), different impacts of prevention measures arise. While only few policy measures items have a significant effect in schools with a relatively low percentage of dropouts, schools with a relatively high percentage of dropouts benefit from all but two dropout prevention measures. These two educational measures are advisory teams and dual tracks. It is observed that schools with a relatively higher dropout level benefit the most from dropout prevention measures.

Three remarks are relevant at this point. First, despite the rich data set, it was not possible to draw conclusions on the causal process. Causal identification is impossible due to simultaneous implementation of policy actions. Nevertheless, as we rigorously control for various background characteristics of the students, the neighborhood and the schools, and as we allow for a time trend in the data (i.e. control for potential time effects), our results give a clear indication on the lower-bound of the influence of the policy measures on dropout reduction. Second, the covenants between regions and government were signed in the school year 2005-06 for 14 regions, and in 2007-08 for all 39 regions. Our analysis starts in the school year 2005-06, as the registration system improved remarkably from 2005-06 onwards, and as the first incentives were agreed on at the start of this school year. It should, however, be noted that the interventions agreed on in the convenant are only intended interventions by the regions. To our best knowledge, there is no information on the certificate of realization of these intended policy measures. Moreover, the implementation of some measures might take some time or might only yield effects after some years. Nevertheless, qualitative 
research has pointed out that the assessed measures were being effectively implemented in regions and schools soon after they were established (De Bruijn et al., 2010). This enables us to gauge, for the first time, the influence of the policy interventions. Third, although the central focus of the Chapter is on the Netherlands, its impact goes far beyond this specific country. On the one hand, dropout policy is high on the political agenda in nearly all industrialized countries. Given that economies are increasingly knowledge-driven, the ensuing penalty of dropping out is increasingly large. Hence, further reducing dropout rates is an important policy issue. On the other hand, our analysis reveals some best-practice policy, which might also be insightful for other countries.

Next Chapter 5 analyzes the effectiveness of a one year increase in the compulsory education age on the school dropout rates. 



\section{Chapter 5}

\section{The Compulsory Education Age}

"[...] as labour markets tighten, increased competition for jobs might potentially be felt particularly strongly by those having entered the market only recently, who still find themselves in more vulnerable market positions and have relatively little work experience."

(Gangl, 2002, p.68)

\subsection{Introduction}

Compulsory school-age has a relatively young history in most developed countries. The US and most Western European countries introduced compulsory education laws in the second half of the nineteenth century and the beginning of the twentieth century (Lleras-Muney, 2001, 2005; Murtin and Viarengo, 2009). There are three main reasons to introduce compulsory education laws. First, they aim at protecting students from too early labor market entrance (OECD, 1983; Kaufman et al., 2004). The minimum school age is country-specific and, depending on the type of work involved, regulates labor market entrance. The International Labor Organization (ILO) adopted the Minimum Age Convention in 1973, which many countries have ratified over the past decades (ILO, 2002). For example, the Netherlands

\footnotetext{
${ }^{1}$ Chapter 5 is based on: Sofie J. Cabus and Kristof De Witte (2011). Does School Time Matter? On the Impact of Compulsory Education Age Change on School Dropout. Economics of Education Review 30(6), 1384-1398.
} 
ratified the Minimum Age Convention in 1976, agreeing on a minimum compulsory school-age of 15 . Germany (in 1976) agreed on a school-age of 15, Belgium (in 1988) on a school-age of 15 and the United Kingdom (2000) on a school-age of 16. A similar pattern is observed in the US. By 1918, all states had stipulated compulsory education age and child labor laws to regulate labor market entrance as from 14 year-olds. For most states, the compulsory education age increased to 16 (Lochner and Moretti, 2001; Lleras-Muney, 2005).

As a second reason for compulsory education, Shavit and Müller (1998) and Gangl (2002) indicate that educational outcomes' expectations have risen. Societies developed from an industrial towards a knowledge-driven economy resulting in greater demand for high-skilled workers. ${ }^{2}$

Third, investment in human capital is considered as one of the main drivers of prosperity and growth (see, among others, Becker, 1992; Schultz, 1967). A well-educated labor force is a condition for economic productivity (Spence, 1973), promotes good citizenship (Milligan et al., 2004), and enhances economic development (Aghion and Howitt, 1998). On the contrary, low-educated people have a higher probability to take low-skilled jobs or, have a higher risk of becoming (long-term) unemployed (OECD, 2008), among other risks (for an extensive overview, see Psacharopoulos, 2007). Low-skilled workers are more vulnerable to pile up serious life-hampering problems, such as intergenerational poverty (Bowles, 1972), poor health (Groot and Maassen van den Brink, 2007), and exclusion from society (Sparkes, 1999). Once entered, it is difficult to escape the downward-moving spiral - a handicap often passed on to the next generation (McLanahan, 1985).

\footnotetext{
${ }^{2}$ Note that the rising expectations can be observed in the increasing enrollment rates, which were higher in the US than in Europe. The difference can be attributed to higher youth mobility, less elite students, and rapid response to technological change (Golding and Katz, 2008).
} 


\section{Compulsory education in the literature}

This chapter focusses on the impact of compulsory education on school dropout. This is a rather atypical stance, as most of the literature focusses on the impact of schooling on wages or other labor market outcomes (for some examples, see Brunello and Raffaele, 1999; Card, 1995, 1999; Colm and Walker, 1995; Duflo, 1998; Garen, 1984; Heckman and Vytlacil, 1998; Kane et al., 1999; Mincer, 1974). To position this chapter, we summarize some of the previous literature on compulsory education.

Angrist and Krueger (1991) were among the first to use compulsory education laws to estimate the returns to schooling (and early school-leaving). Using compulsory education laws as an instrument, they find that about 25 percent of potential dropouts stay longer in school because of compulsory schooling laws. Moreover, they provide support for the beneficial impact of longer school attendance on earnings, indicating returns of about 7.5 percent.

Oreopoulos $(2003,2006,2007)$ reports significant effects of compulsory education on income for the US, Canada, UK and Ireland. He reports an average increase in annual income of about 10 to 15 percent and discusses other positive benefits such as more employment.

Pischke and von Wachter (2005) estimated by a two stage least squares model the return of compulsory education laws in Germany on wages over the period 1948 to 1970 . Although most of the literature reports returns in the order of 10 to 15 percent (e.g. Acemoglu and Angrist, 2000; Aakvik et al., 2003; Oreopoulos, 2003, 2006, 2007), Pischke and von Wachter do not observe any increase in earnings. Moreover, they find no explanation for the role of labor market institutions or the existence of an apprenticeship training system in Germany. Similar results have been found in Oosterbeek and Webbink (2004). They estimated the long-term wage effects of an extra year of lower vocational education in the Netherlands, combined with an in- 
crease in compulsory school-age. Using a difference-in-differences approach, they found generally small effects on wages.

Compulsory education has also been correlated with non-pecuniary outcomes. Lochner and Moretti (2004) and Anderson (2010) observe a positive correlation with crime. A low educational attainment has further been considered as an indicator for a low health status (Lleras-Muney, 2005; Albouy and Lequien, 2009; Powdthavee, 2010), for behaviour problems (Ekstrom et al., 1986), or a low socioeconomic status (Swadener, 1995; Herbert and Reis, 1999). Students with teenage births violate compulsory education laws more often (Black, 2008; Silles, 2011) (see also Chapter 1).

The impact of compulsory education on dropout rates and, consequently, obtaining a higher secondary certificate, has not been extensively examined. The early literature on the effect of increased compulsory education age on educational attainment is found in Lang and Kropp (1986). They observe an ambiguous effect. On the one hand, compulsory schooling laws may only affect students who consider early school-leaving. On the other hand, compulsory education may affect the schooling decision of all age groups (i.e. students who are not directly affected by an increased schooling age). Using maximum likelihood estimation and a Monte Carlo experiment, the results of Lang and Kropp support the latter hypothesis. Wenger (2002) estimated the impact of an increased compulsory education age on the schooling decision and school choice by a bivariate Probit model. She finds that potential dropout students are most likely to be affected, and that students in state schools are increasingly affected compared with students in private schools. Van der Steeg and Webbink (2006) stress the importance of the additional years in school because of an increase in compulsory school-age - even if the pupil still drops out of school too early. They promote the use of a sliding scale, which means that more education leads to better labor market outcomes, irrespective of actually obtaining the school-leaving certificate. 
To identify the research question, we use a recent policy change in the Netherlands. ${ }^{3}$ Before the introduction of the 'Qualification Law' on 1 August 2007, students could leave education on their 17th birthday. ${ }^{4}$ Since the policy change, 17 year old students should stay in school until they obtain a certificate, or reach the age of 18 . Every student below the age of 23, who did not obtain a higher secondary certificate before leaving school, is considered as an early school-leaver. The identification strategy, proposed in this chapter, exploits the birthday-related variation in the law (an extensive discussion follows in Section 2).

The remainder of the chapter is structured as follows. In Section 5.2, we outline the identification strategy to estimate the effect of an increase in compulsory school-age on dropout at secondary education. Next, Section 5.3 describes the data. We present the results in Section 5.4. The final Section 5.5 contains conclusions and a discussion, including some policy advice, and comments on the limitations of the research.

\subsection{Identification strategy}

The causal impact of one additional year of compulsory education on dropout is estimated on administrative data of all students going to school in Amsterdam, in the Netherlands. Amsterdam has among the largest dropout rates in the Netherlands (see Section 4). ${ }^{5}$ The policy reform requires more insight into the organization of higher secondary education in the Netherlands. One may find a brief description of the Dutch educational system in

\footnotetext{
${ }^{3}$ Note that the Dutch Ministry of Education also adapted alternative dropout prevention measures (such as the 2005-2006 covenant). However, given the earlier implementation and our specific set-up (see below), to our best knowledge, there is no significant bias in the results.

${ }^{4}$ Note that a major exception was 'partial compulsory education', which indicated that students younger than 17 could take courses for only 1 or 2 days a week.

${ }^{5}$ In the Netherlands, there are 39 RMC-regions (Regionaal Meld- en Coordinatiepunt). Of these 39 RMC-regions, 17 percent of total dropout in the year 2007 are registered in four regions: Amsterdam (5.7 percent), Haaglanden (5.3 percent), Utrecht (4.6 percent) and Rijnmond (5.8 percent).
} 
Chapter 4. We observe that vocational students have higher dropout rate than vwo and havo students (e.g. De Witte and Rogge, 2010; Tieben and Wolbers, 2008). As an illustration, Figure 5.1 plots the dropout rates of the Municipality of Amsterdam for (1) all students, (2) vwo and havo students and (3) mbo students. Thereafter, we set out the proposed identification strategy and methodology.

\section{Identification - The intuition}

The earlier compulsory education law, dated 1969, was changed in 2007. The law of 1969 mandated pupils to attend school until their 17 th birthday. ${ }^{6}$ After 1 August 2007, mandatory school attendance increased to the age of 18 or until a higher secondary certificate is obtained. The goal is - as mentioned before - to obtain a minimal qualification for labor market entrance. Pupils leaving school before obtaining a higher secondary certificate are considered as dropouts. Registration of dropouts takes place up to the age of 23, which means that pupils can still gain their certificate after reaching their 18th birthday.

To estimate the causal impact of compulsory education on early schoolleaving, here the implementation of the policy reform in the Netherlands is considered. On the one hand, students who were born before 1 August 1990, and, hence, are 17 years old on the date of the policy reform, are exempted from the policy reform. They have to attend school until their 17th birthday has been reached. On the other hand, students born after 1 August 1990 are liable to comply with the new Qualification Law. The Qualification Law implies mandatory school attendance until the age of 18 has been reached or until a qualification has been obtained. To force the implementation of the

\footnotetext{
${ }^{6}$ The 1969 Compulsory Education Law obliges youngsters to attend 12 full academic years in state schools (when not enrolled in private schooling). In fact, students can register for apprenticeships outside the school after their 16th birthday (i.e. partial compulsory education or dual tracks). Compulsory education starts on the student's 5th birthday. If the student reaches the age of 5 one month or more after the start of a new academic year, students are obliged to enroll for the next academic year.
} 
law, improved registration has been developped. Moreover, truancy officers can fine the parents of the truant (for an evaluation, see De Witte and Csillag, 2010). After the age of 18, and thus after adulthood has been reached, parents are no longer responsible for their child attending school. An adolescent without a qualification has the responsibility to obtain a higher secondary certificate, but is no longer obliged to attend school. Consequently, the 2007 Qualification Law implies a one-year increase in compulsory education age: from 17 to 18 . It is clear that 1 August serves as a discontinuous date. ${ }^{7}$ To find out the effect of a one-year increase in compulsory education age, one can easily compare the average dropout rates of the student group born before 1 August 1990 with the average dropout rates of the student group born after 1 August 1990.

However, if the identification is in doubt, the estimates are biased (Imbens and Rosenbaum, 2005). Using day of birth as an instrument raises two issues. First, the date of birth randomly assigns individuals to a control or a treatment group and, as a consequence, unobserved individual heterogeneity should be, on average, the same in both the control- and the treatment group. Using date of birth as an instrument for random assignment to the treatment has recently been discussed in the literature by Buckles and Hungerman (2010) and Bound et al. (1995). In particular, Buckles and Hungerman (2010) argue that socioeconomic characteristics statistically differ between children born in different months of the year, mainly as a result of teenage or unwanted pregnancies. ${ }^{8}$ For the data concerned in our study, differences between the control- and the treated students are

\footnotetext{
${ }^{7}$ It is important to note that thanks to this discontinuity, students in the control group and the treatment group belong to the same classes. Consequently, other policy measures to reduce dropout (such as the convenant) will have a similar effect on both the treatment and the control group. In other words, without the evaluated policy change, the average observed outcomes would move parallel over time in both the treatment and the control group. The DiD model is thus not biased due to alternative policy measures.

${ }^{8}$ It appears that unwanted pregnancies are often conceived in the summer months, which results in more children with a low socioeconomic status being born in the winter months. Note that, in this respect, unwanted pregnancies are positively associated with a low socioeconomic status (see Buckles and Hungerman, 2010).
} 
examined. However, no significant differences are found in observed student characteristics between the control group and the treatment group students. In addition to this argument, the teenage birth rate is rather low in the Netherlands compared with the United States. In the US, the teenage birth rate is 41.5 per 1,000 (Martin et al., 2010), while this rate is only 18 per 1,000 in the Netherlands (Statistics Netherlands, 2011).

As a second intricate issue, it might be the case that both liable (to the Qualification Law) and non-liable students sit together in the same class, unless there has been retention in grade(s) during the school career. One can argue that the characteristics of students born in the first half of the year should not differ significantly from those of students born in the last half of the year. ${ }^{9}$ Particularly for school dropout, however, age matters. Students of the former group are more likely to drop out as they can legally leave secondary education sooner than students from the latter group. Agerelated aspects are controlled for by taking other cohorts into account (e.g. the 1989 cohort). But, in doing so, time-related aspects can bias the results (Heckman et al., 1999), for example: (1) a revival of the economy resulting in more available jobs for low-skilled people; or (2) sensitization on the relevance of a higher secondary certificate among students. Hence, age- and time-effects are controlled for in the analysis. With this, a difference-indifferences (DiD) methodology is applied.

Before using the $\mathrm{DiD}$, a potential outcome framework is set out as proposed by Rubin $(1974,1987)$. This non-parametric framework has two major advantages: (1) it does not impose a priori assumptions on the functional form of the data; and (2) it allows us to visualize the effect (without controlling for covariates). Secondly, a parametric approach is used to get the DiD estimator, having controlled for observed heterogeneity and, as far as possible, for peer effects using fixed-effects models.

\footnotetext{
${ }^{9}$ While, in kindergarten and primary education, the differences between students born in the two year halves might be significant, this effect arguably fades out.
} 


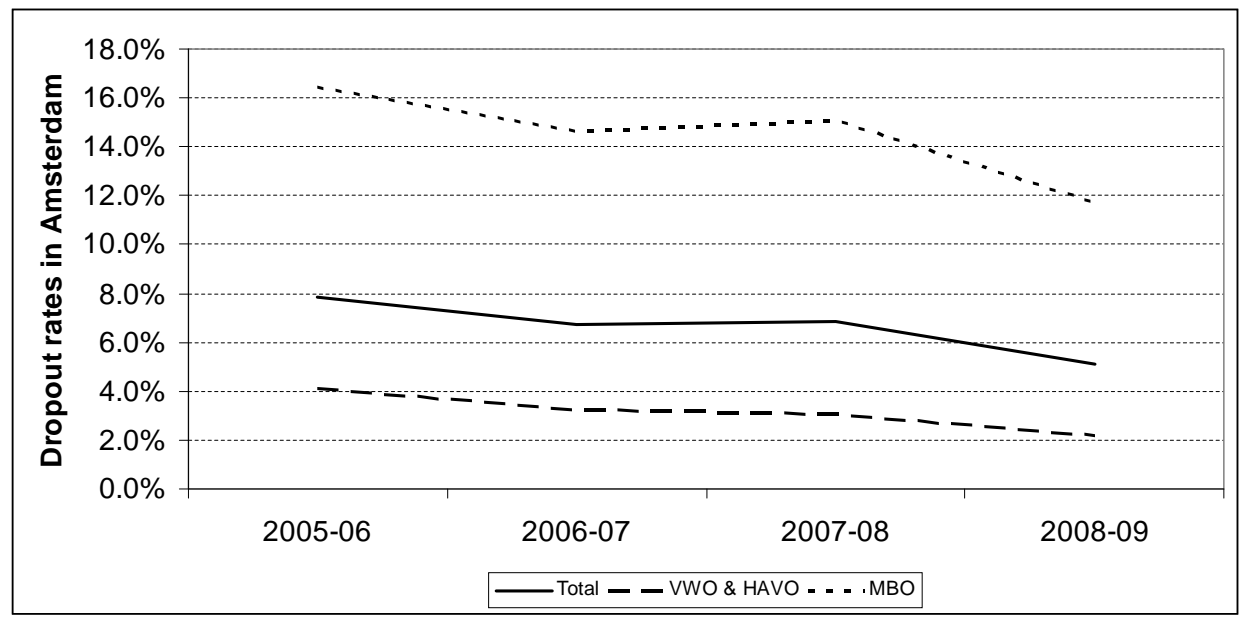

Figure 5.1: Dropout rates in the Municipality of Amsterdam for: (1) the total sample; (2) pre-university and general education (vwo and havo); and (3) vocational education (mbo) (Source: Statistics Netherlands).

Table 5.1: Cross-table treatment and control group using two time periods 2006-2007.

\begin{tabular}{rrr}
\hline \hline Control group & $\mathbf{2 0 0 6}$ & $\mathbf{2 0 0 7}$ \\
\hline \multirow{2}{*}{ Treatment group $0 ; \mathrm{t}=0$} & $\mathrm{~d}=0 ; \mathrm{t}=1$ \\
& $\mathrm{~d}=1 ; \mathrm{t}=0$ & $($ cohort 1990$)$ \\
& $\mathrm{d}=1 ; \mathrm{t}=1$ \\
& $($ cohort 1989$)$ & $($ cohort 1990$)$ \\
\hline \hline
\end{tabular}




\section{Identification - The analysis}

The discontinuous date of the policy reform, that is, 1 August, allows us to identify a treatment and a control group. The control group consists of the non-liable students (born before 1 August) and the treatment group consists of the liable pupils (born after 1 August). Non-liable students are denoted by $(D=0)$, and liable students by $(D=1)$. The evaluation point in time is denoted by $(t=0)$ for 2006 (evaluation of cohort 1989), and $(t=1)$ for 2007 (evaluation of cohort 1990). The composition of the control- and treatment groups over time is summarized in Table 5.1.

The individual's potential outcome at time $t$ in the absence of the treatment is denoted by $Y_{0}(t)$. In the same way, $Y_{1}(t)$ represents the individual's potential outcome at time $t$ when exposed to the treatment. The conventional DiD estimator requires that, in absence of the treatment (in this case, without the policy change), the average observed outcomes for the treatment- and the control groups move parallel over time (Heckman, 1990; Abadie, 2003). Under the former assumption, the parametric (DiD) estimator is computed as follows:

$$
Y_{i}=\alpha_{0}+\alpha_{1} D_{i}+\alpha_{2} T_{i}+\theta D_{i} T_{i}+\sum \beta_{j} X_{j i}+U_{i}
$$

where $\alpha_{0}$ denotes the intercept; $D_{i}$ is an indicator of the treatment status; $T_{i}$ is a time indicator (before and after policy reform); $X_{j i}$ is a vector with the individuals' observable characteristics; and $U_{i}$ is a residual. We are interested in the estimate of $\hat{\theta}$, which is the effect on dropping out, given the policy reform (i.e. the student is denoted by $D=1$ and $T=1$ ). If selection into the treatment group is correlated with the error term $U_{i}, \theta$ cannot be consistently estimated. However - as argued before - we do not observe any correlation between day of birth and observed characteristics. Random assignment by date of birth to one of both groups seems a reasonable as- 
sumption. ${ }^{10}$ In addition, in a parametric analysis, it is easier to control for observed heterogeneity.

\subsection{Data and descriptive statistics}

The data consists of combined registered data (BRON data: see Chapter 4) of the Dutch Ministry of Education, Culture, and Science with registered data of the Municipality of Amsterdam (DMO Amsterdam). BRON data do not provide crucial information on date of birth, which is required for the identification strategy. Data from DMO Amsterdam do, however, provide this necessary information. Using the students' personal identification number, the DMO Amsterdam data can be combined with the BRON data. ${ }^{11}$

The combined data set provides information on about 45,000 students in secondary education attending schools in Amsterdam during the school years 2005-06 to 2008-09. Rich information on the covariates is available. For example, there is information on gender, birthday, ethnicity, place of residence, household composition, poverty status, school-type (vwo, havo, vmbo, mbo), school track or enrollment status.

In the Netherlands, a school year starts on 1 August and ends one year later on 31 July. Students' enrollment (or dropout) decision is registered after the start of the school year, that is, on 1 October. Students, who were enrolled on 1 October of the previous school year, but did not enroll for a new school year, are assigned the dropout status. ${ }^{12}$

Evaluation of student enrollment on October 1st has one major implication. On 1 October, treatment group students are aged 16 or 17. A student born between 1 August and 1 October will be registered with an age of 17,

\footnotetext{
${ }^{10}$ Extensive alternative explorations on the data further strengthen this evidence.

${ }^{11}$ We do not lose any observations of the DMO Amsterdam data because it is combined with BRON data.

${ }^{12}$ Note that this, official, definition of dropout has two consequences. First, it is possible to re-enroll and to drop out more than once. Consequently, in the course of time, some students will be registered more than once as an early school-leaver. Second, if a student drops out after 1 October and re-enrolls before 1 October of the next year, we do not observe this student as a dropout.
} 
Table 5.2: Descriptive statistics of compulsory education age evolution (number of observations and relative frequency).

\begin{tabular}{|c|c|c|c|c|c|}
\hline & & 1989 & $\%$ & 1990 & $\%$ \\
\hline \multicolumn{6}{|l|}{ Total sample } \\
\hline Control group $(D=0)$ & & 3,667 & $57.30 \%$ & 3,629 & $55.90 \%$ \\
\hline Treatment group $(\mathrm{D}=1)$ & & 2,728 & $42.70 \%$ & 2,863 & $44.10 \%$ \\
\hline \multicolumn{6}{|l|}{ Dropout rates } \\
\hline Control group $(D=0)$ & & $9.73 \%$ & & $12.08 \%$ & \\
\hline Treatment group $(D=1)$ & & $9.08 \%$ & & $8.91 \%$ & \\
\hline Difference $(D=0-D=1)$ & $\mathrm{t}$-value & 0.88 & & 4.11 & \\
\hline \multicolumn{6}{|l|}{ Higher secondary diploma } \\
\hline Control group $(\mathrm{D}=0)$ & & $28.09 \%$ & & $29.40 \%$ & \\
\hline Treatment group $(D=1)$ & & $16.50 \%$ & & $17.70 \%$ & \\
\hline Difference $(D=0-D=1)$ & $\mathrm{t}$-value & 10.97 & & 10.95 & \\
\hline \multicolumn{6}{|l|}{ Gender } \\
\hline \multirow{2}{*}{ Control group $(\mathrm{D}=0)$} & Male & 1,803 & $49.20 \%$ & 1,737 & $47.90 \%$ \\
\hline & Female & 1,864 & $50.80 \%$ & 1,892 & $52.10 \%$ \\
\hline \multirow[t]{2}{*}{ Treatment group $(\mathrm{D}=1)$} & Male & 1,317 & $48.30 \%$ & 1,405 & $49.10 \%$ \\
\hline & Female & 1,411 & $51.70 \%$ & 1,458 & $50.90 \%$ \\
\hline Difference $(D=0-D=1)$ & $\mathrm{t}$-value & -0.71 & & 0.97 & \\
\hline \multicolumn{6}{|l|}{ School Types } \\
\hline \multirow[t]{6}{*}{ Control group $(D=0)$} & mbo & 2,172 & $59.20 \%$ & 2,224 & $61.30 \%$ \\
\hline & brug & 8 & $0.20 \%$ & 4 & $0.10 \%$ \\
\hline & lwoo & 115 & $3.10 \%$ & 102 & $2.80 \%$ \\
\hline & vmbo & 162 & $4.40 \%$ & 139 & $3.80 \%$ \\
\hline & havo & 469 & $12.80 \%$ & 430 & $11.80 \%$ \\
\hline & vwo & 741 & $20.20 \%$ & 730 & $20.10 \%$ \\
\hline \multirow[t]{6}{*}{ Treatment group $(\mathrm{D}=1)$} & mbo & 1,218 & $44.60 \%$ & 1,285 & $44.90 \%$ \\
\hline & brug & 7 & $0.30 \%$ & 2 & $0.10 \%$ \\
\hline & lwoo & 175 & $6.40 \%$ & 196 & $6.80 \%$ \\
\hline & vmbo & 311 & $11.40 \%$ & 306 & $10.70 \%$ \\
\hline & havo & 493 & $18.10 \%$ & 493 & $17.20 \%$ \\
\hline & vwo & 524 & $19.20 \%$ & 581 & $20.30 \%$ \\
\hline Difference $(D=0-D=1)$ & t-value & -9.01 & & -10.4 & \\
\hline
\end{tabular}

Note: Continued on the next page. 
(Table 5.2 - Continued)

\begin{tabular}{|c|c|c|c|c|c|}
\hline & & 1989 & $\%$ & 1990 & $\%$ \\
\hline \multirow{4}{*}{$\begin{array}{l}\text { Household Composition } \\
\text { Control group }(D=0)\end{array}$} & & & & & \\
\hline & One household head & 404 & $11.00 \%$ & 373 & $10.30 \%$ \\
\hline & Two household heads & 3,245 & $88.50 \%$ & 3,232 & $89.10 \%$ \\
\hline & Unknown & 18 & $0.50 \%$ & 24 & $0.70 \%$ \\
\hline \multirow[t]{3}{*}{ Treatment group $(\mathrm{D}=1)$} & One household head & 335 & $12.30 \%$ & 318 & $11.10 \%$ \\
\hline & Two household heads & 2,382 & $87.30 \%$ & 2,530 & $88.40 \%$ \\
\hline & Unknown & 11 & $0.40 \%$ & 15 & $0.50 \%$ \\
\hline Difference $(D=0-D=1)$ & t-value & 1.55 & & 1.06 & \\
\hline \multicolumn{6}{|l|}{ Ethnicity } \\
\hline \multirow[t]{8}{*}{ Control group $(\mathrm{D}=0)$} & Netherlands & 1,186 & $32.30 \%$ & 1,140 & $31.40 \%$ \\
\hline & Suriname & 605 & $16.50 \%$ & 622 & $17.10 \%$ \\
\hline & Aruba & 82 & $2.20 \%$ & 92 & $2.50 \%$ \\
\hline & Turkey & 378 & $10.30 \%$ & 357 & $9.80 \%$ \\
\hline & Morocco & 718 & $19.60 \%$ & 699 & $19.30 \%$ \\
\hline & Non-western migrant & 414 & $11.30 \%$ & 429 & $11.80 \%$ \\
\hline & Western migrant & 280 & $7.60 \%$ & 288 & $7.90 \%$ \\
\hline & Unknown & 4 & $0.10 \%$ & 2 & $0.10 \%$ \\
\hline \multirow{8}{*}{ Treatment group $(\mathrm{D}=1)$} & Netherlands & 975 & $35.70 \%$ & 1,007 & $35.20 \%$ \\
\hline & Suriname & 473 & $17.30 \%$ & 444 & $15.50 \%$ \\
\hline & Aruba & 58 & $2.10 \%$ & 76 & $2.70 \%$ \\
\hline & Turkey & 250 & $9.20 \%$ & 269 & $9.40 \%$ \\
\hline & Morocco & 433 & $15.90 \%$ & 477 & $16.70 \%$ \\
\hline & Non-western migrant & 311 & $11.40 \%$ & 344 & $12.00 \%$ \\
\hline & Western migrant & 224 & $8.20 \%$ & 243 & $8.50 \%$ \\
\hline & Unknown & 4 & $0.10 \%$ & 3 & $0.10 \%$ \\
\hline Difference $(D=0-D=1)$ & t-value & 2.46 & & 1.57 & \\
\hline
\end{tabular}


whereas a student born after 1 October will be registered with an age of 16. This does not bias the results, but in contrast enhances findings when taking, for example, a smaller window around the cut-off point 1 August (e.g. by taking one month before and one month after 1 August as the window, dropout rates of 17 year-olds can be compared with students who, on average, only differ by liability status). This smaller window is used in the robustness analysis.

Summary statistics are presented in Table 5.2, where a distinction is made between the student composition of the control- and treatment group in the year 2006 (cohort 1989) and 2007 (cohort 1990). Moreover, Table 5.2 provides statistical information on the comparability between the controland the treatment group (estimated by a t-statistic).

Only the observations of the cohorts 1989 and 1990 are kept in the sample. Furthermore, the dropout rates of the cohort 1989 in 2006 and cohort 1990 in 2007 are evaluated. We have 12,887 students in the data set (see Table 5.2). Using the birthday as cut-off point, we assign 6,395 pupils of the cohort 1989 to the control group or the treatment group. Of this, 3,667 and 2,728 students were born, respectively, before and after 1 August. 603 students eventually dropped out of school without a higher secondary certificate. Similarly, we assign 6,492 pupils of the cohort 1990 to either the control group or the treatment group, resulting in, respectively, 3,629 students and 2,863 students. The total dropout number in this cohort amounts to 691 students.

Concerning the comparability between the treatment- and control group, the t-statistic finds a large resemblance between the control- and the treatment group for gender, household composition and ethnicity. Despite this, significant differences in school-type choices are observed. This might be intuitive as there are more groups to compare. In addition, older pupils are more likely to enroll in higher grades, which may result in changing 
school-type (e.g. the transition from pre-vocational education to senior secondary vocational education). Student composition with respect to schooltype choices is a confounding (age-related) factor that has to be controlled for to identify the unambiguous effect of compulsory education on dropout. To cancel out the slightest effect of the previously mentioned covariates, they are also taken into account in the parametric analyses.

\subsection{Impact of compulsory education}

Subsection 5.4.1 presents the results of the non-parametric analysis, where observed heterogeneity is not accounted for. Subsection 5.4.2 deals with the results of a parametric DiD analysis, which controls for a rich set of covariates and, as far as possible, for possible peer effects.

\subsubsection{Non-parametric results}

Before the policy reform, the average observed outcomes of dropping out of secondary education in the control group $(E[Y \mid d=0, t=0)])$ and the treatment group $(E[Y \mid d=1, t=0)])$ amounted, respectively, to 9.73 percent and 9.08 percent. The observed difference is not significant. After the policy reform, students who were exempted from the policy's implications $(E[Y \mid d=0, t=1)])$ dropped out at a significantly higher rate (in comparison to the year before) of 12.08 percent. For liable students $(E[Y \mid d=1, t=1)])$, an average outcome of 8.91 percent is observed, which is not significantly different to the dropout rate before the policy reform.

The non-parametric estimate is equal to -2.52 percentage points. This effect is mainly driven by the students in the control group (i.e. students born before 1 August). Indeed, no significant difference is observed in dropout rate between students born after 1 August (i.e. the treatment group students) in the 1989 cohort and the 1990 cohort. This suggests that the treatment group students did not alter their dropout decision after the increase in com- 
pulsory education age, which is not surprising, as 16 year-olds under the old and new compulsory education law could not legally leave education.

As the effect is situated in the control group, we test for anticipations of the policy change. In particular, we check whether the increase in the average observed outcome among 17 year-olds of the cohort 1990 is related to factors such as: (1) a revival in the economy (e.g. Olsen and Farkas, 1989; Pittman, 1993; Marks and Fleming, 1999); or (2) influences among peers (e.g. Cooper et al., 2005; Frölich and Michaelowa, 2005). In the next paragraph, we explore the Dutch labor market and demand for labor to identify a possible demand shock. In the parametric analysis of subsection 5.4 .2 , we control for observed heterogeneity and potential influences among peers.

\section{Demand for labor}

To test whether the sharp increase in dropout among the non-liable students in the 1990 cohort is driven by the economy, the annual change in employment among 15-25 year-olds people is explored. Indeed, a revival in the economy may result in more available jobs for low-skilled students, pulling them out of school. In Figure 5.2, which presents the annual change in employment for students, we observe more job opportunities in the year 2007 compared with the year 2006 (an increase of more than 4 percentage points). Following the economic upturn, the total number of vacancies had soared to a record height of 250,000 in the third quantile of 2007, particularly in the industry, construction and trade sectors (Statistics Netherlands, 2011). In 2007, the demand for young workers is three times as high as it was in the year 2003, when the total number of vacancies was at its lowest point.

Under the 1969 Compulsory Education Age Law (i.e. $t=0)$ ), 17 year-olds students could legally leave secondary education and enter the labor market. 


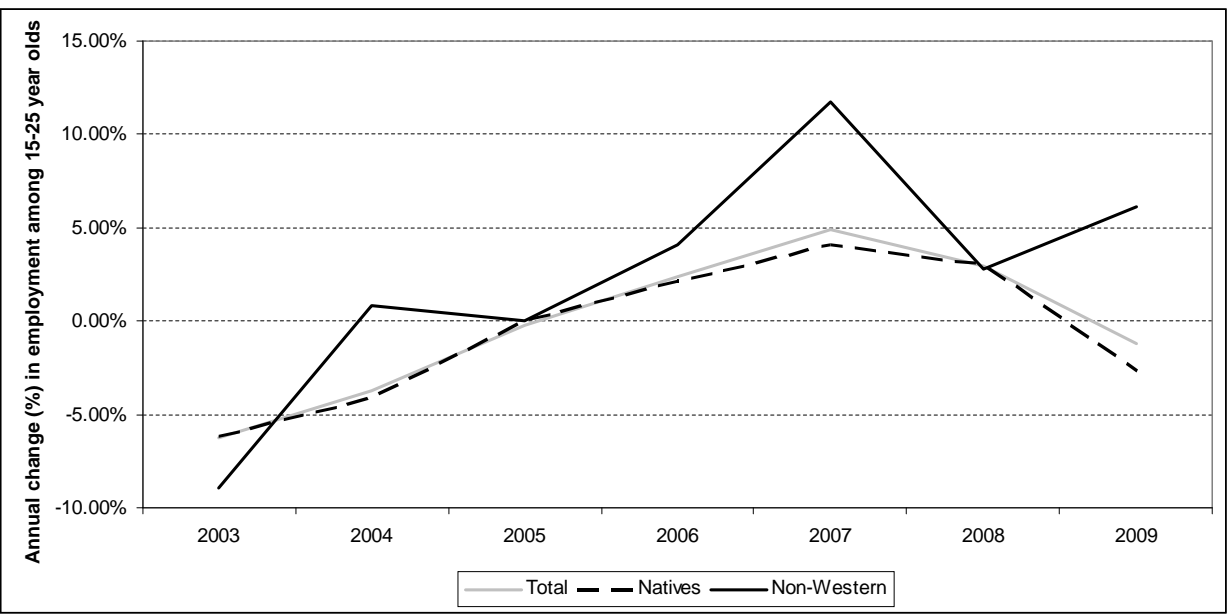

Figure 5.2: Percentage annual change in employment among 15-25 year-olds (source: Statistics Netherlands).

This would change after 1 August 2007, as pupils without a higher secondary certificate had to stay in school (i.e. $t=1$ ). The latest cohort of students who could legally leave education on their 17th birthday are students from the 1990 cohort born before August 1 (i.e. $t=1 ; d=0$ ). Given the economic upturn and the resulting increase in vacancies, an arguable explanation of the increase in dropout among non-liable students might come from taking up job market opportunities by the control group students (as the treatment group students were not allowed to drop out). In other words, it seems that employers grasped the last opportunity to employ low educated students (it would take 2 years before the next cohort entered the labor market). ${ }^{13}$ If that is the case, the parallel time-trend assumption could be violated and the estimate of $\hat{\theta}$ may be inconsistent. This is considered in the next subsection.

\footnotetext{
${ }^{13} \mathrm{An}$ in-depth analysis on this suggestion is considered to be beyond the scope of this chapter, and is left for further research. At least, we observe in employment data of Statistics Netherlands a significantly higher employment rate of $15-25$ year-olds people in the first 5 months of 2007 than in 2006. Moreover, the percentage increase of $15-25$ aged employed people was significantly higher in the first 5 months of 2007 than 2006 (average increase of 0.24 percent versus 0.08 percent), while it was similar in the following six months (0.22 percent in 2007 versus 0.25 percent in 2006).
} 


\section{Parallel Time-Trend Assumption}

At this point, it is important to take the crucial identifying restriction underlying the difference-in-differences analysis into consideration: the parallel time-trend assumption (Abadie, 2003; Bertrand et al., 2003). A critical assessment of this assumption is necessary as the non-parametric analysis may indicate that the assumption is violated, because the increase in dropout among the control group students can be attributed to an economic revival and not to the policy reform. If the economic revival is the main driver of the estimate of $\hat{\theta}$ and not the policy reform, then $\hat{\theta}$ would also have been estimated in absence of the treatment. As a result, the estimate of $\hat{\theta}$ is not the effect of an increase in compulsory school-age.

A careful evaluation indicates that the parallel time-trend assumption is not violated. There are three reasons for this.

First, students are observed from the cohorts 1988 to 1991 in the sample. We plot normalized dropout rates (January $1989=1$ ) among 16 or 17 yearolds (according to their date of birth) over the period 2005-2008, as given in Figure 5.3. The figure presents how many students born in a particular month, for example, January, left their secondary school. ${ }^{14}$ In 2005, students from the 1988 cohort were 16 or 17 year-olds. The same is true for cohort 1989 in 2006, cohort 1990 (in 2007), and cohort 1991 (in 2008). Thus, it is possible to plot dropout rates of these four cohorts and visualize the movement over time for students of the same age. In Figure 5.3, three outlying months are observed: January, February, and July 2007. Although dropout rates from 2005 to 2008 have a concave downward-sloping curve, indicating that dropout rates decline over time, it can be seen that cohort 1990 has, on average, higher dropout rates than the other three cohorts. The dashed line of Figure 5.3, representing regression without the period 1/1990 - 8/1990, shows that this would not have been the case without taking cohort

\footnotetext{
${ }^{14}$ Note that we do not observe the timing of leaving school, only the month in which a dropout is born.
} 
1990 into consideration: the curve moves smoothly downwards over time. ${ }^{15}$ This fact indicates that in 2007 an unusual event took place which only affected students born between January and August 1990. A formal test also verifies this finding. To do this, we compare by a t-statistic students born in January (control group) with students born in August (treatment group). The estimate of $\hat{\theta}$ is equal to -5.23 and significant at a $10 \%$-level.

Second, a more detailed definition of school dropout is applied. Thanks to detailed data for Amsterdam students, it is possible to observe students who left school for longer than 2 weeks (but who might come back after that period). We denote this period as 'truancy' although it is similar to school dropout for a particular period. In 2007, relatively high truancy rates were observed in the months June (10.81 percent), July (8.18 percent) and August (54.79 percent). It seems that 17 year-olds non-liable students attended school until the end of the school year 2006-07. Thereafter, they dropped out of school (by not enrolling into the new school year 2007-08) without having a higher secondary certificate. At this given point in time, the total number of vacancies soared to a record high (see Subsection 5.4.1). Having in mind that date of birth randomly assigns individuals to the control- or the treatment group and, as a consequence, (un)observed individual heterogeneity should be, on average, the same in the control- and the treatment group, we do not find relevant differences between liable and non-liable students, except concerning their liability status. ${ }^{16}$ An exogenous labor demand shock should have affected liable students in the same way as non-liable students, but no evidence is found for this.

Third, we discuss the economic revival at the time of analysis. The demand for young workers in 2007 was three times as high as in the year 2003. However, the normalized monthly change in employment between

\footnotetext{
${ }^{15}$ To allow for a plot, the dropout rates of the cohort 1990 are equal to the averages of cohorts 1988, 1989 and 1991.

${ }^{16}$ We allow for heterogeneity in the control- and the treatment group in the following Section 5.4.2, and find a persistent effect.
} 
CHAPTER 5. THE COMPULSORY EDUCATION AGE

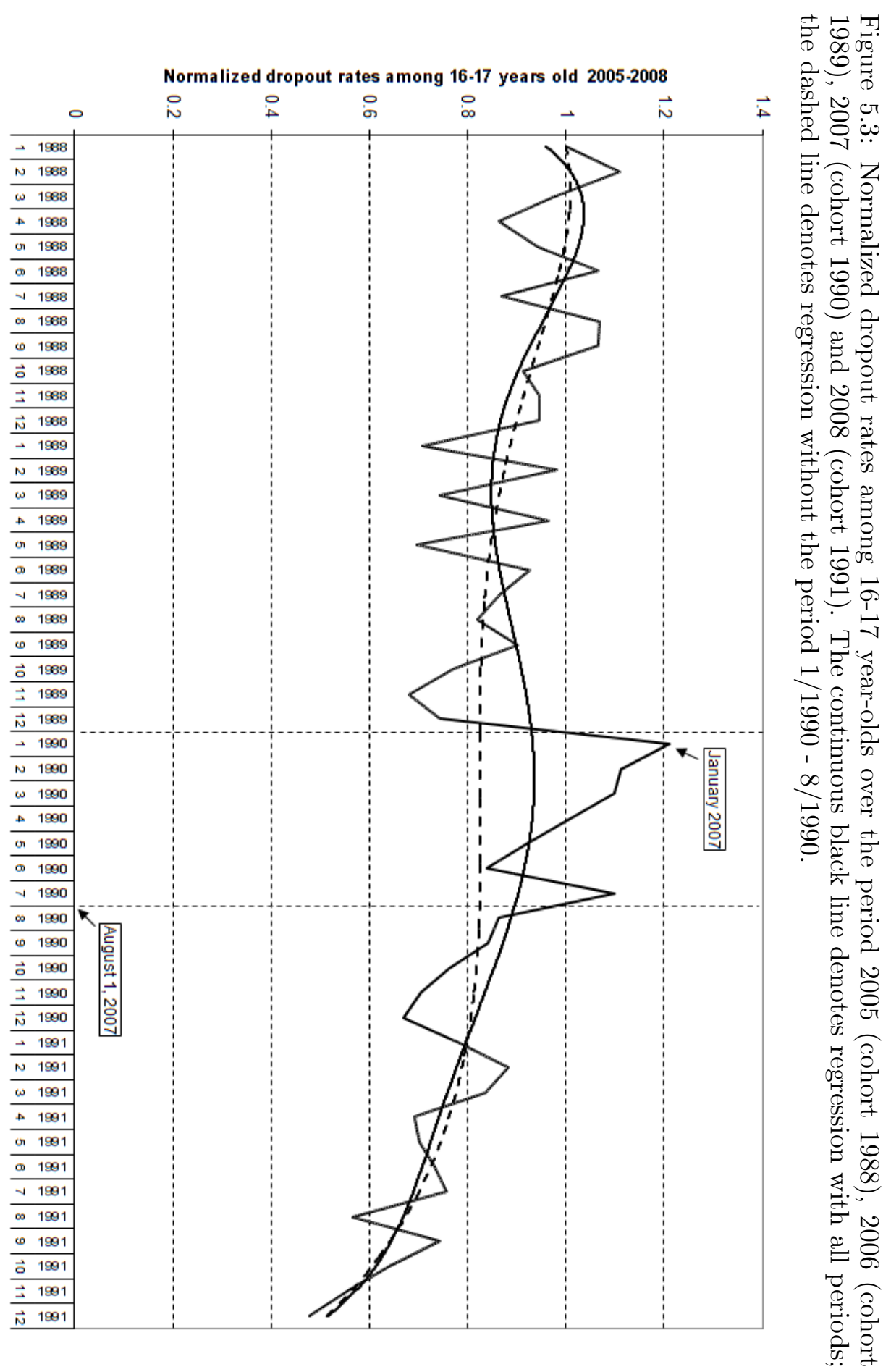




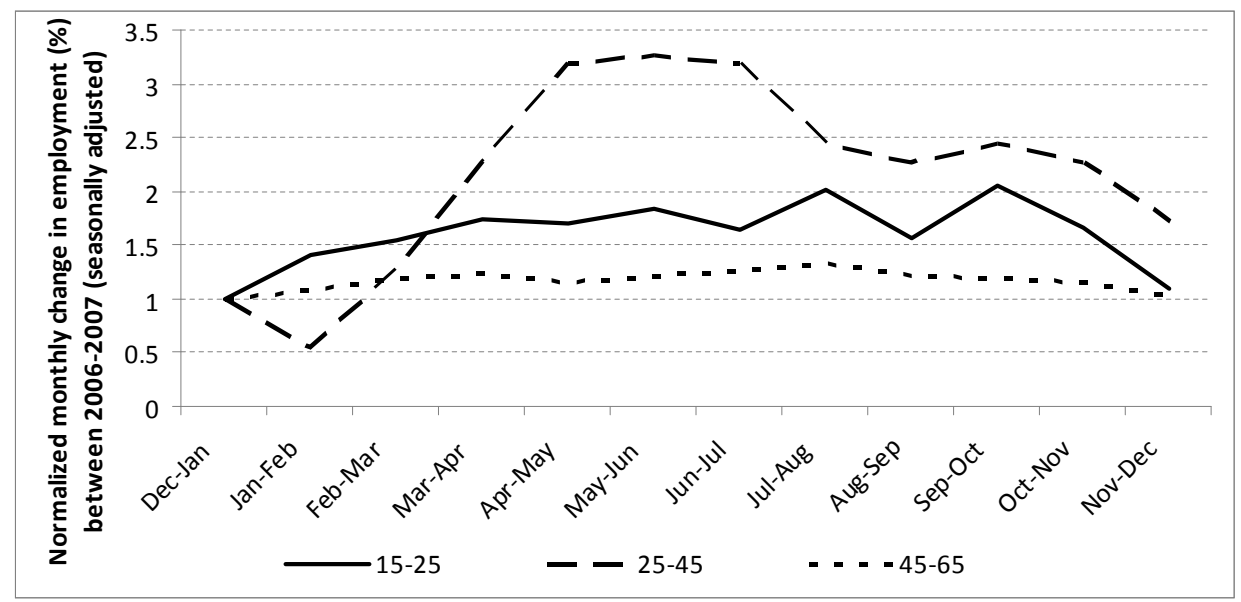

Figure 5.4: Normalized percentage monthly change in employment between 2006-2007 (seasonally adjusted)

2006-07 indicates that the largest impact was on 25-45 year-olds (see Figure 5.4). Among the group 15-25 year-olds, job market opportunities were on average the same in 2007 compared with $2006 .^{17}$ This may indicate that only a specific group of students has been spotted to fill the 2007 vacancies: that is, students born before 1 August 1990.

In sum, the parallel time-trend seems not to be violated.

\subsubsection{Difference-in-differences estimation}

To allow for heterogeneity in the control- and treatment group, a DiD model is estimated. The results of four model specifications are summarized in Table 5.3. A first model estimates the DiD estimator in its simplest form, that is, without taking covariates into account. The outcome of $\hat{\theta}$ is equal to -2.52 percentage points (significant at the $5 \%$-level). This is in line with the non-parametric outcome. The treatment indicator $\left(D_{i}\right)$ suggests that students in the treatment group $(D=1)$ have a lower probability of dropping out, although this is not significant. Similar to the non-parametric estima-

\footnotetext{
${ }^{17} \mathrm{P}(\mathrm{T}<=\mathrm{t})$ two-tail $=0.7167$.
} 
tions, a significant higher dropout rate in the experimental year $(t=1)$ is observed. In 2007, dropout was 2.35 percentage points higher than in 2006 . The estimation results give confidence in the accuracy of the non-parametric estimations, where a similar outcome was obtained.

A second model includes covariates, such as individual (gender, ethnicity), family (household composition), and school-type characteristics. The interaction effect is slightly lower, whereas the estimate is equal to -2.45 percentage points at the $5 \%$ significance level.

\section{Influence of peer effects}

Peer effects are likely to occur among students sitting in the same class, as some students are liable to the policy change while others are not. This violates the Stable Unit Value Assumption (SUTVA), i.e. it is assumed that the potential outcomes are independent of actual treatment assignment $(\mathrm{Ru}-$ bin, 1978). The announcement of the Qualification Law and its implications took place in the first half of the year 2007, when 'compulsory education days' were organized to inform parents and students about the policy reform and its implications. Thereafter, teachers took responsibility at the start of the new school year 2007 to discuss the policy implications with students. Spillover effects are expected among students in the year 2007, but not in the year 2006. The average observed outcomes of the cohort 1989 are not affected by peer effects (in contrast with the average observed outcomes of the cohort 1990).

The sign of the effect from peers is not unambiguous. On the one hand, the literature indicates that students who are kept longer in school due to the policy change may have a bad influence on their peers. For example, potential dropout students are more likely to show disruptive behavior in class, in turn negatively affecting school motivation of their classmates or teachers (Wenger, 2002; Anderson, 2010). On the other hand, a student from the treatment group may positively influence the control group students, as the 
Table 5.3: DiD outcomes with various model specifications.

\begin{tabular}{|c|c|c|c|c|}
\hline & "Model 1 & 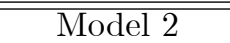 & 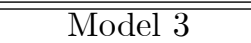 & 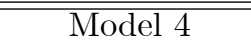 \\
\hline Specification & DiD & DiD & $\begin{array}{c}\text { Fixed effects at } \\
\text { school level }\end{array}$ & $\begin{array}{c}\text { Fixed effects at } \\
\text { neighborhood }\end{array}$ \\
\hline$D\left(\hat{\alpha}_{1}\right)$ & $\begin{array}{c}-0.0065 \\
(-0.88)\end{array}$ & $\begin{array}{c}-0.0108 \\
(-1.48)\end{array}$ & $\begin{array}{l}-0.0098 \\
(-1.32)\end{array}$ & $\begin{array}{c}-0.0139 \\
(-1.83)\end{array}$ \\
\hline$T\left(\hat{\alpha}_{2}\right)$ & $\begin{array}{l}0.0235 \\
(-3.22)\end{array}$ & $\begin{array}{l}0.0234 \\
(-3.29)\end{array}$ & $\begin{array}{l}0.0228 \\
(-3.17)\end{array}$ & $\begin{array}{l}0.0227 \\
(-3.05)\end{array}$ \\
\hline$D * T(\hat{\theta})$ & $\begin{array}{c}-0.0252 \\
(-2.38)\end{array}$ & $\begin{array}{r}-0.0247 \\
(-2.38)\end{array}$ & $\begin{array}{c}-0.0241 \\
(-2.3)\end{array}$ & $\begin{array}{c}-0.0228 \\
(-2.12)\end{array}$ \\
\hline Covariates $\left(X_{j i}\right)$ & None & $\begin{array}{r}\text { Individual, } \\
\text { family and } \\
\text { school-type } \\
\text { characteristics }\end{array}$ & $\begin{array}{r}\text { Individual, } \\
\text { and family } \\
\text { characteristics }\end{array}$ & $\begin{array}{r}\text { Individual, } \\
\text { family, } \\
\text { and school-type } \\
\text { characteristics }\end{array}$ \\
\hline Constant & Yes & Yes & Yes & Yes \\
\hline R-squared & 0.0019 & 0.0521 & 0.0812 & 0.113 \\
\hline Obs. $(N)$ & 12,849 & 12,784 & 12,784 & 12,784 \\
\hline
\end{tabular}

Note 1: T-values between brackets.

Note 2: Robust standard errors are used to control for heteroskedasticity. Chi-squared(1) $=81.93 ;$ Prob $>\mathrm{chi}^{2}=0.0000$.

Note 3: Gender and ethnicity are the individual characteristics. As family characteristics, household composition is included. School-type characteristics refer to pre-vocational and vocational education, general secondary education and pre-university education. Postcode information captures neighborhood characteristics. Fixed-effects are included for students and neighborhoods in order to cluster information and, with this, to control for peer effects at student level (Model 3) and neighborhood level (Model 4).

Note 4: Model 3 has also been estimated by means of pooled OLS, using clustered standard errors at the student level. Similar results were found. 
former type of student may influence the latter to stay at school (Rumberger and Palardy, 2005). Jencks and Mayer (1990) add to this discussion that the sign of peer effects is far from final and deciding. Using all students going to school in Amsterdam, it is likely that, depending on the school or class involved, both kind of peer effects influence the dropout decision, and therefore may cancel each other out.

To approximate peer effects, a $\mathrm{DiD}$ is estimated with fixed-effects (e.g. Wooldridge, 2002). Fixed effects models allow us to control for time-constant unobserved factors, in order to test whether the effects of time-constant variables have changed over time. As such, fixed-effects at the school or neighborhood level also capture other time-invariant information, such as the certificate of law enforcement in the school or neighborhood. In this way, it is tested whether the effects of school institutions (e.g. Rumberger, 2004; Plank et al., 2005) or neighborhoods (e.g. Blue and Cook, 2004; Rumberger and Lamb, 2003; Rumberger, 2004) influence the average observed outcomes of dropping out over time. For example, significant effects of particular neighborhoods on dropping out indicate influences on students living in these neighborhoods.

Including fixed-effects at the school-level in Model 3 results in a significant (at the 5\%-level) interaction effect of -2.41 percentage points. After controlling for various covariates at the individual and family level, and, after accounting for school fixed-effects, a significant favorable impact of the policy change is found. Model 4 approximates peer effects at the neighborhood level by including students' postcode information on place of residency. The estimate of $\hat{\theta}$ is equal to -2.28 percentage points, and is significant at the 1\%-level. In sum, the fixed effects models indicate that unobserved factors of time-constant variables do not cancel out the interaction effect. This might indicate that peer effects have no crucial impact on the estimates of $\hat{\theta}$ 
Among other robustness analyses below, an indicator for retention in grade is used to improve the precision of the peer effect estimates.

\subsubsection{Robustness analysis}

This subsection estimates various robustness analyses to check the results. First, the analysis is performed by taking a different cohort (1988) to control for age- and time-effects. Next, the window around the cut-off point 1 August is narrowed down, taking into account only students born during July and August. Third, the impact of compulsory education on early school-leaving among different school-type choices and ethnicities is tested. To conclude, the focus is on students with retention in grade.

\section{Cohort 1988}

A first robustness test compares the 1990 cohort (i.e. the cohort liable to the increase in compulsory education age) with the 1988 cohort. By increasing the time span between the two evaluated cohorts, the Heckman et al. (1999) critique that economic revival or sensitization might influence the results is explored. The estimation results reveal that the significant (at the 1\%-level) interaction effect equals -3.37 percentage points. This is slightly higher compared with the 1989 cohort. This further strengthens our previous argument that the increase in dropout among non-liable 17 year-olds in the year 2007 was rather exceptional, and might be attributed to the economic upturn and the resulting increased demand for low-skilled labor.

\section{Smaller window}

Up to now, the control group has been defined as students born from 1 January to $31 \mathrm{July}$, and the treatment group as student born from 1 August to 31 December. The window is narrowed down to a smaller group of students. In particular, only students who were born one month before and one month after the cut-off point of 1 August are included in the analysis. 
CHAPTER 5. THE COMPULSORY EDUCATION AGE

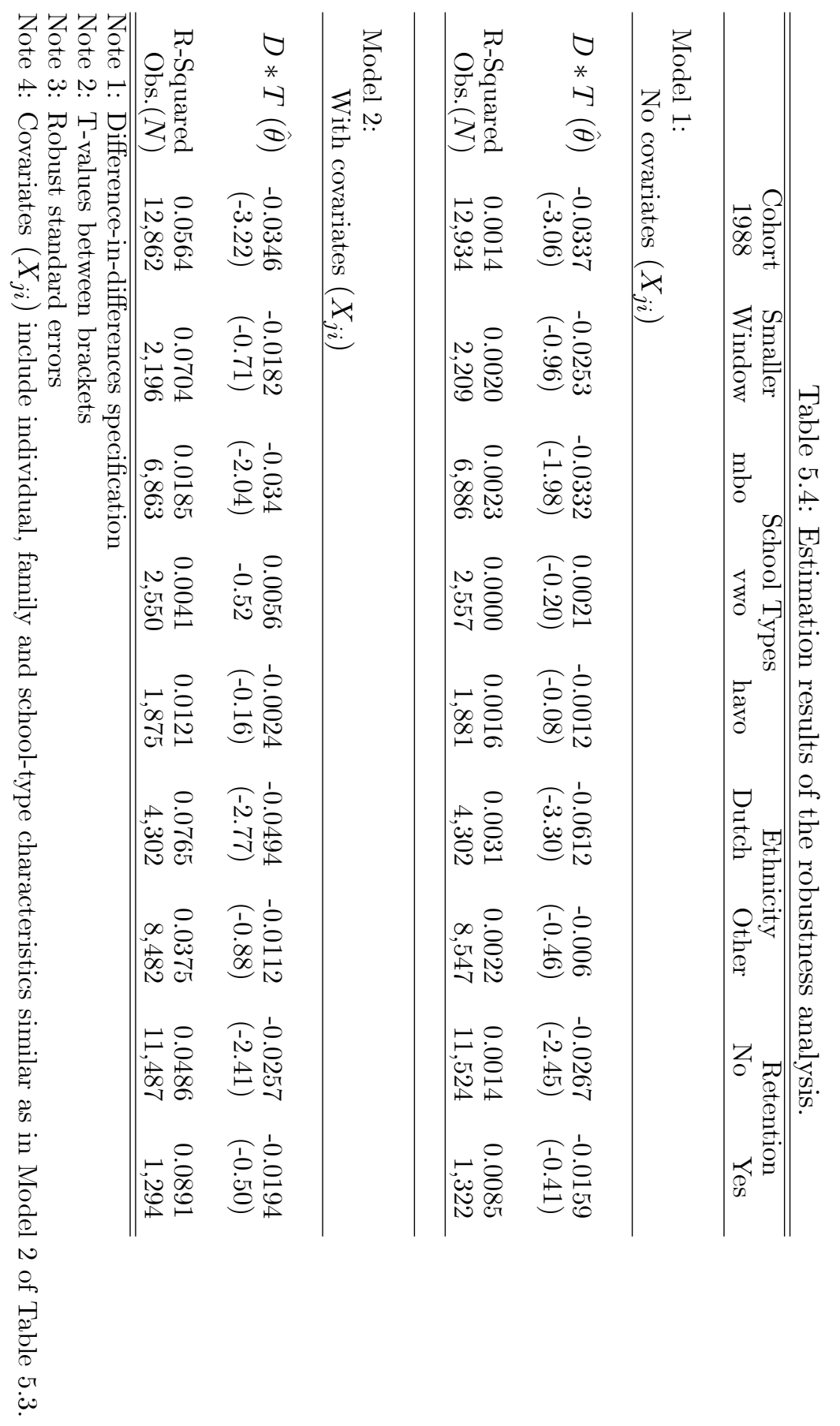


This means that only students born during the summer break months July and August are taken into account. The July students are exempted from the policy reform's implication, whereas the August students are not. As the evaluation of dropout rates between July and August students takes place on 1 October, in the sample they both have the age of 17 . The former group is merely less than one month older than the latter, but differs by liability status. The estimate of $\hat{\theta}$ without controlling for covariates is equal to -2.52 percentage points and, hence, is similar to the previous results of Model 1. The t-statistic on the interaction effect drops as a result of the smaller group in the analysis (which is intuitive, as fewer students are included in the sample).

\section{Heterogeneity of the treatment effect among student groups}

The sample in Model 1 to 4 includes all students of the cohorts 1989 and 1990 attending secondary school in the city of Amsterdam. Because of individual heterogeneity of the treatment effect, it can be expected that the impact of an increase in compulsory education is for some groups of students higher than it is for other groups. This third robustness analysis narrows down the sample to particular groups of students.

First, consider the estimate of $\hat{\theta}$ for different school-type choices. Vocational students (mbo) are more vulnerable to dropping out of secondary education. It is observed that the interaction effect for vocational students is largest, equal to -3.32 percentage points, and significant at the $10 \%$-level. After controlling for some covariates (see Model 2), the interaction effect increases in value to -3.40 percentage points $(\mathrm{P}>0.05)$.

Taking only pre-university education (vwo) and senior general secondary education (havo) into account, it can be observed that the estimates of $\hat{\theta}$ are no longer significant. After controlling for covariates, the insignificant interaction effects of vwo and havo are equal to, respectively, 0.56 and 0.24 percentage points. 
Second, we present the results of DiD analysis applied to different ethnic groups. The focus is first on native Dutch students. Performing the analysis without controlling for covariates, the estimate of $\hat{\theta}$ is significant (at the 1\%-level) and equal to -6.12 percentage points. The interaction effect declines to -4.94 percentage points after controlling for covariates (but is still significant). In contrast, significant results are not observed for non-native students. The DiD-estimates before and after controlling for covariates are, respectively, -0.060 and -0.100 percentage points. The results indicate that Dutch students benefit most from the 2007 compulsory education law.

\section{Retention in grade}

In the above analysis of peer effects, retention in grade was not taken into account. A control group student without retention in grade is less likely to be influenced by peers than a student with one or more years of retention in grade, because the latter student shares the same class as liable students. Retention in grade is, moreover, often referred to as a strong predictor of school dropout (e.g. Goldsmith and Wang, 1999; Roderick et al., 2000). Hence, an increased compulsory education age may result in less student motivation to stay in school.

This subsection provides a robustness analysis for peer-effects estimation. A dummy variable is created to indicate retention in grade. ${ }^{18}$ In the sample, there are 799 students ( 10.95 percent) and 525 students (9.39 percent) with retention in grade, respectively, in the control group and the treatment group. ${ }^{19}$ Restricting the sample to retention students and estimating the DiD model delivers insignificant results. The estimate of $\hat{\theta}$, using robust standard errors and without controlling for covariates, is insignificant (at the $10 \%$-level), and is equal to -1.59 percentage points. Note, however, the

\footnotetext{
${ }^{18}$ We note that, by construction, students did not enter the 5 th or the 6 th grade. As a result, we track students with retention in grade in 4 th grade or lower. This implies, for example, that transition from VMBO to $\mathrm{MBO}$ has not (yet) taken place.

${ }^{19}$ The correlation between school dropout and retention in grade is 4.69 and significant at the $1 \%$-level.
} 
smaller group in the analysis. The t-statistic on the interaction effect drops. Next, the same analysis is performed keeping only students without retention in grade in the sample. The interaction effect is equal to -2.67 percentage points and is significant at the 5\%-level. The results suggest that retention in grade partially captures the increase in dropout (as visualized in Figure 4) among non-liable 17 year-olds in the year 2007. However, using clustered standard errors at the school level, the estimate of $\hat{\theta}$ for students with one or more years of retention in grade is equal to -0.8 percentage points and is insignificant (at the $10 \%$-level). ${ }^{20}$

\subsection{Conclusion}

The impact of compulsory education age on dropout at secondary education has received little attention in the evidence-based literature. This fifth chapter has dealt with the effect of a 1-year increase in compulsory education age on school dropout. The influence of increased compulsory education is examined by exploiting this policy change in the Netherlands.

First, in a non-parametric analysis, a direct impact of 2.52 percentage points fewer dropouts is observed, owing to the increase in compulsory education. A closer inspection of the results, however, reveals that the latter observation is mainly driven by an increase in dropout among 17 year-olds students who were exempted from the policy's implications.

Second, a structural equation was estimated for dropout using DiD methodology. Without controlling for covariates, the OLS regression of the DiD estimate confirms the non-parametric computation of -2.52 percentage points. Next, we have elaborated the DiD model by implementing observable characteristics, such as gender, ethnicity, household composition and school-type choices. The effect slightly declines to -2.47 percentage points, significant at the 5\%-level.

\footnotetext{
${ }^{20}$ The interaction effect of students without retention in grade is equal to -2.45 percentage points significant at the $5 \%$-level.
} 
Potential peer effects were approximated by estimating a fixed-effects model at: (1) the school level; and (2) the neighborhood level. At the school level, the effect is still significant at a 5\%-level, and is equal to -2.41 percentage points. Controlling for peer effects at the neighborhood level has a larger impact on the DiD estimate, as the effect declines to a significant (at the 5\%-level) -2.28 percentage points.

Various robustness tests pointed to similar results. The largest impact has been observed among vocational students (-3.32 percentage points) and Dutch natives (-6.12 percentage points). Only for students with retention in grade is a significant decrease in early school-leaving not observed.

Although the results reveal a significant decrease in dropout owing to the compulsory education law, some caution is necessary. The observed effect arises almost completely from the fact that control group students left school at the legal school-leaving age after the policy reform. Given the economic revival at the time of the policy reform, this may suggest an anticipation of job market opportunities. On the contrary, students liable to the policy reform did not significantly alter their dropout decision.

As a major issue for discussion, the results of this chapter point to the unintended consequences of straightforward policy making. Even though the new Qualification Law did not intentionally influence control group students, the results suggest that the policy reform caused a labor demand shock for semi- and unskilled students. The effect is local in nature as it only affected a small group of students.

Finally, it is necessary to draw attention to some limitations of this study. This study provides no insights in the lifetime gains of education for the affected students, leaving many open questions with respect to their perspectives. In the literature, the importance of a higher secondary certificate is stressed in order to enter the labor market successfully and to avoid life-time disadvantages. Further research should bring more insights into 
the role of labor market incentives and the returns to education within the scope of school dropout determinants.

In Chapter 6, the effectiveness of enhanced commitment of the student to the school, peers, and teachers in order to reduce school dropout is evaluated. 



\section{Chapter 6}

\section{Student Commitment in Vocational Education}

"[...] schools are at least partly responsible for high student turnover and, consequently, should help address the problem."

(Rumberger and Larson, 1998, p.2)

\subsection{Introduction}

Enrollment rates in vocational education and training (VET) are high in many OECD countries. In the United States, almost half of all high school students and about one-third of college students are enrolled in VET study subjects (Weltz, 2005). Among EU-15 countries, this share increases to 60 percent for boys and 50 percent for girls over the period 2000 to 2008 (Eurostat, 2011). Following these high enrollment rates, government expenditure on VET captures a large share of total expenditure on secondary education. It captures the largest share in the United States, and among European Member States public spending, especially on VET, is highest in Finland (1.1 percent of GDP), Austria and the Netherlands (both allocated 1 percent of GDP) in 2005. Sweden and Denmark follow with, respectively, 0.8 percent and 0.6 percent of GDP (Eurostat, UOE).

\footnotetext{
${ }^{1}$ Chapter 6 is based on: Cabus, S.J. (2013). Does enhanced student commitment reduce school dropout? Evidence from two major dropout regions in the Netherlands. Regional Studies, In Press.
} 
Despite receiving marked attention, incidence of early school-leaving is highest among students in VET study subjects. According to the definition of the European Commission, a student without a higher secondary certificate who is not further enrolled in education or training between the age of 18-24 is considered a school dropout. ${ }^{2}$ Leaving secondary education without a higher secondary school-leaving certificate is not desirable in a knowledgebased economy, as, among other bad prospects, it may hamper successful labor market entrance and/or cause youth unemployment (see also Chapter 1, 2, and 5). Students are better protected from such bad prospects when they have a certificate at hand (Cedefop, 2008, 2010; European Commission, 2005, 2010b, 2011a, 2011b).

Objectives to reduce school dropout have been formulated by several top governmental officials. The president of the United States Barack Obama (2010) makes a plea in the "Reauthorization of the Elementary and Secondary Education Act" for every American to obtain at least a higher secondary certificate. The United Nations also aim at better educated children in the 2000 Millennium Development Goals. In Europe, at the Lisbon 2000 Summit, the Member States agreed to becoming the "[...] most competitive and dynamic knowledge-based economy in the world, capable of sustainable economic growth with more and better jobs and greater social cohesion (de la Porte et al., 2001, p.2)." In line with the Lisbon Agenda Targets, recently reestablished among the European 2020 Targets, a major challenge for European Union policymakers would be to decline the level of school dropout to a maximum average dropout rate of 10 percent by 2020 . The role of VET within this scope was further strengthened in the Copenhagen Declaration in 2002, signed by all 27 EU Member States. The Declaration stipulated transparency of school-leaving certificates and competences, and performance, quality, and attractiveness of VET systems were to be evalu-

\footnotetext{
${ }^{2}$ In this chapter, high school and secondary education are synonyms. The higher secondary level is equal to the European definition with respect to ISCED-3.
} 
ated every second year. ${ }^{3}$

\section{The role of student motivation and -commitment}

One way to prevent students from early school-leaving is to enhance motivation by commitment of the student to the school, peers, and teachers (Tinto, 1975; Finn, 1989, Rumberger, 2001, 2011; and Chapter 1). However, student motivation and -commitment have a wide angle and are hard to influence, as both depend on many aspects of education (see, among others, Bynum and Thompson, 1983; Rumberger, 1983; Levin, 1987; Ehrenberg and Brewer, 1994; Rumberger and Larson, 1998). Early studies on student motivation have shown the importance of class composition based on the male-female ratio, ethnicity and socioeconomic background (Rumberger, 1983; Levin, 1987). Bynum and Thompson (1983) discuss disproportionally higher dropout rates for sexual majorities and ethnic minorities in class. This has been confirmed in the recent work of Rumberger (2011). The role of the school, peers, and teachers is discussed, as these factors may play a crucial role in the students' general dislike of school. It may coincide with the parental school choice, the school-, or residence environment (Rumberger and Larson, 1998) or mental or physical health of the student (Groot and Maassen van den Brink, 2007).

Across high income countries, several initiatives have been taken over the last decade that especially deal with commitment, and its relationship with the process of student attrition, in order to deal with school dropout. For instance, Belgium, Slovenia, and France have established dropout prevention programs that include individual guidance of students at-risk of school dropout in transition classes. These transition classes aim for, in essence, an improved transition between two consecutive school years. Nordic countries often postpone tracking of students (e.g. by their ability) in educa-

\footnotetext{
${ }^{3}$ The previous evaluation times took place in Maastricht (2004), Helsinki (2006), Bordeaux (2008), and Bruges (2010).
} 
tional tracks up till the age of 16 (e.g. Sweden). Among other advantages/disadvantages, students in Sweden can decide later on in the school career what kind of track would fit best their interests and/or ability. There is also the possibility in Nordic countries to have a break year between lower- and higher secondary education (an extensive overview of dropout prevention programs in the EU-27 Member States is provided in a recent policy document of the European Commission, 2011a). In the US, the National Dropout Prevention Center/Network elaborates on the establishment of community schools. The principal component of a community school is that students can participate in all kinds of activities during or beyond school-time, such as civic engagement or playing music. Here, motivation and commitment to school, peers, and teachers of students (and their parents) are enhanced, but also the neighborhood can play a role in the educative community (Heers et al. 2011). Furthermore, the president of the US Barack Obama provides School Turnaround Grants of about $\$ 900$ billion, and committed financial support to disadvantaged schools (Office of the Press Secretary, Statements \& Releases, March 2010).

\section{Student Commitment in vocational education: a case study}

Despite the widespread use- and diversity of prevention measures aiming at enhancing commitment at all (ability) levels of secondary education, there is only little evidence on the effectiveness of dropout prevention measures in general, and prevention measures with respect to student commitment in particular. This is mainly due to multiple definitions, lack of transparancy, uniformity or wrongly self-reported data of school dropout (Wilson et al., 2011). This chapter contributes to the literature by evaluating the effectiveness of enhanced student commitment on school dropout in one of the EU Member States, the Netherlands. The Netherlands is a particularly interesting case study for an evaluation of dropout prevention measures in VET. First, as from the school year 2005, the Netherlands deals with uni- 
form definitions, registration of school dropout, and numerous background variables in BRON (Basisregister onderwijs). Therefore, the country has implemented a personal identification code that tracks every student in secondary education.

Second, the country has a long history of organizing vocational education and training, and is distinguished from other European countries by providing pre-vocational education (Onstenk and Blokhuis, 2007). A student, who wants to obtain a school-leaving certificate in VET, enrolls in a pre-vocational (VMBO) pathway at the age of 12 and changes to vocational education at the age of 16 . Only after completion of vocational level-2 (graduation age 18), does a student obtain a valid school-leaving certificate (and will not be registered as a school dropout). ${ }^{4}$

Third, in line with the Agenda Targets stipulated in the European 2020 flagship initiatives, i.e. to reduce school dropout to a maximum rate of 10 percent by 2020, the Dutch government focused on dropout prevention measures particularly in VET (for an extensive overview: see aanvalopdeschooluitval.nl). The evidence indicates that the country has performed well in this respect among the EU-15 Member States (Eurostat, 2012). Cabus and De Witte (2012a) have constructed a 'fair' benchmark to rank relative performance with respect to early school-leaving of EU-15 Member States. They show that the Netherlands follows in second position after Luxembourg and attributed its outstanding performance to policymaking in VET.

Fourth, a high level of autonomy in policymaking is delegated to the regional dropout authorities (Ministry of Education, Culture, and Science). Administrative borders separated 39 regional dropout authorities as from 2002. As a result, differences in policymaking may exist between two independent management structures. This feature is a priori useful for an

\footnotetext{
${ }^{4}$ In total four different levels of vocational education and training exist in the Netherlands, namely: (1) assistant training; (2) basic vocational training; (3) intermediate vocational training; and (4) specialist training.
} 
experimental set-up.

\section{The intervention}

At the start of the school year 2008, policy efforts in the Netherlands aimed at enhancing student commitment to the school, peers, and teachers by simplifying the transition between the pre-vocational level and the vocational level. This transition time may be considered to be difficult in the Netherlands, as students need to switch schools from a pre-vocational school to a vocational school, because the pre-vocational school does not offer vocational education or training. ${ }^{5}$ In addition, a long summer break, of about three months between May and August of the school year, follows after successful graduation from pre-vocational education. Students may then lose connection with their school, peers, and teachers (O2L, 2007; Oberon, 2008). Dutch policymaking shifted therefore to a focus on crossing system boundaries (also referred to as climbing up the "vocational educational column" or "smoothing transition") (Onstenk and Blokhuis, 2007).

The intervention in practice implies that youngsters are assessed by the pre-vocational school, and go through an intake procedure in the vocational school at the start of the school year. Potential dropout students are individually guided during the summer break and at the start of the school year. This is done in several ways. First, communication between the prevocational school and the vocational school is improved by making up a file containing detailed information on the student and his/her school curriculum. This file is created by the pre-vocational school and is transferred to the vocational school. The vocational school staff can then easily use this file, among other things, with advices on- and follow-up of the at-risk student. As such, the pre-vocational school remains closely associated with the student in transition. Second, there is an intake conversation of the student

\footnotetext{
${ }^{5}$ Students choose their vocational school, learning pathway and study subjects in the school year previous to the start of the first year of vocational education.
} 
with the vocational school. Third, once in the vocational school, the potential dropout student receives attention from mentors, coaches, care and advisory teams, and other peers, in order to individually guide the student and anticipate potential problems after the transition to the new vocational school. To conclude, in some cases, students have the possibility to remain in their school and to attend classes from familiar teachers (for more information on the intervention, see Ministry of Education, Culture, and Science: Aanval op Schooluitval.nl). ${ }^{6}$

The chapter proceeds as follows. In Section 6.2, the identification strategy to estimate the impact of enhanced student commitment on school dropout is proposed. Data and descriptive statistics are presented in Section 6.3, and the results in Section 6.4. The final Section 6.5 provides the conclusion and a discussion.

\subsection{Identification strategy}

Two large $\mathrm{RTCs}^{7}$ are used in a quasi-experimental set-up to evaluate the intervention, namely: (1) RTC Amsterdam, the treatment group, and (2) RTC Utrecht, the control group. There are three reasons for the focus on Amsterdam and Utrecht, all of which are considered highly important for an quasi-experimental set-up. First, regional dropout authority Amsterdam and Utrecht are considered major dropout regions. ${ }^{8}$ As from 2002, a regional administrative dropout border strictly separated in total 39 regional dropout authorities. The distance between Amsterdam and Utrecht is limited, as one

\footnotetext{
${ }^{6}$ This dropout prevention measure involves a small government experiment called VM2 with start date 1 August 2008. The experiment streamlined pre-vocational and vocational education and training in one location. In total 20 schools were selected for the VM2 experiment, mainly with locations in Amsterdam or Rotterdam (rijksoverheid.nl).

${ }^{7}$ The Adult and Vocational Education Act (Wet Educatie en Beroepsonderwijs, WEB) brought first harmony in VET in 1996. One major implications of the WEB was the opening up of new large regional training centers (RTCs). The RTCs replaced about 400 small vocational schools with 40 large Centers which were delegated autonomy and responsibility (Ministry of Education, 2006).

${ }^{8}$ In total there are four major dropout regions in the Netherlands: Amsterdam, Utrecht, Rotterdam, and Den Haag.
} 
may easily drive across the border in 15 to 30 minutes. Figure 6.1 plots the regional dropout authorities on a map of the Netherlands. RTC Amsterdam is located in regional dropout authority Amsterdam, and RTC Utrecht in regional dropout authority Utrecht. The Centers' locations are clustered in the city of Amsterdam and Utrecht. Students have freedom of choice of their school in the Netherlands. They may travel across borders to go to school in another regional dropout authority. However, only a few youngsters travel across the regional dropout border.

Second, both RTCs capture small vocational schools under one regional management structure, and similar study subjects in VET are offered to students enrolled in vocational education or training (ISCED 3). This feature supports comparability of the centers.

Third, written agreements, called covenants, between the Ministry of Education, Culture, and Science, the dropout region and the schools or Centers stipulated dropout prevention measures in 2007-08 (for an extensive description, see De Witte and Cabus, 2013). The covenant of regional dropout authority Amsterdam mainly aimed at students in vocational education and training, as 30 percent of a total budget of $€ 7.4$ million over four school years is especially assigned to simplifying the transition of vocational students. In contrast, the written agreement of regional dropout authority Utrecht only assigned 17 percent of a total budget of $€ 3.5$ million over four school years. In addition, students enrolled in RTC Amsterdam participated in the government experiment, whereas those enrolled in RTC Utrecht were not selected (rijksoverheid.nl).

\subsubsection{Using regional borders as an instrument}

Advantage is taken of differences in treatment intensity between the control group and the treatment group to estimate the impact of enhanced student commitment on school dropout. A similar approach is discussed by Frölich and Lechner (2004) who used differences in treatment intensity 


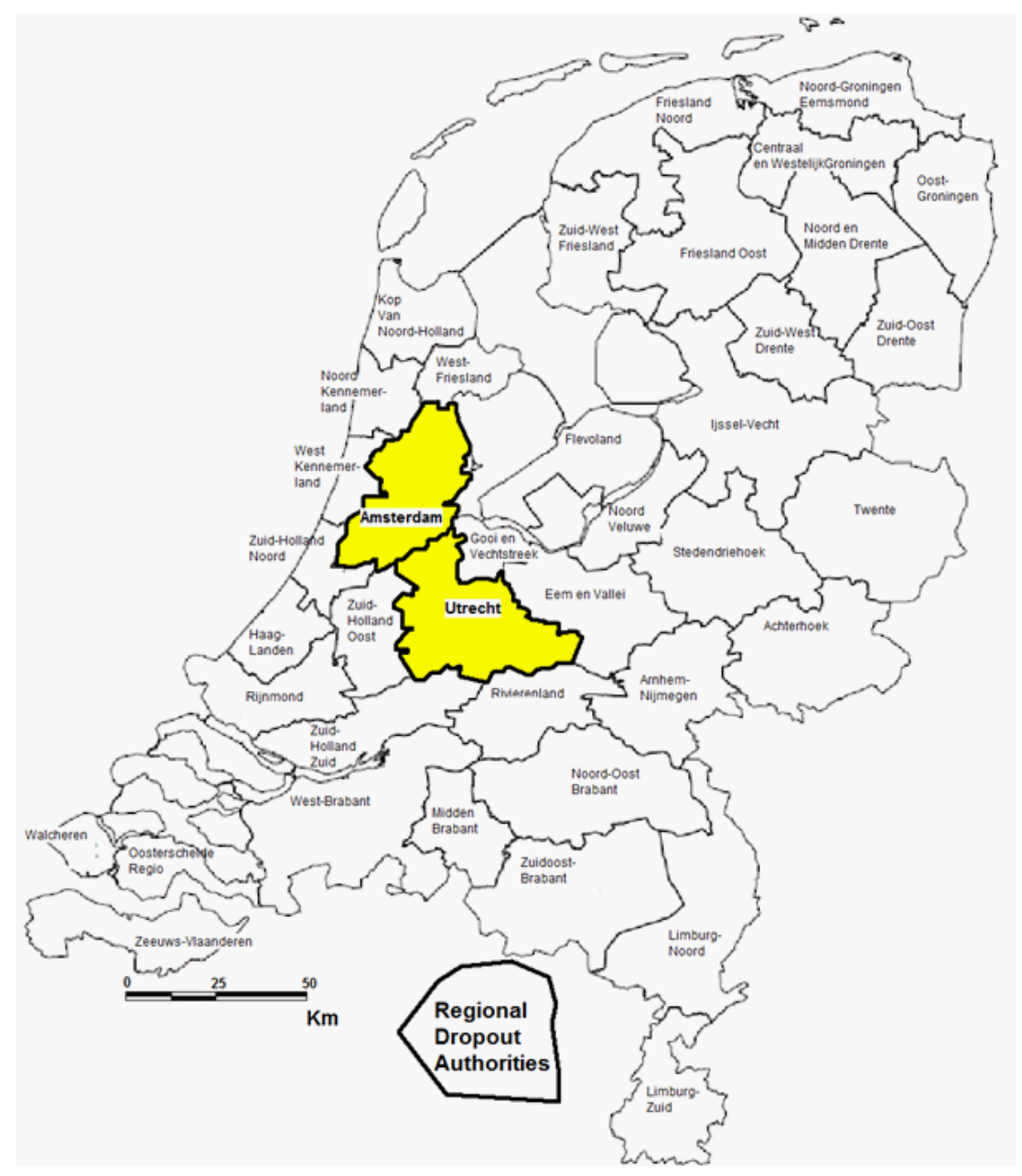

Figure 6.1: Overview of the regional dropout authorities in the Netherlands: RTC Utrecht is located in dropout authority Utrecht, and RTC Amsterdam in dropout authority Amsterdam. (Source: own handling of DUO). 
as an instrument for the evaluation of labor market policies. As differences in treatment intensity come from differences in the underlying student population, one needs to consider an omitted variables bias due to differences in student characteristics between the control group and the treatment group. Using essential covariates available in the data (see section 6.3), such as gender, ethnicity, household composition, residence, income, vocational level, pathway, and study subject, reduce the omitted variable bias considerably. Differencing student outcomes between the control group and the treatment group (first difference), within control group and treatment group (second difference), and over time (third difference), further accounts for an omitted variables bias. This identification strategy is easily implemented in a difference-in-differences-in-differences $(D i D i D)$ estimation (Imbens and Wooldridge, 2007). ${ }^{9}$ This estimation procedure will now be explained.

\section{A between-group indicator (first difference)}

Students of RTC Amsterdam (Center A) are assigned to the treatment group $\left(D_{i}=1\right)$ and RTC Utrecht (Center B) to the control group $\left(D_{i}=0\right)$. Center A and Center B have full autonomy in its school dropout policy. Students in transition from the pre-vocational level (VMBO) to the vocational level $(\mathrm{MBO})$ are denoted by a transition status, i.e. they made the transition from any VMBO school to Center A or Center B. One may easily compare students in transition to Center A with those in transition to Center B. However, a simple comparison raises two serious issues: (1) other dropout prevention measures may influence students' dropout decision; and (2) regional differences in treatment intensity are explained by differences in student population across the border.

Unobserved student characteristics may differ among regions, which hampers statistical inference. In previous literature on identification of treatment

\footnotetext{
${ }^{9}$ Throughout this chapter, the notation for a difference-in-differences-in-differences identification strategy may be abbreviated by $(D i D i D)$.
} 
effects, omitted variable bias is a serious reason for concern (i.e. ability or self-selection bias, selection of unobservable characteristics) (for example, see Angrist and Pishke, 2009). It is not possible to observe the counterfactual, i.e. students making the transition to Center B instead of Center A, and vice versa. To encounter these raised issues, a within-group deviation or second difference is used.

\section{A within-group indicator (second difference)}

Using other students going to school in either Center A or Center B who are not subject to the discussed student commitment policy may account for other dropout prevention measures, as well as further reduce the omitted variables bias. The first results of the 2007-08 covenant are to be evaluated in the subsequent school year 2008-09 (Ministry of Education, Culture, and Science). The first cohort fully subject to the covenant policy changes are students born in the year 1992. Without retention in grade, these students made the transition from VMBO to MBO at the start of the school year 2008-09, and are 16 year-olds. As follows student outcomes from the 1992 cohort are compared with the 1991 cohort. Students of the cohort 1991 are 17 year-olds at the start of the school year 2008-09, but are not subject to the 2007-08 covenant policy changes with respect to simplifying the transition from VMBO to MBO. Without retention in grade, students from the 1991 cohort made the transition one year before the policy change, i.e. at the start of the school year 2007-08. ${ }^{10}$

Using two different age groups gives rise to another issue: older students have a higher risk of school dropout (Roderick, 1994; Jimerson, 1999; Attwood and Croll, 2006). At the evaluation point, students are aged 16 or 17, and age differences may bias the results. A simple time indicator or third difference may solve this problem.

\footnotetext{
${ }^{10}$ Among other national policy effects, the effect of the 2007 increased compulsory education age is captured by the interaction effect $(C * T)$ (see Section 6.4).
} 


\section{A time indicator (third difference)}

Using two time periods has two major advantages, namely: (1) it is possible to control for effects that are constant over time; and (2) the initial level of dropout is taken into account, i.e. the level of school dropout before the policy change. The former further reduces bias due to omitted variables by capturing time-fixed effects. The latter is crucial for the experimental set-up, as before the policy change the level of school dropout in Center A might have been higher than in Center B. In that case, Center A needs relatively less effort to reduce school dropout than Center B.

A time indicator is implemented using two other cohorts before the policy change. To avoid any effects from the 2007-08 covenant policy changes on these other two cohorts, the school year 2006-07 denotes the time period before the policy change. The cohorts 1990 and 1989 have, respectively, 16 and 17 year-olds students in 2006-07. A standard before-after dummy variable is used to mark the two time periods, where $(T=0)$ denotes the school year 2006-07, and $(T=1)$ the school year 2008-09.

A between-group, a within-group, and a time indicator are the principal components of a DiDiD framework (e.g. Imbens and Wooldridge, 2007). A structural dropout equation is estimated as follows,

$$
\begin{aligned}
Y_{i} & =\alpha+\beta D_{i}+\gamma C_{i}+\delta T_{i}+\eta_{1}\left(D_{i} * C_{i}\right)+\eta_{2}\left(C_{i} * T_{i}\right)+\eta_{3}\left(D_{i} * T_{i}\right) \\
& +\theta\left(D_{i} * C_{i} * T_{i}\right)+U_{i}
\end{aligned}
$$

where $\left(Y_{i} \in\{0,1\}\right)$ denotes the observed dropout status of an individual $(i=1,2, \ldots, N) ;\left(D_{i}\right)$ the treatment status; $\left(C_{i} \in\{0,1\}\right)$ a cohort-intransition indicator; and $\left(T_{i} \in\{0,1\}\right)$ a time indicator In addition there are four interaction effects, first the treatment and cohort indicator $\left(D_{i} * C_{i}\right)$, second the time and cohort indicator $\left(C_{i} * T_{i}\right)$, third the treatment and time 
Table 6.1: Cross-table of treatment and control group using four cohorts 1989 to 1992 and two time periods 2006 and 2008.

\begin{tabular}{l|ll|l|ll}
\hline$(D=0)$ & 2006 & 2008 & $(D=1)$ & 2006 & 2008 \\
\hline$(C=0)$ & 1989 & 1991 & $(C=0)$ & 1989 & 1991 \\
$(C=1)$ & 1990 & 1992 & $(C=1)$ & 1990 & $\mathbf{1 9 9 2}$ \\
\hline
\end{tabular}

indicator $\left(D_{i} * T_{i}\right)$, and fourth the treatment, cohort and time indicator $\left(D_{i} * C_{i} * T_{i}\right)$. The estimate of interest is $(\hat{\theta})$, known as the DiDiD estimate. This estimate captures the average treatment effect of the treated, namely: the extra effort that is exerted in the case of the treatment group in Amsterdam (i.e. more budget available for transition policies, and the government experiment). Thus, the $D i D i D$ estimate captures the effect of the transition policy on school dropout among 16 year-olds students in RTC Amsterdam the year after the policy had been implemented (i.e. the cohort 1992 in 2008), and compares it with 17 year-olds students in RTC Amsterdam (i.e. the cohort 1991 in 2008), and 16 and 17 year-olds control students in RTC Utrecht (i.e. cohorts 1991 and 1992 in 2008), and the situation before the policy reform in RTC Amsterdam and RTC Utrecht (i.e. the cohorts 1989 and 1990 in 2006). The DiDiD setting is summarized in Table 6.1. The cohort 1992 in 2008 is highlighted, representing the estimate of $(\hat{\theta})$.

\subsubsection{Some additional drawbacks}

Five additional drawbacks are discussed to sustain the identification restrictions of a DiDiD analysis. First, spillover effects may occur, which violates the Stable Unit Treatment Value Assumption (SUTVA). This assumption implies that the potential outcomes are independent of actual treatment assignment (Rubin, 1974, 1978). Freedom of school choice implies that a student may cross borders to switch school. Although the number of students 
involved is rather low, spillover effects cannot be neglected. An indicator for Switch school $\left(S_{i}\right)$ is included in equation 6.2, capturing the spillover effects (or switch-school effects). Precision of the estimate is further increased by using a rich set of covariates $\left(X_{j i}\right)$ correlated with the outcome $\left(Y_{i}\right)$, such as individual, family, or neighborhood characteristics. It may then be written as:

$$
\begin{aligned}
Y_{i} & =\alpha+\beta D_{i}+\gamma C_{i}+\delta T_{i}+\eta_{1}\left(D_{i} * C_{i}\right)+\eta_{2}\left(C_{i} * T_{i}\right)+\eta_{3}\left(D_{i} * T_{i}\right) \\
& +\theta\left(D_{i} * C_{i} * T_{i}\right)+\psi S_{i}+\sum \phi_{j} X_{j i}+U_{i}
\end{aligned}
$$

Second, more precision of the estimate is established by clustering the standard error using zip-code information on student residence. Clustered standard errors control for heteroskedasticity and, additionally, for correlation within the clusters. As a result of this estimation procedure, one obtains estimates controlled for peer effects at the neighborhood level. In addition, differences in the degree of law enforcement are also captured using clustered standard errors.

Third, there are differences in school characteristics between RTC Amsterdam and RTC Utrecht which may hamper or foster school policy in practice. As a robustness analysis, it is useful to control for regional differences in school characteristics by including them in $\left(X_{j i}\right)$. This may (partly) capture the policy effect. For example, more students in business administration instead of health care may increase school dropout. Controlling for study subject in the regression interacts with the policy effect, as it may be a part of the transition policy. It is useful to see to what extent these estimates are significant and capture the policy effect.

Fourth, the crucial difference-in-differences identification restriction, called the 'common time trend assumption', is relaxed in a DiDiD estimation. Nonetheless, the common trend is briefly discussed in section 6.4. 
Fifth, differences in labor market characteristics between region A and region B may affect a student's dropout decision. Differences in wage settings (push factors) or labor market opportunities (pull factors) have received considerable attention in the literature (e.g. Shavit and Müller, 1998; Gangl, 2002). This fourth drawback is also discussed in section 6.4.

\subsection{Data and descriptive statistics}

This chapter uses the BRON-data (BasisRegister ONderwijs). The BRONdata is an administrative panel data source, covering all students going to school in the Netherlands over the years 2004 to 2009. Registration and definition of dropout improved remarkably in 2005. Since 2005, the Dutch definition of an early school-leaver or school dropout is stipulated as: a youngsters below the age of 23 , who was enrolled in school on 1 October of a given year, but who is not enrolled in the following year on 1 October, and who has not obtained a higher secondary certificate. ${ }^{11}$ The data contain a rich set of individual- and school characteristics, such as gender, age, family composition, ethnicity, residence, income, study subject, pathway, and enrollment (dropout) status. Table 6.2 summarizes the characteristics of the student population $[N=12,233]$ who enrolled in RTC Amsterdam or RTC Utrecht after the successful accomplishment of a pre-vocational pathway. Table 6.3 presents school characteristics in totals (2006 or 2008) or averages (2006 to 2008).

\section{Student and school characteristics}

Despite the short distance between RTC Utrecht and RTC Amsterdam, there are large differences in student characteristics. One may consider RTC Utrecht a white school, as about 80 percent of the student sample

\footnotetext{
${ }^{11}$ Note that, according the 1969 Compulsory Education Age Law, students start primary education compulsory on their 5 th birthday. If the student reaches the age of 5 one month or more after the start of a new school year, students can only enroll in primary education the next school year.
} 
Table 6.2: Descriptive statistics of student characteristics.

\begin{tabular}{|c|c|c|c|c|}
\hline & 2006 & 2008 & 2006 & 2008 \\
\hline & \multicolumn{2}{|c|}{$(D=0)$} & \multicolumn{2}{|c|}{$(D=1)$} \\
\hline \multicolumn{5}{|l|}{ (1) Transition } \\
\hline \multirow[t]{2}{*}{16 year-olds } & 1,563 & 1,275 & 2,077 & 1,796 \\
\hline & $(56.50 \%)$ & $(52.40 \%)$ & $(58.0 \%)$ & $(52.0 \%)$ \\
\hline \multirow[t]{2}{*}{17 year-olds } & 1,202 & 1,158 & 1,506 & 1,656 \\
\hline & $(43.50 \%)$ & $(47.60 \%)$ & $(42.0 \%)$ & $(48.0 \%)$ \\
\hline total & 2,765 & 2,433 & 3,583 & 3,452 \\
\hline \multicolumn{5}{|l|}{ (2) Dropout(1 if yes) } \\
\hline 16 year-olds & $7.90 \%$ & $6.10 \%$ & $10.30 \%$ & $5.20 \%$ \\
\hline 17 year-olds & $9.10 \%$ & $11.90 \%$ & $11.00 \%$ & $9.20 \%$ \\
\hline \multicolumn{5}{|l|}{ (3) Spillover } \\
\hline total & $2.10 \%$ & $1.20 \%$ & $1.10 \%$ & $0.40 \%$ \\
\hline \multicolumn{5}{|l|}{ (4) Gender (1 if male) } \\
\hline total & $50.90 \%$ & $50.20 \%$ & $48.80 \%$ & $49.00 \%$ \\
\hline \multicolumn{5}{|l|}{ (4) Family $^{(2)}$} \\
\hline total & $1.80 \%$ & $1.80 \%$ & $6.60 \%$ & $7.00 \%$ \\
\hline \multicolumn{5}{|l|}{ (5) Ethnicity } \\
\hline Dutch & $82.80 \%$ & $82.40 \%$ & $59.80 \%$ & $57.00 \%$ \\
\hline Maroccan & $2.40 \%$ & $2.30 \%$ & $7.70 \%$ & $8.60 \%$ \\
\hline Turkish & $2.70 \%$ & $3.20 \%$ & $4.10 \%$ & $5.30 \%$ \\
\hline Suriname/Aruba & $3.30 \%$ & $2.80 \%$ & $16.10 \%$ & $15.40 \%$ \\
\hline Other non-Western & $2.40 \%$ & $2.50 \%$ & $6.70 \%$ & $7.30 \%$ \\
\hline Other Western & $4.60 \%$ & $4.40 \%$ & $5.60 \%$ & $6.50 \%$ \\
\hline \multicolumn{5}{|l|}{ (6) Residence } \\
\hline Amsterdam & $0.20 \%$ & $0.20 \%$ & $33.90 \%$ & $36.40 \%$ \\
\hline Utrecht & $14.50 \%$ & $13.50 \%$ & $1.10 \%$ & $1.30 \%$ \\
\hline Medium municipalities & $10.20 \%$ & $11.30 \%$ & $24.50 \%$ & $25.30 \%$ \\
\hline Little municipalities & $74.90 \%$ & $74.90 \%$ & $40.10 \%$ & $36.70 \%$ \\
\hline Other & $0.10 \%$ & $0.10 \%$ & $0.40 \%$ & $0.30 \%$ \\
\hline \multicolumn{5}{|l|}{ (7) Poverty } \\
\hline total & $39.40 \%$ & $40.10 \%$ & $66.10 \%$ & $67.30 \%$ \\
\hline
\end{tabular}

Note 1: All shares relate to the percentage share of students in transition (indicator 1) who have successfully finished a VMBO pathway in the previous school year, and enroll in a MBO pathway in a particular school year $(T=\{0,1\})$ to RTC Utrecht $(D=0)$ or RTC Amsterdam $(D=1)$.

Note 2: Percentage share of students living in a single parent household. 
Table 6.3: School characteristics and enrollment trends of 16 and 17 yearolds students in transition to RTC Amsterdam or RTC Utrecht.

\begin{tabular}{|c|c|c|c|c|}
\hline & \multicolumn{2}{|c|}{$\begin{array}{l}\text { RTC Utrecht } \\
(D=0) \\
2006-08\end{array}$} & \multicolumn{2}{|c|}{$\begin{array}{c}\text { RTC Amsterdam } \\
(D=1) \\
2006-08\end{array}$} \\
\hline Staff & \multirow{2}{*}{\multicolumn{2}{|c|}{2,313}} & & \\
\hline Employment & & & \multicolumn{2}{|c|}{2,860} \\
\hline FTE & \multicolumn{2}{|c|}{1,754} & \multicolumn{2}{|c|}{2,248} \\
\hline Share designated ${ }^{(2)}$ & \multicolumn{2}{|c|}{$77.00 \%$} & \multicolumn{2}{|c|}{$79.00 \%$} \\
\hline Share of teachers & \multicolumn{2}{|c|}{$63.80 \%$} & \multicolumn{2}{|c|}{$63.40 \%$} \\
\hline Age of teachers & \multicolumn{2}{|c|}{48.1} & \multicolumn{2}{|c|}{47.5} \\
\hline & 2006 & 2008 & 2006 & 2008 \\
\hline & \multicolumn{2}{|c|}{$(D=0)$} & \multicolumn{2}{|c|}{$(D=1)$} \\
\hline \multicolumn{5}{|l|}{ Vocational-level } \\
\hline \multirow[t]{2}{*}{ Vocational-1 } & 79 & 56 & 153 & 55 \\
\hline & $(2.90 \%)$ & $(2.30 \%)$ & $(4.30 \%)$ & $(1.60 \%)$ \\
\hline \multirow[t]{2}{*}{ Vocational-2 } & 813 & 774 & 979 & 869 \\
\hline & $(29.40 \%)$ & $(31.80 \%)$ & $(27.30 \%)$ & $(25.20 \%)$ \\
\hline \multirow[t]{2}{*}{ Vocational-3 } & 464 & 393 & 708 & 694 \\
\hline & $(16.80 \%)$ & $(16.20 \%)$ & $(19.80 \%)$ & $(20.10 \%)$ \\
\hline \multirow[t]{2}{*}{ Vocational-4 } & 1,409 & 1,210 & 1,743 & 1,834 \\
\hline & $(51.00 \%)$ & $(49.70 \%)$ & $(48.60 \%)$ & $(53.10 \%)$ \\
\hline \multicolumn{5}{|l|}{ Study subject } \\
\hline \multirow[t]{2}{*}{ Business } & 726 & 718 & 1,813 & 1,689 \\
\hline & $(26.30 \%)$ & $(29.60 \%)$ & $(50.60 \%)$ & $(48.90 \%)$ \\
\hline \multirow[t]{2}{*}{ Engineering } & 914 & 753 & 956 & 982 \\
\hline & $(33.10 \%)$ & $(31.10 \%)$ & $(26.70 \%)$ & $(28.40 \%)$ \\
\hline \multirow[t]{2}{*}{ Health care } & 1,125 & 952 & 814 & 781 \\
\hline & $(40.70 \%)$ & $(39.30 \%)$ & $(22.70 \%)$ & $(22.60 \%)$ \\
\hline \multirow{3}{*}{$\begin{array}{r}\text { Pathway } \\
\text { School-based }\end{array}$} & & & & \\
\hline & 2,239 & 1,867 & 3,209 & 3,007 \\
\hline & $(81.10 \%)$ & $(76.80 \%)$ & $(89.60 \%)$ & $(87.20 \%)$ \\
\hline \multirow[t]{2}{*}{ Work-Based } & 523 & 565 & 371 & 443 \\
\hline & $(18.90 \%)$ & $(23.20 \%)$ & $(10.40 \%)$ & $(12.80 \%)$ \\
\hline
\end{tabular}

Note 1: All shares relate to the percentage share of students in transition (indicator 1) who successfully finished a VMBO pathway in the previous school year and then enrolled in an MBO pathway in a particular school year $(T=\{0,1\})$ to RTC Utrecht $(D=0)$ or RTC Amsterdam $(D=1)$.

Note 2: The share designated is equal to the average percentage share of one fulltime equivalent (FTE). 
are a Dutch natives. On the contrary, RTC Amsterdam may be considered a black school where almost halve of the student sample is of other than Dutch origin. Nearly half of these Centers' population is immigrant, most likely from Morocco, Suriname or Aruba. This is particularly interesting for evaluating policy's effectiveness with respect to different ethnic groups.

Furthermore, slightly more males than females and only a few single parents are observed in the control group $(D=0)$. Students are most likely to live in little municipalities. About 39.4 percent of the sample students have to deal with poverty. ${ }^{12}$ In the treatment group $(D=1)$, there are slightly more females than males. About 6-7 percent of the students are part of a single-parent household. Most students of RTC Amsterdam live in the Municipality of Amsterdam (33.9 percent and 36.4 percent over 2006-2008) or in small or medium-sized municipalities (about 60 percent). Remarkably, two-thirds of the student population lives in poverty.

RTC Utrecht employs 2,313 people, representing a total of 1,753.5 fulltime equivalents (FTEs). RTC Amsterdam offers employment to 2,860 people representing 2,247.5 FTEs. The share designated is equal to the average percentage share of one FTE (e.g. teachers have on average a 0.7 FTE employment contract). RTC Amsterdam has a slightly higher share designated than RTC Utrecht: 0.79 compared with 0.77 (of one FTE). For both Centers, almost two-thirds of all staff employed are teachers and one-third support staff. The age of a teacher employed in RTC Utrecht or RTC Amsterdam is relatively old: respectively, 48.1 and 47.5 year-olds.

The treatment and control group are highly comparable with respect to level, courses, and learning pathways offered to their students. ${ }^{13}$ Students

\footnotetext{
${ }^{12}$ The poverty measure (APCG) indicates that a student lives in what is called a poverty area. The area may be denoted by low income, received benefits, or unemployment status.

${ }^{13}$ After successful finishing a pre-vocational pathway, one may choose between two types of vocational learning pathways: a work-based, or a school-based pathway. The work-based pathway (BBL) is most comparable to learning a craft by on-the-job training. It implies one or two days in school and three to four days (60 percent or more) on-the-job training. The student then receives an employment contract. The school based pathway (BOL) stands for education in school combined with an internship (e.g., for a period of 6
} 
can choose a subject in business administration, engineering or health care. Only a few students choose to study a combination of subjects, and are therefore left out of Table 6.3. For RTC Utrecht and RTC Amsterdam, most sample students (about 80 percent) enroll in a school-based pathway vocational level-2 (about 30 percent) or level-4 (about 50 percent). About half of the treatment group population is enrolled in business administration study subjects, whereas about 40 percent of the control group population is enrolled in health care study subjects. To conclude, there is a slightly increased enrollment in work-based pathways over the years.

\section{Transition and dropout}

The percentage share of 16 and 17 year-olds students in control group $(D=$ 0 ) and treatment group $(D=1)$ is highly comparable over the years. On average, fewer 16 year-olds students are made the transition to a vocational pathway offered by RTC Amsterdam or RTC Utrecht in 2008 compared with 2006.

With respect to the control group, 7.9 percent (9.1 percent) of students aged 16 (17) dropped out in 2006. In 2008 this percentage share of dropout students aged 16 decreased to 6.1 percent, whereas it increased for dropout students aged 17 to 11.9 percent. In contrast, the rate of early school-leaving in RTC Amsterdam decreased for both 16 year-olds students and 17 yearolds students over 2006 to 2008: from 10.3 percent to 5.2 percent (aged 16) and 11.0 percent to 9.2 percent (aged 17). Among 16 year old students, the decline is extraordinary and might be a first indication for relatively successful policymaking in RTC Amsterdam compared with RTC Utrecht.

Students, who switched school from RTC Amsterdam to RTC Utrecht, or the other way around, are captured in spillovers (see the SUTVA assumption). For both age groups together, this indicator reduced remarkably over months). There is no employment contract. Both pathways lead to the same vocational certificate, and students (or employers) may want to switch during their course of study between both pathways (Borghans and Smits, 1999). 
the observed time-span 2006 to 2008 from about 2.1 percent to 1.2 percent in the control group to 1.1 percent and 0.4 percent, respectively, in the treatment group.

\subsection{Results}

Tables 6.4 and 6.5 present the summary results of a DiDiD estimation. To sustain a common support (i.e. accounting for potential heterogeneity of the treatment effect among different student groups), the analysis is performed separately on native Dutch- and ethnic minority students (denoted by "Ethnic"). Ethnic minority students include Moroccan, Turkish, Surinamese or Aruban, and other Western or non-Western ethnicities.

Model 1 estimates a DiDiD setting without considering spillover effects or controlling for covariates. In the next three models, spillover effects (Model 2), student characteristics (Model 3), and school characteristics (Model 4) are controlled for. All of these four models are estimated by OLS using robust standard errors to control for heteroskedasticity. Note that, in Model 4, we include the vocational level as a dummy variable (there are in total four levels, see Table 6.3, Section 6.3). The vocational level is a good approximate for the difficulty of the vocational pathway the student has chosen. In this way, the DiDiD effect is controlled for effects that play a role at the aggregated vocational level (e.g. the difficulty of a pathway). We observe that the vocational level is negatively associated with school dropout $(\rho=-0.2021$, significant at the 1\%-level), indicating that school dropout is clustered among the relatively low vocational levels, so that the transition policy could have an heterogenous effect across different difficulty levels. This in line with the previous literature on student achievement, the ability to successfully finish a study, and its association with school dropout (e.g. Finn, 1989; Dustmann and van Soest, 2007; Dalton et al., 2009; Rumberger, 2011). To conclude, in Model 5, highest precision of the estimate is 
obtained using 2-digit zip code information (i.e. the level of the municipality) on students' residence to cluster the standard errors (for an elaborated discussion on this, see Kézdi, 2004).

The results of the DiDiD indicators are discussed as follows.

First, consider the results of native Dutch students in Table 6.4. The estimate of $(\hat{\beta})$ denotes the between-group indicator (i.e. first difference), also known as the treatment indicator $(D)$. It compares the average school dropout rate of 16 and 17 year-olds students of RTC Amsterdam $(D=1)$ with RTC Utrecht $(D=0)$. The estimated results of all the Models 1 to 5 show that the average school dropout rate of RTC Amsterdam is significantly higher than RTC Utrecht. The estimate of $(\hat{\beta})$ is about 3 percentage points higher in RTC Amsterdam than in RTC Utrecht. As such, overall, the dropout problem is more persistent in the treatment group than in the control group.

The within-group, cohort or age indicator $(C)$ (i.e. second difference) is estimated by $(\hat{\gamma})$. The summary results of the Models 1 to 3 indicate that 17 year-olds students, who made the transition one year before the 16 year-olds students, and conditional on the treatment indicator and time indicator, do not have a relatively increased likelihood of school dropout. However, once controlled for school characteristics, we observe that the estimate of $(\hat{\gamma})$ becomes significant.

The estimate of $(\hat{\delta})$ denotes the time indicator $(T)$ (i.e. third difference). The estimate of $(\hat{\delta})$ across the four models is equal to about 2 percentage points, and insignificant in Models 1 to 4. Only in Model 5, the estimate of $(\hat{\delta})$ becomes significant.

Spillover effects or the effects of switching school are estimated by $(\hat{\psi})$. The estimate of $(\hat{\psi})$ is equal to about -6 percentage points and highly significant (i.e., significance at 1\%-level in Models 1 to 3, and at 5\%-level in Models 4 and 5). Conditional on the treatment-, between-group-, and 
within-group- indicator, native Dutch students have a decreased likelihood of dropping out of school when they switch school from RTC Utrecht to RTC Amsterdam.

Second, consider the results for ethnic minority students in Table 6.5. The estimate of $(\hat{\beta})$ is not significantly different from zero in Models 1 to 5 , indicating that the average dropout rate in RTC Amsterdam does not statistically differ from the average dropout rate in RTC Utrecht. Thus, the dropout problem is not more persistent in RTC Amsterdam than in RTC Utrecht with respect to the ethnic minority students. Note that this is in contrast to what has been estimated for native Dutch students in Table 6.4.

Also in contrast to the estimation results of native Dutch students, is the statistical inference with respect to the estimate of $(\hat{\delta})$. This estimate is equal to about 7 percentage points across the models and significant at the 5\%-level. As such, compared with native Dutch students, an increasing share of other Ethnic groups have left education early over time.

In line with the estimates of Table 6.4, spillover effects are negatively associated with school dropout. However, here, the coefficient is relatively low, and not significant.

To conclude, the estimate of $(\hat{\gamma})$ of the within-group indicator is equal to about 1 percentage point, but not significant.

\subsubsection{Results ascribed to other policymaking}

The results ascribed to other policymaking (other than transition policies) are discussed as follows: (1) policymaking over time; (2) policymaking across regional dropout authorities; and (3) policymaking within the regional dropout authorities.

\section{Policymaking over time}

First, consider the interaction effect of the treatment and the cohort indicator $\left(\hat{\eta}_{1}\right)$. The interaction effect captures policymaking aimed at 16 year-olds 
Table 6.4: Estimation results for native Dutch students.

\begin{tabular}{|c|c|c|c|c|c|}
\hline & $\begin{array}{l}\text { Model } 1 \\
\text { Dutch }\end{array}$ & $\begin{array}{l}\text { Model } 2 \\
\text { Dutch }\end{array}$ & $\begin{array}{c}\text { Model } 3 \\
\text { Dutch }\end{array}$ & $\begin{array}{l}\text { Model } 4 \\
\text { Dutch }\end{array}$ & $\begin{array}{l}\text { Model } 5 \\
\text { Dutch }\end{array}$ \\
\hline$D(\hat{\beta})$ & $\begin{array}{r}0.0311 \\
(2.14)\end{array}$ & $\begin{array}{r}0.0309 \\
(2.13)\end{array}$ & $\begin{array}{r}0.0319 \\
(2.14)\end{array}$ & $\begin{array}{r}0.0264 \\
(1.83)\end{array}$ & $\begin{array}{r}0.0245 \\
(1.95)\end{array}$ \\
\hline$C(\hat{\gamma})$ & $\begin{array}{l}-0.0183 \\
-(1.57)\end{array}$ & $\begin{array}{r}-0.0179 \\
-(1.53)\end{array}$ & $\begin{array}{l}-0.0166 \\
-(1.41)\end{array}$ & $\begin{array}{l}-0.0262 \\
-(2.30)\end{array}$ & $\begin{array}{l}-0.0262 \\
-(2.83)\end{array}$ \\
\hline$T(\hat{\delta})$ & $\begin{array}{r}0.0187 \\
(1.37)\end{array}$ & $\begin{array}{r}0.0185 \\
(1.36)\end{array}$ & $\begin{array}{c}0.0213 \\
(1.55)\end{array}$ & $\begin{array}{c}0.0164 \\
(1.24)\end{array}$ & $\begin{array}{r}0.0178 \\
(1.95)\end{array}$ \\
\hline$D * C\left(\hat{\eta}_{1}\right)$ & $\begin{array}{r}0.0136 \\
(0.73)\end{array}$ & $\begin{array}{r}0.0137 \\
(0.74)\end{array}$ & $\begin{array}{r}0.0122 \\
(0.66)\end{array}$ & $\begin{array}{r}0.0061 \\
(0.34)\end{array}$ & $\begin{array}{r}0.0086 \\
(0.63)\end{array}$ \\
\hline$C * T\left(\hat{\eta}_{2}\right)$ & $\begin{array}{l}-0.0280 \\
-(1.62)\end{array}$ & $\begin{array}{l}-0.0283 \\
-(1.64)\end{array}$ & $\begin{array}{l}-0.0310 \\
-(1.81)\end{array}$ & $\begin{array}{l}-0.0301 \\
-(1.80)\end{array}$ & $\begin{array}{l}-0.0311 \\
-(2.06)\end{array}$ \\
\hline$D * T\left(\hat{\eta}_{3}\right)$ & $\begin{array}{l}-0.0481 \\
-(2.40)\end{array}$ & $\begin{array}{l}-0.0481 \\
-(2.40)\end{array}$ & $\begin{array}{l}-0.0494 \\
-(2.45)\end{array}$ & $\begin{array}{l}-0.0419 \\
-(2.14)\end{array}$ & $\begin{array}{l}-0.0415 \\
-(2.43)\end{array}$ \\
\hline$D * C * T(\hat{\theta})$ & $\begin{array}{c}-0.0083 \\
-(0.33)\end{array}$ & $\begin{array}{l}-0.0082 \\
-(0.33)\end{array}$ & $\begin{array}{l}-0.0083 \\
-(0.33)\end{array}$ & $\begin{array}{r}0.0022 \\
(0.09)\end{array}$ & $\begin{array}{r}0.0016 \\
(0.07)\end{array}$ \\
\hline$S(\hat{\psi})$ & & $\begin{array}{l}-0.0565 \\
-(2.81)\end{array}$ & $\begin{array}{l}-0.0532 \\
-(2.64)\end{array}$ & $\begin{array}{r}-0.0512 \\
-(2.57)\end{array}$ & $\begin{array}{l}-0.0509 \\
-(2.30)\end{array}$ \\
\hline Covariates & None & $\begin{array}{r}\text { Spillover } \\
\text { effects }\end{array}$ & $\begin{array}{r}\text { Spillover } \\
\text { effects, } \\
\text { Student } \\
\text { variables }\end{array}$ & $\begin{array}{r}\text { Spillover } \\
\text { effects, } \\
\text { Student } \\
\text { variables, } \\
\text { School } \\
\text { variables }\end{array}$ & $\begin{array}{r}\text { Spillover } \\
\text { effects, } \\
\text { Student } \\
\text { variables, } \\
\text { School } \\
\text { variables }\end{array}$ \\
\hline Obs. & 8,397 & 8,397 & 8,397 & 8,397 & 8,397 \\
\hline $\mathrm{F}$ & 9.16 & 8.99 & 12.66 & 14.09 & \\
\hline Prob $>$ F & 0.0000 & 0.0000 & 0.0000 & 0.0000 & \\
\hline R-squared & 0.0070 & 0.0074 & 0.0150 & 0.0621 & 0.0732 \\
\hline Root MSE & 0.2857 & 0.2857 & 0.2848 & 0.2780 & 0.2775 \\
\hline Std. error & Robust & Robust & Robust & Robust & $\mathrm{Cl}(71)$ \\
\hline
\end{tabular}

Note: t-values between brackets. 
Table 6.5: Estimation results for Ethnic minority students.

\begin{tabular}{|c|c|c|c|c|c|}
\hline & $\begin{array}{c}\text { Model } 1 \\
\text { Ethnic }\end{array}$ & $\begin{array}{c}\text { Model } 2 \\
\text { Ethnic } \\
\end{array}$ & $\begin{array}{c}\text { Model } 3 \\
\text { Ethnic }\end{array}$ & $\begin{array}{c}\text { Model } 4 \\
\text { Ethnic }\end{array}$ & $\begin{array}{c}\text { Model } 5 \\
\text { Ethnic }\end{array}$ \\
\hline$D(\hat{\beta})$ & $\begin{array}{r}0.0072 \\
(0.32)\end{array}$ & $\begin{array}{r}0.0065 \\
(0.28)\end{array}$ & $\begin{array}{r}0.0220 \\
(0.86)\end{array}$ & $\begin{array}{r}0.0176 \\
(0.74)\end{array}$ & $\begin{array}{r}0.0299 \\
(0.81)\end{array}$ \\
\hline$C(\hat{\gamma})$ & $\begin{array}{r}0.0138 \\
(0.51)\end{array}$ & $\begin{array}{r}0.0140 \\
(0.52)\end{array}$ & $\begin{array}{r}0.0133 \\
(0.50)\end{array}$ & $\begin{array}{r}0.0000 \\
(0.00)\end{array}$ & $\begin{array}{r}-0.0018 \\
-(0.08)\end{array}$ \\
\hline$T(\hat{\delta})$ & $\begin{array}{r}0.0755 \\
(2.30)\end{array}$ & $\begin{array}{r}0.0752 \\
(2.29)\end{array}$ & $\begin{array}{c}0.0734 \\
(2.25)\end{array}$ & $\begin{array}{r}0.0742 \\
(2.33)\end{array}$ & $\begin{array}{r}0.0768 \\
(2.30)\end{array}$ \\
\hline$D * C\left(\hat{\eta}_{1}\right)$ & $\begin{array}{l}-0.0303 \\
-(0.99)\end{array}$ & $\begin{array}{l}-0.0305 \\
-(0.99)\end{array}$ & $\begin{array}{l}-0.0313 \\
-(1.02)\end{array}$ & $\begin{array}{l}-0.0288 \\
-(0.96)\end{array}$ & $\begin{array}{l}-0.0278 \\
-(0.94)\end{array}$ \\
\hline$C * T\left(\hat{\eta}_{2}\right)$ & $\begin{array}{l}-0.1324 \\
-(3.31)\end{array}$ & $\begin{array}{l}-0.1326 \\
-(3.32)\end{array}$ & $\begin{array}{l}-0.1310 \\
-(3.29)\end{array}$ & $\begin{array}{l}-0.1196 \\
-(3.11)\end{array}$ & $\begin{array}{l}-0.1186 \\
-(3.43)\end{array}$ \\
\hline$D * T\left(\hat{\eta}_{3}\right)$ & $\begin{array}{c}-0.0783 \\
-(2.15)\end{array}$ & $\begin{array}{l}-0.0781 \\
-(2.15)\end{array}$ & $\begin{array}{l}-0.0774 \\
-(2.13)\end{array}$ & $\begin{array}{l}-0.0726 \\
-(2.04)\end{array}$ & $\begin{array}{r}-0.0773 \\
-(1.97)\end{array}$ \\
\hline$D * C * T(\hat{\theta})$ & $\begin{array}{r}0.1075 \\
(2.40)\end{array}$ & $\begin{array}{r}0.1078 \\
(2.41)\end{array}$ & $\begin{array}{r}0.1061 \\
(2.37)\end{array}$ & $\begin{array}{r}0.1007 \\
(2.32)\end{array}$ & $\begin{array}{r}0.1016 \\
(2.45)\end{array}$ \\
\hline$S(\hat{\psi})$ & & $\begin{array}{l}-0.0173 \\
-(0.47)\end{array}$ & $\begin{array}{l}-0.0243 \\
-(0.65)\end{array}$ & $\begin{array}{l}-0.0284 \\
-(0.72)\end{array}$ & $\begin{array}{l}-0.0336 \\
-(0.99)\end{array}$ \\
\hline Covariates & None & $\begin{array}{r}\text { Spillover } \\
\text { effects }\end{array}$ & $\begin{array}{r}\text { Spillover } \\
\text { effects, } \\
\text { Student } \\
\text { variables }\end{array}$ & $\begin{array}{r}\text { Spillover } \\
\text { effects, } \\
\text { Student } \\
\text { variables, } \\
\text { School } \\
\text { variables }\end{array}$ & $\begin{array}{r}\text { Spillover } \\
\text { effects, } \\
\text { Student } \\
\text { variables, } \\
\text { School } \\
\text { variables }\end{array}$ \\
\hline Obs. & 3,817 & 3,817 & 3,817 & 3,817 & 3,817 \\
\hline $\mathrm{F}$ & 4.87 & 4.29 & 8.63 & 7.35 & \\
\hline Prob $>F$ & 0.0000 & 0.0000 & 0.0000 & 0.0000 & \\
\hline $\mathrm{R}$-squared & 0.0094 & 0.0094 & 0.0175 & 0.0627 & 0.0730 \\
\hline Root MSE & 0.2730 & 0.2730 & 0.2726 & 0.2663 & 0.2664 \\
\hline Std. error & Robust & Robust & Robust & Robust & $\mathrm{Cl}(47)$ \\
\hline
\end{tabular}

Note 1: t-values between brackets.

Note 2: "Ethnic" denotes ethnic minority students and includes Moroccan, Turkish, Surinames or Aruban, and other Western or non-Western ethnicities. 
students in RTC Amsterdam over time (i.e. the cohorts 1989 and 1992). The estimate of $\left(\hat{\eta}_{1}\right)$ is not significant in the Models 1 to 5 for native Dutchand other ethnic groups. The results indicate that there are no policies over time that significantly have affected students' school dropout behavior (i.e. for cohorts 1989 and 1992).

\section{Policymaking across regional dropout authorities}

Second, consider the interaction effect $\left(\hat{\eta}_{2}\right)$ of the time and cohort indicator. The interaction effect of $\left(\hat{\eta}_{2}\right)$ captures policies across regional dropout authorities (or state policies) that effectively affect student outcomes. Among other policies, the 2007 policy change of the compulsory education age may be considered in this respect. Although the effect of the compulsory education age change cannot be disentangled from other policies across regional dropout authorities, it is reasonable to argue that this national policy reform has had a major share in the estimated effect of $\left(\hat{\eta}_{2}\right)$ (for an evaluation of the short-run effect, see Cabus and De Witte, 2011a).

The largest effects are identified for ethnic minority students. The likelihood to drop out of school significantly decreased with as much as -13 percentage points significant at the 1\%-level (see Models 1 to 3). In Models 4 and 5 , this effect slightly declines in absolute values to -12 percentage points significant at $1 \%$-level. With respect to the native Dutch students, Model 2 to 5 indicate policy effectiveness of about -3 percentage points significant at the $5 \%$-level.

\section{Policymaking within regional dropout authorities}

Third, the interaction effect $\left(\hat{\eta}_{3}\right)$ multiplies the treatment indicator with the time indicator. This interaction effect captures policymaking aimed at 16 (cohort 1992) and 17 (cohort 1991) year-olds students in the treatment group in 2008-09 compared with the control group and base year 2006-07. Thus,

the DiDiD estimate is controlled for other dropout prevention measures 
(as a bundle of activities) effective within the control- and the treatment group. The results indicate that policymaking within the treatment group $(D=1)$ significantly affect student outcomes. For native Dutch students, the estimate of $\left(\hat{\eta}_{3}\right)$ is equal to -4.81 percentage points significant at the $5 \%$-level. This effect is fairly robust to controlling for student characteristics, school characteristics, and clustering the standard error at the zip code level.

For ethnic minority students, the effect is equal to -7.83 percentage points significant at the 5\%-level in Model 1 . Again, it is observed that the estimate of $\left(\hat{\eta}_{3}\right)$ is robust to including various covariates.

\subsubsection{Effectiveness of enhanced student commitment}

The DiDiD estimate of $(\hat{\theta})$ denotes the effect on school dropout of enhanced student commitment (denoted by transition policies). It interacts the treatment, time and cohort indicator.

For native Dutch students, the results of Model 1 to 5 indicate a very small negative effect of enhanced student commitment on school dropout, but it is not significant. Further controlling for spillover effects in Model 2, student characteristics in Model 3, school characteristics in Model 4, and clustered standard errors in Model 5, does not change the statistical inference with respect to the estimate of $(\hat{\theta})$. Thus, it is argued that enhanced student commitment did not reduce school dropout among native Dutch students.

In contrast, with respect to the results for ethnic minority students, the estimate of $(\hat{\theta})$ is equal to 10.75 percentage points significant at the $5 \%$-level in Model 1. This result is fairly robust to controlling for various covariates, including information at the student-level, school-level, and zip code-level. The effect remains about 10 percentage points, and does not loose its significance.

The estimation results with respect to the ethnic minority students can be explained in terms of three factors: (1) data accuracy; (2) labor market 
tendencies; and (3) enrollment tendencies. First, data accuracy might be a possible explanation for the wide variety observed among the estimated policy effects. Before 1999, there were about three possible definitions of 'foreigners' or 'non-natives' based on country of origin and nationality in the Netherlands. To avoid further existing confusion, an unequivocal definition has been created and widely accepted: a person is considered as 'non-native' when one of the parent was born abroad (Netherlands Central Bureau for Statistics). In view of improved dropout registration as from 2005, lack of data accuracy is an unlikely explanation for the estimation results.

Second, labor market opportunities are important as they may have a "pull effect" on youngsters: labor market principals pull students out of school (Gangl, 2002; Pietro, 2007; Borghans, 2007; Allen and Meng, 2010; Cabus and De Witte, 2011a). As a result of a labor market pull effects, market tendencies may offset the benefits of policymaking to keep students in class. In previous research, Cabus and De Witte (2011a) indicated that this pull effect is considerable in the Netherlands, especially for students in vocational education and training study subjects, and hence may not be neglected. Ideally, this pull effect should be similar in Amsterdam and Utrecht for the results to hold.

Table 6.6 presents the percentage share of early school-leavers aged 17 or younger, with or without a job or social security or unemployment benefits in the Municipalities of Amsterdam and Utrecht over the period 2005-2008 (Netherlands Central Bureau for Statistics). According to Table 6.6, slightly more job market opportunities are observed for early school-leavers in the Municipality of Utrecht than in the Municipality of Amsterdam. However, most students who left secondary education without a school diploma are jobless and without social security or unemployment benefits. It is shown that job market opportunities for early school-leavers in the Municipalities of Amsterdam and Utrecht follow a similar, parallel, pattern over time. Not 
Table 6.6: Job market opportunities for youngsters aged 17 or younger without a school-leaving certificate.

\begin{tabular}{lrrrr}
\hline & 2005 & 2006 & 2007 & 2008 \\
\hline Municipality of Utrecht & & & & \\
Total number of ESL & & & & \\
ESL without a job or benefits & 1,020 & 1,300 & 1,010 & 880 \\
& $(59.8 \%)$ & 770 & 580 & 540 \\
ESL with a job (no benefits) & 400 & 490 & 400 & $(61.4 \%)$ \\
& $(39.2 \%)$ & $(37.7 \%)$ & $(39.6 \%)$ & $(36.4 \%)$ \\
Other & 10 & 40 & 30 & 20 \\
& $(1.0 \%)$ & $(3.1 \%)$ & $(3.0 \%)$ & $(2.2 \%)$ \\
Municipality of Amsterdam & & & & \\
Total number of ESL & & & & \\
ESL without a job or benefits & 1,790 & 1,860 & 1,660 & 1,400 \\
& $(63.7 \%)$ & 1,210 & 1,060 & 940 \\
ESL with a job (no benefits) & 600 & 650 & $(63.9 \%)$ & $(67.1 \%)$ \\
Other & $(33.5 \%)$ & $(32.8 \%)$ & $(34.3 \%)$ & $(31.4 \%)$ \\
& 50 & 40 & 30 & 20 \\
& $(2.8 \%)$ & $(2.1 \%)$ & $(1.8 \%)$ & $(1.5 \%)$
\end{tabular}

Note 1: Percentage share of the total number of school dropouts between brackets. Note 2: Netherlands Central Bureau for Statistics (CBS).

Note 3: ESL denotes early school-leavers.

unexpected, as distance between RTC Utrecht and RTC Amsterdam is quite small. A major advantage of this experimental set-up is that both Centers, Amsterdam and Utrecht, are liable to the same (economic) conditions, such as market conditions, the country's economic growth, standards with regard to valid school-leaving certificates, the choice of study subjects, and other country and time effects which play a crucial role in early school-leaving. This strengthens validity of the results.

Third, enrollment tendencies in the first year of VET are discussed for ethnic minority students compared with native Dutch students. Over the period 2006 to 2008 , about 60 percent of ethnic minority students in the first year of VET in RTC Amsterdam chose to study a subject in business administration, compared with only 40 percent in RTC Utrecht. Compared with 
native Dutch students, only 27 percent of student are enrolled in business administration in RTC Utrecht, compared with 46 percent in RTC Amsterdam. In addition to this finding, ethnic minority students have fewer part-time educational arrangements than native Dutch students. From these facts and figures, it is argued that ethnic minority students who enroll in the first year of VET more often choose difficult pathways or educational arrangements than native Dutch students. In line with the literature, student commitment to school, peers, and teachers may drive the individual enrollment decision differently among the student groups distinguished (Pittman, 1991). For example, career-related motivation, a student's sense of belonging, and the need to prove one's self-worth may be important determinants of study choice. On the other hand, lack of peer or family support may negatively affects student enrollment decisions (e.g. Pascarella et al., 1987; Hurtado and Carter, 1997; Phinney et al., 2006).

Notwithstanding the evidence in the descriptive statistics of this chapter (Section 6.3), and the various arguments from the previous literature, the summary results of Model 4 in Table 6.5 have indicated that the difficulty of the vocational school career of ethnic minority students is not able to capture the DiDiD effect. Allen and Meng (2010) provide alternative explanations in this respect. The authors have conducted a questionnaire among 5,660 early school-leavers in the Netherlands in various educational streams. For the total of respondents (i.e. native Dutch included), about 21.1 percent of early school-leavers reported that they dropped out of school because of a wrong study choice. That is the second most-reported dropout determinant, followed by labor market opportunities (21.9 percent) and (mental) illness (18.4 percent). However, only 1.8 percent of dropouts reported that the study load was too heavy. Allen and Meng (2010) further argue that ethnic minority students are less likely to discuss their dropout decision, as they are more often suspended during their school career, and more often forced 
by the school to leave.

\subsection{Conclusion}

One particular dropout prevention measure in the Netherlands aimed at enhanced student commitment in VET and is evaluated in this paper. This particular dropout prevention measure deals with smoothing the transition from the pre-vocational school to the vocational school by offering increased care for students: they are followed during the summer break, go through an intake procedure, and communication between the pre-vocational- and vocational school is enhanced. Also a small government experiment offered students the possibility to remain in their pre-vocational school, and to attend classes from familiar teachers.

Students in transition to the first year of vocational education and training offered in Amsterdam (RTC Amsterdam, the treatment group) and Utrecht (RTC Utrecht, the control group) were used for a quasi-experiment. Using regional borders as an instrument, and accounting for differences in the underlying student population in a DiDiD estimation, the results indicate that school dropout did not decline in RTC Amsterdam compared with RTC Utrecht, and the situation before the transition policy reform. However, we do observe that a successful transition from the pre-vocational school to the vocational school is a key factor for students to benefit dropout prevention (as a bundle of measures and actions not including the transition policy) that is mainly implemented in the vocational schools. Thus, vocational students have a significant lower risk of dropping out of school, once they have made a good transition, owing to prevention measures, not including the transition policy, in RTC Amsterdam.

The results further indicate that the transition to the first year of VET increasingly failed for ethnic minority students in the year after the implementation of the transition policy. Evidence indicates that ethnic minority 
students: (1) choose more difficult pathways or educational arrangements than native Dutch students (e.g. business administration study subjects, full-time study work, and school-based pathways); and (2) are more often suspended or forced to leave school (early). Further research in this respect should identify potential problems arising from the 'school accountability' regulatory framework. School accountability has won attention over the last decade to make parents and school staff responsible for the educational attainment of youngsters. Illustrative is the performance bonus of 2,500 euros per dropout less in Dutch schools. The focus on a knowledge-base society increasingly put stress on households and school staff to reach targets (e.g. such as the Lisbon Agenda Targets translating into national, regional and school targets). Reaching targets may enhance the exclusion of weak performers in schools, as schools, in general, do not want to miss out on their performance bonus. Potential dropout students could then be especially selected for exclusion, and the good idea of dropout prevention would then completely miss its goal. Further research, for example, by means of interviews or qualitative research, should find out whether the transition policy in particular, or school accountability in general, motivate schools to carry into effect a 'gatekeeper policy'.

A final point of discussion deals with the generalization of the results, as presented in this study. The estimation results cannot be unambiguously generalized to other countries that have implemented similar interventions aiming at, for example, simplifying the transition between two consecutive years or schools. As shown in this study, the underlying problems to school dropout are heteregenous among individuals and, therefore, interventions can have distinct impacts across different student populations. But also differences in the education system between countries can play a crucial role in the interpretation of educational outcomes. We consider this as an important scope for further research. 



\section{Part III}

General Conclusion 



\section{Chapter 7}

\section{Challenges for Prevention Policy: What and for Whom?}

"[...] it is possible to view efforts to improve educational outcomes for at-risk populations as a public investment that may have benefits for the entire society in excess of investment costs (Levin et al., 2006, p.1)."

\subsection{Introduction}

This dissertation has explored dropout prevention policy, in general, and prevention policy in the Netherlands, in particular. It includes: (1) a conceptual model based on the previous literature; (2) a benchmarking model which ranks EU-12 countries' performance; (3) an evaluation of the registration of school attendance and unauthorized school absenteeism; (4) an exploration of the covenant dropout prevention measures; (5) an analysis of the effectiveness of a one-year increase of the compulsory education age; and (6) an analysis of the effectiveness of enhanced student commitment in vocational education and training.

Different micro-econometric techniques have been used to evaluate dropout prevention policy (in the Netherlands), and consist of a literature review, a panel data model, a Bayesian duration model, a Probit model, quantile

\footnotetext{
${ }^{1}$ Chapter 7 is based on: Sofie J. Cabus and Kristof De Witte (2013). Why do Students Leave Education Early? - Theory and Evidence on high school dropout rates. TIER, Maastricht University, Working Paper.
} 
regressions, and difference-in-differences estimation. Table 7.1 summarizes the main contributions of this dissertation to the literature by contents, evaluation method, and chapter.

This subsection combines the findings from the various chapters by presenting a theoretical model on why students leave education early, with an empirical application, and a policy discussion, in line with these findings. We start with Chapter 1 in which we show that early school leaving has multiple origins. Previous work points to the dynamic and cumulative process in which students accumulate problems before leaving education early. This process is known as the process of 'student attrition', which has various underlying factors. For example, students are more likely to drop out of school if they have one or more years of retention in grade (Planc et al., 2005), or suffer from bad health shocks (Lleras-Muney, 2005; Albouy and Lequien, 2009; Powdthavee, 2010). In addition, Attwood and Croll (2006) and Henry (2007) also argued the importance of lack of interest in schooling, as revealed by truancy behavior (e.g. Chapter 3). And, among others, Spady (1970), Tinto (1975), Jencks and Mayer (1990), Wenger (2002) and Anderson (2010) point to the influence of the student's commitment to the school, peers, and teachers, and his/her motivation (e.g. Chapter 6).

Furthermore, the economic cycle has its influence on school dropout. 'At-risk' students are more likely to drop out of school in times of an economic revival in response to the increased availability of (temporary) job market opportunities (e.g. Light, 1995; Shavit and Müller, 1998; Gangl, 2002; Allensworth, 2005). This is particularly observed among vocational students with internships, as they have a closer connection with the labor market compared with their peers enrolled in academic educational tracks (e.g. Chapter 5).

This final chapter contributes to the growing literature on school dropout by proposing, and empirically testing, a theoretical framework designed to 
Table 7.1: The main contributions to the literature by contents, evaluation method and chapter.

\begin{tabular}{|c|c|}
\hline $\begin{array}{l}\text { Contents } \\
\text { Evaluation method } \\
\text { (Chapter) }\end{array}$ & Main findings \\
\hline $\begin{array}{l}\text { Literature review } \\
\text { Conceptual model } \\
\text { (Chapter 1) }\end{array}$ & $\begin{array}{l}\text { Successful dropout prevention programs should include } \\
\text { measures targeted at home and school, as well as labor } \\
\text { market institutions and their interaction. }\end{array}$ \\
\hline $\begin{array}{l}\text { Cross-country study } \\
\text { Benchmarking model } \\
\text { (Chapter 2) }\end{array}$ & $\begin{array}{l}\text { A 'fair' benchmark should standardize the school dropout } \\
\text { rate for exogenous influences (e.g. economic cycle) before } \\
\text { ranking the educational policy performance of countries. } \\
\text { Countries with high enrollment rates in } \mathrm{VET}^{1} \text { are } \\
\text { developing more successful dropout prevention programs. }\end{array}$ \\
\hline $\begin{array}{l}\text { Registration of school attendance } \\
\text { Bayesian duration model } \\
\text { (Chapter 3) }\end{array}$ & $\begin{array}{l}\text { Complete, reliable and valid data are indispensable for } \\
\text { dropout prevention. Unauthorized truancy is most } \\
\text { prevalent in } \mathrm{VET}^{1} \text { and accurately identifies students } \\
\text { at-risk of dropping out of school. }\end{array}$ \\
\hline $\begin{array}{l}\text { Evaluation of } 10 \text {-menu items } \\
\text { Panel Probit model } \\
\text { (Chapter } 4 \text { ) }\end{array}$ & $\begin{array}{l}\text { Dual track, optimal track, and mentoring and coaching } \\
\text { are prevention measures that reduce the risk of students } \\
\text { leaving secondary education early. The prevention } \\
\text { measures are mainly aimed at vocational students. }\end{array}$ \\
\hline $\begin{array}{l}\text { Evaluation of } 10 \text {-menu items } \\
\text { Quantile regression } \\
\text { (Chapter 4) }\end{array}$ & $\begin{array}{l}\text { Vocational schools have relatively high dropout rates } \\
\text { and are benefitting the most from dropout prevention. }\end{array}$ \\
\hline $\begin{array}{l}\text { The compulsory education age } \\
\text { Difference-in-differences } \\
\text { (Chapter 5) }\end{array}$ & $\begin{array}{l}\text { A one-year increase of the compulsory education age } \\
\text { has ambiguous effects on school dropout. Vocational } \\
\text { control students most likely anticipated job market } \\
\text { opportunities in response to the policy reform. }\end{array}$ \\
\hline $\begin{array}{l}\text { Student commitment in VET } \\
\text { Difference-in-differences } \\
\text { (Chapter 6) }\end{array}$ & $\begin{array}{l}\text { A good transition from the pre-vocational to the } \\
\text { vocational school is a key factor for successful } \\
\text { dropout prevention. }\end{array}$ \\
\hline
\end{tabular}

Note: VET denotes vocational education and training. 
model enrollment of youngsters in secondary education. The model relates school dropout to time preferences, motivation, aspirations, opportunity costs, and policy measures. This contrasts with the previous literature, which has mainly focussed on what risk factors correlate with early schoolleaving. Theoretical frameworks to model the school attendance decision of students in secondary education are rare. To the best of our knowledge, there is only one earlier paper by Funkhouser (1999). He discusses a reduced-form model for school attendance decisions in relation to economic conditions in Costa Rica. Our model differs from that of Funkhouser (1999), as he works with repeated cross-sections, and starts from time allocation within a household. This paper uses a panel data set to study the decision of individual students to leave education early. Furthermore, in his model, Funkhouser (1999) takes the household as the main decision unit. In our model, we suggest a focus on the individual student rather than the household, as, particularly in developed countries, students may act autonomously, independently, and often contrary to parental wishes.

This chapter is related to earlier work. Light and Strayer (2000) have investigated to what extent college quality influences graduation rates. The authors model the individual student's decision to attend college at two subsequent points in time. The decision to stay in higher education in period 2 is intertwined with the quality of college in period 1. Light and Strayer (2000) find that the likelihood to graduate from college increases with college quality, and succesful college choice.

Keane (2002) also has constructed a discrete choice model for the decision to attend higher education (college) in the US. In a similar way to Cameron and Heckman (1998), the model of Keane (2002) accounts for financial aid and borrowing constraints, factors highly associated with the attendance decision of college students.

Our model was inspired by the work of Cameron and Heckman (1998) 
and Keane (2002): we used a two-period discrete time model, in which students make a decision to stay at school conditional on their time constraint, motivation constraint, job market aspirations, and current (school or national) policy measures (see Section 2). The latter variables allow us to explicitly model, and forecast, the influence of dropout prevention policies on early school-leaving.

The theoretical model was empirically tested on a cohort of Dutch vocational students. This cohort of students is referred to as VOCL99 (Voortgezet Onderwijs Cohort Leerlingen). The VOCL99 data consist of about 4,000 vocational students who were followed over the years 1999-2005. The data include information on students' school and labor market experiences. Considering only vocational students in the empirical application is attractive as the majority of dropout students in the Netherlands drops out of vocational study tracks.

Using the data we can estimate the influence of individual preferences on school dropout. The results and model assumptions can be used to forecast the influence of policy measures on school dropout rates in a given state of economic development. The outcomes of the model accurately predict actual enrollment rates over the period 2000-2011. They further suggest that, by intensifying the policy measures, the Dutch government should be able to reach the European Horizon 2020 goals. Finally, it is observed that a very strict dropout prevention policy could yield nearly maximum enrollment rates (i.e. 97\%) in schools by the year 2017. However, the annual budget for such a similar dropout prevention policy amounts to $€ 574$ million or $0.10 \%$ of the Dutch GDP.

This final chapter proceeds as follows. The theoretical framework is outlined in Section 7.2, and the empirical application, together with the data, in Section 7.3. Section 7.4 presents the results of the empirical application, and Section 7.5 concludes. As explained above, the theoretical framework 
together with its empirical application allows us to estimate a parameter of 'policy strictness' that the Netherlands must reach to attain, among other objectives, the EU Agenda Targets as set in both the past (i.e. the Lisbon Agenda Targets), and for the future (i.e. EU 2020 Horizon). With respect to Dutch dropout prevention policy in the past, Section 7.6 contains a policy discussion that combines the findings from the various chapters. Dealing with the policy challenges for the future, Section 7.7 suggests an important area for further research.

\subsection{Theoretical Framework}

\section{Outline of the model}

This section presents a theoretical model that explains the dropout decision of students from various angles, and which is in line with the previous literature on school dropout. The discrete choice model builds on the previous work of Cameron and Heckman (1998) and Keane (2002), both of whom have focussed on the college attendance decision of students. One major difference between enrollment in college and secondary education is that students in secondary education are obliged to attend school until the compulsory education age has been reached. Notwithstanding the compulsory nature of school attendance in secondary education, students can take unauthorized absence from school for various reasons (Attwood and Croll, 2006; Henry, 2007). Unauthorized school absenteeism is discussed in the subsection 'time allocation'.

In the previous literature, lack of motivation to attend school has been highlighted as a major determinant of dropping out of school (see, among others, Adams and Becker, 1990; Jencks and Mayer, 1990; Wenger, 2002; De Witte and Rogge, 2009; Anderson, 2010). In the subsection 'motivation and aspirations', we position intrinsic and extrinsic motivation in our theoretical framework. The former type of motivation can be influenced by job market 
aspirations (Coleman, 1984; Ruhm, 1997; Light, 1998, 1999; Shavit and Müller, 1998), whereas the latter type of motivation can be encouraged by parents, peers, or teachers.

After incorporating the time constraint, the motivation constraint, job market aspirations, and dropout prevention policy into the theoretical model, we are able to derive a value function (i.e. the value of education). The value function reveals the main drivers of school dropout behavior - and which particular determinants prevent students from dropping out of school.

\section{Time allocation}

We use a discrete time model (time $=\{$ period 1 , period 2$\})$ to address the cumulative process of student attrition as referred to by, among others, Tinto (1975), Finn (1989), and Newman et al. (1992). This indicates the lack of interest in schooling, or disengagement from school, which eventually leads to school dropout. Finn (1985) refers to this process as 'withdrawal' of the student from school.

Students below the compulsory education age have to attend school, otherwise they have an unauthorized absence from school (also called truancy). Assume that, in each time period, school-age students make a decision on the time they devote to study $(0 \leq s \leq 1)$, and the time they play truant $\left(0 \leq h_{a} \leq 1\right)$. The utility from school attendance is denoted by $(\phi)$, and the utility from extracurricular activities by $\left(a_{1}\right)$. The total study time is the sum of compulsory school attendance $\left(s_{\text {compulsory }}\right)$ and the hours of study at home ( $\left.s_{\text {homework }}\right)$ (e.g. time spent on homework or study for a test):

$$
s=s_{\text {compulsory }}+s_{\text {homework }}
$$

Note that, by including $s_{\text {homework }}$ in equation (7.1), we consider study time at home as an important - non-negligible - part of the study curriculum, as in many EU Member States, such as the Netherlands, doing home- 
work or studying for a test are graded. Nevertheless, it is straightforward to delete study time at home from equation (7.1), if only the compulsory time at school is considered.

The total study time $(s)$ and duration of the truancy spell $\left(h_{a}\right)$ should not be larger than the total time endowment $(L)$. The time constraint for a regular school attendee in each time period reads as follows:

$$
L-s-h_{a} \geq 0,
$$

The remaining endowed time is called leisure: $l=L-s-h_{a}$. For students who have dropped out of school, $s$ is equal to 0 (i.e. no time spent in school and no study hours at home). Consequently, a dropout student in period 1 has the following time constraint:

$$
L-h_{a} \geq 0
$$

At this point, it is necessary to make an important remark on compulsory school attendance in order to understand the difference between equation (7.2) and equation (7.3). While students have the obligation to attend school, they might (illegally) skip some classes. Compulsory school attendance can, therefore, be modeled as a continuum from full school attendance $\left(s_{\text {compulsory }}=1, h_{a}=0\right)$, via truancy during some periods $\left(1 \geq s_{\text {compulsory }} \geq 0,1 \geq h_{a} \geq 0\right)$, to early school-leaving $\left(s_{\text {compulsory }}=0\right.$; $\left.h_{a}=1\right)$. In this continuum, the total time a student spends compulsorily at school may be smaller than the duration of the truancy spell. The difference between equation (7.2) and equation (7.3) is, therefore, the total time devoted to study time at home. Consequently, for any individual, we can rewrite equation (7.2) as:

$$
L-s_{\text {homework }}-\left(s_{\text {compulsory }}+h_{a}\right) \geq 0,
$$

where $(s=0)$ and $\left(L-h_{a} \geq 0\right)$ if a student drops out of school. 


\section{Motivation and aspirations}

Students obtain positive utility from intrinsic motivation (denoted by $m$ ) and negative utility from extrinsic motivation (denoted by y) (e.g. parents may punish their children if they are absent from school). We assume that both $m$ and $y$ follow a standard normal distribution. With respect to the former type of motivation, Ehrenberg and Brewer (1994) and Adams and Becker (1990) discuss general dislike of school and lack of student motivation as important drivers of the dropout decision. With respect to the latter type of motivation, for instance, parents, peers and teachers have a critical role in influencing school attendance behavior (see, e.g., Jencks and Mayer, 1990; Wenger, 2002; Rumberger and Palardy, 2005). The role of motivation can now be formalized in a motivation constraint. ${ }^{2}$ Note that $y_{1}$ should be smaller than $m_{1}$ for a student to yield a positive utility from motivation with respect to school attendance.

Students receive utility from school attendance if the motivation to attend school is greater than the opportunity cost of schooling and the extrinsic motivation. The opportunity cost of schooling corresponds to the utility $(a)$ from extracurricular activities in and outside the school (i.e. in the first time period $\left.a_{1}\right)$ times the time $(h)$ allocated to them: $a_{1} h_{a}$. Algebraically, a student stays in school if:

$$
m_{1} \geq a_{1} h_{a}+y_{1}
$$

where the subscript 1 denotes the first time period.

Students can be motivated to achieve academic success by job market aspirations (e.g. Allensworth, 2005). Students with higher job market aspirations attach higher value to education. Conversely, given the signaling function of schooling, students with a better schooling record (e.g. absence

\footnotetext{
${ }^{2}$ Note that, by construction of the variable $m$, we consider a rather broad definition of motivation, as it includes intrinsic motivation, extrinsic motivation, and aspirations.
} 
of truancy, a higher secondary school certificate), will obtain a better job market position. This is denoted by a higher utility in the second time period $\left(a_{2}\right)$. Denote by $(\rho)$ the discount factor for the value attached in period 2 to school attendance.

Suppose now that students obtain utility from three sources: leisure ( $l$, where $L \geq l \geq 0$ ); the activities they undertake while playing truant $(c)$; and schooling $(\phi)$. The utility function is denoted by:

$$
\begin{aligned}
\lambda & =u(c, l, \phi), \\
& =u(c, l)+\phi .
\end{aligned}
$$

We assume that the utility function $(\lambda)$ follows a uniform distribution with minimum value 0 and maximum value 1 , and is concave in both arguments. Intuitively, we can explain the relevance of $(\lambda)$ in the motivation constraint by socioeconomic tendencies: technological change and economic development (i.e. growing GDP) have changed the lifestyle of people over the past decades. Before the Second World War, people had only a little (money for) spare time. However, since the 1960s the global market economy has had a direct positive influence on the sale of consumption goods and/or the availability of leisure time. Given the concavity in $c$ and $l$, the marginal utility from consumption and leisure decreases if $c$ and/or $l$ increase (see also Glewwe and Jacoby, 2004). Furthermore, students have to attend school longer to find a connection with the labor market. We assume that the utility from schooling $(\phi \sim N(\mu, 1))$ follows a standard normal distribution. Thus, we can expect that, with an overall higher utility from schooling, in combination with a decreasing marginal utility from consumption and leisure, socioeconomic tendencies positively influence the decision to attend school. 


\subsubsection{Decision rule to attend school}

Using the explanatory variables within the scope of the time- and motivation constraint, we construct a value function $(V)$, which denotes, in essence, the value attached to a school-leaving certificate conditional on (compulsory) school attendance. In period 1, students maximize the sum of current utility $\lambda$, and the discounted utility from the next time period. ${ }^{3}$ Similar to Keane (2002), the value function then equals:

$$
\begin{aligned}
V_{s}= & \max _{\{h, m\}} u\left(y_{1}+a_{1} h_{a}-m_{1}, L-s-h_{a}\right) \\
& +\phi+\rho^{-1} u\left(a_{2}, 1\right) .
\end{aligned}
$$

Note that, in the second time period, students left school and started work such that the following holds: $c=a_{2} ; l=1$ and $\phi=0$.

The value function for a student who dropped out of school equals:

$$
\begin{aligned}
V_{0}= & \max _{\{h, m\}} u\left(y_{1}+a_{1} h_{a}, L-h_{a}\right) \\
& +\rho^{-1} u\left(a_{2}, 1\right) .
\end{aligned}
$$

Comparing the two equations brings insights into the decision rule of the student to attend school. A student will attend school if and only if (see Keane, 2002):

$$
\text { Stay at school if: } \frac{\phi}{\lambda_{1}}>m+a_{1} s .
$$

The left-hand side of equation (7.8) indicates the utility a student obtains from schooling relatively to total utility. $a_{1} s$ is the opportunity cost from

\footnotetext{
${ }^{3}$ Note that the discounted value can differ between different types of students. For facilitating the interpretation of the value function, here, we assume a similar discounted value for all types of students. However, in the empirical application (see Section 7.3), we relax this assumption by including a measure of student-specific discounted value in the estimation.
} 
school attendance (i.e. a student may not participate in extracurricular activities if in school), and $m$ the utility from intrinsic motivation. As long as the relative utility from schooling is larger than the utility from intrinsic motivation and the opportunity costs, students stay at school.

\subsubsection{Policy influence}

The recent focus on educational performance to foster nations' competitiveness in a globalizing world (e.g. the Europe 2020 Strategy in the EU; the No Child Left Behind Act in the US) has placed early school-leaving high on the policy agenda. National governments, municipalities, and schools are gradually putting a strict dropout prevention policy into effect. Examples in this respect are: improved registration of unauthorized school absence, the introduction of community schools to motivate students, or an increased compulsory education age (European Commission, 2011a, 2011b). Similar 'policy' actions influence the decision rule of students to attend school (i.e. equation 7.8). Denote the impact of policy actions by $\theta$. Allowing for policy influence, the decision rule equals:

$$
\text { Stay at school if: } \quad \frac{\phi}{\lambda_{1}}>(1-\theta) m+a_{1} s .
$$

In sum, students will stay at school when the benefits from dropping out $\left(\frac{\phi}{\lambda_{1}}\right)$ are higher than the efforts (i.e. direct costs $m$, and the opportunity costs $a_{1} s$ due to school attendance). Using the motivation constraint in equation (7.5), one can see that, owing to a stricter policy, the utility from intrinsic motivation decreases. A stricter dropout prevention policy $(\theta)$ lowers the costs of intrinsic motivation and, thus, increases the probability that students attend school. 


\subsection{Empirical test for the decision rule}

\section{The empirical strategy}

We can empirically test the decision rule in equation (7.8). This proceeds in two steps. In the first step, we estimate a discrete choice model (e.g. a probit model), in which the dependent variable equals the ex-post observation on whether students have dropped out of school, and the independent variables consist of proxies for motivation, time, aspirations, and a discount factor. We then may write:

$$
\operatorname{Pr}\left(\text { certificate }_{i, 1}=1 \mid s, h_{a}, m, \phi, \rho, y\right),
$$

where the outcome variable is the attendance decision of individual $i \in$ $\{1,2, \ldots n\}$ in period $1 ; s$ is a vector of study hours; $h_{a}$ a vector of time allocated to extracurricular activities; $m$ a vector that measures the utility from the intrinsic motivation of students; $\phi$ a vector that captures the utility from compulsory school attendance; $\rho$ a vector that measures the job market aspirations of youngsters; and $y$ a vector that measures the utility from extrinsic motivation. From this probability model, we can reveal, for the average student, the risk associated with each independent variable of becoming a school dropout.

In a second stage, using the estimated coefficients of equation (7.10), we estimate:

$$
\text { Educational attainment }=\frac{\Phi(\hat{\phi})}{\lambda_{1}}-\Phi\left((1-\theta) \hat{m}+\hat{s} a_{1}\right)
$$

where $\Phi(\cdot)$ is a normal probability function. We use the normal probability function to derive educational attainment in explicit form (i.e. enrollment rates). The values for $\theta, \lambda_{1}$, and $a_{1}$ cannot be estimated from the probability model, but require assumptions. We assume that $a_{1}$ follows a uniform distribution (i.e. in the interval $[0,1])$. A value of 0 would indicate that students 
do not attach any utility to truancy, whereas a value of 1 suggests that students derive all utility from truancy. As both extremes $\left(a_{1}=0 ; a_{1}=1\right)$ are unlikely, we start from the median student (i.e. $a_{1}=0.5$ ). Other assumptions on the value of $a_{1}$ are straightforward to implement. Assumptions on $\lambda_{1}$ (total utility) and $\theta$ (degree of policy interventions) are part of a sensitivity analysis in Section 7.4.

\section{Underlying data and variables}

The empirical application relies on rich survey data of a cohort of Dutch students (VOCL99, Voortgezet Onderwijs Cohort Leerlingen). The survey VOCL99 began in 1999, and is a national representative sample of students in the Netherlands (Kuyper et al., 2003a, 2003b, 2005; Zijsling et al., 2005, 2007). Although VOCL99 is the last but one wave, it is the latest wave where information on early school-leaving is currently available. The VOCL99 data consist of about 19,391 students, attending school in 126 different school locations. However, only students in a pre-vocational track (so-called 'vmbo' in the Dutch education system) filled in the exit survey (i.e. after graduation or school dropout). The previous literature indicates that it is particularly those students who are heavily at-risk of school dropout (Borghans et al., 2000; Borghans, 2007; Onstenk and Blokhuis, 2007). Including only these students limits the sample of VOCL99 students to 3,968 observations $(N)$. Six years after entering secondary education, these students were asked to fill out a questionnaire on past study behavior, school experiences, and current experiences in higher education or in the job market. ${ }^{4}$ Most sample students (78.0\%) graduated from pre-vocational education in 2003 (i.e. following the regular pattern). $10.9 \%$ had already graduated from vmbo one year ahead of schedule, while $9.4 \%$ graduated one year late. A remaining $1.7 \%$ had two

\footnotetext{
${ }^{4}$ Note that, without retention in grade, a regular student takes three years to complete lower vocational education. If a student has successfully graduated from lower vocational education, he/she can start in upper vocational education (so-called 'mbo'). Only the latter course of study can result in a higher secondary diploma, which is necessary to be no longer considered as a school dropout.
} 
Table 7.2: Definition of the variables in the VOCL99 questionnaire.

\begin{tabular}{|c|c|}
\hline & Dependent variable (Educational attainment) \\
\hline \multirow{11}{*}{ Question 1} & When did you leave school without a certificate? \\
\hline & 1. I don’t know anymore \\
\hline & 2. In 7 th grade \\
\hline & 3. After 7 th grade \\
\hline & 4. In 8th grade \\
\hline & 5. After 8th grade \\
\hline & 6. In 9th grade \\
\hline & 7. After 9th grade \\
\hline & 8. In 10th grade \\
\hline & 9. After 10th grade (HAVO or VWO) \\
\hline & 10. After 10th grade: failed the VMBO exam \\
\hline \multicolumn{2}{|r|}{ Hours of study (s) } \\
\hline \multirow[t]{12}{*}{ Question 6} & How long did you study a day on average during the final grade? \\
\hline & 1. I don't know anymore \\
\hline & 2. I did not do homework \\
\hline & 3. Less than $1 / 2$ hour a day \\
\hline & 4. $1 / 2$ to 1 hour a day \\
\hline & 5. 1 to 1.5 hours a day \\
\hline & 6. 1.5 to 2 hours a day \\
\hline & 7. 2 to 2.5 hours a day \\
\hline & 8. 2.5 to 3 hours a day \\
\hline & 9. 3 to 3.5 hours a day \\
\hline & 10. more than 3.5 hours a day \\
\hline & Hours of truancy $(\mathrm{h})-(1)$ \\
\hline \multirow[t]{8}{*}{ Question 11} & How often were you unauthorized absent from school last year? \\
\hline & 1. Never \\
\hline & 2. One or several times \\
\hline & 3. Every month at least once \\
\hline & 4. Every week at least once \\
\hline & 5. Every week at least two or three times \\
\hline & 6. At least every day \\
\hline & Hours of truancy $(\mathrm{h})-(2)$ \\
\hline \multirow[t]{6}{*}{ Question 12} & How long were you every time unauthorized absent from school? \\
\hline & 1. One or two hours of class \\
\hline & 2. A half of school day \\
\hline & 3. A total school day \\
\hline & 4. Multiple days in a row \\
\hline & 5. fluctuating \\
\hline
\end{tabular}

Note: Continued on the next page. 
(Table 7.2 - Continued)

Motivation (m)

Question 5.12 Mark the answer best fitting your opinion

In that final grade I most often did like going to school.

1. do not agree

2. agree a little

3. agree

4. totally agree

Scale discount factor (rho)

Question 17 Below there are 6 choices that represent your future in four years.

Tick where appropriate.

In four years I would like to...

1. be enrolled in education

2. have paid work

3. be enrolled in education and have paid work

4. live on (unemployment or social) benefits

5. do the housekeeping

6. do volunteer work

Education for job (phi)

Question 21 What is the educational level necessary for that job?

1. None

2. VMBO (pre-vocational)

3. HAVO (general secondary)

4. VWO (pre-university)

5. MBO 1 (vocational-1)

6. MBO 2 (vocational-2)

7. MBO 3 (vocational-3)

8. MBO 4 (vocational-4)

9. HBO (adult vocational)

10. University

11. Other, namely...

Scale school attendance (y)

Question 5.17 Attending school is important

1. do not agree

2. agree a little

3. agree

4. totally agree 
Table 7.3: Descriptive statistics of a sample of pre-vocational students in the VOCL99 survey (percent share).

\begin{tabular}{|c|c|c|c|}
\hline & \multicolumn{2}{|c|}{ Educational attainment } & \multirow[t]{2}{*}{ Total } \\
\hline & certificate & dropout & \\
\hline $\mathrm{N}$ & 3,732 & 236 & 3,968 \\
\hline \multicolumn{4}{|l|}{ study time a day $(s)$} \\
\hline No study time & 0.3390 & 0.1190 & 0.1321 \\
\hline less than 1 hour & 0.2203 & 0.3020 & 0.2971 \\
\hline 1 hour or more & 0.4407 & 0.5790 & 0.5708 \\
\hline \multicolumn{4}{|l|}{ hours of truancy a day $(h)$} \\
\hline 0 hours & 0.4788 & 0.4810 & 0.4808 \\
\hline $0-4$ hours & 0.5000 & 0.5176 & 0.5167 \\
\hline 4-8 hours & 0.0212 & 0.0013 & 0.0026 \\
\hline \multicolumn{4}{|l|}{ motivation $(m)$} \\
\hline 0 (don’t like attendance) & 0.4110 & 0.1254 & 0.1424 \\
\hline 1 (only like attendance a little) & 0.2500 & 0.2945 & 0.2918 \\
\hline 2 (like attendance) & 0.2331 & 0.4373 & 0.4252 \\
\hline 3 (like attendance very much) & 0.1059 & 0.1428 & 0.1406 \\
\hline scale discount factor $(\rho)$ & & & \\
\hline 0 (don't like education in 4 years) & 0.3051 & 0.2757 & 0.2775 \\
\hline 1 (only like education a little in 4 years) & 0.2458 & 0.2800 & 0.2780 \\
\hline 2 (like education in 4 years) & 0.2076 & 0.2353 & 0.2336 \\
\hline 3 (like education very much in 4 years) & 0.2415 & 0.2090 & 0.2109 \\
\hline \multicolumn{4}{|l|}{ education for job $(\phi)$} \\
\hline No education & 0.1017 & 0.0177 & 0.0227 \\
\hline pre-vocational (vmbo) & 0.0805 & 0.0445 & 0.0466 \\
\hline general (havo) & 0.0424 & 0.0139 & 0.0156 \\
\hline pre-university (vwo) & 0.0127 & 0.0021 & 0.0028 \\
\hline vocational (mbo-1) & 0.0254 & 0.0110 & 0.0118 \\
\hline vocational (mbo-2) & 0.0847 & 0.0606 & 0.0620 \\
\hline vocational (mbo-3) & 0.1441 & 0.1442 & 0.1442 \\
\hline vocational (mbo-4) & 0.1864 & 0.2093 & 0.2079 \\
\hline adult vocational (hbo) & 0.2373 & 0.3934 & 0.3841 \\
\hline university & 0.0466 & 0.0678 & 0.0665 \\
\hline other & 0.0381 & 0.0356 & 0.0358 \\
\hline \multicolumn{4}{|l|}{ scale school attendance $(y)$} \\
\hline 0 (not important) & 0.3814 & 0.0707 & 0.0892 \\
\hline 1 (little important) & 0.2542 & 0.2610 & 0.2606 \\
\hline 2 (important) & 0.2500 & 0.4523 & 0.4403 \\
\hline 3 (very important) & 0.1144 & 0.2160 & 0.2099 \\
\hline
\end{tabular}


(Table 7.2 - Legend)

$s$ : Study time measured by the additional hours of study a day after compulsory school time.

$h$ : Extracurricular activities measured by hours of work a day.

$m$ : Utility from intrinsic motivation for schooling measured by a Likert scale.

$\rho$ : Discount factor measured by the likelihood to be in education in four years' time.

$\phi$ : Utility from school attendance measured by the minimum qualifications for the desired future job.

$y$ : Importance of school attendance measured by a Likert scale.

years retention in grade. In total, $2.10 \%$ of sample students failed the final vmbo exam.

Table 7.3 provides some descriptive statistics of the data, while Table 7.2 in the Appendix presents the relevant questions from the survey. Note that we distinguish between students who did obtain a certificate, and those who did not. The dependent variable measures whether a student finally obtained a certificate of secondary education (i.e. a vocational, a general education, or a pre-university certificate). Students who left school without a certificate obtain a value of 0 , while graduates with an upper secondary certificate obtain a value 1 . From our cohort of secondary school students, $94.0 \%$ graduated with at least a pre-vocational certificate.

Next, consider the independent variables. First, we consider the daily study time at home. This was ascertained by asking the students the question: 'How long did you study a day on average during the final grade?' We observe that $13 \%$ of the total sample responded that they did not study after school time. Thus, the majority of students studied one or more hours a day per week after compulsory school attendance. Note that dropout students, on average, studied less hours at home than students who did obtain their certificate. Second, the survey asked students about their unauthorized school attendance $(h)$ by two questions: (1) How many times a week were 
you absent from school over the last school year? And (2) How many hours did you not attend school during the absence? From these two variables, we computed the hours of absence a day per week, which serves as a proxy for $h .^{5}$ Almost one in two students was never absent from school, and one in every two students was absent for less than four hours a day per week. Only very few students were absent for one full day per week. While those numbers might seem very high, they are in line with other surveys and observations. Third, students were asked whether they liked to attend school. This serves as a proxy for the intrinsic motivation $(m) .43 \%$ of the students replied that they did not like or only to a small exent liked to attend school. We observe a significant difference in this respect between dropout students $(66 \%)$ and graduates (42\%). Fourth, to obtain information on the discount variable $(\rho)$, students were asked whether they would like to be in education in four years time. In line with the expectations, this variable is equally distributed between the four response groups. Next, students were asked what in their opinion was the education level necessary to obtain their desired job $(\phi)$. This serves as a proxy for the utility from school attendance. For most students, the education necessary for the desired future job demands at least vocational education or training (mbo). About $7 \%$ of graduates responded that they were aiming for a university education, compared to $5 \%$ for dropout students. Only $2 \%$ of students with a certificate said that they did not need an upper secondary certificate for the job. This percent share can be compared with $10 \%$ among dropout students. Finally, the students were asked about the importance of school attendance $(y)$ presenting them with the statement 'Attending school is important'. The respondents could then mark on a four-point Likert scale whether they agreed with the statement or not. More than $60 \%$ of the students responded that school at-

\footnotetext{
${ }^{5}$ Note that, because of self-reporting, this variable might be prone to measurement errors. Underlying analysis by Zijsling and van der Werf (2007) indicates that this is not a serious issue in the VOCL, mainly because students were only asked about their truancy behavior after graduation.
} 
Table 7.4: Correlation matrix.

\begin{tabular}{|c|c|c|c|c|c|c|c|}
\hline & certificate & $s$ & $h_{a}$ & $m$ & $\rho$ & $\phi$ & $y$ \\
\hline certificate & 1 & & & & & & \\
\hline$s$ & $\begin{array}{r}0.1235 \\
(0.0000)\end{array}$ & 1 & & & & & \\
\hline$h_{a}$ & $\begin{array}{r}-0.1357 \\
(0.0000)\end{array}$ & $\begin{array}{r}-0.1302 \\
(0.0000)\end{array}$ & 1 & & & & \\
\hline$m$ & $\begin{array}{r}0.1630 \\
(0.0000)\end{array}$ & $\begin{array}{r}0.2435 \\
(0.0000)\end{array}$ & $\begin{array}{r}-0.1086 \\
(0.0000)\end{array}$ & 1 & & & \\
\hline$\rho$ & $\begin{array}{r}-0.0122 \\
(0.3843)\end{array}$ & $\begin{array}{r}-0.0009 \\
(0.9563)\end{array}$ & $\begin{array}{r}0.0422 \\
(0.0028)\end{array}$ & $\begin{array}{r}0.0597 \\
(0.0000)\end{array}$ & 1 & & \\
\hline$\phi$ & $\begin{array}{r}0.1391 \\
(0.0000)\end{array}$ & $\begin{array}{r}0.0792 \\
(0.0000)\end{array}$ & $\begin{array}{r}-0.0435 \\
(0.0018)\end{array}$ & $\begin{array}{r}0.0993 \\
(0.0000)\end{array}$ & $\begin{array}{r}0.2468 \\
(0.0000)\end{array}$ & 1 & \\
\hline$y$ & $\begin{array}{r}0.1933 \\
(0.0000)\end{array}$ & $\begin{array}{r}0.3649 \\
(0.0000)\end{array}$ & $\begin{array}{r}-0.1570 \\
(0.0000)\end{array}$ & $\begin{array}{r}0.4643 \\
(0.0000)\end{array}$ & $\begin{array}{r}0.1254 \\
(0.0000)\end{array}$ & $\begin{array}{r}0.1277 \\
(0.0000)\end{array}$ & 1 \\
\hline
\end{tabular}

Note: P-values between brackets.

tendance was important to very important. For those students who did not find school attendance important, we observe significant differences between dropout students $(38 \%)$ and graduates $(7 \%)$.

The data used in the empirical test are survey data. This has some inherent advantages and disadvantages (e.g. Bos et al. 1992). Concerning the advantages, survey data allow us to obtain valuable insights, for instance, into the students' living environment, attitudes, and motivation, which are rarely captured in administrative data. However, a major disadvantage of using surveys, is that the data might be prone to significant measurement errors, for example, due to self-reporting of behavior or attrition. Referring to the survey used in this paper, Zijsling and van der Werf (2007) argue that 
the degree of measurement errors is rather low. Moreover, they show that the data are representative for all Dutch pre-vocational students, and that the individual questionnaire items are valid. A second issue might arise from multicollinearity between the explanatory variables. We can easily check for this by simple pairwise or inter-item correlation tests. Table 7.4 in the Appendix shows a relatively low, though significant, correlation between the variables.

\subsection{Results}

\section{First stage}

The first stage of the identification strategy involves the estimation of equation (7.10). To facilitate the interpretation, we have standardized the variables before estimating the probit regression. The results of the probit estimation are provided in the appendix (see Table 7.5). The probability of obtaining a certificate increases with study hours $(\hat{s}=0.0524$, although not significant), utility from intrinsic motivation $(\hat{m}=0.1061$, significant at the $1 \%$-level $)$ and extrinsic motivation $(\hat{y}=0.2432$, significant at the $1 \%$-level). It is remarkable that the extrinsic motivation has a larger influence on the probability to obtain a certificate than the intrinsic motivation. The perceived utility from school attendance increases the probability of obtaining a higher secondary degree by $18 \%(\hat{\phi}=0.1876$, significant at the $1 \%$-level). On the other hand, the higher the value attached to future education, the less likely it is a student has obtained his/her certificate in period 1 ( $\hat{\rho}=-0.0827$, significant at the 5\%-level). Finally, and perhaps most importantly, the number of hours spent on extracurricular activities is negatively associated with lower educational attainments $\left(\hat{h}_{a}=-0.0817\right.$,

significant at $1 \%$-level). This finding is in line with the previous literature indicating that unauthorized school absenteeism increases the likelihood of dropping out of school (Schaefer and Millman, 1981; Henry, 2007; Sutphen, 
2010; Cabus and De Witte, 2012b).

\section{Second stage}

In the second stage of the empirical strategy, the estimated coefficients from Table 7.5 are used to predict the graduation rates in equation (7.9). The results are presented in Table 7.6 for different assumptions on the total utility $\lambda$, and the degree of policy interventions $\theta$. By modeling $\theta$ in a second-order polynomial function $\left(\theta+\theta^{2}\right)$, we assume that additional policy measures have an accelerating effect on early school-leaving. ${ }^{6}$ The variable $\theta$ ranges from 0 , i.e. total lack of policy on early school-leaving, to 1, i.e. an extremely strict policy on school dropout. Concerning the variable $\lambda$, we argued before that $\lambda$ is concave in $c$ and $l$. Therefore, lower values of $\lambda$ correspond to higher values of consumption and leisure, and thus to a higher GDP. While, theoretically, $\lambda$ can range from 1 (i.e. the numerair) to 0 (i.e. a total inelastic utility from additional consumption and leisure), in Table 7.6 we only present values of $\lambda \geq 0$.6. Smaller values of $\lambda$ are unrealistic and deliver unreliable results.

The assumptions on $\lambda$ are in line with theories on human capital accumulation, economic development and technological change (Nelson and Phelps, 1966; Schultz, 1967; Becker, 1965, 1992; Mincer, 1974). In the early 1900s, consumption and leisure were highly valued, as people worked hard and for many hours a day. As such, one may reasonably argue that utility from consumption and leisure was very high $(\lambda$ near 1$)$ and enrollment in school very low. Socioeconomic tendencies over the past century have created welfare, and the (household) income has increased substantially. Nowadays, a considerable share of the population works in sedentary jobs for about eight hours a day, leaving more time for people to attain a proper education. Technological change has also changed the demand from low-skilled to highskilled workers. One may reasonably argue that, today, the value attached

\footnotetext{
${ }^{6}$ In contrast, a first-order function in $\theta$ assumes that the influence of $\theta$ is constant for each marginal increase.
} 
to future education is higher than it has been over the past century. As a result of these tendencies towards knowledge, a drop in $\lambda$ increases school enrollment substantially.

The results in Table 7.6 suggest that, holding $\lambda$ constant, policy interventions have an accelerated impact on the reduction of school dropout. For example, under the assumption of an average utility of consumption and leisure of $(\lambda=0.6)$, an increase in the level of the dropout prevention policies by a quantile (from 0.25 to 0.5 ) reduces school dropout by about 3 percentage points from $15 \%$ to $12 \%$. Nevertheless, a very strict policy might keep almost all students at school (i.e. under $\theta=1.00$ and $\lambda=0.6$, the school dropout rate equals only $2.3 \%$ ). School dropout declines by about 14.8 percentage points as result of the introduction of a strict dropout prevention policy (i.e. from $(\theta=0.00)$ to $(\theta=1.00))$. On the other hand, the utility from consumption and leisure has a more pronounced effect on enrollment rates. For example, if utility from consumption and leisure decreases (e.g. by an increase in GDP) from $(\lambda=1)$ to $(\lambda=0.6)$, the graduation rates soar under a constant policy from $19.3 \%$ to about $82.9 \%$.

\section{Policy Modeling}

In 2005, the Dutch dropout rate amounted to $13.5 \%$ (Eurostat). As shown in Table 7.6, the resulting school attendance of $86.5 \%$ corresponds to $\lambda=$ 0.6 and $\theta=0.40$. Under a stable real GDP in the period 2005-2008 (i.e. $\lambda$ remains 0.6 ), we observed in the Netherlands an increase in the school attendance rate to $88.6 \%$. This corresponds to $\theta=0.52$. 

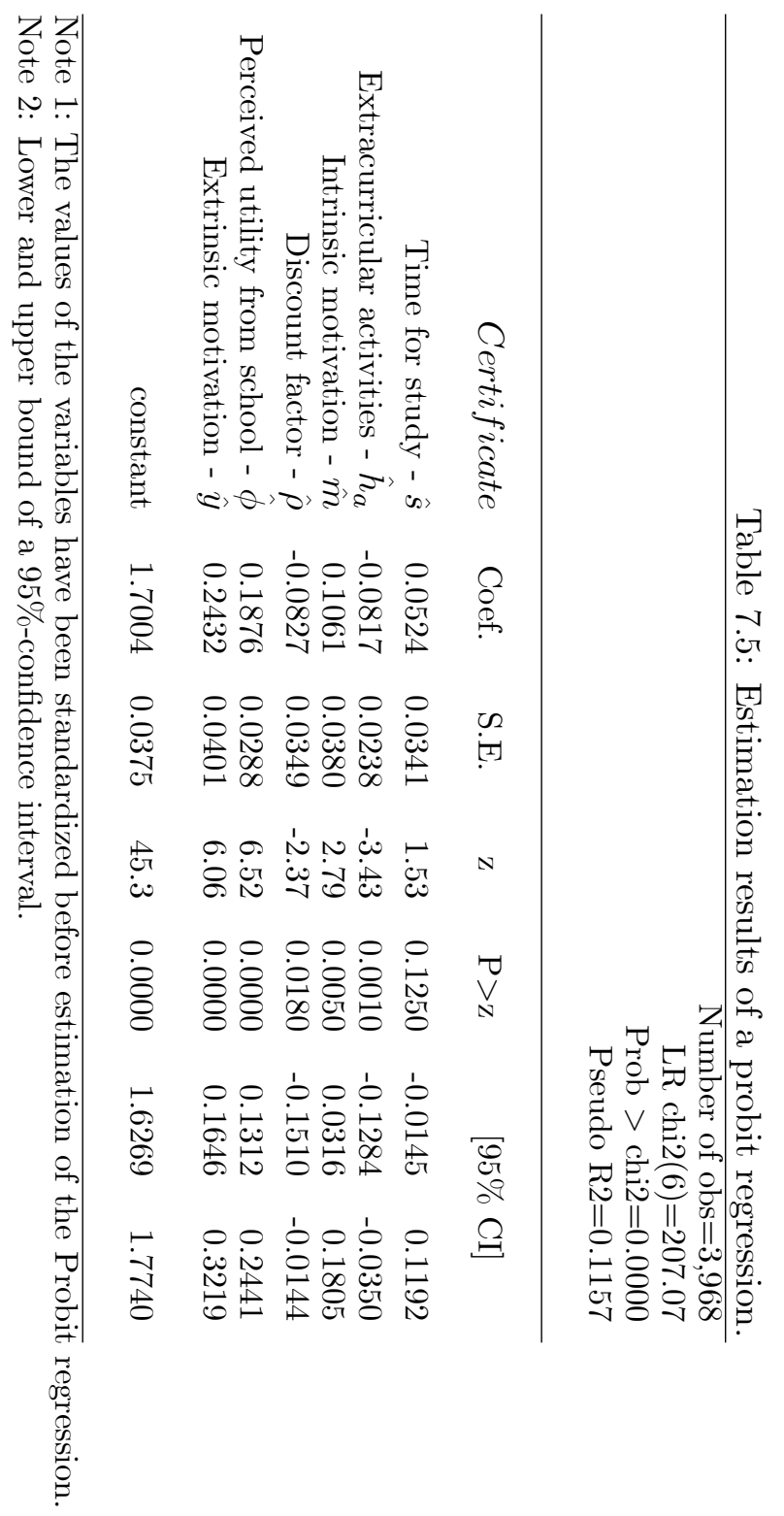
Table 7.6: School attendance rate based on decision rule of equation (9).

\begin{tabular}{llllll}
\hline & $\lambda=1$ & $\lambda=0.9$ & $\lambda=0.8$ & $\lambda=0.7$ & $\lambda=0.6$ \\
\hline$\theta=0.00$ & $19.3 \%$ & $29.9 \%$ & $43.1 \%$ & $60.2 \%$ & $82.9 \%$ \\
$\theta=0.25$ & $21.4 \%$ & $32.0 \%$ & $45.2 \%$ & $62.3 \%$ & $85.0 \%$ \\
$\theta=0.50$ & $24.4 \%$ & $35.1 \%$ & $48.3 \%$ & $65.3 \%$ & $88.1 \%$ \\
$\theta=0.75$ & $28.7 \%$ & $39.3 \%$ & $52.5 \%$ & $69.6 \%$ & $92.3 \%$ \\
$\theta=1.00$ & $34.1 \%$ & $44.7 \%$ & $58.0 \%$ & $75.0 \%$ & $97.7 \%$
\end{tabular}

where the function of $\theta$ is denoted by a second-order polynomial $\left(\theta+\theta^{2}\right)$.

While the underlying data for the empirical analysis originate from 200506, it is clear that they can be used for long-run predictions of the effects of dropout prevention policy on early school-leaving. Figure 7.1 plots the actual and predicted school dropout rates for the Netherlands. The predictions are presented for an increase in the prevention policy intensity $\theta$ by 5 percentage points each year, and under a ceteris paribus assumption for $\lambda .{ }^{7}$ From Figure 7.1 we observe that the predictions generated by our model fit the observed data extremely well. Our model is, therefore, able to explain the observed increase in school enrollment rates in the period 2000-2010.

The available budget for Dutch dropout prevention policy has increased from $€ 313$ million in 2008 to $€ 400$ million in 2011 . Every 5 percentage points increase in $\theta$ has, therefore, cost about $€ 29$ million. Extrapolating this insight, we can forecast that, if policymakers aim for a maximum dropout prevention policy intensity (i.e. $\theta=1$ ), ceteris paribus, the total budget is estimated $€ 574$ million per annum. Expressed as a percentage of GDP, this

\footnotetext{
${ }^{7}$ As GDP (PPP, constant 2005 international \$) increased in the Netherlands from 2000 to 2011 on average by only $0.67 \%$ (World Bank indicators), it can be assumed that $\lambda$ stayed nearly constant during this period.
} 
CHAPTER 7. CHALLENGES FOR PREVENTION POLICY: WHAT AND FOR WHOM?

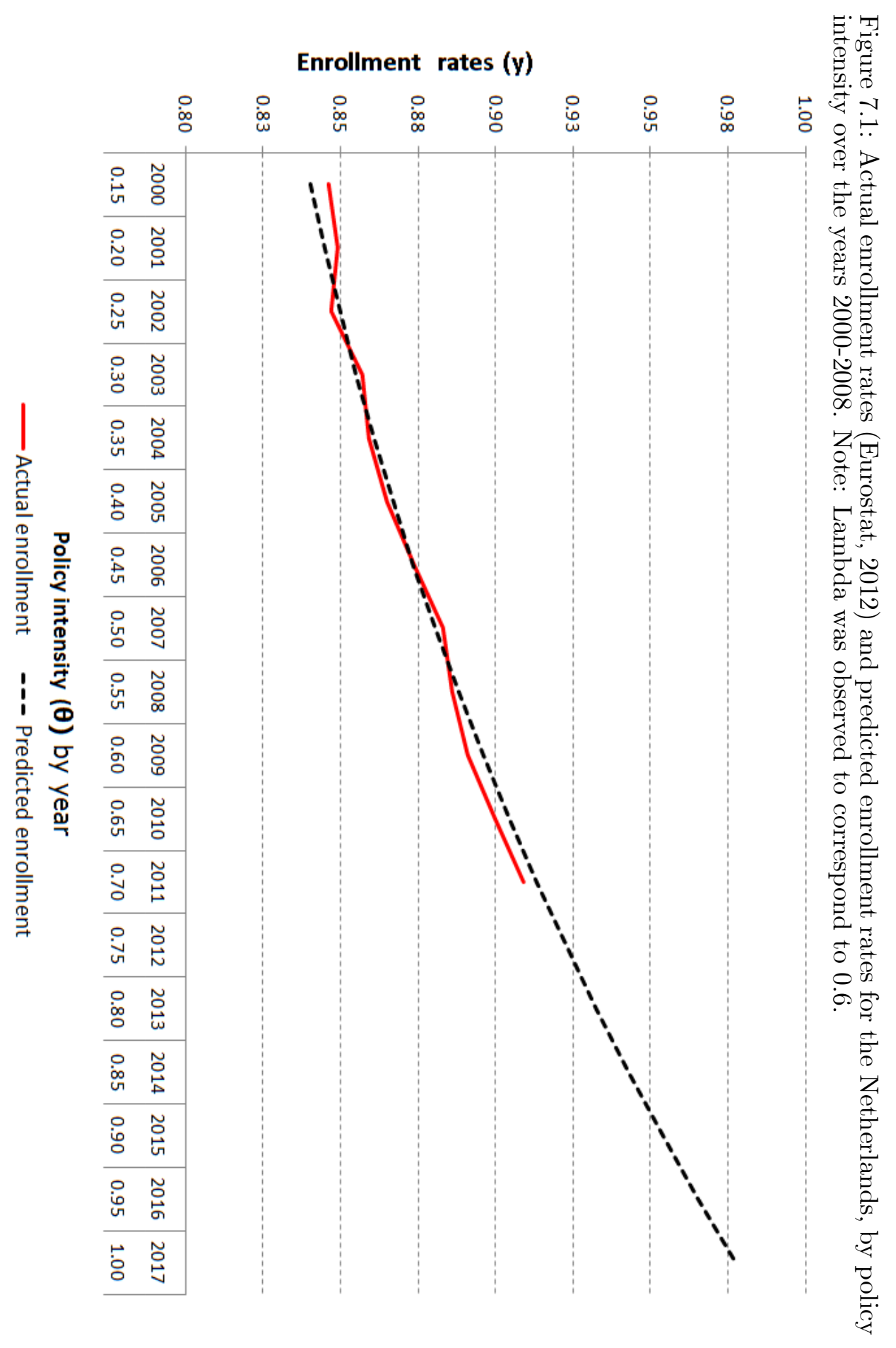


corresponds to a budget (in Purchasing Power Parity in 2005 international $\$$ ) rising from $0.07 \%$ in 2011 to $0.10 \%$ in 2017.

\subsection{Conclusion}

This chapter has contributed to the growing literature on school dropout by proposing and empirically testing a theoretical model of the decision making of students to stay at school in secondary education. The model is inspired by the work of Cameron and Heckman (1998) and Keane (2002). In line with the literature on educational achievement, in general, and school dropout, in particular, we construct a two-period discrete time model in which students make a decision to stay at school conditional on their time constraint, motivation constraint, job market aspirations, and current (school or national) policy measures. Thus, we start by modifying the theoretical framework of Keane (2002) to match the dropout decision of secondary education students. The way the model is constructed allows us to distinguish between the influence of policy making and economic growth on early schoolleaving. As economic development increases the importance attached to a higher secondary degree, an increasing GDP reduces the occurence of early school-leaving. On the other hand, a stricter policy with respect to early school-leaving reduces school dropout, but it requires that scarce resources are allocated to this policy. The decision rule derived from the theoretical model is empirically tested on Dutch survey data concerning vocational students. While the data originate from 1999, we are able to explain the observed Dutch school enrollment rates over the period 2000-2010. Moreover, the empirical application can be used to forecast the influence of a stricter school dropout prevention policy or of an increase in economic development. For example, for the Netherlands we observe that the Dutch government can easily reach the European Horizon 2020 target of $8 \%$ for early school-leaving. Our results indicate that an increase of one point in policy strictness costs 
about $€ 5.8$ million.

The theoretical model could be elaborated in several ways. First, the model does not explore other sources of utility arising from, for example, class composition and educational quality. An extension to other time periods is also worth exploring. Second, the empirical model does not include additional control variables. Previous research has argued that, among other school dropout determinants, gender, ethnicity, socioeconomic background, and place of residence play an important role in the decision of students to drop out (Chapter 1 and Chapter 6). By controlling for similar variables, the accuracy of the model might be further improved. Third, the empirical model has only been tested on the Netherlands. To facilitate alternative applications to other countries, the Stata-code is available upon request.

The theoretical model and empirical results from this chapter provide various avenues for discussion and further research. Throughout this dissertation, we have explored dropout prevention measures in the Netherlands over the past decade, and, finally, have identified the annual budget necessary to make the Dutch dropout prevention policy feasible. Section 7.6 now discusses these policy challenges from the past decade. Furthermore, the empirical results from this chapter have also identified to what extent the annual budget should increase: namely, to $€ 0.6$ billion or 0.10 percent of Dutch GDP, to reduce the dropout rate to nearly 3 percent. Further research should identify whether, and how, this annual budget should be spent to be (cost-) effective, and which challenges for prevention policy will then have to be met. Section 7.7 presents this new area for further research.

\subsection{Policy discussion}

\subsubsection{Schools, not policymakers, are making prevention policy feasible.}

Many government officials and policymakers across OECD countries have developed prevention programs to reduce dropping out of secondary edu- 
cation towards meeting the supra-national Agenda Targets. However, it is the schools, not the policymakers, which are making dropout prevention policy feasible. Many dropout prevention measures are implemented by the schools, and aim at the student/individual (Chapter 4). Dropout prevention policy at the school site is enhanced by delegating (policy) autonomy to the schools, so that school staff and teachers can adjust their prevention policy to the composition of the student population in school. The Dutch covenants, which are written agreements signed by the Ministry of Education, Culture, and Science, the Regional Dropout Authorities, and the schools, can then be useful tools for supporting prevention measures to match the student composition in schools. Consequently, schools can better reach the potential dropout student if he/she is attending class at the school site. We provide evidence in line with this statement. It is observed that: (1) truants are three times more likely to leave education early before the end of the compulsory education age is reached (Chapter 3); (2) students in practical-oriented (i.e. work-based) pathways are more likely dropping out of school compared with their school-based peers (Chapter 4 and Chapter $5)$; and (3) students drop out of school if they fail to make a good transition between two consecutive years or two different schools (Chapter 6). 
7.6.2. Should I leave, or should I stay? Or should I come back another day? Three tips for not considering dropping out of school: (1) find the school that suits you best; (2) be suspicious of frank employers (who offer you a bright future without a certificate); and (3) do not take part in extreme sports.

Previous research on school dropout and its determinants can be divided in two strands. The first strand deals with the underlying factors of student attrition, and largely explains why some youngsters leave education before their secondary school-leaving certificate is obtained. For instance, deteriorating student motivation may arise from several factors, ranging from low ability and socioeconomic background, via class composition and disconnection with peers and teachers, to teenage pregnancy, bad health, or involvement in juvenile crime (Chapter 1). We have contributed to this first strand of literature by evaluating the effectiveness of student motivation/commitment policies in improving the transition between two consecutive years and schools, and find that motivation/commitment is hard to influence (Chapter 6). The policy did not reduce early school-leaving among native Dutch students, and even increased the school dropout rate among ethnic minority students. However, it is also observed that, once the transition to the vocational school is successfully made, dropout prevention as a bundle of measures/interventions implemented by the school reduced the school dropout rate among both native Dutch- and ethnic minority students. This finding fully supports the idea that preventive measures/interventions - in school - can only work if the student connects with the school.

The second strand of the literature indicates that labor market conditions can have an impact on the schooling outcomes of, especially, vocational students. We have contributed to this second strand of the literature by evaluating the impact of a one-year increase in the compulsory education age on school dropout (Chapter 5). The previous literature has argued that compulsory education age legislations are preventing school-aged (vocational) youngsters from sacrificing school for the labor market and, thus, from leav- 
ing school early. The Dutch government increased the compulsory education age from 17 to 18 years old in the year 2007. In the first instance, we find that fewer (-2.5 percentage points) students dropped out of school owing to a one-year increase in the compulsory education age. However, this result was mainly driven by Dutch control students, enrolled in vocational study subjects, and without retention in grade, who left in the period immediate after the policy reform, i.e. in the summer months of the year 2007. Treatment students did not change their dropout decision. Given the economic revival at the time of the compulsory education age change, control students most likely anticipated job market opportunities. Indeed, we could reasonably argue that employers pulled a last available cohort of low-skilled 17 year-olds students out of school in response to the changing compulsory education age law. As a result, from 2007, the next cohort of low-skilled youngsters who still could legally leave education (early), would not have been available for two years. 
7.6.3. Both schools and employers are at least partially responsible for students dropping out of school, and, consequently, should help address the problem.

Rumberger and Larson (1998, p.2) argue that "[...] schools are at least partly responsible for high student turnover and, consequently, should help address the problem." School accountability in this respect increasingly won attention over the last decade to make parents, school staff, and teachers responsible for the educational attainment of youngsters. Illustrative of this is the performance bonus of $€ 2,500$ for each dropout less in Dutch schools compared with the base year 2005-06. This traditional regulatory framework is in line with the literature on the underlying factors of student attrition, and mainly deals with the link between home and school institutions.

There is indeed a particular and important role for parents, school staff, and teachers, in helping (to motivate) children to obtain a certificate, and find a connection with the labor market. However, we indicate that successful dropout prevention policies should also aim at the link between home/school and labor market institutions and its relationship with early school-leaving. This existing link could be an argument for employer accountability besides that of parents and school staff.

Employer accountability deals with employers who are considered responsible for their employees' competitiveness in the labor market. If employers are indeed responsible for their employees' competitiveness, then (1) there may well be more opportunities for youngsters to obtain an (equivalent) secondary school-leaving certificate in the labor market; and (2) there is no longer a clear cut-off between school and work. Thus, employer accountability may well be an argument for a close collaboration between education and labor market institutions, for example, by elaborating on accredited dual tracks, adult education, school-work contracts, on-the-job training, or other educational arrangements, and the active implementation of the concept of lifelong learning (Chapter 4). For instance, school dropouts could be 
acknowledged with a certificate equivalent to a higher secondary certificate that should overrule a lifelong risk indicator (e.g. NVQ). Although many of these concepts have already been 'invented' in the past, there is very little evidence on their effectiveness in terms of better schooling, and labor market, outcomes. In addition, employer accountability also may well be an argument for a particular role for government officials and policymakers to provide employers with incentives that make them actively participating in the general (social) debate on leaving secondary education early. 
7.6.4. School dropout is expensive for an individual, and for society. Thus, school dropout can no longer be an option, and, therefore, policymakers should invest $€ 0.6$ billion a year in keeping our children in school.

It is observed that school dropouts have higher private costs than their peers who have graduated, as they are more liable to long-run unemployment, physical or mental problems, poverty, and exclusion from society. School dropouts also impose higher burdens on society than their peers with a higher secondary certificate, burdens which are attributable to (juvenile) crime, unemployment allowances, social security benefits, and loss in tax revenues.

However, dropout prevention is expensive, too. Levin et al. (2006, p.1) argue in this respect that:

"The investment criterion is a simple one: public investments are worth making if the benefits exceed the costs. Even if education is expensive, poor and inadequate education for substantial numbers of our young may have consequences that are even more costly. Such an analysis goes beyond the more basic question of social justice. If life chances depend heavily on education, it is important that inequalities in education associated with race, gender, immigrant status, language, and handicap be redressed as a basis for equalizing opportunities in a democratic society. But, even beyond the issue of injustice is the question of whether a poor quality education has consequences for the larger society. Social science research shows that poor education imposes social burdens via lower incomes and economic growth, lower tax revenues, and higher costs of such public services as health, criminal justice, and public assistance. In this respect, it is possible to view efforts to improve educational outcomes for at-risk populations as a public investment that may have benefits for the entire society in excess of investment costs." 
Thus, public investments in lowering the school dropout rate should be balanced against private costs, and social costs as well. In view of this, every euro of investment in reducing the level of school dropout in countries, regions, or schools, will also be an investment beyond the problem of school dropout. School dropout in this respect is increasingly considered as the key to achieving other (supra-) national policy targets in high-income countries. However, public resources are scarce, and not every euro of investment in lowering school dropout rates is, therefore, by definition well-spent. This calls for more evaluations on the (cost-) effectiveness of dropout prevention measures/programs, so that only those measures/programs which have been proved to work continue to exist.

\subsection{Further research}

Every chapter in this dissertation has already highlighted the scope for further research especially with respect to the subject of interest in that particular chapter. The main aim of this section is, therefore, to outline further research that goes beyond the scope of this dissertation.

A first possibility for further research concerns the impact of retention in grade on early school-leaving. Retention in grade has not been discussed in-depth because of considerable data difficulties (Chapter 3). In the previous literature, it has been argued that an educational policy aimed at students with retention in grade is far more fundamental in nature when considering the initial reason for grade repetition, i.e. school readiness or school failure (see Datar, 2006; Snow, 2006). As a consequence, students may pile up their retention in grade even from early childhood. They reach the compulsory education age before obtaining a secondary certificate by definition. (Early) retention in grade thus necessarily implies that, ultimately, students must do one or more years in school voluntarily, i.e. when they are no longer in compulsory education, if they want to obtain a certificate. 
If retention in grade is associated with the underlying factors of student attrition, and youngsters are no longer compelled to stay in secondary education beyond the compulsory school-age, than high rates of school dropout among students with retention in grade can be expected once they reach the compulsory education age. Further research in this field should reveal the usefulness of an active implementation of the Regulation of Qualifications in the Compulsory Education Age Law. Students would then be compelled to stay in school until they had obtained a certificate valid for labor market entrance, rather than until the compulsory education age is reached. This may well be an argument for a role for education in the labor market, as some older students with retention in grade may wish to combine learning and working, for example, for financial reasons. Further research in this respect should then focus on how education in the labor market can be successfully organized for school dropouts, and should identify employer incentives that successfully integrate people at-risk of exclusion into the labor market.

A second possibility for further research should aim at the cost-effectiveness of dropout prevention. We have indicated that dropout prevention is expensive, but that investment in prevention policy goes beyond the problem of school dropout. For reasons of cost-effectiveness, it may be desirable to identify dropout prevention initiatives aiming for at-risk students. It has been discussed that the dropout rate is high especially among vocational students who have already experienced the attractiveness of the labor market while still in school. However, not all vocational students are at-risk of dropping out, and at least some share of the population in school-based curriculums is also at-risk. This calls for a comprehensive cost-effective indicator that is able to identify at-risk students at all educational levels. One particular menu-item of the Dutch dropout prevention program has put emphasis on reporting truants. This prevention measure relies on a good registration system with uniform definitions, such as BRON. It has been indicated that 
school-aged students who have a record of unauthorized truancy, drop out of school at an earlier point in time in their school career than regular school attendees. Unauthorized truancy, therefore, identifies students at-risk of dropping out at all educational (ability) levels.

A third possibility for further research is to identify potential problems arising from the school accountability regulatory framework. There is a particular and important role for parents, school staff, and teachers, so that they can motivate children to obtain a certificate, and find connection with the labor market. The other side of school accountability is that it increasingly puts stress on households and school staff to reach targets (e.g. the Lisbon Agenda Targets translated into national, regional and school targets). Reaching such targets may increase the exclusion of weak performers in schools - schools do not want to miss out on their performance bonus. Students at-risk of dropping out could then be especially selected for exclusion, and the good idea of dropout prevention would then completely miss its goal. Further research should identify and discuss alternative regulatory frameworks for school accountability (e.g. employer accountability).

To conclude, we present a final possibility for further research which deals with the transition from school to work. The transition from school to work is often problematic for youngsters, in general, and vocational students, in particular. In-school work experiences affect the labor market outcomes of (early) school-leaving vocational youth, as they are more likely to take up short-run job market opportunities in times of economic revival. Once on the job market, they are highly sensitive to economic conditions, among other negative circumstances that cause youth unemployment. This raises the question whether, and to what extent, practical-oriented students have an overall higher return to their vocational specialization in the short-run, compared with their academic-oriented peers, so that they are more likely to take up job market opportunities. Further research should identify the 
CHAPTER 7. CHALLENGES FOR PREVENTION POLICY: WHAT AND FOR WHOM?

short-run and long-run return to gaining in-school practical experiences in terms of, for example, labor market wages, or the total number of times they have to apply for a job. 


\section{Bibliography}

[1] Aakvik, A., Salvanes, K. and Vaage, K. (2003). Measuring heterogeneity in the returns to education in Norway using educational reforms. CEPR Discussion Chapter 4088.

[2] Aalen, O. (1976). Nonparametric inference in connection with multiple decrement models. Scandinavian Journal of Statistics 3, 15-27.

[3] Abadie, A. (2003). Semiparametric Difference-in-Differences Estimators. Harvard University and NBER.

[4] Acemoglu, D. and Angrist, J. (2000). How large are human capital externalities? Evidence from compulsory schooling laws. NBER Macroeconomics Annual 15, 9-59.

[5] Adams, J. L. , Becker, W. E. (1990). Course Withdrawals: A Probit Model and Policy Recommendations. Research in Higher Education 31(6), 519-538.

[6] Aghion, P. and Howitt, P. (1994). Growth and unemployment. The Review of Economic Studies 61(3), 477-494.

[7] Aghion, P. and Howitt, P. (1998). Endogenous Growth Theory. MIT Press, Cambridge, Massachusetts.

[8] Aksony, T., \& Link, C. R. (2000). A Panel Analysis of Student Mathematics achievement in the US in the 1990s: Does increasing the 
amount of time in learning activities affect math achievement? Economics of Education Review, 19, 261-277.

[9] Albouy, V. and Lequien, L. (2009). Does compulsory education lower mortality? Journal of Health Economics 28(1), 155-168.

[10] Alexander, K. and Entwisle, D. (1996). Early schooling and educational inequality: Socioeconomic disparities in children's learning. In J. S. Coleman (Ed.), Falmer sociology series. London: Falmer Press, p. 6379 .

[11] Allen, J. and Meng, C. (2010). Voortijdige Schoolverlaters: aanleiding en gevolgen. [Early school-leavers: causes and consequences.] ROA R-2010/9.

[12] Allensworth, E.M. (2005). Dropout Rates after High-Stakes Testing in Elementary School: A Study of the Contradictory Effects of Chicago's Efforts to End Social Promotion. Educational Evaluation and Policy Analysis 27(4), 341-364.

[13] Anderson, D. J. (1998). 'If You Let Me Play': The effects of participation in high school athletics on students' behavior and economic success. Cornell University, Ph.D. Dissertation.

[14] Anderson, D.,M. (2010). In school and out of trouble? The minimum dropout age and juvenile crime. University of Washington.

[15] Anger, S. and Heineck, G. (2009). Do smart parents raise smart Children? The intergenerational transmission of cognitive abilities. Working Paper series SOEPpaper 156.

[16] Angrist, J.D. and Krueger, A.B. (1991). Does compulsory school attendance affect schooling and earnings? The Quarterly Journal of Economics 106 (4), 979-1014. 
[17] Angrist, J.D. and Pishke, J.S. (2009). Mostly Harmless Econometrics: An Empiricist Companion. Princeton University Press.

[18] Asteriou, D. and Agiomirgianakis, G.M. (2001). Human capital and economic growth: time series evidence from Greece. Journal of Policy Modeling 23(5), 481-189.

[19] Astone, N.M. and McLanahan, S.S. (1991). Family structure, parental practices and high school completion. American Sociological Review 56,309-320.

[20] Astone, N.M. and McLanahan, S.S. (1994). Family Structure, Residential Mobility, and School Dropout: A research note 31(4), 575-584.

[21] Attwood, G. and Croll, P. (2006). Truancy in secondary school pupils: prevalence, trajectories and pupil perspectives. Research Papers in Education 21(4), 467-484.

[22] Auditdienst Ministry of Education, Culture, and Science. 2007. Rapport van bevindingen over Thema-Onderzoek VSV 2007 [Report on school dropout 2007]. Den Haag: Education Inspection, Ministry of Education, Culture, and Science.

[23] Barro, R.J. (1991). Economic growth in a cross-Section of countries. The Quarterly Journal of Economics 106(2), 407-443.

[24] Barro, R.J. and Lee, J.W. (1993). International comparisons of educational attainment. Journal of Monetary Economics 33(3), 363-394.

[25] Barron, J.M., Mark C. Berger, and Black, D.A. (1997). Employer Search, Training, and Vacancy Duration. Economic Inquiry 35 (1), 167-192. 
[26] Barron, J.M., Ewing, B.T., and Wadell, G.R. (2000). The effects of high school athletic participation on education and labormarket outcomes. Review of Economics and Statistics 82, 409-421.

[27] Bean, J.P. (1980). Dropouts and turnover: the synthesis and test of a causal model of student attrition. Research in Higher Education 12, 155-187.

[28] Bean, J.P. and Metzner, B.S. (1985). A conceptual model of nontraditional undergraduate student attrition. Review of Educational Research 55 (4), 485-540.

[29] Becker, G. S. (1965). A theory of the allocation of time. Economic Journal 75, 493-517.

[30] Becker, G.S. (1992), Human Capital and the Economy. Proceedings of the American Philosophical Society 136 (1), 85-92.

[31] Becker, G.S. (1993). Human Capital. A theoretical and empirical analysis with special reference to education. Third Edition. National Bureau of Economic Research, The University of Chicago Press, Ltd. London.

[32] Beekhoven, S. and Dekkers, H. (2005). Early school leaving in the lower vocational track: triangulation of qualitative and quantitative data. Adolescence 40(157), 197-213.

[33] Bell, A. J., Rosen, L. A. and Dynlacht, D. (1994). Truancy intervention. Journal of Research and Development in Education 27, 203-211.

[34] Benhabib, J., Spiegel, M.M. (1994). The role of human capital in economic development. Evidence from aggregate cross-country data. Journal of Monetary Economics 34, 143-173. 
[35] Berktold, J., Geis, S. and Kaufman, P. (1998). Subsequent educational attainment of high school dropouts. Washington, DC : US Dept. of Education, Office of Educational Research and Improvement, National Center for Education Statistics.

[36] Bertrand, M., Duflo, E. and Mullainathan, S. (2003) How Much Should we Trust Differences-in-Differences Estimates? The Quarterly Journal of Economics 119 (1), 249-275.

[37] Besley, T., Bevan, G. and Burchardi, K. (2009). Naming \& Shaming: The Impacts of Different Regimes on Hospital Waiting Times in England and Wales. CEPR Discussion Chapter DP7306.

[38] Black, S.E., Devereux, P.J. and Salvanes, K.G. (2008). Staying in the classroom and out of the maternity ward? The effect of compulsory schooling laws on teenage births. The Economic Journal 118, 10251054.

[39] Blue, D. and J. E. Cook (2004). High School Dropouts: Can we Reverse the Stagnation in School Graduation? Study of High School Restructuring 1(2), 1-11.

[40] Bobonis, G.J.and Finan, F. (2009). Neighborhood peer effects in secondary school enrollment decisions. Review of Economics and Statistics 91(4), 695-716.

[41] Borghans, L., W. Smits, J.D. Vlasblom, and V. Jacobs. (1999). Leren en werken in het Nederlandse beroepsonderwijs. Vraag en aanbodontwikkeling voor de BBL 1999-2004 [Vocational education and employment in the Netherlands 1999-2004]. Maastricht: ROA.

[42] Borghans, L. (2007). Schoolverlaters tussen onderwijs en arbeidsmarkt 2006. [School-leavers between education and the labor market]. Maastricht: ROA. 
[43] Borman, G. D., Hewes, G.M., and Brown. S. (2002). Comprehensive school reform and student achievement. Technical Report 59.

[44] Bos, K., Ruijters, A.M., Visscher, A.J. (1992). Absenteeism in secondary education. British Educational Research Journal 18(4), 381395.

[45] Bosch, G. and Charest, J. (2009). Vocational training: international perspectives. Routledge, 324.

[46] Bound, J., Jaeger, D.A., and Baker, R.M. (1995). Problems with instrumental variables estimation when the correlation between the instrument and the endogenous explanatory variable is weak. Journal of the American Statistical Association 90(430), 443-450.

[47] Bowles, S. (1972). Schooling and Inequality from Generation to Generation. Journal of Political Economy 80(3), S219-S51, Part II.

[48] Bradley and Lenton (2006): Dropping out of post-compulsory education in the UK: an analysis of determinants and outcomes. Journal of Population Economics 20, 299-328.

[49] Braxton, J., A. Sullivan and R. Johnson (1997). Appraising Tinto's theory of college student departure. In Smart, J. (eds.). Higher education: Handbook of theory and research. New York, Agathon.

[50] Breslow, N. (1974). Discussion on the Chapter by D.R. Cox. Journal of the Royal Statistical Society, Series B34, 216-217.

[51] Brown, P., Hesketh, A. and Williams, S. (2003). Employability in a knowledge-driven economy. Journal of Education and Work 16(2), 107-126. 
[52] Brunello, G. and Raffaele, M. (1999). The economic returns to schooling for Italian men. An evaluation based on instrumental variables. Labour Economics 6(4), 509-519.

[53] Buckles, K. and Hungerman, D. (2010). Season of birth and later outcomes: old questions, new answers. NBER Working Paper Series 14573.

[54] Burgess, S. and Stefan, P. (2001). Externalities in the Matching of Workers and Firms in Britain. Labour Economics 8 (3), 313-333.

[55] Bynum, J. and W. Thompson (1983). Dropouts, Stopouts and Persisters: the Effects of Race and Sex Composition of College Classes. College and University 59(1), 39-48.

[56] Cabus, S.J. (2013). Does enhanced student commitment reduce school dropout? Evidence from two major dropout regions in the Netherlands. Regional Studies, DOI:10.1080/00343404.2013.799760.

[57] Cabus, S.J. and De Witte, K. (2011a). Does School Time Matter? On the impact of compulsory education age on school dropout. Economics of Education Review 30(6), 1384-1398.

[58] Cabus, S.J. and De Witte, K. (2011b). Invloed van de Leerplichtwet op voortijdig schoolverlaten. [The impact of a one increase in the compulsory education age on school dropout.] Economisch Statistische Berichten 4606, jaargang 96.

[59] Cabus, S.J. and De Witte, K. (2011c). Werkt een actief verzuimbeleid? [Does an active truancy policy work?] Tijdschrift voor Onderwijsrecht en Onderwijsbeleid, T.O.R.B 2011-1012 (1). 
[60] Cabus, S.J. and De Witte, K. (2012a). Naming and shaming in a 'fair' way. On disentangling the influence of policy in observed outcomes. Journal of Policy Modeling 34(5), 767-787.

[61] Cabus, S.J. and De Witte, K. (2012b). School Absenteeism and Dropout, A Bayesian Duration Model. TIER, Maastricht University, Working Paper.

[62] Cabus, S.J. and De Witte, K. (2013). Why do Students Leave Education Early? - Theory and Evidence on high school dropout rates. TIER, Maastricht University, Working Paper.

[63] Cameron, S.V. and Heckman, J.J. (1998). Life cycle schooling and dynamic selection bias: Models and Evidence for Five Cohort of American Males. Journal of Political Economy 106(2), 262-333.

[64] Card, D. (1995). Using Geographic variation in college proximity to estimate the return to schooling. In: Aspects of labor market behaviour: Essays in honour of John Vanderkamp. Toronto; Buffalo and London: University of Toronto Press, 201-222.

[65] Card, D. (1999). The causal effect of education on earnings. Handbook of labor economics 3, 1801-1863.

[66] Cedefop (2008). The shift to learning outcomes. Conceptual, political and practical developments in Europe. European Centre for the Development of Vocational Training, 56.

[67] Cedefop (2010). Changing qualifications. A review of qualification policies and practices. European Centers for the Development of Vocational Training, 272. 
[68] Ceulenaere, B., A. Willemsen, R. van der Aa, F. van Zuthpen, and C. Groen. 2009. Case studies MKBA voortijd schoolverlaten [Case studies cost-benefit analysis on school dropout]. Rotterdam: Ecorys.

[69] Chatterji, P. (2006a). Does alcohol use during high school affect educational attainment? Evidence from the National Education Longitudinal Study. Economics of Education Review 25, 482-497.

[70] Chatterji, P. (2006b). Illicit drug use and educational attainment. Health Economics 15, 489-511.

[71] Christou, C. and Haliassos, M. (2006). How do students finance human capital accumulation? The choice between borrowing and work. Journal of Policy Modeling 28(1), 39-51.

[72] Cleves, M., W. Gould, R. Gutierrez and Y. Marchenko (2008). An introduction to survival analysis using Stata - second edition. Stata Press.

[73] Coleman, James S. (1984). The Transition from School to Work." In: Research in Social Stratification and Mobility 3, edited by Donald J. Treiman and Robert V. Robinson, 27-59. Greenwich: CT: JAI Press.

[74] Colm, H. and Walker, we. (1995). Estimates of Economic Return to Schooling in the UK. Economics, Finance and Accounting Department Working Paper Series 540195.

[75] Cooper, C.R., Chavira, G., et al. (2005). From Pipelines to Partnerships: A synthesis of Research on How Diverse Families, Schools and Communities Support Children's Pathways Through School. Journal of Education for Students Places at Risk 10 (4), 407-432.

[76] Cox, D. (1972). Regression models and life tables. Journal of the Royal Statistical Society B 34, 187-202. 
[77] Currie, J. (2009). Health, wealthy, and wise: socioeconomic status, poor health in childhood, and human capital development. Journal of Economic Literature 471, 87-122.

[78] Currie, J. and Moretti, E. (2003). Mother's education and the intergenerational transmission of human capital: Evidence from college openings. Quarterly Journal of Economics 118(4), 1495-1532.

[79] Datar, A. (2006). Does delaying kindergarten entrance give children a head start. Economics of Education Review 25, 43-62.

[80] Dalton, B., Gennie, E., Ingels, S.J. (2009). Late High School Dropouts: Characteristics, Experiences, and Changes Across Cohorts (NCES 2009-307). National Center for Education Statistics, Institute of Education Sciences, US Department of Education. Washington, DC.

[81] Davies, J.D. and Lee, J. (2004). To attend or not to attend? Why some students chose school and others reject it. Support for Learning 21(4), 204-209.

[82] De Bruijn, H., M. Groenleer, H. van der Voort, M. Noordink, B. Dunning, and B. Gooskens. 2010. Inzicht in resultaat 2 [Results 2]. TU Delft.

[83] de la Porte, C. , Pochet, P. and Graham, R. (2001). Social benchmarking, policy-making, and the instruments of new governance in the EU. Observatoire social européen (OSE): Brussels.

[84] De Witte, K. and Cabus, S.J. (2013). Dropout prevention measures in the Netherlands, an explorative evaluation. Educational Review 65(2), 155-176. 
[85] De Witte, K., Cabus, S.J., Thyssen, G., Groot, W. and Maassen van den Brink, H. (2013). A critical review of the literature on school dropout. Educational Research Review 10, 13-28.

[86] De Witte, K. and Csillag, M. (2012) Does anybody notice? On the impact of improved truancy reporting on school dropout. Education Economics, 1-20.

[87] De Witte, K. and Rogge, N. (2012). Dropout from secondary education: all's well that begins well. European Journal of Education. In Press.

[88] De Witte, K. and van Klaveren, C. (2012), Comparing students by a matching analysis - on early school-leaving in Dutch cities. Applied Economics 44 (28), 3679-3690.

[89] de Zwart, S., F. Zwaneveld, Y. Hamdam, S. Schenk, M. Hamdam. 2009. Maatschappelijke kosten-batenanalyse Time In en Sportklassen [Cost-benefit analysis Time In and Sport Classes]. Berenschot and RebelGroup.

[90] DesJardin, S., D. Ahlburg and B. McCall (1999). An event history model of student departure. Economics of Education Review 18, 375390.

[91] DesJardin, S., D. Ahlburg and B. McCall (2002). A temporal investigation of factors related to timely certificate completion. The Journal of Higher Education 73 (5), 555-581.

[92] Drew, S. (2004). The power of school-community collaboration in dropout prevention. In F. P. Schargel \& J. Smink (Eds), Helping students graduate: A strategic approach to dropout prevention. Larchmont, NY: Eye on Education, p. 65-77. 
[93] Duflo, E. (1998). Schooling and labor market consequences of school construction in Indonesia: Evidence from an unusual policy experiment. MIT Department of Economics.

[94] Dustmann, C., van Soest, A. (2007) Part-Time Work, School Success and School Leaving. Empirical Economics 32, 277-299.

[95] Dynarski, M. and Gleason, P. (1998). How can we help? What we have learned from federal dropout-prevention programs. Princeton, N.J.: Mathematica Policy Research, Inc.

[96] Eckstein, Z. and Wolpin, K.we. (1999). Why youths drop out of high school: the impact of preferences, opportunities, and abilities. Econometrica 67(6), 12951339.

[97] Effron, B. (1977). The efficiency of Cox's likelihood function for censored data. Journal of the American Statistical Association 72, 557565.

[98] Ehrenberg, R.G. and Brewer, D.J. (1994). Do school and teacher characteristics matter? Evidence from high school and beyond. Economics of Education Review 13(1), 1-17

[99] Ekstrom, R., Goertz, M.E., Pollack,J.M. and Rock, D.A. (1986). Who Drops Out of High School and Why? Findings from a National Study. Teachers College Record 87(3), 356-373.

[100] Elliot, D.and Voss, H. (1974). Delinquency and drop out. TorontoLonden, Lexington.

[101] Elstad, E. (2009). Schools which are named, shamed and blamed by the media: school accountability in Norway. Educational Assessment, Evaluation and Accountability 21 (2), 173-189. 
[102] Employment Taskforce. (2003). Jobs, Jobs, Jobs, Creating More Employment in Europe. Report of the Employment Taskforce chaired by Wim Kok, Brussels.

[103] Entwisle, D.R., K.L. Alexander and L. Steffel-Olson (2004). Temporary as Compared to Permanent High School Dropout. Social Forces 82(3), 1181-1205.

[104] Entwisle, D.R., K.L. Alexander and L. Steffel-Olson (2005). Urban Teenagers. Work and Dropout. Youth Society 37 (3), 3-31.

[105] Epstein, J.L., and Sheldon, S.B. (2002). Present and accounted for: improving student attendance through family and community involvement. The Journal of Educational Research 95(5), 308-318.

[106] European Commission (2005). Study on access to education and training, basic skills and early school-leavers. Brussels: European Commission.

[107] European Commission (2006). Detailed Analysis of progress towards the Lisbon Objectives in education and training: Analysis of Benchmarks and indicators? Brussels: European Commission.

[108] European Commission (2010a). Europe 2020. A European Strategy for smart, sustainable and inclusive growth. Brussels: European Commission.

[109] European Commission (2010b). Reducing early school-leaving. Proposal for a Council Recommendation on policies to reduce early schoolleaving. Brussels: European Commission.

[110] European Commission (2011a). Tackling early school-leaving: A key contribution to the Europe 2020 Agenda. Brussels: European Commission. 
[111] European Commission (2011b). Trends in European education during the last decade. Brussels: European Commission.

[112] Farkas, G., Grobe, R.P., Sheehan, D. and Shuan, Y. (1990). Cultural Resources and School Success: Gender, Ethnicity, and Poverty Groups within an Urban School District. American Sociological Review 55, 4661.

[113] Farrington, D., B. Gallagher, L. Morley, R. Legger and D. West (1986). Unemployment, school leaving and crime. British Journal of Criminology 26 (4), 335-356.

[114] Felner, R.D., Ginter, M. and Primavera, J. (1982). Primary prevention during school transitions: social support and environmental structure. American Journal of Community Psychology 10(3), pp.277.

[115] Felner, R.D., Primavera, J. and Cause, A.M. (1981). The impact of school transitions: A focus for preventive efforts. American Journal for Community Psychology 9, 449-459.

[116] Fergusson, D.M., Horwood, L.J. and Beautrais, A.L. (2003). Cannabis and educational achievement. Society for the study of addiction to alcohol and other drugs 98, 1681-1692.

[117] Finn, J.D. (1989). Withdrawing from School. Review of Educational Research 59, 117-42.

[118] Firestone, W.A. and Rosenblum, S. (1988). Building commitment in urban high schools. Educational Evaluation and Policy Analysis 10(4), 285-299.

[119] Fried, H., Lovell, C.A.K., Schmidt, S. (2008). The Measurement of Productive Efficiency and Productivity Growth. Oxford University Press. 
[120] Frölich, M. and Lechner, M. (2004). Regional treatment intensity as an instrument for the evaluation of labor market policies. IZA Discussion Paper 1095.

[121] Frölich, M. and Michaelowa, K.L. (2005). Peer effects and textbooks in primary education: evidence from Francophone Sub-Saharan Africa. IZA Discussion Paper 1519.

[122] Funkhouser, E. (1999). Cyclical economic conditions and school attendance in Costa Rica. Economics of Education Review 14, 31-50.

[123] Gamerman, D. (1991). Dynamic Bayesian Models for Survival Data. Journal of the Royal Statistical Society. Series C (Applied Statistics) 40(1), 63-79.

[124] Gangl, M. (2002). Changing labor market and early career outcomes: Labour Market Entry in Europe over The Past Decade. Work Employment Society 16(1), 67-90.

[125] Garen, J. (1984). The return to schooling: a selectivity bias approach with a continuous choice variable. Econometrica 52, 1199-1218.

[126] Garnier, H., Stein, J. and Jacobs, J. (1997). The process of dropping out of high school: a 19-year perspective. American Educational Research Journal 34, 395-419.

[127] Garry, E. M. (1996). Truancy: First step to a lifetime of problems [Bulletin]. Washington, D.C.: United States Department of Justice, Office of Justice Programs, Office of Juvenile Justice and Delinquency Prevention.

[128] Glewwe, P. and Jacoby, H.G. (2004). Economic growth and the demand for education: is there a wealth effect? Journal of Development Economics 74, 33-51. 
[129] Goldschmidt, P. and J. Wang (1999). When can schools affect dropout behavior? A longitudinal multilevel analysis. American Educational Research Journal 36, 715-738.

[130] Griliches, Z. (1977) Estimating the returns to schooling: some econometric problems. Econometrica 45(1), 1-22.

[131] Groot, W. and H. Maassen van den Brink (2007). The Health Effects of Education. Economics of Education Review 26, 186-200.

[132] Groot, W. and Maassen van den Brink, H. (2000). Overeducation in the labor market: a meta-analysis. Economics of Education Review $19,149-158$.

[133] Hafner-Burton, E. (2008). Sticks and Stones: Naming and Shaming the Human Rights Enforcement Problem. International Organization $62(4), 689-716$.

[134] Hahn, J., Todd, P. and van der Klauw, W. (2001). Identification and Estimation of Treatment Effects with a Regression-Discontinuity Design. Econometrica 69(1), 201-209.

[135] Hall, Robert E. (2005). Employment Fluctuations with Equilibrium Wage Stickiness. American Economic Review 95 (1), 50-65.

[136] Hanushek, E. and L. Wößmann (2007). The role of education quality in economic growth. The World Bank, Policy Research Working Paper 4122 .

[137] Hanushek, E.A. and Jorgenson, D.W. (1996). Improving America's schools: the role of incentives. Board on Science, Technology, and Economic Policy: National Research Council. 
[138] Hanushek, E.A., Wößmann, L. (2010). How Much Do Educational Outcomes Matter in OECD Countries? Economic Policy, FiftySecond Panel Meeting, Hosted by EIEF.

[139] Hausman, J.A. and Woutersen, T. (2010). Estimating a SemiParametric Duration Model without Specifying Heterogeneity. MIT and Johns Hopkins University working Chapter series.

[140] Heckman, J. J. (1990). Varieties of Selection Bias. American Economic Review 80, 313-318.

[141] Heckman, J.J. and Vytlacyl, E. (1998). Instrumental variables methods for the correlated random coefficient model: Estimating the rate of return to schooling when the return is correlated with schooling. Journal of Human Resources 23, 974-987.

[142] Heckman, J.J., Ichimura, H. and Todd, P. (1997). Matching as an econometric evaluation estimator: evidence from evaluating a job training programme. Review of Economic Studies 64, 605-654.

[143] Heckman, J.J., Lalonde, R.J. and Smith, J.A., (1999). The economics and econometrics of active labor market programs. In: O. Ashenfelter and D. Card (ed.), Handbook of Labor Economics 1(3), 1865-2097.

[144] Heers, M., Van Klaveren, C., Groot, W. and Maassen van den Brink, H. (2011). Community schools unfolded: A review of the literature. TTIER, Maastricht University, Working Paper 11/04, 1-36.

[145] Helm, C.M. and Burket, C.W. (1989). Effects of computer-assisted telecommunications on school attendance. The Journal of Educational Research 82, 362-365.

[146] Henry, K.L. (2007). Who's skipping school: characteristics of truants in 8th and 10th grade. Journal of School Health 77(1), 29-35. 
[147] Heppen, J. B., and Therriault, S. B. (2008). Developing Early Warning Systems to Identify Potential High School Dropouts. Issue Brief. National High School Center.

[148] Herbert, T.P. and Reis, S.M. (1999). Culturally Diverse HighAchieving Students in an Urban High School. Urban Education 34(4), 428-457.

[149] Hibbert, A., and K. Fogelman (1990). Future lives of truants: Family formation and health-related behavior. British Journal of Educational Psychology 60, 171-179.

[150] Hirschi, T. (1969). Causes of Delinquency. Berkeley: University of California Press.

[151] Hjort, N. L. (2003). Topics in non-parametric Bayesian statistics (with discussion). In: Highly Structured Stochastic Systems, P. J. Green, N. L. Hjort and S. Richardson, eds., 455-487.

[152] Holter, N., W. Bruinsma, 2009. Wat werkt bij het voorkomen van voortijdige schoolverlaten? [School dropout prevention: What works?] Nederlands Jeugdinstituut (NJI).

[153] Hsiao, C. (2003). Analysis of Panel Data. Cambridge University Press.

[154] Hurtado, S. and Carter, D.F. (1997). Effects of college transition and perceptions of the campus racial climate on Latino college students' sense of belonging. American Sociological Association 70(4), 324-345.

[155] Ibrahim, J. G., Chen, M.-H. and Sinha, D.( 2005). Bayesian Survival Analysis. Encyclopedia of Biostatistics.

[156] ILO (2002). A future without child labor. Global report under the Follow-up to the ILO Declaration on Fundamental Principles and Rights at Work. Geneva: ILO. 
[157] Imbens, G. and Wooldridge, J. (2007). What's New in Econometrics? NBER Lecture Notes 10.

[158] Imbens, G.W. and Rosenbaum, P.R. (2005). Robust, accurate confidence intervals with a weak instrument: quarter of birth and education. Journal of Royal Statistical Society Series A 168(1), 109-126.

[159] Jarjoura GR (1993). Does dropping out of school enhance delinquent involvement? Results from a large-scale national probability sample. Criminology 31.

[160] Jarjoura GR (1996). The conditional effect of social class on the dropout-delinquency relationship. Journal of Research in Crime and Delinquency 33.

[161] Jencks, C. and Mayer, S.E. (1990). The social consequences of growing up in a poor neighborhood. In: L. Lynn Jr. \& M. G. H. McGeary (Eds.), Inner-city poverty in the United States. Washington D.C.: National Academy Press.

[162] Jimerson, S.R. (1999). On the failure of failure: Examining the association between early grade retention and education and employment outcomes during late adolescence. Journal of School Psychology 37, 243-272.

[163] Jung, H-S. and Thorbecke, E. (2003). The impact of public education expenditure on human capital, growth, and poverty in Tanzania and Zambia: a general equilibrium approach. Journal of Policy Modeling 25(8), 701-725.

[164] Kalbfleisch, J.D. (1978a). Likelihood methods and non-parametric testing. Journal of the American Statistical Association 83, 167-170. 
[165] Kalbfleisch, J.D. (1978b). Non-parametric Bayesian analysis of survival time data. Journal of the Royal Statistical Society. Series B (Methodological) 40(2), 214-221.

[166] Kalbfleisch, J.D. and Prentice, R.L. (2002). The Statistical Analysis of Failure Time Data. Wiley Series in Probability and Statistics. 2nd Edition.

[167] Kalbfleisch, J.D. and Prentice, R.L.(1973). Marginal likelihoods based on Cox's regression and life model. Biometrika 60, 267-278.

[168] Kane, J. (1994). College entry by blacks since 1970: the role of college costs, family background, and the returns to education. Journal of Political Economy 102, 878-911.

[169] Kane, T,. Rouse, C. and Staiger, D. (1999). Estimating the returns to education when schooling is misreported. NBER Working Paper 7235.

[170] Kaplan, E. and P. Meier (1958). Nonparametric estimation from incomplete observations. Journal of the American Statistical Association $53,457-481$.

[171] Kapteyn, A. (2010). What can we learn from (and about) Global Aging? Demography 47, S191-209.

[172] Kapteyn, A., Smith, J.P., van Soest, A. (2007). Vignettes and SelfReports of Work Disability in the United States and the Netherlands. American Economic Review 97(1), 461-473.

[173] Kaufman, P., Alt, M. N., Chapman, C.D. (2004). Dropout Rates in the United States: 2001 (NCES 2005-046). US Department of Education. Washington, DC: National Center for Education Statistics.

[174] Keane, K.J. (2002). Financial aid, borrowing constraints, and college attendance: Evidence from structural estimates. American Economic 
Review 92(2), Papers and Proceedings of the One Hundred and Fourteenth Annual Meeting of the American Economic Association, 293297.

[175] Kézdi, G. (2004) Robust Standard Error Estimation in Fixed-Effects Panel Models. Hungarian Statistical Review Special (9), 96-116.

[176] Koenker, R. and Basset, G. (1978). Regression Quantiles. Econometrica.46(1), 33-50.

[177] Koop, G., Dale, J.P. and Tobias, J.L. (2007). Bayesian Econometric Methods. Volume 7, Cambridge University Press.

[178] Krueger, A.B., Lindahl, M., (1998). Education for growth in Sweden and the world. NBER Working Paper Series w7190.

[179] Krueger, A.B., Lindahl, M., (2001). Education for Growth: Why and For Whom? Journal of Economic Literature 39(4) , 1101-1136.

[180] Kuyper, H., Lubbers, M.J. \& Werf, M.P.C. van der (2003a). VOCL'991: Technisch Rapport. [Technical report 99-1]. Groningen: GION.

[181] Kuyper, H. \& Werf, M.P.C. van der (2003b). VOCL'99: de resultaten in het eerste leerjaar. [Results of grade 7]. Groningen: GION.

[182] Kuyper, H. \& Werf, M.P.C. van der (2005). VOCL'99-3: Prestaties en opvattingen van leerlingen in de derde klas van het voortgezet onderwijs. [Results of grade 10]. Groningen: GION.

[183] Landais, C., Michaillat, P. and Saez, E. (2010). Optimal unemployment insurance over the business cycle. NBER working Chapter 16526.

[184] Lang, K. and Kropp, D. (1986). Human capital versus sorting: the effects of compulsory attendance laws. The Quarterly Journal of Economics, 609-624. 
[185] Lee, V.E. and Burkam, D.T. (2003) Dropping out of high school: the role of school organization and structure. American Educational Research Journal 40(2), 353-393.

[186] Levin, H.M. (1987). New schools for the disadvantaged. US Department of Education. Office of Educational Research and Improvement.

[187] Levin, H.M. (1989). Financing the education of at-risk students. Educational Evaluation and Policy Analysis 11(1), 47-60.

[188] Levin, H. Belfield, C. Muennig, P. and Rouse, C. (2006). The Costs and Benefits of an Excellent Education for America's Children. Teachers College, Columbia University.

[189] Levin, H.M. and Rouse, C.E. (2012). The True Cost of High School Dropouts. Published in the New York Times on January 25, 2012.

[190] Licht, B.G., Gard, T. and Guardino, C. (1991). Modifying School Attendance of Special Education High School Students. The Journal of Educational Research 84(6), 368-373.

[191] Light, A and Strayer, W (2000) Determinants of college completion. Journal of Human Resources 35(2), 299-332.

[192] Light, A. (1995). Hazard model estimates of the decision to reenroll in school. Labour Economics 2(4), 381-406.

[193] Light, A. (1998) Estimating the Returns to Schooling: When Does the Career Begin? Economics of Education Review 17, 31-45.

[194] Light, A. (1999). High School Employment, High School Curriculum, and Post-School Wages. Economics of Education Review 18, 291-309.

[195] Lleras-Muney, A. (2001). Were compulsory attendance and child labor laws effective? NBER Working Paper 8563. 
[196] Lleras-Muney, A. (2005). The Relationship Between Education and Adult Mortality in the United States. Review of Economic Studies 72, $189-221$.

[197] Lochner, L. and Moretti, E. (2004a). The Effect of Education on Crime: Evidence from Prison Inmates, Arrests, and Self-Reports. American Economic Review 94(1), 155-189.

[198] Lochner, L. and Moretti, E. (2004b). Does education improve citizenship? Evidence from the United States and the United Kingdom. Journal of Public Economics 88(9-10), 1667-1695.

[199] Lucas, R. and Lammont, N. (1998) Combining Work and Study: An Empirical Study of Full-Time Students in School, College and University. Journal of Education and Work 11(1), 41-56.

[200] Luginbuhl, R. and Webbink, D. (2009). Do inspections improve primary school performance? Educational Evaluation and Policy Analysis $31(3), 221-237$.

[201] Luyten, H., Bosker, R., Dekkers, H. and Derks, A. (2003). Dropout in the lower secondary tracks of Dutch secondary education: predictor variables and variation among schools. School effectiveness and school improvement 14(4), 373-411.

[202] Mankin, N.G., Romer, D., Weil, D. (1992). A contribution to the empirics of economic growth. Quarterly Journal of Economics 107(2), 407-437.

[203] Marks, G. and Fleming, N. (1999). Early School Leaving in Australia: Findings from the 1995 Year LSAY Cohort. Research Report. ACER. 
[204] Martin, J.A., Hamilton, B.E., Sutton, P., Ventura, S.J., Mathews, T.J. and Osterman, J.K. (2010). Births: Final Data for 2008. National Vital Statistics Reports 59(1).

[205] Martin, P., Rogers, C.A. (2000). Long-term growth and short-term economic instability. European Economic Review 44, 359-381.

[206] Mason, A., Street, A. (2006). Publishing outcome data: is it an effective approach? Journal of Evaluation in Clinical Practice 12 (1), $37-48$.

[207] Mayer, S. (1991). How much does a high school's racial and socioeconomic mix affect graduation and teenage fertility rates? In: C. Jencks \& P. Peterson (Eds.), The Urban Underclass, 321-341.

[208] McArdle, J.J. and Hamagami, F. (1994). Logit and Multilevel Logit Modeling of College Graduation for 1984-1985 Freshman StudentAthletes. Journal of the American Statistical Association 89(427), 1107-1123.

[209] Mclanahan, S.S. (1985). Family structure and the intergenerational transmission of poverty. American Journal of Sociology 90, 873-901.

[210] McNeal, R.B. (1997). Are students being pulled out of high school? The effect of adolescent employment on dropping out. Sociology of Education 70, 206-220.

[211] McNeal, R.B. (1999). Parental Involvement as Social Capital: Differential Effectiveness on Science Achievement,Truancy, and Dropping Out. Social Forces 78(1), 117-144.

[212] Mikami. A. (2005). Economy report (Japan). The Vocational Education and Training (VET) for Youth Forum. 
[213] Milligan, K., Moretti, E. and Oreopoulos, P. (2004). Does education improve citizenship? Evidence from the United States and the United Kingdom. Journal of Public Economics 88 (9), 1667-1695.

[214] Mincer, J. (1974). Schooling, Experience and Earnings. Columbia University Press, New York.

[215] Ministry of Education, Culture, and Science (2006). The education system in the Netherlands. Dutch Eurydice Unit: Den Haag.

[216] Ministry of Education, Culture, and Science (2008). Kerncijfers 20032007 Ministry of Education, Culture, and Science, Culture and Sciences: Den Haag.

[217] Ministry of Education, Culture, and Science (2010). Voortijdig schoolverlaten: Cijfers en beleid [Early schoolleaving: Facts and figures]. Letter to the Chairman of the Tweede Kamer der StaatenGeneraal, February 17.

[218] Mirowsky, J. and Ross, C.E. (2003). Education, Social Status and Health. Walter de Gruyter, Inc. New York.

[219] Müller, W. and Gangl, M. (2003). Transitions From Education to Work in Europe - the Integration of Youth into EU Labour Markets. Oxford: Oxford University Press, 277-305.

[220] Murtaugh, P., L. Burns and J. Schuster (1999). Predicting the retention of university students. Research in Higher Education 40, 355-371.

[221] Murtin, F. and Viarengo, M. (2009). The expansion and convergence of compulsory schooling in Western Europe 1950-2000. Economica, $1-22$.

[222] Nelson (1970).Hazard plotting methods for analysis of life data with different failure modes. Journal of Qualitative Technology 2, 126-149. 
[223] Nelson, P.S., Simoni, J. M., and Adelman, H. S. (1996). Mobility and school functioning in the early grades. Journal of Educational Research 89(6), 365-369.

[224] Nelson, R. and Phelps, E. (1966). Investment in humans, technological diffusion, and economic growth. American Economic Review 51(2), 69-75.

[225] Newman, F. (1992). Student engagement and achievement in American secondary schools. New York: Teachers College Press.

[226] Oberon. 2008. De belevingswereld van voortijdig schoolverlaters. Een onderzoeksrapportage. [Research report on early school-leavers]. Utrecht: Oberon.

[227] O’Donnell, O., van Doorslaer, E., Wagstaff, A., Lindelow, M. (2008). Analyzing health equity using household survey data. A guide to techniques and their implementation. Washington D.C.: The World Bank.

[228] OECD (1983). Compulsory schooling in a changing world. Paris: OECD.

[229] OECD (1999). Preparing Youth for the 21st Century: The Transition from Education to the Labour Market. Paris: OECD.

[230] OECD (2001). Education at a Glance. Paris: OECD.

[231] OECD (2003). Ageing and Employment Policies - Spain. Paris: OECD.

[232] OECD (2006). Employment Outlook. Paris: OECD.

[233] OECD (2008). Jobs for youth. The Netherlands. Paris: OECD.

[234] OECD (2009). Education at a Glance: OECD Indicators. Paris: OECD. 
[235] OECD (2011). OECD Labour Market Statistics (2011). Paris: OECD.

[236] Olsen, R.J. and Farkas, G. (1989). Endogenous Covariates in Duration Models and the Effect of Adolescent Childbirth on Schooling. Journal of Human Resources 24 (1), 39-53.

[237] Onstenk, J. (2004). Innovation in vocational education in the Netherlands. Vocal 5, 17-21.

[238] Onstenk, J. and Blokhuis, F. (2007) internship in the Netherlands: connecting school- and work-based learning. Education + Training 94(6), 489-499.

[239] Oosterbeek, H. and Webbink, D. (2004). Wage effects of an extra year of lower vocational education: Evidence from a simultaneous change of compulsory school leaving age and program length. Department of Economics, University of Amsterdam and NOW-pragram "Scholar".

[240] Oreopoulos, P. (2003). Do dropouts drop out too soon? International evidence from changes in school-leaving laws. NBER Working Papers 10155.

[241] Oreopoulos, P. (2006). The compelling effects of compulsory schooling: evidence from Canada. Canadian Journal of Economics 39 (1), 23-52.

[242] Oreopoulos, P. (2007). Do dropouts drop out too soon? Wealth, health and happiness from compulsory schooling. Journal of Public Economics 91 (11-12), 2213-2229.

[243] Ottinger, C. (1991). College going, persistence, and completion patterns in higher education: what do we know? American Council on Education, Research Briefs 2. 
[244] O2L. (2007). Voorkomen is beter dan uitvallen. Docenten uit het MBO over voortijdig schoolverlaten. [Dropout prevention in vocational education.] Organize 2 Learn.

[245] Pascarella, E. en Terenzini, P. (1991). How college affects students: findings and insights from twenty years of research. Jossey-Bass, San Francisco, CA.

[246] Pascarella, E.T., Smart, J.C., Ethington, C.A. and Nettles, M.T. (1987). The influence of college on self-concept: a consideration of race and gender differences. American Educational Research Journal $24(1), 49-77$.

[247] Phillips, J. and Kelly, D. (1979). School failure and delinquency: which causes which? Criminology, pp.194-207.

[248] Phinney, J.S., Dennis, J. and Osorio, S. (2006). Reasons to attend college among ethnically diverse college students. Cultural Diversity and Ethnic Minority Psychology 12(2), 247-366.

[249] Pietro, G.D. (2007). Regional labor market conditions and university dropout rates: Evidence from Italy. Regional Studies 40(6), 617-630.

[250] Pischke, J-S. and von Wachter, T. (2005). Zero returns to compulsory schooling in Germany: evidence and interpretation. NBER Working Papers 11414.

[251] Pissarides, C.A. (1985). Short run equilibrium dynamics of unemployment, vacancies and real wages. American Economic Review 75(4), 676-690.

[252] Pissarides, C.A. (2000). Equilibrium unemployment theory. 2nd Edition Cambridge, MA: MIT Press. 
[253] Pissarides, C.A. (2009). The Unemployment Volatility Puzzle: Is Wage Stickiness the Answer? Econometrica 77 (5), 1339-1369.

[254] Pittman, R.B. (1991). Social factors, enrollment in Vocational/Technical courses, and high school dropout rates. The Journal of Educational Research 84(5), 288-295.

[255] Pittman, R.B. (1993). The 21th Century and Secondary School AtRisk Students: What's Ahead for Teachers in Rural America? Conference Proceedings.

[256] Pittman, R.B. and Haughwout, P. (1987). Influence of high school size on dropout rate. Educational Evaluation and Policy Analysis 9(4), 337-343.

[257] Plank, S., DeLuca, S., Estacion, A. (2005). Dropping Out of High School and the Place of Career and Technical Education: A Survival Analysis of Surviving High School. National Research Center for Career and Technical Education, S.P.M.N. \& National Dissemination Center for Career and Technical Education, C.O.H.

[258] Pong, S.-L. and Ju, D.B. (2000). The effects of change in family structure and income on dropping out of middle and high school. Journal of Family Issues 21,147-169.

[259] Powdthavee, N. (2010). Does education reduce the risk of hypertension? Estimating the biomarker effect of compulsory schooling in Engeland. Journal of Human Capital 4, 173-202.

[260] Psacharapoulos, G. (2007). The cost of school failure - A feasibility study. European Expert Network on Economics of Education. 
[261] Psacharapoulos, G. and R. Layard (1979). Human capital and earnings: British evidence and critique. Review of Economic Studies 46, 485-503.

[262] Quintini, G., Martin, J., Martin, S. (2007) The changing nature of the school-to-work transition process in OECD countries. IZA Discussion Chapter series 2582

[263] Reich, C., Young, V. (1975). Patterns of Dropping out. Interchange $6(4), 6-15$.

[264] Researchcentrum voor Onderwijs en Arbeidsmarkt (ROA). (2009a). Zonder certificate. Aanleiding, kansen en toekomstintenties. [Without certificate. Causes, opportunities and prospects.]. ROA R-2009/1

[265] Research Centre for Education and the Labour Market (ROA). (2009b). Schoolverlaten tussen onderwijs en arbeidsmarkt [School dropouts between school and the labor market]. ROA R-2009/4.

[266] Researchcentrum voor Onderwijs en Arbeidsmarkt (ROA). (2007). De arbeidsmarkt naar opleiding en beroep tot 2012. [The labor market by education and profession.] ROA R-2007/4.

[267] Roderick, M. (1994) Grade retention and school dropout: investigating the association. American Educational Research Journal 31(4), 729759 .

[268] Roderick, M., Nagoaka, J., Bacon, J. and Easton, J. (2000). Update: Ending Social Promotion. Consortium on Chicago School Research, Chicago

[269] Roebuck, C.M., French, M.T. and Dennis, M.L (2004). Adolescent marijuana use and school attendance. Economics of Education Review 23(2), 133-141. 
[270] Rojvithee, A. (2005). Economy report (Thailand). The Vocational Education and Training (VET) for Youth Forum.

[271] Romer, P. (1990). Endogenous technological change. Journal of Political Economy 99(5), 71-102.

[272] Rosenzweig, M.R. (1988). Human capital, population growth, and economic development: Beyond correlations. Journal of Policy Modeling 10(1), 83-111.

[273] Rubin, D. (1974). Estimating causal effects of treatments in randomized and nonrandomized studies. Journal of Educational Psychology 66, 668-701.

[274] Rubin, D. (1978). Bayesian Inference for causal effects: the role of randomization. Annals of Statistics 6, 34-58.

[275] Ruhm, C (1997). The Extent and Consequences of High School Employment. Journal of Labor Research 16, 293-303.

[276] Rumberger, R.W. (1983). Dropping out of high school: the influence of race, sex, and family background. American Educational Research Journal 20(2), 199-220.

[277] Rumberger, R.W. (1987) High school dropouts: A review of issues and evidence. Review of Educational Research 57, 101-121.

[278] Rumberger, R.W. (2001). Who drops out of school and why. Chapter prepared for the National Research Council, Committee on Educational Excellence and Testing Equity Workshop, School Completion in Standards-Based Reform: Facts and Strategies, and incorporated into their report, Understanding Dropouts: statistics, strategies, and high-stakes testing, edited by A. Beatty, U. Neiser, W. Trent, and J. Heubert, Washington: National Academy Press. 
[279] Rumberger, R.W (2004). Why students drop out of school. In Gary Orfied (Ed.), Dropouts in America: Confronting the Graduation Rate Crisis. Cambridge, MA: Harvard Education Press.

[280] Rumberger, R.W. (2011). Why students dropout of high school and what can be done. Harvard University Press.

[281] Rumberger, R.W. and Lamb, S.P. (2003). The early employment and further education experiences of high school dropouts: a comparative study of the United States and Australia. Economics of Education Review $22,353-366$.

[282] Rumberger, R.W. and Larson, K.A. (1998). Student mobility and the increased risk of high school dropout. American Journal of Education $107(1), 1-35$.

[283] Rumberger, R.W. and Palardy, G.J. (2005) Does segregation still matter? The impact of student composition on academic achievement in high school. Teachers College Record 7(9), pp.1999-2045.

[284] Rumberger, R.W. and Thomas, S.L. (2000). The distribution of dropout and turnover rates among urban and suburban high schools. Sociology of Education 73, pp.39-67.

[285] Schaefer, C.E. and H.L. Millman (1981). How to help children with common problems. New York: Von Nostrand Reinhold.

[286] Schargel, F. and Smink, J. (2004). Helping students graduate: A strategic approach to dropout prevention. Larchmont, NY: Eye on Education.

[287] Schmidt Schilling, M.G. (2005). Economy report (Chile) The Vocational Education and Training (VET) for Youth Forum. 
[288] Schultz, T. (1967). The Economic Value Education. New York: Columbia University Press.

[289] Schweinhart, L. J., and Widart, D. P. (1985). Evidence that good early childhood programs work. The Phi Delta Kappan 66 (8), 545-551.

[290] Shavit, Y. and Müller, W. (1998). From school to work. A comparative study of educational qualifications and occupational destinations. New York: Clarendon Press Oxford.

[291] Sheldon, S.B. (2007). Improving student attendance with school, family, and community partnerships. Journal of Educational Research 100(5), 267-275.

[292] Silles, M.A. (2011) The effect of schooling on teenage childbearing: evidence using changes in compulsory education laws. Journal of Population Economics 24(2), 761-777.

[293] Singer, J.D. and Willet, J.B. (1993). It's about Time: Using DiscreteTime Survival Analysis to Study Duration and the Timing of Events. Journal of Educational Statistics 18(2), 155-195.

[294] Slavin, R.E. and Fashola, O.S. (1998). Show me the evidence! Proven and promising programs for America's schools. New York: Corwin.

[295] Smith, P. (2002). Analysis of failure and survival data. Chapman and Hall, Boca Raton.

[296] Snow, K.L. (2010). Measuring school readiness: conceptual and practical considerations. Early Education and Development 17(1), 7-41.

[297] Solow, R.M. (1957). Technical change and the aggregate production function. Review of Economics and Statistics 39(3), 312-320. 
[298] Soukiazis, E. and Castro, V. (2005). How the Maastricht criteria and the stability and growth pact affected real convergence in the European Union: A panel data analysis. Journal of Policy Modeling 27(3), 385399.

[299] Spady, W. (1970). Dropouts from higher education: an interdisciplinary review and synthesis. Interchange 1, 64-85.

[300] Spady, W. (1971). Dropouts from higher education: toward an empirical model. Interchange 2, 38-62.

[301] Sparkes, J. (1999). Schools, Education and Social Exclusion. Centre for Analysis of Social Exclusion, London School of Economics.

[302] Spence, M. (1973). Job market signaling. The Quarterly Journal of Economics 87(3), 355-374.

[303] Srinivasan, T.N. (1988). Population growth and economic development. Journal of Policy Modeling 10(1), 7-28.

[304] Steinberg, L., Dornbusch, S.M. and Brown, B.B. (1992). Ethnic differences in adolescent achievement. American Psychologist 47, 723-729.

[305] Strand, S. and Demie, F. (2007). Pupil mobility, attainment and progress at secondary school. Educational Studies 33(3), 313-331.

[306] Sutphen, R.D., Ford, J.P., and Flaherty, C. (2010). Truancy interventions: a review of the research literature. Research on Social Work Practice 20(2), 161-171.

[307] Swadener, B.B. (1995). Children and Families 'At Promise': Deconstructing the Discourse of Risk. In: B.B. Swadener and S. Lubeck (Eds.). Albany: State University of New York. 
[308] ter borgt, T., van Lieshout, M., Doornwaard, S., Eijkemans. Y., 2009. Middelengebruik en voortijdig schoolverlaten. Twee onderzoeken naar de actuele en gepercipieerde rol van alcohol en cannabis in relatie tot spijbelen, schoolprestaties, motivatie en uitval [Drugs and alcohol abuse in relationship with unauthorized school absenteeism], Universiteit Utrecht and Trimbos-instituut.

[309] Thyssen, G., K. De Witte, W. Groot, H. Maassen van den Brink (2010). De stereotypen van voortijdig schoolverlaten. [The stereotypes of early school-leaving]. Impuls voor onderwijsbegeleiding 41(3), 151153.

[310] Tieben, N., and M. Wolbers. 2010. Success and failure in secondary education: Socio-economic background effects on secondary school outcome in the Netherlands, 1927-1998. British Journal of Sociology of Education 31(3), 277-90.

[311] Tinto, V. (1975). Dropout from higher education: A theoretical synthesis of recent research. Review of Educational Research 45, 89-125.

[312] Topel, R. (1999). "Labor markets and economic growth." In: Handbook of Labor Economics, edited by Orley Ashenfelter and David Card. Amsterdam: Elsevier.

[313] Traag, T. and van der Velden, R. (2008). Early school-leaving in the Netherlands. ROA-RM 2008-03.

[314] US Department of Education (2010). In: Chapman, C., Laird, J. KewalRamani, A. Trends in High School Dropoutand Completion Rates inthe United States: 1972-2008. Compendium Report. US Department of Education, National Center for Education Statistics. NCES 2011012, 104. 
[315] United Nations (2003) Governance indicators: A Users' Guide. United Nations Development Programme and the European Commission.

[316] Valentine, J.C., Hirschy, A.S., Bremer, C.D., Novillo, W., Castellano, M. and Banister, A. (2011). Keeping At-Risk Students in School : A Systematic Review of College Retention Programs. Educational Evaluation and Policy Analysis 33(2), 214-234.

[317] van den Berg, G.J. (2000). Duration Models: specification, identification, and multiple durations. In: James J. Heckman and Edward Leamer, editors, Handbook of Econometrics V.

[318] van der Steeg, M. and Webbink, D. (2006). Voortijdig schoolverlaten in Nederland: omvang, beleid en resultaat. [Early school-leaving in the Netherlands.] CPB Document 107.

[319] van der Steeg, M., van Elk, R. and Webbink, D. (2008). Did the 2006 covenants reduce school dropout in the Netherlands? CPB document 177.

[320] Vandenbussche, J., Aghion, P., and Meghir, C. (2006). Growth distance to frontier and composition of human capital. Journal of Economic Growth 11(2), 97-127.

[321] Verschelde, M., Hindriks, J., Rayp, G. and Schoors, K. (2010). Explaining social segregation in Belgium: an index decomposition approach. UGent. Working Paper 10.69.

[322] Weltz, G.H. (2005). Economy report (United States). The Vocational Education and Training (VET) for Youth Forum.

[323] Wenger, J. (2002). Does the dropout age matter? How mandatory schooling laws impact high school completion and school choice. Public Finance and Management 2(4), 507-543. 
[324] Wilson, S.J. Tanner-Smith, E.E., Lipsey, M.W., Steinka-Fry, K. and Morrison, J. (2011). Dropout prevention and intervention programs: effects on school completion and dropout among school-aged children and youth. Campbell Systematic Reviews 8, DOI: 10.4073/csr.2011.8.

[325] Wooldridge, J.M. (2010). Econometric analysis of cross Section and panel data - Second Edition. MIT Press.

[326] Yamada, T., Kendix, M., \& Yamada, T. (1996). The impact of alcohol consumption and marijuana use on high school graduation. Health Economics 5, 77-92.

[327] Zigler, E. and Styfco, S.J. (1994). Is the High/Scope Perry Preschool Better Than Head Start? Yes and No. Early Childhood Research Quarterly 9, 269-287.

[328] Zijsling, D.H., Kuyper, H., Lubbers, M.J. \& Werf, M.P.C. van der (2005). VOCL'99-3: Technisch Rapport. [Technical report 99-3]. Groningen: GION.

[329] Zijsling, D.H. and van der Werf, M.P.C. (2007). VOCL99schoolverlaters VMBO. Beschrijving van het bestand. [Description of the VOCL99 data]. Groningen: GION. 



\section{Summary}

In the year 2011 in the EU-27 about 6 million youngsters left education early. The European Commission has defined an early school-leaver (or school dropout) as a youngster below the age of 24 without a higher secondary certificate, and who is not enrolled in education or training. The school dropout rate in the Netherlands in 2011 was 9.1 percent, in accordance with the European definition (Eurostat, 2012). ${ }^{1}$

School dropout is a serious problem. The previous literature has indicated that youngsters who leave education without a certificate have bad prospects in life. For instance, dropout students are more likely to have a bad connection with the labor market and/or to be in long-term unemployment (Reich and Young, 1975; Gangl, 2002). Youngsters without a certificate also have more mental or physical health problems (Groot and Maassen van den Brink, 2007; Albouy and Lequien, 2009) or a higher risk of poverty and exclusion from society (Bowles, 1972; Sparkes, 1999) compared with secondary school graduates. Furthermore, school dropout is a burden to society. Levin and Rouse (2012) have estimated the true cost of high school dropout at $\$ 1$ trillion over an 11- year time span. These costs mainly cover social security benefits and unemployment benefits, costs of

\footnotetext{
${ }^{1}$ Note that the Dutch definition is different from the definition of the European Commission. A school dropout in the Netherlands is defined as a youngster between the age of 12 and 23 who leaves education without a valid secondary diploma (at least vocational level 2, general secondary or pre-university education). (Accessed at: www.aanvalopdeschooluitval.nl, 08/29/2012).
} 
public services and losses of tax payments. Thus, school dropout is not only undesirable for the individual but also for society. The problem of leaving education early is therefore increasingly perceived as a bad signal that calls for immediate action from parents, schools, policymakers, and government officials.

\section{Early school-leaving in the previous literature}

\subsection{The risk factors of school dropout}

The E.U. Member States have formulated ambitious plans with respect to school dropout among the 2000 Lisbon Agenda Targets. Early school-leaving should be reduced from 20 percent in 2000 to 10 percent in 2010. School dropout is increasingly considered as the key to reaching other Agenda Targets, and has recently been restated among the Europe 2020 Agenda Targets. Early school-leaving should no longer be an option (for more information on the Europe 2020 Agenda Targets, see: ec.europa.eu).

Already in 2000 many E.U. countries have undertaken action to reduce school dropout (European Commission, 2005, 2006, 2010b, 2011a). School dropout is an intricate problem, though. The underlying risk factors or determinants of school dropout can be quite diverse in nature (Rumberger, 2011). To better understand the problem of early school-leaving, in Chapter 1 we map the determinants of school dropout. Figure 1.3 in Chapter 1 shows the leading determinants of school dropout. These determinants have been assigned to three institutions in which the individual takes part: namely, home (family), school, and the labor market. Youngsters leave education early because of problems at home or at school. Students are more likely to leave education without a certificate when they have a history of unauthorized truancy (Attwood and Croll, 2006; Henry, 2007), juvenile crime (Lochner and Moretti, 2004; Anderson, 2010) or drug abuse (Fergusson et al., 2003; ter Borgt et al., 2009). Further research indicates that school 
dropout is associated with the socioeconomic status of the household (Levin, 1987), parental involvement in school, and the ability and motivation of the student (Adams and Becker, 1990). In addition, the labor market plays a crucial role in triggering the decision to drop out of school. For instance, youngsters have particular aspirations with respect to their future job which directly influence their choices in education. In this respect, the literature indicates that students are more likely to move from education to a job before graduating from school when their job market aspirations are relatively low (Shavit and Müller, 1998). The attraction of the labor market is especially high for vocational students.

Students are often piling up problems before the actual decision to leave education early is made (De Witte and Rogge, 2012). Because the risk factors of school dropout are so diverse in nature across countries, regions, schools or students, it is very difficult to determine the best way to tackle the problem. The previous literature that aims to estimate the effectiveness of dropout prevention measures is indeed limited (Wilson et al., 2011). This calls for more research on the effectiveness on dropout prevention measures, interventions, and actions. Therefore, we have carried out an empirical study on the effectiveness of dropout prevention.

\subsection{The Netherlands at the summit of the E.U.-12}

In Chapter 2 we position the performance of the Netherlands among twelve EU Member States, in relation to the European Lisbon Target of a school dropout rate of 10 percent. Many EU countries have paid a different level of attention to the issue of early school leaving (Eurostat, 2011a). Regulation at the European level is typically driven by a benchmarking policy that compares the educational performance of the benchmark country with that of the worst performers - a policy known as 'naming and shaming'. We have chosen the following EU Member States: Austria, Belgium, Denmark, Finland, France, Germany, Luxembourg, Netherlands, Portugal, 
Spain, Sweden, and United Kingdom. According to the traditional European benchmark, Portugal (-8.2 percentage points) and the Netherlands (-4.0 percentage points) are the best performers among the EU-12 over the period 2000-2008. On the other hand, Sweden (+4.9 percentage points), Spain $(+2.8$ percentage points $)$ and Finland $(+0.8$ percentage points $)$ had an increase in school dropout during this period. We count these countries among the worst performers.

If only policy measures were to influence the schooling outcomes of youngsters, a 'naming and shaming' incentive could be appropriate. However, if other influences co-determine the school dropout level, a mere comparison of educational policy performance is nearly meaningless. The naming and shaming incentive is then inaccurate and favors countries which are influenced by positive exogenous influences. This is the case with respect to the traditional European benchmark for two main reasons. First, the 12 countries selected for this study had a very different level of school dropout in 2000: for instance, Portugal (43.6 percent), Spain (29.1 percent), the United Kingdom (18.2 percent), the Netherlands (15.4 percent) and Sweden (7.3 percent).

Second, previous research has shown that economic conditions play an important role in the level and change of early school-leaving rates (Cabus and De Witte, 2012a). These economic conditions consist of technological change, economic development, growth of per capita gross domestic product, and the economic cycle, and can be quite distinct across countries. In the long-run technological change has altered the industry structure from a labor-intensive to a knowledge based society (Nelson and Phelps, 1966; Schultz , 1967; Becker, 1993; Cedefop, 2008, 2010; European Commission, 2010a, 2011b). There is a general higher demand for knowledge. Thus, youngsters have to attend school longer to find a connection with the labor market. At the same time, there is a decline in the demand for low-skilled 
labor, keeping potential school dropouts at school.

Other economic conditions such as the economic cycle also play an important role in the short-run. The total number of (temporary) jobs available for relatively low-skilled youngsters increases in times of an economic revival. Then, those students with practical experiences are particularly attractive on the labor market (Borghans et al., 1999; Borghans, 2007). Research in the international literature indicates that vocational students are more likely to move from education to a job in times of an economic revival (Shavit and Müller, 1998; Müller and Gangl, 2003). However, youngsters without a certificate in the labor market are most vulnerable for economic swings. In times of an economic downturn, they are not only more likely to lose their job compared with graduates, but are also less likely to find a new job (OECD, 2008). Not having a certificate gives potential new employers a signal of incompetence for the job (Spence, 1973). We can conclude, therefore, that school dropouts are losing competitiveness on the labor market due to their dropout decision. Consequently, they face a higher risk of long-run unemployment.

We propose a new benchmark in Chapter 2 that accounts for the role of economic conditions. The benchmarking model distinguishes the influences of economic conditions from dropout prevention policy on the level and change of early school-leaving rates. The results indicate that Portugal did not perform well.

The 'fair' benchmarking model show that Luxembourg (-2.40 percentage points) and the Netherlands (-1.19 percentage points) are the best performers, while Portugal (+12.91 percentage points) and Spain $(+5.02$ percentage points) did not reduce the rate of early school-leaving as a result of prevention policy performance over the period 2000-2008. The results of Chapter 2 further indicate that those countries with prevention programs geared to vocational education and training and quality of educational provision are 
most successful in reducing dropout. We consider these two elements to be key factors in successful dropout prevention policy. The Netherlands is, therefore, an interesting case study. The country ranks in second position after Luxembourg and has one of the oldest histories in organizing vocational education and training. In the following chapters, we focus on Dutch dropout prevention measures, interventions and/or actions which particularly aim at vocational education and training.

\section{Effectiveness of the Dutch prevention policy}

\subsection{Registration and truancy}

In line with the Lisbon Agenda Targets, in 2005 the Dutch government launched a policy framework called 'Tackling School Dropout'. The national goal set then was to reduce the total number of new school dropouts from 70,000 in 2002 , to 35,000 in 2012 , and ultimately to 25,000 in 2016. Among other actions, the Dutch policy framework has improved the registration of students' school attendance and their curriculum in BRON (BasisRegister ONderwijs). The registration system improved considerably as a result of the use of a unique identification number to track every student in the Netherlands who is following secondary education. This is quite unique among the EU-27. Only Germany, Italy and the United Kingdom have implemented the use of such a personal identification number (European Commission, 2011a). The registration of unauthorized absence from school also improved as a result of uniform reporting at the digital office. ${ }^{2}$ Improved registration can be considered of major importance in dropout prevention, as a good measurement instrument is indispensable when it comes to the evaluation of the effectiveness of prevention policy. It also provides incentives for schools and regions to improve on their performance. From the

\footnotetext{
${ }^{2}$ As from 1 August 2009, reporting truancy to the digital office has become compulsory for all schools in secondary education, vocational education and training and adult education (www.aanvalopdeschooluitval.nl, 08/29/2012).
} 
school year 2005-06 the Ministry of Education, Culture, and Science paid school institutions a fixed amount of 2,000 euros for each dropout reduction compared with the base year. In 2007 the performance bonus was increased to 2,500 euros. Since 2012 the total number of new dropouts has to be compared with the previous year instead of the base year 2005 (more information on the performance bonus can be obtained from the official website: www.aanvalopdeschooluitval.nl).

We evaluated the BRON data reliability and validity in Chapter 3. The analysis shows that overall there is a good registration and follow-up in BRON of students aged below 18. However, the results further indicate that the registration of school attendance is inaccurate beyond the age of 18. It concerns students who have had one or more years of retention in grade and, who, consequently, did not graduate at the age of 18 . We observe in the data that schools do report the students' absenteeism at the digital office. However, the compulsory education age official does not confirm the precise nature of the truancy spell. We can rightly question whether the nature of the truancy spell is unauthorized beyond the school-age of 18, as students are no longer compelled to attend school. We provide a more in-depth discussion on this issue in Chapter 5.

A good follow-up of unauthorized truancy is desirable (Bos et al., 1992). The previous literature indicates that unauthorized truancy is one of the best predictors of a forthcoming dropout decision (Henry, 2007; De Witte and Csillag, 2012). In this respect, the Results in Chapter 3 indicate that schoolage students with a preceding unauthorized truancy record leave school at an earlier point in time in their school career than regular school attendees. The truancy decision leads to a substantial accumulated school dropout risk by the age of 17 . The likelihood of truants leaving education early before reaching the age of 18 increases by as much as 35 percent compared with students who attend school on a regular basis. Thus, unauthorized truancy 
can be a useful policy instrument to identify students at-risk, and prevent them from school dropout.

\subsection{The 2007 covenants}

Covenants are signed written agreements on dropout prevention measures, interventions, and actions between the Ministry of Education, Culture, and Science, the regional dropout authorities and the schools. In total, there were about five rounds. The first round was in 2005 , when only 14 out 39 regional dropout authorities (RMCs) and their schools, together with the Ministry of Education, Culture, and Science signed the agreements in the covenants. The impact of the first round of covenants has been analyzed by van der Steeg et al. (2008). The authors indicate that early school-leaving was not reduced in the 14 RMCs in the year 2005-06 in comparison with the other RMCs. In 2007 there was a second round of covenants signed by all of 39 RMCs, the Ministry of Education, Culture, and Science and the schools. This second round of covenants has been analyzed in Chapter 4 . The final round of covenants has been organized in the year 2012 and can be evaluated soon.

The 2007 covenants contain a list of measures and actions to reduce dropout, known as 'menu-items', from which the regions and schools could choose. We summarize them as follows: (1) reporting truants; (2) changing subject; (3) guidance towards the students' optimal track or profession; (4) apprenticeship; (5) mentoring and coaching; (6) the availability of care and advisory team; (7) smoothing the transition from the pre-vocational to the vocational level; (8) extended school day; (9) dual track; and (10) frequent intakes. While most policy measures correlate negatively with the individual dropout decision, only 'mentoring and coaching' (i.e. matching students with a coach from public or private organizations), 'optimal track or profession' (e.g. work placement) and 'dual track' (i.e. re-entering education for dropout students) have a significant negative impact on the individual's 
dropout decision. These measures particularly aim for dropout prevention in vocational schools or schools with a relatively high dropout rate. Optimal track deals with a better connection of the student with the job market by work placement, writing a letter of application, apprenticeship programs and creating a portfolio. Mentoring and coaching provide students with a coach from public or private organizations. Dual tracks are, in fact, a curative measure, as it deals with school dropouts who re-enter education in a tailored educational track often involving school-work contracts.

The results of Chapter 4 can be embedded in the findings of Chapter 1 and Chapter 2. First of all, vocational education and training have a strong connection with the labor market (Ministry of Education, Culture, and Science, 2006; Onstenk and Blokhuis, 2007). This strong connection leads to higher dropout rates among vocational students compared with students following academic tracks. Dutch policymakers can then reduce early school-leaving in vocational education by regulating or limiting the impact of the labor market on students (e.g. as a result of school-work contracts) or by integrating education in the labor market or vice versa (e.g. as a result of the accreditation of National Vocational Qualifications (NVQ)). Second, the previous literature has indicated that vocational students are more likely than students following academic tracks to pile up problems at home and at school, and eventually leading to their dropping out of school (see Figure 1.3, Chapter 1). Here mentoring and coaching, guidance towards the students' optimal track or profession can play a crucial role in preventing those students from leaving education early.

\subsection{The compulsory education age}

A measure that especially aims to limit the influence of the labor market on school age students is the compulsory education age. The previous literature has argued that the reason why compulsory education was introduced about a century ago was to prevent students from entering the labor market 
too early (e.g. child labor) (ILO, 2002; Murtin and Viarengo, 2009). In the summer months of 2007, the Dutch Ministry of Education, Culture, and Science changed the Compulsory Education Age Law of 1969 by the Regulation on Qualifications. According to this law students compulsorily attend school up till the age of 16 (full-time) and 17 (part-time). The Regulation on Qualifications stipulates that students have to attend school compulsorily up till the age of 16 (full-time). Furthermore, students are compelled to obtain a qualification (i.e. a secondary certificate of at least mbo level-2, havo or vwo) between the age of 16 and $18 .^{3}$ Thus, the introduction of the Regulation on Qualification in the year 2007 increased the compulsory education age from 17 to 18 year-olds. The impact on school dropout of this one year increase in the compulsory education age was analyzed in Chapter 5. We compared the average dropout rate among 16 year-olds (the intervention group) with 17 year-olds (the control group) before and after the change of the Compulsory Education Age Law. 17 year-olds students with a birth date between 1 January and 1 August 1990 are a suitable control group, as they were exempted from being affected by the increased compulsory education age. Therefore, they still could legally leave school in the year 2007 at the age of 17. At the same time, 16 year-olds students born between 1 August and 31 December 1990 were affected by the policy change.

The results indicate a decline in the average dropout rate by -2.5 percentage points significant at the 5 percent level. A closer examination of the effect, however, reveals that the effect on school dropout was mainly driven by control group students. We observe an average school dropout rate of 9.0 percent in 2006, and 8.9 percent in 2007 among 16 year-olds students, and 9.7 percent in 2006 and 12,1 percent in 2007 among 17 year-olds students. Given the good economic conditions at the time of the policy change, we

\footnotetext{
${ }^{3}$ Note that several combinations of part-time schooling and part-time working are still possible between the age of 16 and 18 under the Regulation of the Qualifications in the Compulsory Education Age Law.
} 
argue that control students anticipated job market opportunities in response to the changing compulsory education age. We provide evidence in Chapter 4 that the labor market tightness, an indicator of the share of vacancies filled in reaction to a demand or supply shock, and corrected for seasonal effects, changed substantially in the summer months of 2007 (Cabus and De Witte, 2011a). One may then reasonably argue that employers pulled the last available cohort of low-skilled youngsters out of school in response to the changing qualification age law. As a result, the next cohort for labor market participation would not have been available for another two years. This is not desirable in times of an economic revival. The results indicate that an increasing share of Dutch 17 year-olds (control) students did indeed enroll in vocational tracks, and, without retention in grade, left education without certificate in the immediate period after the policy reform.

\subsection{Transition from pre-vocational to vocational education}

We have evaluated the transition from pre-vocational to vocational education and training in Chapter 6. This transition is considered to be a difficult process in the Netherlands, because students have to physically switch schools, and may then lose connection with their school, peers and teachers (Onstenk and Blokhuis, 2007; Oberon, 2008). More specifically, we have evaluated the transition of 16 year-olds students enrolling in the Regional Training Center (RTC) Amsterdam and RTC Utrecht. Students without retention in grade make the transition at the age of 16. RTC Amsterdam has heavily invested in an improved process of transition compared with RTC Utrecht. 16 year-olds students in transition to RTC Amsterdam were therefore assigned to the intervention group, and 16 year-olds students in transition to RTC Utrecht to the control group.

The results of Chapter 6 indicate that school dropout did not decline in RTC Amsterdam compared with RTC Utrecht before and after the transition policy. We observe, however, that a successful transition from the 
pre-vocational school to the vocational school is a key factor for students to benefit from dropout prevention (as a bundle of measures and actions) that is mainly being implemented in the schools. 16 year-olds students have a significantly lower risk of dropping out of school once they have made a good transition. This supports the idea that preventive rather than curative measures should be used for dropout prevention.

To conclude, we discuss the issue that ethnic minority students are increasingly failing to make a good transition from the pre-vocational to the vocational school. The evidence on this indicates that ethnic minority students choose more difficult educational pathways or educational arrangements than native Dutch students. The previous literature adds that students with a foreign ethnicity are also more often suspended or forced to leave school, or even refused admission (Pittman, 1991; Allen and Meng, 2010).

\section{Conclusion}

Economic development and technological change have challenged the systems and structures of society wherein education is organized. Illustrative in this respect is the concept of the knowledge base that goes hand in hand with a lower demand for low-skilled youngsters. Students now have to attend school longer to find a connection with the labor market. The demand for knowledge not only requires more from educational provision, but also keeps more potential school dropouts in school. However, we cannot use this trend alone to put the problem of early school-leaving into perspective. Furthermore, even though school dropout can happen in all kinds of educational (ability) tracks, the problem is most apparent in the vocational tracks. Vocational youngsters are most likely to anticipate job market opportunities in times of good economic prospects. But the job market opportunities are often temporary in nature. Once school dropouts have lost their job, they 
face a higher risk of long-term unemployment because they do not have a certificate. A certificate signifies competence for the job. As such, youngsters lose their competitiveness in the labor market, as the lack of certificate is a bad signal for new employers. Thus, early school-leaving is not only desirable for the youngster, but may also lead to high costs for society due to the payment of social security or unemployment benefits and loss in tax revenues. The problem asks for attention from parents, schools, policymakers and government officials.

In 2005, the Dutch Ministry of Education, Culture, and Science launched a policy framework known as 'Tackling School Dropout', and here we have explored the effectiveness of dropout prevention policy in the Netherlands. Figure 1.3 in Chapter 1 shows all the evaluated dropout prevention measures, interventions, or actions. This Figure traces the dynamic relationship between the institutions home (family), school and labor market which play a role in a student's dropout decision. One can position the individual (or student), together with the prevention policy measures in the middle of Figure 1.3. This is in line with the findings of Chapter 1 and Chapter 4, which indicate that most prevention measures, interventions, or actions aim at the individual to reduce early school-leaving. We have also mapped the determinants of school dropout in Figure 1.3. These determinates have a relationship with each other in the dynamic framework. For instance, problems at home can also provoke problems at school, or vice versa. The relationship between the three institutions of labor market, school, and family has led to heterogeneous educational provision. Students with relatively high abilities can follow the academic educational tracks in secondary education so that they can ultimately enroll in higher education. These students feel the attractiveness of the labor market to a lesser extent. Vocational students, however, are already connected with the labor market from a young age, for example, as a result of apprenticeships or school-work contracts that allow students 
to learn part-time in school and part-time on the job. Here school dropout prevention policy in the Netherlands has made a marked difference. Guidance towards the students' optimal educational track or profession and the coaching of youngsters on the job can provide assistance to students with respect to their decisions on study tracks, part-time schooling, or applying for a job. NVQ and dual tracks can further connect those in education to the labor market, or vice versa. After all, the learning process is a task not only of the school but also of the labor market. 


\section{Samenvatting}

Veel jongeren ondervinden de gevolgen van voortijdig schoolverlaten. Volgens de definitie van de Europese Commissie verlieten in 2011 in de EU27 ongeveer 6 miljoen jongeren $(13,5 \%)$ het onderwijs zonder diploma. ${ }^{4}$ In overeenstemming met de Europese definitie observeren we in Nederland in 2011 een percentage voortijdig schoolverlaten van 9,1\% (Eurostat, 2012).

Het probleem van voortijdig schoolverlaten (vsv) is urgent. Uit internationaal onderzoek blijkt dat leerlingen die het onderwijs verlaten zonder startkwalificatie geen rooskleurige toekomst hebben. ${ }^{5}$ Ze hebben onder andere een grotere kans op een slechte aansluiting met de arbeidsmarkt en op langdurige werkloosheid (Reich en Young, 1975; Gangl, 2002). Jongeren zonder startkwalificatie hebben ook meer mentale en fysieke gezondheidsproblemen (Groot en Maassen van den Brink, 2007; Albouy en Lequien, 2009) en een hoger risico op armoede en maatschappelijke uitsluiting (Bowles, 1972; Sparkes, 1999) in vergelijking met jongeren mét startkwalificatie. Bovendien is vsv een probleem dat hoge maatschappelijke kosten met zich meebrengt. In de Verenigde Staten worden de echte kosten van vsv geschat op $\$ 1$ triljoen over een periode van 11 jaar (Levin en Rouse, 2012). Dit bedrag dekt voornamelijk sociale zekerheidsuitkeringen en werkloosheidsvergoedingen, kosten

\footnotetext{
${ }^{4}$ De Europese definitie stelt dat elke jongere van 18 tot 24 jaar een voortijdig schoolverlater is als hij/zij over maximaal een lager secundair diploma beschikt en als hij/zij niet meer in het onderwijs is ingeschreven. (Eurostat geraadpleegd op 29 augustus 2012).

${ }^{5}$ Merk op dat de Nederlandse definitie verschilt van de Europese definitie. In Nederland is elke jongere van 12 tot 23 jaar die het voortgezet onderwijs zonder startkwalificatie (havo, vwo, mbo-2) verlaat een voortijdig schoolverlater (www.aanvalopdeschooluitval.nl, geraadpleegd op 29 augustus 2012).
} 
van publieke dienstverlening en verliezen aan belastinginkomsten. Voortijdig schoolverlaten is dus schadelijk voor de jongere zelf en ook voor de samenleving. De uitstroom van jongeren uit het onderwijs zonder diploma wordt dan ook in toenemende mate gezien als een signaal dat actie vraagt van ouders, scholen en publieke overheden.

\section{Vsv in de internationale literatuur}

\subsection{Het probleem van voortijdig schoolverlaten}

De Europese raad heeft tijdens een bijeenkomst in Lissabon besloten om vsv met de helft terug te dringen van $20 \%$ in 2000 naar 10\% in 2010. Deze ambitieuze doelstelling werd in 2010 opnieuw geformuleerd in het kader van de Europa 2020-strategie. De EU-kerndoelen met betrekking tot voortijdig schoolverlaten stellen dat het percentage voortijdige schoolverlaters lager moet zijn dan 10\% tegen 2020 (meer informatie over de Europa 2020 kerndoelen kan men terugvinden op de website van de Europese Commissie: ec.europa.eu).

$\mathrm{Al}$ na het startschot op de Europese top in Lissabon hebben lidstaten acties ondernomen om vsv te verminderen (European Commission, 2005, 2006, 2010b, 2011a). Vsv is echter een complex fenomeen. De resultaten uit internationaal onderzoek tonen aan dat onderling sterk verschillende problemen de beslissing beïnvloeden om de school voortijdig te verlaten (Rumberger, 2011). Om het probleem van vsv beter te begrijpen, hebben we in hoofdstuk 1 aan de hand van de internationale literatuur de determinanten van vsv en de risicofactoren die kunnen leiden tot vsv in kaart gebracht. Figuur 7.7 (zie ook hoofdstuk 1) vat deze determinanten samen en wijst ze toe aan een van de drie instituties waarvan de jongere deel uitmaakt: thuis (gezin), school en arbeidsmarkt. Jongeren verlaten de school zonder startkwalificatie omdat ze problemen hebben thuis of op school. Sommige jongeren hangen bijvoorbeeld tijdens de schooluren rond op straat (Attwood 
en Croll, 2006; Henry, 2007) en raken op die manier soms betrokken bij criminaliteit (Lochner en Moretti, 2004; Anderson, 2010) of experimenteren met drugs (Fergusson e.a., 2003; ter Borgt e.a., 2009).

Onderzoek toont verder aan dat kinderen die opgroeien in families met een lage socio-economische status of in achterstandsbuurten vaker minder lang naar school gaan dan kinderen uit welgestelde families of buurten (Levin, 1987). Andere belangrijke determinanten van vsv zijn het gebrek aan betrokkenheid van de ouders bij de school en het gebrek aan betrokkenheid en motivatie van de leerling om op school goede prestaties te halen (Adams en Becker, 1990). Ten slotte speelt de arbeidsmarkt ook een belangrijke rol in vsv. Jongeren hebben bijvoorbeeld de ambitie in het leven om te studeren voor een toekomstige baan. Het gebrek aan ambities met betrekking tot de toekomstige baan verhoogt de kans van jongeren om de arbeidsmarkt te betreden nog voor een startkwalificatie wordt behaald (Shavit en Müller, 1998).

Vaak is het een combinatie van determinanten die uiteindelijk leidt tot vsv (De Witte en Rogge, 2012). De problemen van jongeren thuis, op school of in hun leefomgeving stapelen zich op en vaak verlaten ze de school voortijdig omdat ze een baan vinden. Omdat de determinanten van vsv en de leerlingenpopulatie in scholen, buurten, regio's of landen zo divers zijn, is het zeer moeilijk om te bepalen welke preventiemaatregelen zullen werken in de strijd om vsv terug te dringen. De internationale literatuur die zich specifiek richt op de evaluatie van preventiebeleid in het veld van vsv is dan ook beperkt (Wilson e.a., 2011). We weten dus heel weinig over de effectiviteit van preventiemaatregelen. Meer aandacht voor onderzoek naar de effectiviteit van maatregelen, interventies en acties die schooluitval verminderen is dan ook noodzakelijk. Daarom hebben we een empirisch onderzoek uitgevoerd naar de effecten van het Nederlandse preventiebeleid op vsv. 


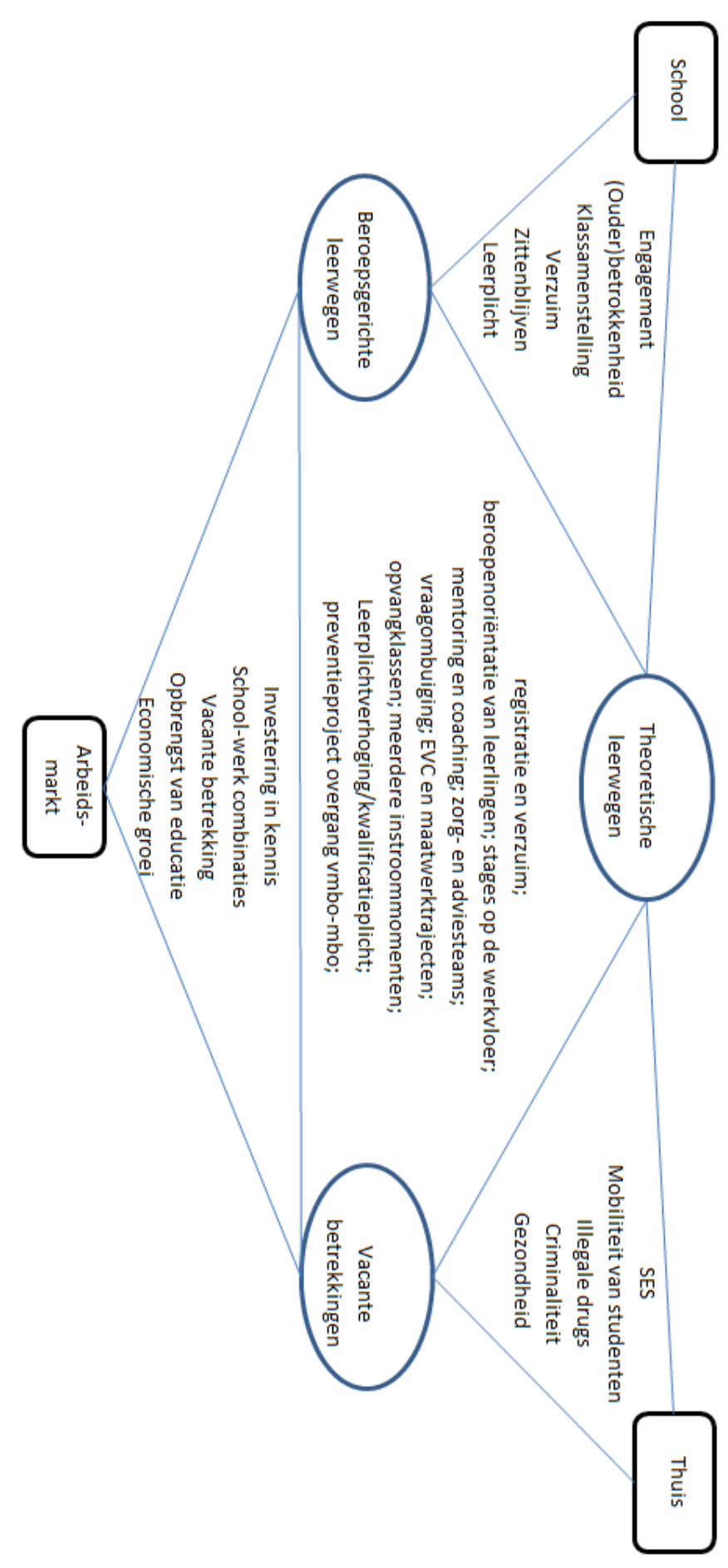




\subsection{Nederland aan de top van EU-12 landen}

In overeenstemming met de Europese doelstellingen heeft Nederland de laatste jaren een stevige campagne gevoerd in de strijd met vsv. In hoofdstuk 2 hebben we de prestaties van het Nederlandse preventiebeleid gekaderd in de Europese doelstelling om schooluitval te verminderen tot $10 \%$ in 2010 . Op het Europese niveau wordt vaak gebruik gemaakt van een rankschikking van landen volgens hun prestaties. Voor onze analyse kozen we hieruit 12 EU lidstaten waarvoor relevante gegevens beschikbaar waren: België, Denemarken, Duitsland, Finland, Frankrijk, Luxemburg, Nederland, Oostenrijk, Portugal, Spanje, Zweden en het Verenigd Koninkrijk. Volgens de traditionele Europese rangschikking voeren Portugal (-8,2 procent punt) en Nederland (-4,0 procent punt) het meest succesvolle preventiebeleid over de periode 2000-2008. Zweden (+4,9 procent punt), Spanje $(+2,8$ procent punt) en Finland ( $+0,8$ procent punt) kennen een stijging in de omvang van schooluitval en vinden we als laatste terug in de rangschikking. De traditionele rangschikking gaat er vanuit dat de geobserveerde vermindering in vsv enkel en alleen te danken is aan het preventiebeleid dat EU-12 landen de laatste jaren hebben gevoerd. Dit is echter niet het geval. Ten eerste vertrokken de EU-12 landen in 2000 vanuit heel verschillende startposities. Zo lag de uitstroom van jongeren uit het onderwijs zonder voortgezet onderwijs (vo) diploma in Portugal op 43,6\%, in Spanje op 29,1\% in het Verenigd Koninkrijk op 18,2\%, in Nederland op 15,4\% en in Zweden op $7,3 \%$. Ten tweede toont onderzoek aan dat de economische omstandigheden in de Europese lidstaten een belangrijke invloed hebben op het probleem van vsv (Cabus en De Witte, 2012). Deze economische omstandigheden kunnen heel erg verschillen per land. Concreet gaat het om de volgende economische omstandigheden: economische ontwikkeling en technologische innovaties, de groei van het bruto binnenlands product per hoofd van de bevolking en de economische cyclus. 
Economische ontwikkeling en innovaties hebben de systemen en structuren van de samenleving en de industrie grondig gewijzigd (Cedefop, 2008, 2010; European Commission, 2010a, 2011b). Welvarende landen zijn hierbij geëvolueerd van een arbeidsintensieve naar een kennisgerichte maatschappij (Nelson en Phelps, 1966; Schultz , 1967; Becker, 1993). Deze veranderingen gaan onder andere gepaard met een grotere vraag naar kennis, ook bij schoolverlaters. We volgen dus langer onderwijs om aansluiting te vinden met de arbeidsmarkt. Tegelijk is er een afname van de vraag naar laaggeschoolde arbeid op de arbeidsmarkt. Dit houdt een groter aandeel potentiële voortijdige schoolverlaters op school.

Op de korte termijn spelen echter ook andere belangrijke economische factoren een rol. Zo stijgt tijdens een economische opleving het aantal (tijdelijke) banen op de arbeidsmarkt. In zulke omstandigheden, zijn jongeren met een beroepsgerichte scholing erg aantrekkelijk op de arbeidsmarkt (Borghans e.a., 1999; Borghans, 2007). De internationale literatuur toont aan dat jongeren dan ook sneller en vaker de schoolbanken inruilen voor de arbeidsmarkt (Shavit en Müller, 1998; Müller and Gangl, 2003). Tijdens een periode van lage economische groei zijn deze jongeren zonder kwalificatie echter heel kwetsbaar op de arbeidsmarkt. Zij verliezen niet alleen sneller hun baan in vergelijking met gekwalificeerde jongeren, maar vinden vaak ook moeilijker opnieuw een baan (OECD, 2008). Het gebrek aan startkwalificatie geeft potentiële nieuwe werkgevers namelijk een signaal van onbekwaamheid voor de baan (Spence, 1973). We kunnen dus stellen dat een voortijdig schoolverlater aan competitiviteit op de arbeidsmarkt verliest na het nemen van de uitvalbeslissing waardoor ze vaker ten prooi vallen aan langdurige werkloosheid.

In hoofdstuk 2 stellen we een nieuwe rangschikking van de EU-12 landen voor die de prestaties van landen corrigeert voor de invloed van economische omstandigheden op vsv. Hierdoor is de nieuwe rangschikking in staat om 
onderwijsbeleid van economische invloeden te scheiden. Bij een toepassing van de gecorrigeerde rangschikking op de 12 Europese lidstaten, stellen we vast dat Portugal ( $+12,91$ procent punt) en Spanje $(+5,02$ procent punt) geen succesvol onderwijsbeleid hebben gevoerd. Deze landen hebben vooral voordeel gehaald uit de economische invloeden die vsv hebben verminderd en worden dus als laatste gerangschikt. De rangschikking positioneert Luxemburg (-2,40 procent punt) en Nederland (-1,19 procent punt) aan de top van de EU-12 landen. Beide landen hebben dankzij hun onderwijsbeleid vsv succesvol verminderd over de periode 2000-2008. Verder stellen we in hoofdstuk 2 vast dat preventieprogramma's die gericht zijn op het verminderen van vsv in het beroepsonderwijs en op verbetering van de onderwijskwaliteit, er beter in slagen vsv te verminderen. Zij blijken in die zin de sleutelfactoren voor een succesvol preventiebeleid. In lijn met deze conclusies richten we onze aandacht in de volgende hoofdstukken vooral op preventiemaatregelen en interventies die vsv wensen terug te dringen in het Nederlandse beroepsonderwijs.

\section{Effectiviteit van het preventiebeleid}

\subsection{Registratie en verzuim}

In 2005 heeft de Nederlandse overheid een preventieprogramma gelanceerd, met als slogan 'Aanval op de schooluitval'. De nationale doelstelling richt zich op een halvering van het aantal nieuwe vsv'ers van 70,000 in 2002 naar 35,000 in 2012 en naar een verdere daling tot 25,000 in 2016. De campagne heeft onder andere de registratie van de schoolloopbaan van leerlingen in BRON verbeterd (het Basisregister Onderwijs). Elke leerling in het Nederlandse onderwijs beschikt sinds 2005 over een identificatienummer voor de registratie van de schoolloopbaan en zijn of haar achtergrondkenmerken. Dit is uniek in het internationale veld. Alleen Duitsland, Italië en het Verenigd Koninkrijk hebben ondertussen een dergelijk identificatienummer in het on- 
derwijs geïmplementeerd (European Commission, 2011a). Ook de melding van ongeoorloofde afwezigheid van school bij het digitale verzuimloket werd verbeterd. ${ }^{6}$ Dit zijn belangrijke maatregelen geweest om vsv te bestrijden. Een goed meetinstrument is immers cruciaal om het preventiebeleid te evalueren op succes of falen en het eventueel bij te sturen. Het geeft scholen en regio's ook een stimulans om zichzelf te verbeteren. Zo keert het Ministerie van Onderwijs, Cultuur en Wetenschappen (OCW) in elk schooljaar na 2005-06 een prestatiebonus uit van 2,000 euro aan instellingen die vsv verminderen ten opzichte van het basisjaar 2005-06. In 2007 werd deze prestatiebonus verhoogd tot 2,500 euro. Sinds 2012 wordt het toekennen van de prestatiesubsidie aan instellingen gebaseerd op het percentage nieuwe vsv'ers van een instelling (meer informatie is ter beschikking op de website: www.aanvalopdeschooluitval.nl). ${ }^{7}$

In hoofdstuk 3 hebben we de betrouwbaarheid en validiteit van het registratiesysteem geanalyseerd. De analyse toont aan dat de registratie van de schoolloopbaan van leerlingen in het Nederlandse voortgezet onderwijs nagenoeg volledig en betrouwbaar is voor alle leerplichtige jongeren. Verder stellen we vast dat ongeoorloofd verzuim van leerlingen na de leeftijd van 18 jaar niet goed wordt opgevolgd in het registratiesysteem. Het betreft hier leerlingen die vertraging hebben opgelopen in de schoolloopbaan (zittenblijvers). Zij studeren niet af op 18-jarige leeftijd, maar moeten omwille van hun vertraging in de schoolloopbaan nog een aantal jaren naar school om een diploma te halen. Uit de analyse blijkt dat de school het spijbelgedrag van leerlingen ouder dan 18 jaar wel degelijk meldt bij het digitale verzuimloket. De registratiegegevens van ongeoorloofd verzuim tonen aan dat de reden van verzuim van leerlingen ouder dan 18 jaar pas na lange tijd of

\footnotetext{
${ }^{6}$ Vanaf 1 augustus 2009 wordt het melden van ongeoorloofd verzuim aan het digitale verzuimloket verplicht voor alle scholen in voortgezet onderwijs, beroepsonderwijs en volwasseneducatie (www.aanvalopdeschooluitval.nl, geraadpleegd op 29 augustus 2012).

${ }^{7}$ Dit is het aantal nieuwe vsv'ers ten opzichte van het aantal deelnemers in de leeftijd van 12 tot 23 jaar.
} 
in sommige gevallen niet wordt bevestigd door de leerplichtambtenaar. We kunnen ons hier de vraag stellen of er na de leeftijd van 18 jaar nog sprake is van ongeoorloofd verzuim omdat een leerling ouder dan 18 jaar niet meer onderhevig is aan de regeling van de kwalificatieplicht. In hoofdstuk 5 gaan we hier dieper op in.

Een goede opvolging van ongeoorloofd verzuim is wenselijk (Bos e.a., 1992). De internationale literatuur toont aan dat ongeoorloofd verzuim een van de beste voorspellers is van een latere beslissing om de school voortijdig te verlaten (Henry, 2007; De Witte en Csillag, 2012). De analyse in hoofdstuk 3 toont aan dat spijbelaars veel vroeger in de schoolloopbaan het voortgezet onderwijs zonder diploma verlaten dan reguliere leerlingen. Onze schatting laat zien dat spijbelgedrag de kans op vsv voor het bereiken van de leeftijd van 18 verdrievoudigt. Ongeoorloofd verzuim kan dus een nuttige indicator zijn voor jongeren die het risico lopen om zonder diploma het onderwijs uit te stromen. Tegelijk ondersteunt deze analyse ook het pleidooi voor preventiemaatregelen die op langere termijn vsv willen verminderen door ongeoorloofd verzuim tegen te gaan.

\subsection{De convenanten van 2007}

Een convenant is een geschreven overeenkomst waarin het Ministerie van OCW, de Regionale Meld- en Coördinatiepunten (RMC) en de scholen afspraken vastleggen over preventiebeleid, intenties en samenwerking. De convenanten kunnen we indelen in drie verschillende rondes. In het jaar 2005 werd een eerste ronde van convenanten ondertekend door het Ministerie van OCW, 14 Regionale Meld- en Coördinatiepunten (RMC) en de scholen. Het effect van deze eerste ronde van convenanten op het terugdringen van vsv werd onderzocht door van der Steeg e.a. (2008). Zij stellen vast dat vsv in de 14 RMCs die de convenanten hebben ondertekend niet significant gedaald was in vergelijking met de andere RMCs een jaar na de implementatie van de preventiemaatregelen. Een tweede ronde van convenanten werd ondertekend 
in het jaar 2007 door het OCW, 39 Regionale Meld- en Coordinatiepunten (RMC) en de scholen. In hoofdstuk 4 voeren we een analyse uit op deze tweede ronde van convenanten ondertekend in 2007. In tegenstelling tot van der Steeg e.a. (2008) voeren we een afzonderlijke analyse uit voor alle preventiemaatregelen van de convenanten die in 2007 werden geïmplementeerd. Ten slotte wordt er een derde ronde van convenanten georganiseerd in het jaar 2012. Dit nieuwe convenant kan binnenkort worden geëvalueerd.

Zoals in de vorige paragraaf werd aangegeven hebben we in hoofdstuk 4 de preventiemaatregelen zoals bepaald in de convenanten van 2007 geëvalueerd in relatie tot het verminderen van vsv. Deze convenanten bevatten in totaal 10 menu-items waarop RMCs in overleg met het OCW en de scholen kunnen inzetten. Deze menu-items zijn Zorg Advies Team, preventieproject overgang van vmbo naar mbo, mentoring en coaching, vraagombuiging, beroepenoriëntatie in het vmbo, stages, opvangklassen voor vsv'ers, meerdere instroommomenten in het mbo, verzuimbeleid, EVC (elders verworven competenties) en maatwerktrajecten. Hierbij werden de volgende preventiemaatregelen geassocieerd met het terugdringen van vsv: mentoring en coaching, EVC en maatwerktrajecten en beroepenoriëntatie in het vmbo. Dit zijn maatregelen die voornamelijk in het beroepsonderwijs (vmbo en mbo) van kracht zijn en dus in scholen voorkomen met een relatief hoog aandeel voortijdige schoolverlaters. De maatregel mentoring en coaching richt zich op het koppelen van een leerling aan een coach in het bedrijfsleven of een maatschappelijke organisatie. EVC en maatwerktrajecten zijn curatieve maatregelen en worden dus ingezet nadat een leerling de school voortijdig heeft verlaten. Deze maatregelen erkennen de kwetsbare positie van vsv'ers op de arbeidsmarkt. Het accrediteren van EVC en het reguleren van maatwerktrajecten bijvoorbeeld via school-werk contracten geven vsv'ers de kans om alsnog een startkwalificatie te behalen.

De resultaten van hoofdstuk 4 kunnen we goed interpreteren aan de 
hand van de bevindingen uit hoofdstuk 1 en hoofdstuk 2. Ten eerste heeft het beroepsonderwijs in Nederland van oudsher een nauwe connectie met de arbeidsmarkt (OCW, 2006; Onstenk en Blokhuis, 2007). Het is deze nauwe connectie die in vergelijking met havo of vwo tot op heden leidt tot een relatief grote uitstroom uit het beroepsonderwijs zonder diploma. Nederland kan dus het vsv verminderen in het beroepsonderwijs door de invloed van de arbeidsmarkt in het voortgezet onderwijs te reguleren of te beperken (bijvoorbeeld door maatwerktrajecten of beroepenoriëntatie), of door het onderwijs in de arbeidsmarkt te integreren of andersom (bijvoorbeeld door de accreditatie van EVC). Ten tweede toont de internationale literatuur aan dat jongeren in het beroepsonderwijs in vergelijking met jongeren in havo of vwo vaker te kampen hebben met thuis- of schoolproblemen die kunnen leiden tot vsv (zie figuur 7.7; hoofdstuk 1). Mentoring en coaching, beroepenoriëntatie, andere manier van begeleiding en zorg en aandacht voor een student met problemen thuis of op school kunnen in dit geval een belangrijke rol spelen om de student op school te houden (De Witte en Cabus, 2012).

\subsection{De leerplicht/kwalificatieplicht}

Een andere maatregel die de invloed van de arbeidsmarkt in het onderwijs kan beperken, is de leerplichtwet. Dit is het onderwerp van hoofdstuk 5 .

De literatuur toont aan dat de leerplicht ongeveer een eeuw geleden vooral werd ingevoerd om kinderen te beschermen tegen een te vroege intrede in de arbeidsmarkt (bijvoorbeeld kinderarbeid) (ILO, 2002; Murtin en Viarengo, 2009). De overheid heeft in het jaar 2007 een kwalificatieplicht geregeld in de leerplichtwet van 1969. Volgens de leerplichtwet van 1969 waren jongeren verplicht om naar school te gaan tot 16 jaar (voltijds). Vanaf de leeftijd van 16 jaar gold er een partiële leerplicht. Na het invoeren van de kwalificatieplicht zijn "Jongeren tussen de 5 en 18 jaar [...] verplicht om onderwijs te volgen, totdat ze een startkwalificatie hebben. Voor leerlingen 
van 5 tot 16 jaar heet dit de leerplicht, voor jongeren tussen 16 en 18 jaar de kwalificatieplicht (www.rijksoverheid.nl)." Jongeren zijn dus verplicht om naar school te gaan tot het einde van het schooljaar waarin de leeftijd van 18 wordt bereikt of tot het einde van het schooljaar waarin een kwalificatie wordt behaald (bijvoorbeeld havo student kunnen al op 17-jarige leeftijd hun diploma behalen). ${ }^{8}$ Een startkwalificatie staat voor een diploma op minimaal mbo-niveau 2 , havo of vwo.

In hoofdstuk 5 onderzoeken we de effecten van de leerplichtwetswijziging op vsv. Hierbij hebben we de gemiddelde schooluitval onder 16-jarige leerlingen (de interventiegroep) vergeleken met de gemiddelde schooluitval onder 17-jarige leerlingen (de controlegroep) voor en na de verandering in de kwalificatieplicht in het jaar 2007. We gebruiken 17-jarige leerlingen met een geboortedatum tussen 1 januari en 1 augustus 1990 als een controlegroep omdat ze waren vrijgesteld van de verhoging van de kwalificatieplicht in het jaar 2007. Tegelijk waren 16-jarige leerlingen met een geboortedatum tussen 1 augustus en 31 december 1990 niet vrijgesteld van de verhoging van de kwalificatieplicht in 2007. Zij vormen de interventiegroep. Dankzij deze opzet schatten we dat de verhoging van de kwalificatieplicht heeft geleid tot minder schooluitval onder 16-jarige leerlingen (interventiegroep) in vergelijking met 17-jarige leerlingen (controlegroep). Nadere analyse van dit effect toont echter aan dat het effect volledig wordt gedreven door meer schooluitval in de controlegroep. We observeren namelijk een verhoging van het percentage vsv van $9,7 \%$ in 2006 naar $12,1 \%$ in 2007 in de controlegroep terwijl het percentage vsv in de behandelingsgroep lichtjes daalde van 9,0\% in 2006 naar $8,9 \%$ in 2007 .

De 17-jarige leerlingen in de controlegroep mochten in 2007 legaal het onderwijs voortijdig verlaten omdat zij op dat moment nog vrijgesteld waren van de verhoging van de kwalificatieplicht. Het ging om een groep leerlin-

\footnotetext{
${ }^{8}$ We merken op dat tussen de leeftijd van 16 en 18 jaar volgens de regeling van de kwalificatieplicht verschillende combinaties van deeltijdonderwijs nog steeds mogelijk zijn.
} 
gen van Nederlandse herkomst uit het beroepsonderwijs die geen vertraging hadden in de schoolloopbaan. Kortom, het waren meteen inzetbare jongeren op de arbeidsmarkt (Cabus en De Witte, 2011). Om het geschatte effect te staven koppelen we de resultaten aan tendensen op de arbeidsmarkt in 2007. In het jaar 2007 vond een economische opleving plaats en het aantal vacatures stond toen op het hoogste punt sinds 2003. We observeren bovendien dat meer banen op de arbeidsmarkt werden ingevuld door jongeren tussen 15-25 jaar. Een groter aantal Nederlandse jongeren zonder diploma van het beroepsonderwijs heeft dus de schoolbanken ingeruild voor de arbeidsmarkt na de verhoging van de leerplicht in 2007. Door deze leerplichtverhoging werd namelijk het aanbod van laaggeschoolde arbeid verminderd omdat de volgende beschikbare groep leerlingen die het onderwijs legaal mocht verlaten nog een jaar op zich zou laten wachten. Dit is niet wenselijk in een periode van economische opleving. De vraag naar laaggeschoolde arbeid neemt dan namelijk net toe. Het is dus aannemelijk dat werkgevers 17jarige leerlingen uit de controlegroep van de schoolbanken hebben geplukt.

\subsection{De overgang van vmbo maar mbo}

In hoofdstuk 6 wordt de effectiviteit van de preventiemaatregel 'overgang van vmbo naar mbo' geëvalueerd. Deze preventiemaatregel maakt deel uit van de tien menu-items opgenomen in de convenanten. Over het algemeen wordt de overgang van vmbo naar mbo door jongeren moeilijk gevonden omdat ze dan vaak van school moeten wisselen en zo de connectie met andere leerlingen en leerkrachten verliezen (Onstenk en Blokhuis, 2007; Oberon, 2008). Concreet hebben we de overgang van leerlingen van vmbo naar mbo in het ROC Amsterdam en het ROC Utrecht voor en na invoering van de preventiemaatregel geanalyseerd. Leerlingen zonder vertraging in de schoolloopbaan maken de overgang op 16-jarige leeftijd. Het ROC Amsterdam heeft in vergelijking met het ROC Utrecht sterk ingezet op de verbetering van de overgang naar hun ROC. 16-jarige leerlingen die de overgang maken 
naar het ROC Amsterdam na de invoering van de convenanten maatregel werden om die reden toegewezen aan de interventiegroep. Leerlingen die de overgang maken naar het ROC Utrecht werden toegewezen aan de controlegroep.

De resultaten in hoofdstuk 6 tonen aan dat de overgang van 16-jarige leerlingen naar het ROC Amsterdam schooluitval niet effectief heeft verminderd vlak na de invoering van de preventiemaatregel. Wat we wel kunnen vaststellen is dat een soepele overgang van vmbo naar mbo cruciaal is om baat te hebben bij het Nederlandse preventiebeleid dat in grote mate in scholen wordt geïmplementeerd. 16-jarige leerlingen die de overgang succesvol afronden hebben een substantiële lagere kans op vsv dankzij de preventiemaatregelen zoals bepaald in de convenanten van 2007. Dit resultaat onderstreept het Europese gedachtegoed van preventief onderwijsbeleid in plaats van curatief onderwijsbeleid.

Ten slotte stellen we vast dat allochtone jongeren in toenemende mate de aansluiting met mbo mislopen. Onderzoek hieromtrent toont aan dat jongeren met een buitenlandse nationaliteit vaker verkeerde en/of moeilijkere studierichtingen kiezen maar ook vaker worden geschorst en/of van school worden gestuurd of zelfs geweigerd (Pittman, 1991; Allen en Meng, 2010).

\section{Besluit}

Economische ontwikkeling en technologische innovaties hebben de afgelopen decennia de systemen en structuren van de samenleving waarin onderwijs aan jongeren wordt aangeboden uitgedaagd. Het concept van de kennissamenleving is in opmars en heeft de vraag naar laaggeschoolde arbeid verlaagd. Werkgevers vereisen dat we langer naar school gaan om aansluiting te vinden met hun vacatures. De vraag naar kennis stelt dus niet alleen hogere eisen aan het onderwijs, het houdt ook voortijdig schoolverlaters langer op school. Toch kunnen we het probleem van vsv niet relativeren. Hoewel voor- 
tijdig schoolverlaten een probleem is van alle lagen in het onderwijs, is het probleem van vsv het meest urgent in het beroepsonderwijs. Jongeren in het beroepsonderwijs zijn het meest inzetbaar bij een toename van het aantal vacatures als gevolg van een economische opleving. De vacatures zijn echter tijdelijk van aard en stellen een voortijdig schoolverlater voor een moeilijke toekomst. Als ze hun baan verliezen lopen voortijdig schoolverlaters een groter risico op langdurige werkloosheid door het gebrek aan een diploma. In een kennissamenleving is een diploma een signaal van bekwaamheid voor de baan. Voortijdig schoolverlaten is dus niet wenselijk voor de jongere en leidt bovendien tot hoge kosten voor de samenleving. Voortijdig schoolverlaten vraagt om actie van ouders, scholen en publieke overheden.

Met als slogan 'Aanval op de Schooluitval' heeft Nederland de strijd met vsv aangebonden. Figuur $\mathbf{7 . 7}$ (zie ook hoofdstuk 1) vat het Nederlandse preventiebeleid dat in dit proefschrift werd onderzocht samen. De figuur geeft goed de dynamiek weer tussen de verschillende instituties: thuis (het gezin), school en arbeidsmarkt. Het individu (of de student) bevindt zich samen met de preventiemaatregelen in het midden van de figuur. Dit is in overeenstemming met hoofdstuk 1 en hoofdstuk 4 waar wordt aangetoond dat de meeste interventies en maatregelen zich richten op het individu om vsv te verminderen. De determinanten van vsv zijn ondergebracht in de figuur en staan in het dynamische kader in verbinding met elkaar. Hieruit blijkt dat problemen thuis ook problemen op school kunnen uitlokken en andersom. De relatie tussen arbeidsmarkt, school en gezin heeft in Nederland geleid tot een heterogeen onderwijsaanbod. Leerlingen met een relatief hoge capaciteiten kunnen een theoretische leerweg volgen om zo later door te stromen naar het hoger onderwijs. Ze voelen in mindere mate de aantrekkingskracht van de arbeidsmarkt omdat ze vaak voltijds les volgen op school. Leerlingen in het beroepsonderwijs kunnen echter al op jonge leeftijd in aanraking komen met de arbeidsmarkt, bijvoorbeeld door stages op de werkvloer of maatwerktra- 
jecten die toelaten om deeltijds te leren en deeltijds te werken. En hier kan het Nederlandse preventiebeleid winst boeken. Zo kunnen beroepenoriëntatie in het vmbo en coaching van leerlingen op de werkvloer jongeren in het beroepsonderwijs helpen bij het nemen van beslissingen met betrekking tot studiekeuzes, deeltijds leren of het inspelen op een vacature. Curatieve maatregelen zoals EVC en maatwerktrajecten kunnen de link tussen onderwijs en arbeidsmarkt verder stroomlijnen. Het leerproces is immers niet alleen taak van de school maar ook onderdeel van de arbeidsmarkt. 


\section{Biography}

Sofie J. Cabus studied business management at HU Brussels in 2003-07, and public economics at KU Leuven in 2007-08. She worked for one year as a research associate at the Research Institute for Work and Society (HIVAKU Leuven) and at the Center for Disability and Integration (CDI-USG) in 2008-10. In 2010, she enrolled in a PhD in economics at the Top Institute for Evidence Based Education Research (TIER-Maastricht University). In the spring of 2012, she was a visiting scholar at the Teachers College, Columbia University. Sofie Cabus is currently affiliated with Maastricht University as a teacher in the Master of Evidence Based Education Research (MEBIT), and as an active member in the education commission of the Dutch Teachers and Policy Academy (TIER/DTPA). Her research interests are the economics of education, labor economics, health economics, and microeconometric methods and techniques. 


\section{Top Institute for Evidence Based Education Research (TIER)}

The Top Institute for Evidence Based Education Research (TIER) is an inter-university institute that conducts research to develop evidence based education. The institute has three partners: the University of Amsterdam, Maastricht University and the University of Groningen and is located in Amsterdam, Maastricht and Groningen.

TIER contributes to the improvement of the quality of education in the Netherlands by promoting an evidence based approach as a guiding principle in education policy and practice. It accomplishes this by developing (cost) effective education interventions that are grounded in sound scientific research. TIER research is funded by the Ministry of Education, Culture, and Science, and the participating universities through the NWO and complies with the quality standards and evaluation procedures used by NWO.

The author acknowledges financial support of NICIS.

The following books recently appeared in the TIER Research Series:

I. C. Haelermans (2012), On the productivity and efficiency of education. The role of innovations in Dutch secondary education.

II. L. van Welie (2013), They Will Get There! Studies on Educational Performance of Immigrant Youth in the Netherlands.

III. S.J. Cabus (2013), An economic perspective on school dropout prevention using microeconometric techniques. 